\title{
Technological change and skill development in the Arab Gulf countries
}

Citation for published version (APA):

Nour, S. (2005). Technological change and skill development in the Arab Gulf countries. [Doctoral Thesis, Maastricht University]. Datawyse / Universitaire Pers Maastricht. https://doi.org/10.26481/dis.20051110sn

Document status and date:

Published: 01/01/2005

DOI:

10.26481/dis.20051110sn

Document Version:

Publisher's PDF, also known as Version of record

\section{Please check the document version of this publication:}

- A submitted manuscript is the version of the article upon submission and before peer-review. There can be important differences between the submitted version and the official published version of record.

People interested in the research are advised to contact the author for the final version of the publication, or visit the DOI to the publisher's website.

- The final author version and the galley proof are versions of the publication after peer review.

- The final published version features the final layout of the paper including the volume, issue and page numbers.

Link to publication

\footnotetext{
General rights rights.

- You may freely distribute the URL identifying the publication in the public portal. please follow below link for the End User Agreement:

www.umlib.nl/taverne-license

Take down policy

If you believe that this document breaches copyright please contact us at:

repository@maastrichtuniversity.nl

providing details and we will investigate your claim.
}

Copyright and moral rights for the publications made accessible in the public portal are retained by the authors and/or other copyright owners and it is a condition of accessing publications that users recognise and abide by the legal requirements associated with these

- Users may download and print one copy of any publication from the public portal for the purpose of private study or research.

- You may not further distribute the material or use it for any profit-making activity or commercial gain

If the publication is distributed under the terms of Article $25 \mathrm{fa}$ of the Dutch Copyright Act, indicated by the "Taverne" license above, 
(0) 2005 , copyriglyt Sania Satui O. Mohamed-Nour, Manstricht All rights reserved

\section{ISBN 9052784922}

Cover design by Sami Satti O. Molnamed-Notr

Publishod by Universitaire Pers Matstricht

Printed in the Nethetands by Datawyse Maastricht 


\title{
Technological Change and Skill Development in the Arab Gulf Countries
}

\author{
PROEFSCHRIFT \\ ter verkrijging van de graad van doctor \\ aan de Universiteit Maastricht, \\ op gezag van de Rector Magnificus, Prof. Mr. G.P.M.F. Mols, \\ volgens bet besluit van het College van Decanen \\ in het openbaar te verdedigen op donderdag 10 november 2005 om 12.00 uur
}

door

Samia Satti Osman Mohamed-Nour

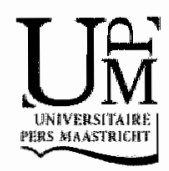


Promotor:

Co-promotor:

Beoordelingscommissie:
Prof. dr. J. Muysken

Dr. Th. Ziesemer

Prof. dr. R. Cowan, voorzitter

Prof. dr. J.A.M. Heijke

Prof. dr. L. K. Mytelka

The Study presented in this Ph.D. Thesis was conducted at Maastricht Economic Research Institute on Innovation and Technology (MERIT), Faculty of Economic and Business Administration, Maastricht University, and fully sponsored by the United Nations University- Institute for New Technologies (UNU-INTECH), Maastricht, The Netherlands. 


\section{Dedication}

For my beloved parents, Alawia and Satti, my sisters and brothers with whom all things are possible 


\section{Preface and Acknowledgements}

I sincerely thank Allah, my God, the Most Gracious, Most Merciful for enabling me to complete my Ph.D. successfully and for often putting so many good people in my way.

In completing my Ph.D. thesis I owe a great debt to many people. I wish to extend

my deep thanks gratitude and appreciation to everyone contributed to the successful completion of my thesis.

First and foremost, I would like to express my sincere thanks, gratitude and deep appreciation to my promoter Professor Joan Muysken and co-promoter Dr. Thomas Ziesemer for their sincere efforts, interest and time they have kindly spent to guide my research. I am extremely grateful and indebted to Pofessor Muysken for his excellent supervision, intellectual guidance and invaluable comments, without which it would have been impossible to complete my thesis. I had the good fortune and honour to train with and work under his supervision. I am very grateful to him for the time he spent to teach me, and sincerely thank him for his interest, wisdom, as well as his extraordinary cooperation and amazing patience in correcting my mistakes and restructuring my inconsistent writing. I sincerely hope that for every $\mathrm{Ph}$.D. candidate there are excellent professors and wise supervisors like Prof. Muysken, who sincerely and practically implement the learning by doing approach or problem-based learning method, a unique distinction characterizing Maastricht university among the other Dutch universities. I wish to extend my extreme gratitude and thanks to Dr. Ziesemer for his excellent supervision and support during the final stage of my thesis. I am very grateful to him for the time he spent in reviewing my thesis with great care and attention, and for his invaluable comments and suggestions that contributed much to the improvement and completion of my thesis. I also thank Dr. Abbas Abdelkarim for his comments, suggestions and supervision, which contributed to my thesis at its early stage. I am grateful to him for facilitating the fieldwork visit.

I gratefully thank the members of the scientific examining committee for their comments and for the time and effort they spent in reviewing my thesis.

I am delighted to gratefully acknowledge the United Nations University-Institute for New Technologies (UNU-INTECH) for the four-year fellowship award and also for the continued generous support through the duration of my Ph.D. study. I also thank the United Nations University-World Institute for Development Economics Research (UNU-WIDER) for the three months' internship, the Ford Foundation and the Lebanese Center for Policy Studies for the Middle East Research Competition (MERC) Grant offered to partially support me in the midst of my research.

I would like to express my gratitude to all the staff members of the UNU/INTECH and the Maastricht Economic Research Institute on Innovation and Technology-MERIT of the University of Maastricht. I am delighted to gratefully thank Prof. Luc Soete, (the joint Director of MERIT and UNU-INTECH) and Prof. Robin Cowan (the Dean of students, MERIT-UNU/INTECH Ph.D. Programme) for both giving me a good opportunity to be a part of the interesting MERIT/UNU-INTECH Ph.D. programme and for their continuous 
cooperation and support during my study. My thank extends to Prof. Lynn Mytelka (former director) and Prof. Lea Velho (formei dean of students), Marc Vleugels (chief administrative staff), Ad Notten (Senior Library Assistant) and Mourik Jan Heupink (Computer Systems Assistant), I am very grateful to them for their help, kind cooperation and assistance during my study and stay at UNU-MNECH. Many special thanks are extended to all colleagues working at UNU-INTECH, especially, Yvonne de Groot, Eveline in de Braek, Ann Kelledy, Monique Raedts, Marijke Roolvink-Batty, Raeleen Waasdorp and Jacqueline van Kesteren, for the wonderful and warm generous support they have kindly given to me and for making INTECH a warm comfortable home for all INTECH people. I would also like to extend my gratitude and special thanks to Corien Gijsbers, Silvana de Sanctis, Wilma Coenegrachts and the secretaries to Prof. Muysken at the Department of Economics, Faculty of Economic and Business Administration Céline Rondagh, Susan Roggen and Fleur Keune for their assistance and kind cooperation. I thank Jane Williams for her kind support and Sophia Gross for her help in editing my thesis.

Special gratitude goes to my roommate Mamata Parhi for her nice friendship and kind cooperation. I especially thank her, Preeti Soni and Márcia da Mota Darós for their warm support, pleasant company, and the nice time we spent during their stay in Maastricht. I am delighted to thank my colleagues Ph.D. students class of 1999: Mamata, Preeti, Minh, Geoffrey, Pedro, Poala, Oxana, Muge, Bulat, Elad, Nicola, and all other UNU-MERIT $\mathrm{Ph}$.D. students. I'm very pleased to have been involved in a truly global and internationally oriented University of Maastricht MERIT-UNU/INTECH Ph.D. programme.

My research benefited from my stay at UNU-WIDER in Helsinki (2002). I thank Prof. Matti Pohjola for his good supervision during my stay there. I also thank Dr. Maiju Perala and all staff for the good hospitality and kind cooperation.

During the field visit and data collection I received considerable help from many people. I thank the directors and staff of the National Human Resources Development Authority and the Centre for Labour Market Research and Information in Dubai, the United Arab Emirates for the good hospitality, cooperation and support during the fieldwork. I thank Mr. Yousef Abdulgheni, Dr. Mohamed Osman and Mr. Abdullah Al Marzoqui for their cooperation, comments and the time they spent in filling in the questionnaire. Many thanks extend to Mr. Omran Tahboub for his valuable assistance during the survey, and $\mathrm{Mr}$. Abdul Azeem Osman for preparing the Arabic translation of the macro survey questionnaire. I thank Mr. Saeed Al-Shaali, Ministry of Labour and the part time researchers: Azhary, Tilal, Hatem and Amin for their helpful cooperation in the collection of the questionnaire from firms. I also thank Dr. Hector Morada for his valuable comments to improve the design of the questionnaires and Anthony Arundel from MERIT, for his comments on the earlier draft of the questionnaire. I thank all the respondents to both surveys. Special thanks also go to Ms. Inam Mubarak and her family for facilitating access to Ministry of Industry- Industrial database, Khawla Abdulrahman. Fatma Al-Hashimi, and Hesham Zaki for facilitating access to secondary data. Many thanks extend to Prof. Ali Abdel Gadir Ali, Dr. Khalid Affan, Dr. Mohammed Attaitallah, Mr. Omer Sharfi, Dr. Omer Bizri and Mr. Hag Ahmed for facilitating access to GOLC and ESCWA database.

I wish to thank Prof. Ali Abdel Gadir Ali, Prof. Suleiman Cohen, Dr. John Cameron and the participants at the UNU/INTECH and MERIT workshops 2001, 2005 , UNU-WIDER seminar 2002, ETIC European Doctoral Training Programme 2003, 
CAPORDE 2004 and DRUID Winter 2005 Ph.D. conference for their useful comments to improve my thesis.

I would like to thank Prof. Mohamed Hashim Awad, Dr. Ahmed Badawi and all my colleagues at the Faculty of Economic and Social Studies, University of Khartoum. My deep thanks go to my friends Ahlam Hamza and Fatma Osman for their sincere prayers and continuous support during my study. I also extend my thanks to all the Sudanese friends in the UAE and the Netherlands, particularly in Maastricht, for their help and warm support during my stay there.

I also thank my grandparents, my aunts, uncles and their families, special thanks go to my uncles Saif and Naser for their support during my field visit and Mubark during my study. My special thanks and gratitude also extend to my brothers- and sisters-in-law: Abdulrahman, Jamal, Fathia, Duha, and to the new generation in my family: Mohamed, Taher, Rawan, Ryan, Lina, Ahmed, Osman and Awaab for their kind support and encouragement.

Last but not least, no words are ever sufficient to express my everlasting gratitude, appreciation and thanks to my beloved, wonderful mother Alawia and father Satti for being the light in my life. Without their warm love, care, sincere prayers and support, it would have been impossible for me to be myself and to continue learning. I feel extremely indebted and grateful to them for inspiring and illuminating me, and I deeply appreciate their unlimited and incredible support, especially during my stay away from home. I owe an impressive debt and feel unable to sufficiently thank my beloved, wonderful sisters: Rashida, Khalda, Eiman and Lana and my brothers: Rashid, Osman, Khalid and Sami for their sincere prayers, amazing and faithful friendship, and generous and incredible support. Together with my parents, they have been the real motivation behind the completion of my thesis and success throughout my life. I feel wonderfully fortunate and incredibly privileged to be a part of them. I sincerely and deeply thank them for having steadily supported and faithfully encouraged my long learning journey in Sudan and the Netherlands.

My sincere thanks. May God bless and bring peace, pleasure and prosperity to all of you.

Samia Satti O. Mohamed-Nour Maastricht, September 15, 2005 


\section{Contents}

Preface and Acknowledgments

Contents

ix

List of Abbreviations

xvi

PART I INTRODUCTION

List of Chapters

ix

$1 \quad$ Chapter 1: General Introduction

2 Chapter 2: Economic Development Challenges in the Gulf and the 10 Need for Skill Upgrading and Technological Development

$2.1 \quad$ Introduction $\quad 10$

2.2 Economic characteristics and strategic problems for development in the 11 Gulf countries

2. 2. 1. 1 Oil and the opportunities for development in the Gulf countries

2. 2. 1.2

Oil and the challenges of development in the Gulf countries

2. 2.2 Structural problems of the labour market in the Gulf countries

2. 2.3 The low skill levels in the Gulf countries

2.2. 4 The low technological level and technological gap in the Gulf countries 23

2. 2.5 The declining productivity of labour and economic growth in the Gulf 28 countries

$\begin{array}{lll}2.3 & \text { Conclusions } & 29\end{array}$

PART II CONCEPTUAL AND THEORETICAL. FRAMEWORK 30

3 Chapter 3: Technological Change and Human Capital: Conceptual Framework, Theoretical and Empirical Literature

3.1 Introduction 31

3. 2 Conceptual framework: definition of technological change and human 32 capital (human skills)

3. 3 Theoretical framework: technological change, human capital and 33 economic growth

3.3.1.1 Economic growth theory and exogenous technical change 33

3.3.1.2 Economic growth theory and endogenous technical change 34

3.3.2 Human capital and economic growth 36

3.3.3 The relationship between technological progress, human capital (skill) 40 and skill upgrading 
3.4 Measurement of technological change and human capital 43

3.4.1 Measurement of technological change 43

3.4.2 Measurement of human capital (human skills)

3.5 Endogenous growth and public policy 49

3.6 Conclusions 54

PART III: EMPIRICAL APPLICATION

4 Chapter 4: Research Methodology and Method of Data Collection 56

4. 1 Motivation and selection of a case study 56

4. 2 The selection of the sample and composition of the surveys 59

4. $3 \quad$ Structure and design of the questionnaire 62

$\begin{array}{lll}4.4 & \text { Conclusions } & 64\end{array}$

$5 \quad$ Chapter 5: Assessment of Skill and Technology Indicators 66

$\begin{array}{ll}\text { Introduction } & 66\end{array}$

5.1 Causes and consequences of deficient educational system 68

A. Causes of deficiency in the educational system 68

B. Consequences of the deficient educational system 69

a. mismatch between the output of education and the market needs 69

$\begin{array}{ll}\text { b. lowering skill levels } & 70\end{array}$

c. hampering transfer of knowledge 71

$\begin{array}{ll}\text { d. poor provision of training } & 72\end{array}$

C. Consequences of the low educational qualifications of foreign 74 workers at the micro/firm level

a. Low skill level and skills mismatch at the micro/firm level 74

$\begin{array}{ll}\text { b. weak technology indicators } & 75\end{array}$

$\begin{array}{ll}\text { c. dependence on foreign technology } & 77\end{array}$

d. Shortage of skilled workers and weak adaptation of imported 80 technologies

5.2 5.2 The impacts of skill upgrading and technological upgrading: Micro- 81 Macro views

$5.3 \quad$ 5.3. Conclusions $\quad 84$

6 Chapter 6: Rellationship between Skill, Technology and Input- 86 Output Indicators

Introduction $\quad 86$

6.1 Data, definition of variables and general characteristics of firms 86

6.1.1 Data and definition of variables $\quad 87$

6.1.2 General characteristics of firms $\quad 87$

6.2 Differences in skill level and requirements and implications across firms 89

6.2.1 Differences in skill level and requirements (education and experience) 90 across firms

6.2.2 The implications of low skill levels across private firms 93

a. Low skill level and skills mismatch (differences in required and 93

attained education)

b. Low skill level and public- private dualüty within oil/chemical 95 industry

c. Low skill level and declining trend of labour productivity 96 
(output/labour and capitallabour ratios).

6.3 Relationships between the required education (occupation), 98 attained/actual education, experience and average wages

6.4 Skill, upskilling (ICT training) and technology (ICT) and imput-output 101 indicators

6.4.1 Skill and the share of spending on technology (ICT) and upskilling (ICT 102 training)

6.4.2 The use of technology, ICT, skill and the demand for skilled workers 105 across firms

6.4.3 The share of spending on ICT and imput-output indicators 106

6.5 Conclusions 108

7 Chapter 7: The Importance (Impacts) of Knowledge at the Macro- 110 Micro Levels

$7.1 \quad$ Introduction $\quad 110$

7.2 Definition, importance, sources and measurement of knowledge in the 111 growth literature

7.3 The hypothesis, stylized facts and data 113

7.3.1 The importance (impacts) of knowledge at the micro-macro levels in the 113 Gulf countries

$\begin{array}{lll}\text { 7.3.2 } & \text { Definition of data and variables } & 114\end{array}$

7.4 The empirical results 115

7.5 Conclusions 119

PART IV POLICY RECOMMENDATIONS, SUMMARY AND CONCLUSIONS 120

8 Chapter 8: Education, Training and Skill Development Policies in 121 the Gulf countries: Macro-Micro Overview

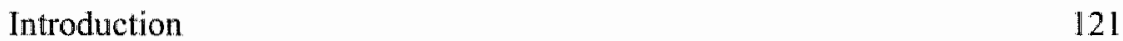

8.1 Characteristics of educational policies in the Gulf countries: supply, 121 demand, quality and impacts

8.1.2 The supply side of educational policies: financial and human resources $\quad 122$

8.1.3 The demand side of educational policies: the demand for and enrolment 125 in education

8.1.4 Return and quality of educational policies: $\quad 128$

8.1.5 The impacts of educational policies on literacy and access to schooling 129 (school life expectancy)

8.2 The impact of educational policies on training policies: large public 130 firms and public policies of training and skills upgrading

8.3 Plans, Policies and mechanisms for skill development: the macro- micro 133 views

8. 3.1 Plans for skill development: the macro- micro views 133

8.3.2 Policies and mechanisms for skill development: the macro-micro views 136

$\begin{array}{ll}\text { a. Reform of educational system } & 136\end{array}$

b. Enhancing the transfer of knowledge/ external schooling effect $\quad 138$

$\begin{array}{ll}\text { c. Enhancing training provision } & 138\end{array}$

$\begin{array}{lll}8.4 & \text { Conclusions } & 140\end{array}$

9 Chapter 9: Summary and Conclusions 
9.1 Research problem, methodology and major findings. $\quad 144$

9.2 Relevance and contribution of the research 150

9.3 Policy recommendations 153

9. 4 Direction for future research $\quad 154$

$\begin{array}{ll}\text { References } & 155\end{array}$

Appendices $\quad 164$

A Appendix A: Questionnaire of the Firm Survey (2002) $\quad 65$

B Appendix B: Questionnaire of the Macro Survey (2002) 179

$\begin{array}{ll}\text { Samenvatting (Summary in Dutch) } & 187\end{array}$

$\begin{array}{lr}\text { Summary in English } & 189\end{array}$

$\begin{array}{lr}\text { About the Author } & 191\end{array}$

List of Tables $\quad$ xii

2.1 Table 2.1 - Population, GDP per-capita, real GDP growth and 11 unemplayment in the Gulf countries (1990-2002)

2.2 Table 2.2 - Proven crude oil and natural gas reserves and the share of oil 13 and non- oil sector in GDP in the Gulf countries (1980-2002)

2.3 Table 2.3- Oil reserves, share of oil in GDP, government revenues and 13 exports in the Gulf countries (1975-1998)

2.4 Table 2.4 - Total number and distribution of operating establishments (factories), capital investment and employment in selected industries in the Gulf countries (1998)

2.5 Table 2.5 - Total number and distribution of establishments (factories), capital investment and employment in the manufacturing industries in the Gulf countries 1998 (defined by industrial categorization).

2.6 Table 2.6 - Exports diversification index in the Gulf countries (19801990)

2.7 Table 2.7- The share of national and foreign labour in total labour force 20 in the Gulf countries (1975-1995)

2.8 Table 2.8 - Skill indicators in the Gulf countries compared to World countries (1992-2000)

2.9 Table 2.9 - Technology indicators in the Gulf countries compared to 25 World countries ( $1990-2002)$

2.10 Table 2.10 - Distribution of R\&D institutional units and full-wime 25 equivalent (FTE) researchers by type of R\&D Institution in the Gulf countries 1996

2.11 Table 2.11 -Technological structure of manufactured exports in the Gulf and developing countries (1985-1997) (\% of total manufactured exports)

2.12.a Table 2.12. a- Demand for and supply of technologies in the Gulf 28 countries (1989-1998) $(\%)$

2.12.b Table 2.12. b- Demand for and supply of technologies in the Gulf 28 countries (1996-1998) (\%)

4.1 Table 4.1- The distribution of chemical and metal industries defined by 59 employment size in the UAE and the Gulf countries (1998- 2000)

4.2 Table 4.2 - The average percentage share of emirates of Abu Dhabi, 60 Dubai and Sharjah in total number of factories, labour, capital and 
medium and large size firms in the chemical and metal industries (2000)

4.3 Table 4.3-Composition of the firm survey in the UAE, 2002

4.4 Table 4.4. Composition of the macro survey in the UAE, 2002

4.5 Table 4.5- Structure, aims and average response rate of the 63 questionnaire in the furm and macro surveys in the UAE, 2002

5.1 Table 5.1 - The Causes of deficient educational system in the UAE, 69 2002

5.2 Table 5.2 - The UAE educational matrix: The distribution of Popullation 70 by educational level (1985-1995)

5.3 Table 5.3 - The Factors constrained the transfer of knowledge/ external 71 schooling effect in the UAE, 2002

5.4 Table 5.4 - The factors constrained the provision of training in the UAE, 73 2002

5.5 Table 5.5 - Main technology and skill indicators defined by firm size and industry level in the UAE, 2002

5.6 Table 5.6 - The effects of increasing use of technology product and process innovations across firms in the UAE, 1999-2001

5.7 Table 5.7 - The channels of technology transfer and their effects on firm production and development of local technology across firms in the UAE, 2002

5.8 Table 5.8 - The shortage of skilled workers and effects across firms in the UAE, 2002 (1999-2001)

5.9 Table 5.9 - The effect of upskilling plan and technological upgrading across firms in the UAE, 2002: Micro view

5.10 Table 5.10 - The effects of technological upgrading, skill upgrading at the aggregate level in the UAE, 2002: Macro view

6.1 Table 6.1- Main characteristics of firms in the UAE (1999-2001) 89

6.2 Table 6.2- Public- private duality: differences in skill indicators, 96 diversification and productivity (1999-2001) (\% and Dirhams)

6.3 Table 6.3 - The vallue and trend of labour productivity (output/abour and capital/labour ratios across firms 1999-200"

6.4 Table 6.4 - Required and actual/ attained education and experience across firms (2001)

6.5 Table 6.5-Differences in the distribution of average wages defined by firm size and industry level (2001)

6.6 Table 6.6 - Correlation between wages (log) actual and required education and experience (2001)

6.7 Table 6.7 - Spending on ICT defined by firm size and industry level (1999-2001) (\% share in total spending)

6.8 Table 6.8 - The relationship between ICT, skill and upskilling across firms (2001)

6.9 Table 6.9 - The relationship between Computer, training and Telecommunication expenditure across firms (1999-2001)

6.10 Table 6.10 - The effects of new technologies on skill level and the demand for workers in the UAE, 2002

6.11 Table 6.11- Total spending on ICT, labour and capital across firms (1999-2001)

6.12 Table 6.12- Total spending on ICT, labour capital, output and profit 108 across firms (1999-2001) 
7.1 Table 7.1-The Determinants of Knowledge in the Gulf societies 115 $(1990-2001)$

7.2 Table 7.2 - The impacts of FTER and codified knowlledge on 116 publications, cooperation and patent actoss the Gulf countries (19902000)

7.3 Table 7.3 - The impacts of tacit and codified knowledge on schooling and GDP across the Gulf countries (1990-2001)

7.4 Table 7.4 - The significance of tacit knowledge across firms, 2001

Table 7.5 - The increased use and effects of skilled workers, scientists and engineers across firms in the UAE, 2002

7.6 Table 7.6 - The determinants/factors enhancing tacit knowledge across firms, 2001

8.1 Table 8.1 - Public expenditures on education in the Gulf countries compared to world countries (1990-2001)

8.2 Table 8.2 - Percentages distribution of current expenditure and current expenditure per pupil as a percentage of GNP per capita by educational level and in the Guilf countries (1990-2001)

8.3 Table 8. 3 - The Distribution of public and private expenditures on education and percentage ratio of private enrolment ratio in the Gulf countries ( $1.990-2000)$

8.4 Table 8. 4 - Pupil-teacher ratio by level of education in the Gulf countries (1990-2001)

8.5 Table 8.5-Enrolment ratios by educational level in the Gulf compared to world countries (1990-2002) $(\%)$

8.6 Table 8.6 - Quality of Education in the Gulf countries: percentage of repetition and transition (1990 - 2002)

8.7 Table 8.7-Educational outcomes: Youth illiteracy rate and school life expectancy in the Gulf countries (1990-2002)

8.8 Table 8.8-Human resources development and training policies in the large public firms in the UAE

8.9 Table 8.9-Plans and tools for skill development: macro-policy makers and experts view

8.10 Table 8. 10- Plans and tools for skill development: micro-firm view 134

8.11 Table 8. 11- Policies and mechanisms for skill development:(a) 137 macro/official view: Reform of educational system

8.12 Table 8. 12 - Policies and mechanisms for skill development: (b) macromicro views: factors enhancing the transfer of knowledge/ extemal schooling effect

8.13 Table 8. 13 - Policies and mechanisms for skill development: (c) macromicro views: promotion of training 2002) (Constant 1995 US\$)

2.2 Figure 2.2- The share of manufacturing in total exports in the Gulf 16 countries (1987-1998)

2.3 Figure 2.3 - The share of manufacturing in GDP in the Gulf countries 
(1987-1998)

2.4 Figure 2.4- The share of industry in total employment in the Gulf 1.6 countries (1980-1999)

2.5 Figure 2.5 - The trend of total GDP in the Gulf countries at current 17 prices (1980-2002) (Million US\$)

2.6 Figure 2.6 - The share of economically active population in economic 19 activities in the Gulf countries 1998

2.7 Figure 2.7 - The share of economically active population in the Gull 23 countries 1998 (defined by occupational level)

5.1 Figure 5.1 Past and Future trends (increase or stability) in the demand for skilled workers across firms

5.2 Figure 5.2 - Short, medium and long run plans of self- reliance on 83 national skills across public and private firm

6.1 Figure 6.1-Differences in the distribution of workers by educational 91 level across firms ( $\%$ share) 2001

6.2 Figure 6.2 - Differences in the distribution of workers by occupational level across firms ( $\%$ share) 2001

6.3 Figure 6.3 - Differences in the educational requirements by occupational 92 level across firms ( $\%$ share) 2001

6.4 Figure 6.4 - Average required years of schooling defined by occupation classes across firms (2001)

6.5 Figure 6.5 - Average years of experience defined by education and 93 occupation classes across firms (2001)

6.6 Figure 6.6- Skills mismatch defined by high medium and low skill 95 levels across firms (2001)

6.7 Figure 6.7- The distribution of occupation classes according to the 99 translated average years of schooling actoss firms (2001)

6.8 Figure 6.8 - The share and trend of total spending on ICT across firms 102 (1999-2001)

6.9 Figure 6.9 - The share and trend of spending on ICT training across 103 firms (1999-2001)

6.10 Figure 6.10: The increasing use of technology, ICT and the demand for 105 high skilled workers across firms, 1999-2001

8.1 Figure 8.1- Gross enrolment in tertiary education in the UAE, Bahrain, 126 Brazil and the Netherlands (1980-1998) (\%)

8.2 Figure 8.2- Relative distribution of tertiary education students (\%) by

fields in the Gulf countries compared to Algeria, India, China and Korea (1994/1997-1999/2000)

8.3 Figure 8.3-Relative distribution of tertiary education students $(\%)$ by attainment levels of higher education in the Gulf countries compared to China and Korea (1999/2000)

\section{List of Schemes}

1.1 Scheme1.I - Research Outline: summary of research aims, hypotheses and structure of the chapters

5.1 Scheme 5.1 - The Causes and Consequences of the Deficient Educational System and the Excessive Use of Unskilled Foreign Workers 


\section{List of Abbrewiations}

\begin{tabular}{|c|c|}
\hline ADNOC & Abu Dhabi National Oil Company \\
\hline AHDR & Arab Human Development Report \\
\hline API & Arab Planning Institute \\
\hline CIS & Community Innovation Survey \\
\hline DUBAL & Dubai Aluminium Company \\
\hline EPO & European Patents Office \\
\hline ERF & Economic Research Fonum for the Arab Countries, Iran and Turkey \\
\hline ESCWA & Economic and Social Commission for Western Asia \\
\hline FDI & Foreign Direct Investment \\
\hline FTER & Full-time equivalent researcher \\
\hline $\mathrm{GCC}$ & Gulf Cooperation Council \\
\hline GDP & Gross Domestic Products \\
\hline GOIC & Gulf Organization for Industrial Consulting \\
\hline GNP & Gross National Product \\
\hline $\mathrm{HCT}$ & Higher Colleges of Technology \\
\hline $\mathrm{ICT}$ & Information and Communication Technology \\
\hline ILO & International Labour Organization \\
\hline $\mathrm{MF}$ & International Monetary Fund \\
\hline $\mathrm{ISCO}$ & International Standards Classification of Occupations \\
\hline ISIC & International Standard Industrial Classification \\
\hline $\mathrm{IT}$ & Information Technology \\
\hline ITU & Intemational Telecommunication Union \\
\hline JULPHAR & Gulf Pharmaceutical Industries \\
\hline KSA & The Kingdom of Saudi Arabia \\
\hline MENA & Middle East and North Africa \\
\hline MOL & Ministry of Labour and Social Affairs \\
\hline MNC & Multinational Corporations \\
\hline MOP & Ministry of Planning \\
\hline OECD & Organisation for Economic Co-operation and Development \\
\hline OPEC & Organisation of the Petroleum Exporting countries \\
\hline$R \& D$ & Research and Development \\
\hline S\&T & Science and Technology \\
\hline $\mathrm{SITC} 7$ & Standard International Trade Classification (SITC) \\
\hline TAI & Technology Achievement Index \\
\hline TANMIA & The National Human Resources Development and Employment Authority \\
\hline TFP & Total Factor Productivity \\
\hline TNCs & Transnational Corporations \\
\hline$\cup A E$ & The United Arab Emirates \\
\hline UIS & UNESCO Institute of Statistics \\
\hline UN & The United Nations \\
\hline UNCOMTRAD & UNCTAD COMTRADE Database \\
\hline UNCTAD & The United Nations Conference on Trade and Development \\
\hline UNDP & United Nations Development Programme \\
\hline UNESCO & United Nations Educational, Scientific and Cultural Organization \\
\hline USPTO & US Patent and Trademark office web site \\
\hline WB & World Bank \\
\hline WDI & World Development Indicators - World Bank \\
\hline WEO & World Economic Outlook - International Monetary Fund \\
\hline WITSA & World Information Technology and Services Alliance \\
\hline
\end{tabular}


PART I

INTRODUCTION 


\section{Chapter 1}

\section{General Introduction}

\section{Introduction}

The aim of this introductory chapter is to give a brief general overview of the research problem and to briefly show the importance, relevance, objectives, questions, hypotheses and the general structure of the thesis.

\subsection{Research Problem, Importance, Relevance and Method}

Economists have long recognized the essential role of technical progress in the creation, acceleration and sustainability of economic growth and improvement of the quality of life in any society. Both the endogenous growth theories and empirical literature acknowledge the importance of human capital accumulation for economic growth. Endogenous growth literature also elaborates on the interaction and complementary relationship between technological progress and human capital to create, reinforce, accelerate and sustain economic growth (cf. Lucas, 1988; Romer, 1990). Moreover, economists also highlight the role of high levels and quality of skills as critical factors for competitiveness associated with the rapid progress of globalization and fast technological progress in the developed and developing countries. Considerable debate in the literature is on the effects of human capital and the diffusion and transfer of technology to the developing countries to accelerate the catching-up process. For instance, the Nelson and Phelps (1966) model allows human capital levels to affect the speed of technological catch-up and diffusion. Romer (1990) has also argued that the level of human capital may have an influence on growth of technological innovation both directly and through its effect on the speed of the "catch-up" process. Benhabiab and Speigel (1994) adapted the Nelson and Phelps (1966) framework to allow for the catching-up of technology with those of the leading countries. In their view, the level of education not only enhances the ability of a country to develop its own technological innovations, but also its ability to adapt and implement technologies developed elsewhere.

In this research we use the framework of and perspectives from the new growth literature to investigate the relevance and importance of skill upgrading and technological development and the interaction between these for economic development in the Gulf countries.' The Gulf countries have strategic importance in the global economy because the region holds $40 \%$ of world oil supplies (Devlin, 1998) and, therefore, affects the trends of oil supply and market. While oil has contributed to the enhancement of economic development in the region, the heavy dependence on it has led to serious challenges now confronting the Gulf countries since oil is an exhaustible resource and, because of the instability of oil

\footnotetext{
'The economies of Bahrain, Kuwait, Oman, Qatar, Saudi Arabia and the United Arab Emirates (UAE) constitute the Gulf countries and also known as the Gulf Cooperation Councill (GCC) countries.
} 
prices, the revenue from oil is uncertain and volatile. Moreover, both the growing employment opportunities and the increased wealth from oil encourages migration to these countries - consequently, migrants, especially unskilled workers, have dominated and caused serious structural imbalances in the labour market in the Gulf.

The GDP of the United Arab Emirates (UAE) is still growing, but GDP per capita is stagnant. ${ }^{2}$ So far, the falling contribution of the oil sector has been compensated by other sectors, but, in our view, the big question is whether or not this will work in the future. We feel that may be somewhat doubtful in light of current stagnation in education, particularly tertiary education. In addition, the high share of foreign workers indicates that the UAE is currently an agglomeration economy. But it may lose this position and become poor if both the oil industry and the complementary ones decline and/or if foreigners move out and there is less work in the government sector. While it is unclear which sector can fill the gap, it is evidently one that will need high levels of education. Therefore, it is quite essential for the government to improve investment and enrolment in education and skill upgrading.

So, the economic growth and sustainable development strategy in the Gulf depends on both a shift in the focus from an oil resources based economy to a technology and skill based economy and on economic diversification. A key part of this strategy is also to shift or to manage the economy away from dependency on the import of high skilled workers in favour of domestic skilled workers. Overcoming these strategic problems and challenges confronting economic development and thereby achieving long run economic growth and sustainable development in the Gulf depends on three main strategies: economic diversification, local technological development and self-reliance on domestic workers to restructuring the labour market. In our opinion the success/fulfilment of these strategies is contingent upon the development of adequate and appropriate skills, skill upgrading and efficient educational and training policies and building of local technological capabilities in the Gulf countries.

In our view, although the development of local technologies is a costly process, it can be funded from the oil revenues and by offering further incentives to motivate private investment in skills, technology and technical education. Moreover, to some extent, the Gulf countries have an option to remain importing technologies and to specialize in fields other than producing machinery and transport equipment (SITC 7). The Gulf countries show deficient skill and technology indicators and a substantial gap when compared to rapidly advanced countries. Therefore, the need for the development of local skills and building local technologies are important not only for fulfilling the above strategies, but also for shortening the gap, building local capacity, improving productivity and competitiveness in the international market (UAE University, 1997; El Sabaa, 1997; Alfakhry, 1999).

In our view, the implementation of these strategies is eminently impeded by the deficient educational system, the large share of unskilled foreign workers and the lack of incentives in the Gulf countries. One should note that many previous studies in the Gulf literature have well- investigated the implications of the excessive use of uneducated foreign workers and lack of incentives in the labour market. However, the impacts of the deficiencies in the educational system have not received an adequate investigation in these studies, despite the well known stylized facts in the endogenous growth literature that highlight the

\footnotetext{
${ }^{2}$ For the empirical investigation in Chapters 5 to 8 we focus on the UAE as a case study of the Gulf countries, due to easy accessibility to data and information and facillities for the fulfilment of the fieldwork.
} 
essential endogenous effect of education for accumulation of human capital and economic growth.

For that reason, our analysis in this research prowides many new and interesting results. Different from other Gulf literature, we identify upskilling as a key element for the fulfilment of the three current strategies in the Gulf. Furthermore, we provide a more comprehensive investigation since we discuss the skills problem from two different perspectives: combining the impacts of the deficient educational system and the high incidence of uneducated foreign workers. In addition ${ }_{4}$ our analysis goes beyond the available Gulf literature and presents a more elaborate and in-depth analysis to assess skill and technological performance in the Gulf since we use a very comprehensive set of indicators than often used in the new growth literature. We use these indicators to analyse the causes and consequences of low skills and technology levels, the link between them and the implications on skills mismatch, and the lack of local efforts for technological development and the consequent dependence on foreign technologies at both the macro and micro levels. In addition, in light of the recent literature that highlights the role of diffused technologies, our analysis uses a broader definition of technological change that considers the role of diffusion in fostering economic growth; and we assess the role of imported technologies and skill in promoting local technologies and local skills. This definition is particularly relevant for our analysis since the Gulf countries are highly dependent on both imported technologies and imported skilled workers to manage them. Our analysis also addresses the policy issues, stresses the role of both public and private educational and training policies and the need for incentives, harmony and collaboration between public-private institutions in upgrading skill and fostering human capital accumulation in the Gulf countries. Finally, our analysis fills the gap in the Gulf literature since we highlight the importance of knowledge and external effects of schooling/the transfer of knowledge and we explore the factors hindering and those contributing toward enhancing the transfer of knowledge at both the macro and micro levels.

Moreover, our research contributes to the few recent studies in the Gulf countries that call for upskilling and the interaction between skills and technology. We investigate the deficiencies in the educational and training systems (UAE University, 1994; Al-Sulayti, 2002; Gray, 1999; Abdelkarim and Haan, 2002); their impacts on skills mismatch; and the duality between public and private sectors (Gray, 1999; Khorshid, 2000; Abdelkarim and Haan, 2002). In addition, we show the impacts on poor technological level, dependence on foreign technologies and the impacts of technologies transfer (Elsabaa, 1997; Haan, 1999). Our analysis presents three new and additional aspects of the duality between public and private sectors with regard to knowledge transfer, upskilling and training policies.

To investigate the research problem we focus on the UAE as a case study of the Gulf countries, and we use a combination of primary and secondary data covering both the macro and micro levels and the results from the macro and firm surveys held in the UAE in 2002. In addition, the survey's data is supported by ten face-to-face interviews with firm managers and five interviews with the officials. The firm survey (2002) on "Technological change and skill development in the UAE manufacturing sector" aims to assess skill and technology indicators and the impacts of unskilled foreign workers amongst the chemical and metal medium and large size establishments in the UAE. The macro survey (2002) on "Skill creation, human resources development and policy intervention" was sent to policy makers and experts in the public and university institutions to examine the causes and con- 
sequences of low skills and the deficient educational system in the UAE. We collected all primary and secondary data personally.

\subsection{Objectives, Hypotheses and Questions of the Research}

Based on the above background, the central themes of this research are: the required skill formation and upskilling of the workers, together with their interaction with technological change; and the interaction between the deficient educational system and the excessive share of uneducated foreign workers and their implications. First, our analysis aims to provide an empirical investigation of the causes and consequences of low skill and technology indicators, in particular, the causes and consequences of the deficient educational system at the macro level and the implications of the excessive use of uneducated foreign workers at the micro level. Second, we examine the interaction between the low skill and technology indicators, the relationships between skill, upskilling and technology indicators, skills mismatch, the uses and impacts of ICT and differences defined by firm size (large and medium size) and industry (chemical and metal) at the micro/firm level. Third, we analyse the inpacts of tacit and codified knowledge at the micro and macro levels respectively and examine the factors hindering and those contributing toward enhancing the transfer of knowledge/external schooling effects at the macro and micro levels. Finally we highlight the need for implementation of consistent policies, increasing incentives and collaboration between public and private educational and training institutions to enhance skil. upgrading, local technological development, economic development and transfer of knowledge.

Grounded on these objectives, our research attempts to answer three sets of questions:

1. What are the major causes and consequences of low skill and technological levels in the Gulf countries? What are the major implications of the interaction between the deficient educational system and the high incidence of uneducated foreign workers at the macromicro levels in the Gulf countries?

2. Does the external effect of schooling/transfer of knowledge occur in the Gulf countries? If not, why does it not yet occur? What are the major factors hindering and those contributing toward enhancing the transfer of knowledge at both the macro and micro levels in the Gulf countries?

3. What are the major policies and mechanisms for upgrading skill, reforming the educational system, enhancing the provision of training and the development of local technologies at both the macro and micro levels in the Gulf countries?

Based on the research questions and objectives, the major hypotheses to be tested in this research are:

1. The Gulf countries need to promote local skills and local technologies in order to implement the three strategies of diversification, building local technological capacity and restructuring the labour market to achieve long term economic growth and sustainable economic development.

2. In the short and medium term, the Gulf countries are unable to rely on local skills and local technologies and will remain heavily dependent on both foreign skills and foreign technologies.

3. The interaction between the deficient educational system and the high incidence of uneducated foreign workers leads to low skill and technology levels and many other serious implications. 
3.a. The deficient educational system is caused by low quality of education and leads to: (a) poor provision of training; (b) low skill levels; (c) skills mismatch; (d) low transfer of knowledge/external schooling effect; (e) weak technology indicators; and (f) dependence on foreign technologies at the macro level.

3.b. The excessive share of low educated foreign workers leads to: (a) low skill levels; (b) serious skills mismatch; (c) poor provision of training; (d) poor technology indicators; (e) weak adaptation of imported technologies; ( $f$ ) dependence on foreign technologies; and ( $g$ ) public-private duality at the micro level.

3.c. The major causes of low levels of local technology are low/a lack of R\&D activities due to a lack of skills, transfer of knowledge, networks and collaboration between universities and industry/firms.

4.a. Irrespective of the observed differences in skill levels and requirements, the high skill requirements and the prevalent low skill levels - due to high share of unskilled foreign workers lead to skills mismatch, public-private duality and contribute to productivity decline across private firms.

4.b. An increase in skill level-share of high skilled in total employment and in firm sizeleads to improved relationships between actual and required education and experience and wages.

4.c. An increase in skill level-share of high skilled in total employment and in firm sizeleads to improvements in the complementary relationships between skill, upskilling and technology (ICT).

5. The use of ICT has positive but insignificant/inconclusive effect at the micro level/across firms.

6. The transfer of knowledge/external schooling effects is unsuccessful at the micro and macro levels. The major reasons behind the low transfer of knowledge/external schooling effects are low educational qualifications, and deficient educational and training systems. The major consequences are the lack of networks and collaboration between universities and firms, low R\&D efforts and low technology indicators.

7. Knowledge has positive impacts at the macro-micro levels; it can be enhanced by many factors.

7.a. At the macro level codified knowledge is positively correlated with economic growth (GDP); and tacit knowledge is positively correlated with schooling.

7.b. At the macro level codified knowledge and FTER show positive complementary relationships with each other and with technology (patents), publications and cooperation.

7.c. At the micro (firm) levell tacit knowledge is positively correlated with technology (expenditures on ICT), upskilling (expenditures on training), profit, productivity, output and output diversification.

7.d. At the micro (firm) level tacit knowledge is positively correlated with market size (firm size, capital, and investmenty and firm age. 8. The Gulf countries need to enhance their public- private educational and training poli-
cies:

8.a. Skill development depends on: (a) reforming the educational system; (b) enhancing the provision of training: (c) planning skill needs and matching educational output with market needs; (e) enhancing the transfer of knowledge/schooling effect; and (d) incentives and collaboration between public and private institutions.

8.b. The promotion of local technology and adoption of appropriate foreign technologies and the interaction between both to foster economic growth in the Gulf countries depends 
on skill development. In particular, an enhancement of: (a) skill upgrading: educational and training systems; (b) R\&D activities; (c) the transfer of knowledge/schooling effects; (d) networks systems; and (e) incentives to motivate collaboration between unversities and firms and between public and private institutions.

8.c. Both upskilling policies (educational and training policies) and transfer of knowledge are consistent at both the macro-micro levels and across public-private sectors.

\subsection{Structure of the Thesis}

Considering the research problem, aims, questions and hypotheses, it is convenient in this initial chapter to set out the structure of the thesis. This research is composed of four parts and nine chapters structured in the following way. Part One presents the introduction and motivation of the research and includes both Chapters 1 and 2 . Chapter 1 presents an introduction and briefly shows the aims, importance, relevance, hypotheses, questions and the general structure of the research. Chapter 2 explains some stylized facts about the Gulf countries that help to investigate more extensively the research problem along with other strategic problems and challenges confronting economic development, the impacts of oil and the Dutch disease in the structure of the labour markets and economies in the Gulf countries. In addition, this chapter aims to assess and elaborate the low skill and technology indicators and the gap in the Gulf compared to rapidly advanced countries and to show some stylized facts that justify and highlight the need for skill upgrading and technological devellopment in these countries.

Part Two presents the conceptual and theoretical framework and includes Chapter 3 , which defines the concepts and describes the measures of technological change and human capital (education) and briefly explains the theoretical and empirical literature on the relationship between human capital, technological changes and economic growth. The purpose of this survey is to provide a background for our study, mainly to highlight the endogenous effects of technical change and human capital as confirmed in the endogenous growth literature to motivate the empirical analysis in the next chapters.

Part Three presents the empirical application and includes Chapters 4 to 7 . Chapter 4 defines the methods of data collection; identifies the motives for performing the macro and firm surveys and selection of a case study; specifies the selection of the sample and the composition, operation, coverage, advantages and limitations of the survey's data; and shows the structure and design of the questionnaire. Next, Chapter 5 uses the data and results from the firm and macro surveys to examine the serious implications of the interaction between the deficient educational system and the high incidence of unskilled foreign workers. In particular, we use the results from the macro survey to show the causes of the deficient educational system and consequences on low skill levels, poor provision of training, skills mismatch and lack of/low transfer of knowledge at the macro level. In addition, we use the results from the firm survey to illustrate the implications of the high incidence of unskilled foreign workers on causing a low skill levels, poor provision of training, skills mismatch, poor technology indicators and a heavy dependence on foreign technologies. Furthermore, we investigate from the micro-macro perspectives the transfer of knowledge, upgrading of skill and technology and their potential implications, and we also present a more comprehensive assessment of technollogy and skill indicators at the micro level. Chapter 6 aims to broaden our analysis in Chapter 5 by providing an in-depth analysis of skill and technology indicators, the relationship between them, and the implications of the preva- 
lence of low-skilled foreign workers on skills mismatch and the public-private duality at the micro level. We use the data from the firm survey (2002) to examine the relationships between skills (actual and required education and experience) and wages; between skill, upskilling (ICT training) and technology (ICT); and between technology (ICT) and inputoutput indicators across firms. We also compare the relevanice of our results to the theoretical framework in Chapter 3 and the findings concerning these relationships in the new growth literature. Chapter 7 extends our analysis in Chapter 5 on the transfer of knowledge. We use the data from the firm survey (2002) at the micro level and some secondary data at the macro level to discuss the importance (impacts) of knowledge in the UAE/Gulf countries. In particular, we check the relevance of some stylized facts about the importance (impacts) of knowledge at the micro-macro levels to the findings in knowledge literature.

Finally, Part Four presents the policies, recommendations and conclusions and includes Chapters 8 and 9 . Chapter 8 concludes our analysis by discussing educational policies, since our earlier analysis in Chapter 5 investigates the causes and consequences of deficient educational and training systems, the lack of knowledge transfer and upskilling, and the results set in Chapters 6 and 7 imply the importance of a good education. From that perspective, therefore, Chapter 8 discusses the supply-demand sides and implications of educational policies in the Gulf countries. In addition, we use the results from the macro and firm surveys (2002) to examine the macro-micro views and suggestions for relevant mechanisms and policies for skill upgrading via an enhancement of the educational system and the provision of training and transfer of knowledge/external schooling effects at the macro-micro levels in the UAE. Finally, Chapter 9 summarizes the major findings, compares the main results with the findings in the general literature and contributions to the Gulf literature and concludes with policy recommendations.

Scheme 1.1 summarizes the main outline of research aims, hypotheses and structure of the chapters.

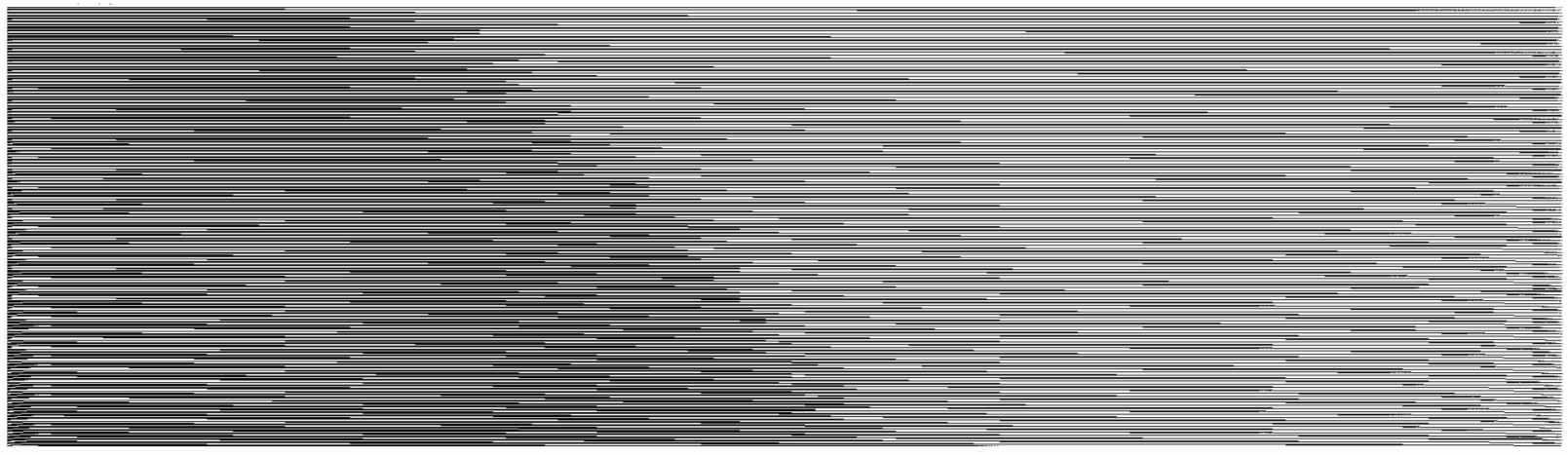




\begin{tabular}{|c|c|c|}
\hline Research aims: & Regermeh Hopotheses & Rosiearelh \\
\hline 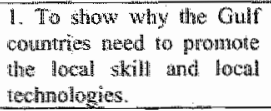 & 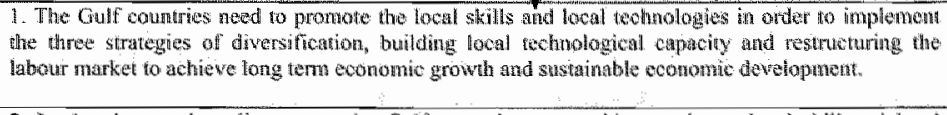 & Chepptict 2 \\
\hline 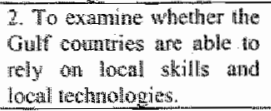 & 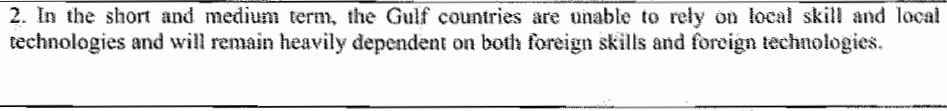 & $\begin{array}{l}\text { Chaphets } \\
2 \text { and } 5\end{array}$ \\
\hline 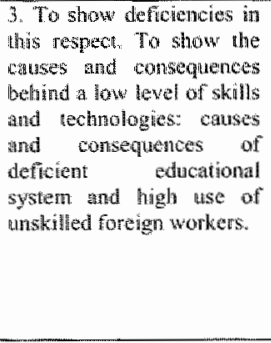 & 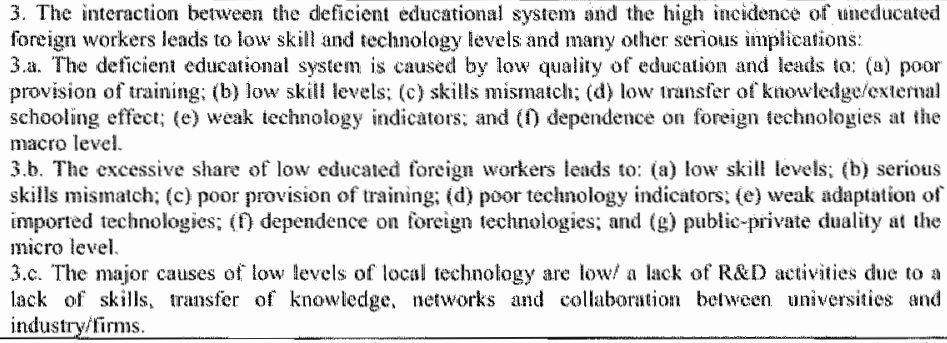 & $\begin{array}{l}\text { Chaphers } \\
2,5,6 \text { intid: } \\
8\end{array}$ \\
\hline $\begin{array}{l}\text { 4. To compare the } \\
\text { relationships between } \\
\text { lechnology, upskilliag, } \\
\text { skill and growsh across } \\
\text { Fmoms. }\end{array}$ & 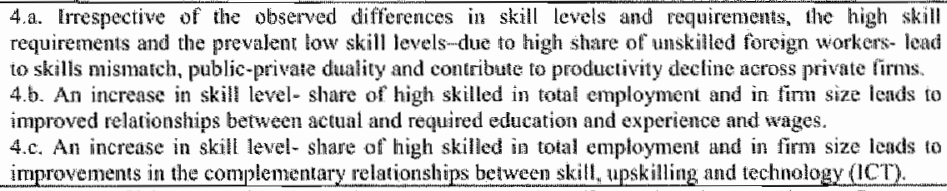 & $\begin{array}{l}\text { Chanders } \\
5,6 \text { bussed } \\
\text { on } 3\end{array}$ \\
\hline $\begin{array}{l}\text { 5. To axamine the effect } \\
\text { of loT at the micro level } \\
\text { acrosis firmes. }\end{array}$ & 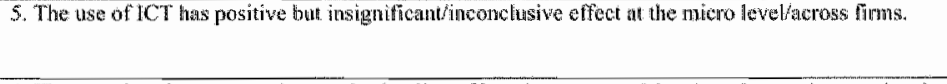 & Chapter 6 \\
\hline 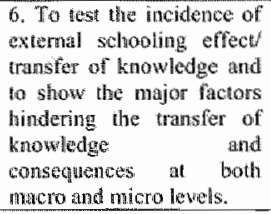 & 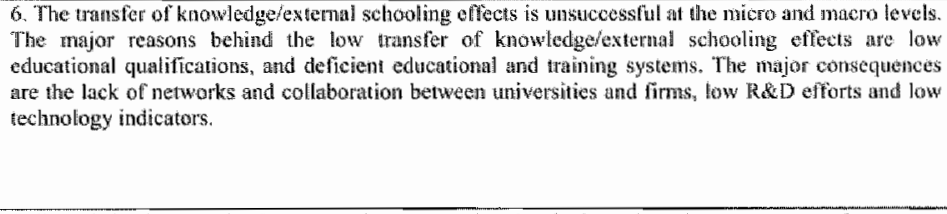 & Chapter 5 \\
\hline 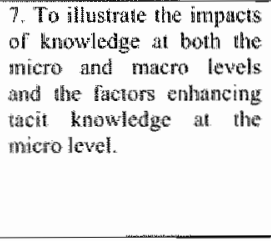 & 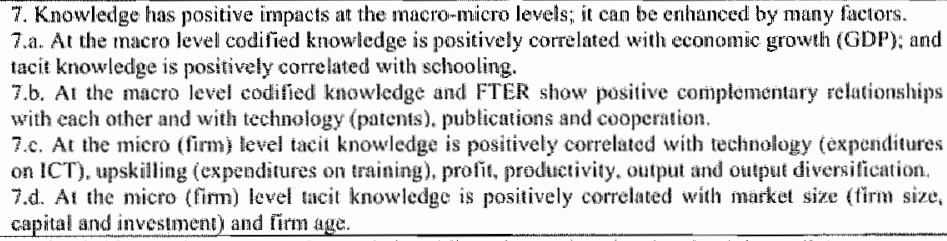 & Chapter 7 \\
\hline 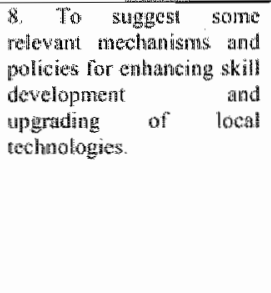 & 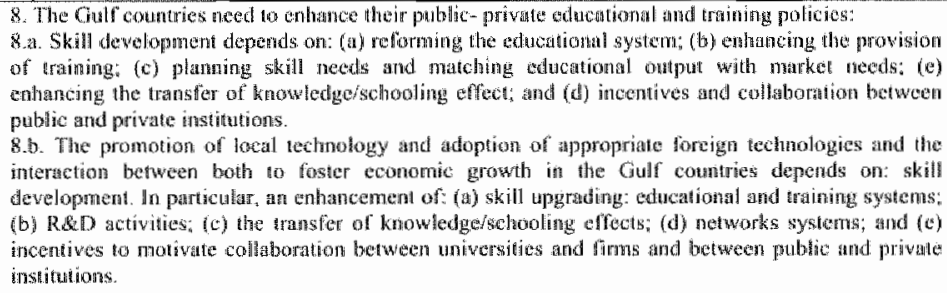 & $\begin{array}{l}\text { Chapters } \\
8 \text { and } 9\end{array}$ \\
\hline
\end{tabular}




\section{Chapter 2}

\section{Economic Development Challenges in the Gulf and the Need for Skill Upgrading and Technological Development}

\section{1 Introduction}

In Chapter 1 we introduced the research problem, the aim of this chapter is twofold: first, to present a background to motivate the research by explaining some stylized facts to examine more extensively the research problem along with other strategic problems confronting economic development in the Gulf countries. Second, to highlight the need for upskilling and technological development in these countries.

The Gulf countries have strategic importance in the global economy because the region holds $40 \%$ of world oil supplies (Devlin, 1998) and therefore affects the trends of oil supply and market. ${ }^{3}$ At the regional level, oil provides a significant contribution for developing the economies and social welfare in the Gulf, in particular, it leads to higher per capita income. However, the Gulf countries are now confronted with serious challenges posed by oil being an exhaustible resource as well as the uncertain and volatile revenues from oil, because of instability of oil prices. Hence, economic growth and sustainable development strategy in the Gulf depends on both a shift in the focus from an oil resources based econony to a technology and skill based economy and on economic diversification. Also part of this strategy is a shift away from the impont of high skilled workers in favour of domestic skilled workers.

Moreover, both the growing employment opportunities and the increased wealth from oil has encouraged migration to the Gulf countries. Consequently, migrant workers have dominated the labour market, particularly in the private sector, which leads to several problematic features such as the low skill levels, duality due to concentration of domestic workers in the public sector and foreign workers in the private sector and a growing unemployment rate. In addition, the Gulf countries suffer from structural problem related to the Dutch disease and lack of incentives, which has also affected the structure of labour mar-

\footnotetext{
"Fasano and lqbal (2003) indicate that the Gulf region accounts for about $45 \%$ of the world's proven oil reserves and $25 \%$ of crude oil exports (Sandi Arabia is the largest oil exporter). The region possesses at least $17 \%$ of the proven global natural gas reserves (Qatar has become the fourth-largest exporter of lique-
fied natural gis).
} 
ket. Moreover, skill and technology indicators in the Gulf countries show poor performance and a substantial gap when compared to international standards. Hence, the upskilling and technological development become imperative to overcome the strategic problems and challenges confronting economic development in the Gulf countries.

The rest of this chapter is organized in the following way. Section 2 explains the role of oil in the Gulf economies, discusses the strategic problems facing the labour market in the Gulf and highlights the need for skill upgrading and technological development; Section 3 concludes.

\section{2 Economic characteristics and strategic problems for development in the Gulf countries}

Since the structure of the Gulf economies is related to oil, it will be useful to start by explaining the role of oil in creating opportunities and challenging economic development in these countries. Next, show the structural problems related to the labour market, skills, technology and productivity.

\subsubsection{Oil and the opportumities for development in the Gulf countries}

The Gulf countries are characterized by a small population (except Saudi Arabia) and a high GDP per capita. According to the UNDP human development indicators the average GDP per capita in all Gulf countries is higher than the world average. Moreover, according to the World Bank classification of economies four of the Gulf countries are amongst the higher income and the other two are amongst the upper medium income economies - see Table 2.1 below.

Table 2.1-Population, GDP per-capiat real GDP growth and wnemployment in the Grlf countries (1990-2002)

\begin{tabular}{|c|c|c|c|c|c|c|c|c|c|c|}
\hline \multirow[t]{2}{*}{ Country } & \multirow{2}{*}{$\begin{array}{l}\text { Population } \\
\text { size } \\
\text { (million) } \\
2002\end{array}$} & \multirow{2}{*}{$\begin{array}{l}\text { GDP/capi } \\
\text { ta (PPP } \\
\text { USS) } \\
2002\end{array}$} & \multicolumn{4}{|c|}{$\begin{array}{l}\text { Real GDP Growth (average annual } \\
\text { change in per cent) }\end{array}$} & \multicolumn{4}{|c|}{$\begin{array}{l}\text { Unemployment (in per cent } \\
\text { of total labour force) }\end{array}$} \\
\hline & & & 1995-2000 Average & 1999 & 2000 & 2001 & 1990 & 1995 & 2000 & 2001 \\
\hline Bahrain & 0.7 & 17,170 & 4.3 & 4.3 & 5.3 & 4.8 & $n /$ a & 10.0 & 12.0 & 12.0 \\
\hline Kuwait & 2.4 & 16,240 & 3.8 & -2.9 & 2.9 & .0 .6 & 0.5 & 1.5 & 2.1 & 2.3 \\
\hline Oman & 2.8 & 13,340 & 3.6 & -0.2 & 5.1 & 7.3 & $\mathrm{~m} / \mathrm{a}$ & $n / a$ & $n / a$ & $n / a$ \\
\hline Qatar & 0.6 & 19,844 & 9.4 & 5.3 & 11.6 & 7.2 & $\mathrm{n} / \mathrm{a}$ & $\mathrm{n} / \mathrm{a}$ & $n / a$ & $n / x$ \\
\hline KSA & 23.5 & 12,650 & 1.9 & -0.8 & 4.9 & 1.2 & $\mathrm{n} / \mathrm{a}$ & $n / a$ & $n / a$ & $\mathrm{~N} / \mathrm{a}$ \\
\hline UAE & 2.9 & 22,420 & 5.7 & 3.9 & 5.0 & 5.1 & $n / a$ & $n / a$ & $n / a$ & n/a \\
\hline Total GCC & 32.9 & 16,944 & 3.3 & 0.3 & 5.1 & 2.5 & 0.5 & 5.8 & 7.1 & 7.2 \\
\hline
\end{tabular}

Sources: (a) UNDP (2004) Human Development Report (2004), (b) The IMF: World Economic Outlook. September 2002 ; MF; staff estimates. I/ Simple average: nationals only for Bathrain.

Although the GDP of the UAE is still growing - see Table 2.1 above -as is the foreign and domestic labour force, GDP per capita remains stagnant - see Figure 2.1 below. This implies that the falling contribution of the oil sector has been compensated so far by other

\footnotetext{
${ }^{4: T}$ The Dutch Disease is a process in which the discovery of natural resources causes a country to experit ence a 'change in the group of reference' from one that aim at generating a trade surplus in manufacturing to one that able to generate a trade surplus in primary commodities. The country experiencing this disease also shows differences between employment in manufacturing. The process of de-industrialisation due to the discovery of natural resources, mainly natural gas apparent from the case of Holland". (cf. Palna, 2003: 21)
} 
sectors - see Table 2.2 bellow. However, the big question from Chapter 1 above is whether or not this will work in the future. The stagnation in education, particularly in tertiary education-see our discussion in Chapter 8 below-makes us fairly sceptical, as we argue in the introductory chapter too. In particular, because investment in human capital is going on all over the world, mainly because a sufficiently high quality of education is essential prerequisite for high value added. In addition, as we explain below, the high share of foreign workers indicates that currently the $\mathrm{UAE}$ is an agglomeration economy. But it may lose this position and become poor if the oil industry and the complementary ones decline and/or if foreigners leave the country and there is less work in the government sector. Although it is unclear which sector could possibly fill the gap, it is clearly one that will need high levels of education. Therefore, it is quite essential for the government to adopt measures to improve investment and enrolment in education and to upgrade skills.

Figure 2.1 - Trend of GDP per capita in the United Arab Emirates (1973-2002) (Constant 1995 US\$)

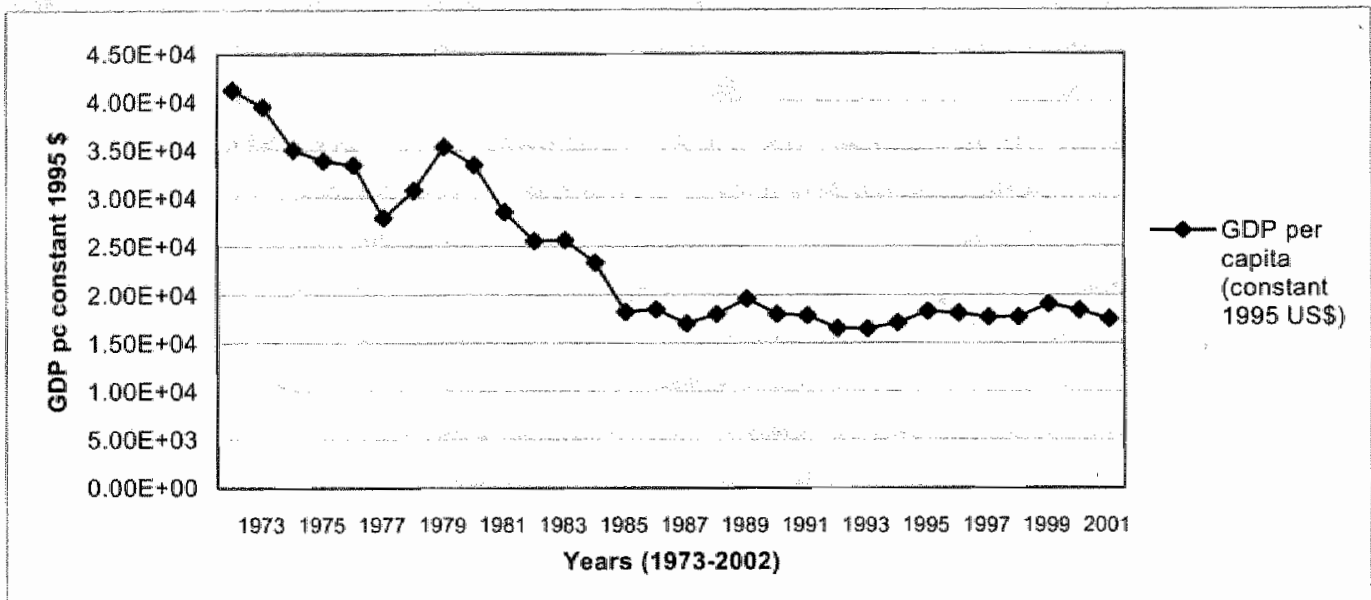

Source: Word Development Indicators Database

One should observe that during the past decades the increasing exploitation and development of oil and natural gas reserves have played an important role in developing the economies and raising government revenues, total exports, GDP and GDP per capita in the Gulf countries. ${ }^{5}$ Tables 2.2 and 2.3 show that despite the declining share of the oil sector compared to the non-oil sector for all Gulf countries, the share of oil sector remains significant and exceeds $30 \%$ of total GDP, $61 \%$ of total government revenues and $68 \%$ of total exports during the period $1975-1995.6,7$

\footnotetext{
"Expect in Bahrain, which shows decreasing trends with respect to both total oil and natural gas reserves.

"The share of oil sector refers to the total share of crude oil and oil inclustries, including refineries, downstream processing and petrochemical, etc. Fasano and Iqbal (2003) indicate that oil contributes about onethird to total GDP and three-fourths to annual government revenues and exports.

${ }^{7}$ Except in the case of Bahrain, where the share of oil in GDP declines from $26 \%$ in 1975 to $18 \%$ in 1995 .
} 


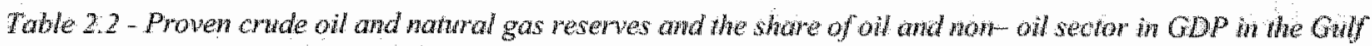
countries $(1980-2002)$

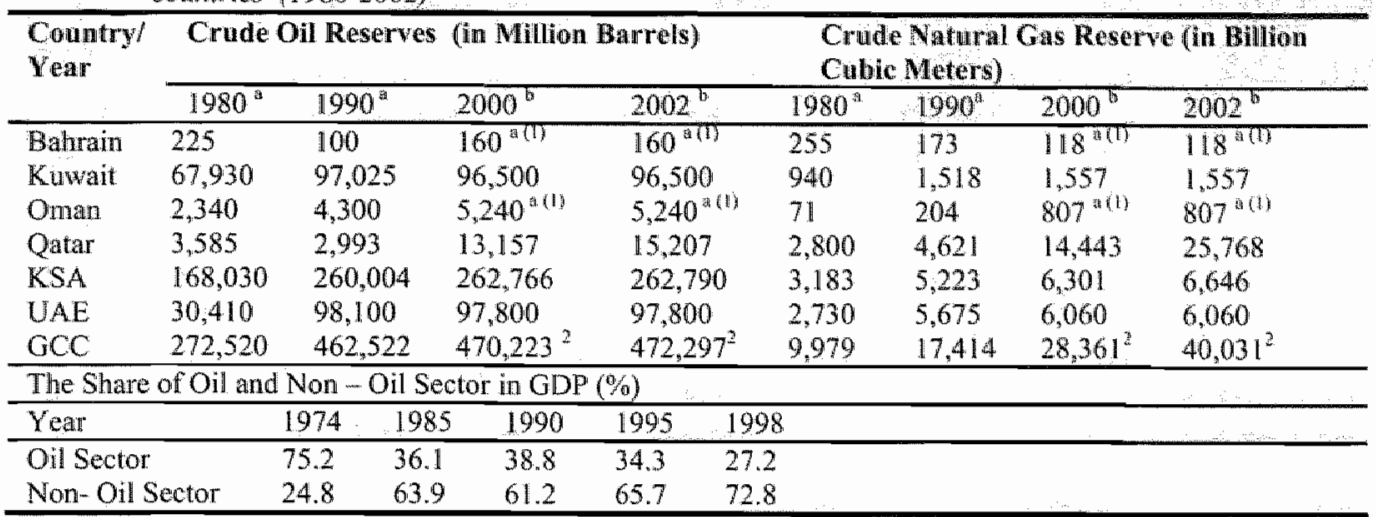

Note: (1) Data refers to 1998 (2) Data excludes Bahrain and Oman

Sources: (a) GOlC Industrial Data Bank (2000b) and (b) OPEC (2002).

Table 2.3 - Oil reserwes, share of oil in GDP government revenwes and exports in he Gulf commities (1975-1998)

\begin{tabular}{|c|c|c|c|c|c|c|c|c|}
\hline \multirow[t]{2}{*}{$\begin{array}{l}\text { Countryl } \\
\text { Year }\end{array}$} & \multirow[t]{2}{*}{$\begin{array}{l}\text { Years of } \\
\text { oill } \\
\text { reserves }\end{array}$} & \multicolumn{2}{|c|}{$\begin{array}{l}\text { Share of oil in } \\
\text { GDP }(\%)^{\mathrm{a}}\end{array}$} & \multicolumn{2}{|c|}{$\begin{array}{l}\text { Share of oil } \\
\text { revenues in } \\
\text { total govern- } \\
\text { ment reve- } \\
\text { nues }(\%)^{\mathrm{a}}\end{array}$} & \multirow[t]{2}{*}{$\begin{array}{l}\text { Share of oil } \\
\text { and gas } \\
\text { exports in } \\
\text { total ex- } \\
\text { ports }(\%)^{a} \\
1975\end{array}$} & \multicolumn{2}{|c|}{$\begin{array}{l}\text { Share of oild, chemical, } \\
\text { machinery, equipment and } \\
\text { manufactured products in } \\
\text { total imports }(\%)^{\circ}\end{array}$} \\
\hline & & 1975 & 1995 & 1975 & 1995 & & 1995 & 1998 \\
\hline Bahrain & 5 & 26 & 18 & 77 & 62 & 86 & 70 & 53.3 \\
\hline Kuwait & 136 & 70 & 48 & 74 & 78 & 92 & 95 & 81 \\
\hline Oman & 17 & 67 & 37 & 90 & 76 & 98 & 85 & 79 \\
\hline Qatar & 20 & 68 & 36 & 89 & 68 & 96 & 76 & 86.6 \\
\hline $\mathrm{KSA}$ & 82 & 71 & 38 & 80 & 71 & 99 & 95 & 75.7 \\
\hline UAE & 110 & 68 & 32 & 85 & 88 & 96 & 69 & 86,4 \\
\hline $\mathrm{GCC}$ & 61.67 & 61.67 & 34.83 & 82.5 & 73.83 & 94.5 & 81.67 & 79.8 \\
\hline
\end{tabular}

Sources: (a) Askari, Nowshirvani and Jaber (1997) and World Development Indicators, and (b) GOlC Industrial Data Bank (2000b).

Moreover, the concentration of oil reserves is the motivating factor for the bulk of the investments in manufacturing and industrial activities in the Gulf countries being concentrated in Saudi Arabia and the UAE. For instance, Table 2.4 shows that these two countries account for $68.3 \%$ of total number of factories, $80.4 \%$ of total capital investment and $77.1 \%$, of total employment. Consequently, they account for $78 \%$ of total chemical, petroleum, coal and plastic products; $57 \%$ of total non-metallic mineral products; $76 \%$ of total basic metallic industries and $73 \%$ of total fabricated metal products, machinery and equipment industrial activities in the Gulf countries.

More recently, the cheap and abundant availability of oil and natural gas in the Gulf region has contributed to an enhancement of the industrial and manufacturing sector; oil, in particular, has promoted the development of the petroleum and petrochemical industries in the Gulf countries. Tables 2.4 and 2.5 indicate that the chemical, petroleum, coal and plastic products; the fabricated metal products, machinery and equipment; and the non-metallic mineral products are the major manufacturing activities in the Gulf and their shares in total number of factories are respectively $18.5 \%, 26.7 \%$ and $17 \%$. In addition, the chemical, petroleum, coal and plastic products category has the highest share among manufacturing 
industries in terms of capital investment, followed by the fabricated metal industries in terms of the total number of factories and employment.

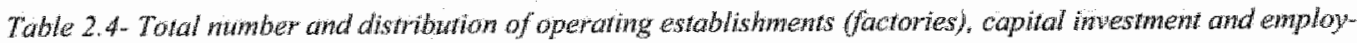
ment in selected mowries in the Gulf combries (1998)

\begin{tabular}{|c|c|c|c|c|c|c|c|}
\hline \multirow[t]{2}{*}{ Country } & \multicolumn{4}{|c|}{ Number of factory $(\%)$} & \multicolumn{2}{|c|}{$\begin{array}{l}\text { Total Capital } \\
\text { investment } \\
\text { (million dollars) } \\
(\%)^{\text {an }}\end{array}$} & \multirow{2}{*}{$\begin{array}{l}\text { Total num- } \\
\text { ber of } \\
\text { workers } \\
(\%) \\
\text { All indus- } \\
\text { mies }(\%)^{2}\end{array}$} \\
\hline & $\begin{array}{l}\text { All } \\
\text { Indusis- } \\
\text { trites } \\
(9 / 0)^{3}\end{array}$ & $\begin{array}{l}\text { Chemical, } \\
\text { Petrolleum, } \\
\text { Coall and } \\
\text { Plastic } \\
\text { Products } \\
(\%)^{\text {b }}\end{array}$ & $\begin{array}{l}\text { Non- } \\
\text { Metallic } \\
\text { Mineral } \\
\text { Products } \\
(\%)^{b}\end{array}$ & $\begin{array}{l}\text { Basic } \\
\text { Metallic } \\
\text { Indius- } \\
\text { tries } \\
(\%)^{\text {b }}\end{array}$ & $\begin{array}{l}\text { Fabricated } \\
\text { Metal Products, } \\
\text { Machinery and } \\
\text { Equipment }(\%)^{\text {b }}\end{array}$ & $\begin{array}{l}\text { All } \\
\text { indus- } \\
\text { tries } \\
(\%)^{\text {gh }}\end{array}$ & \\
\hline \multirow[t]{2}{*}{ Batrain } & 393 & 54 & 58 & 9 & 81 & 5293 & 25554 \\
\hline & $(5.5)$ & (4) & (5) & $(10)$ & (4) & $(6.5)$ & $(4.6)$ \\
\hline \multirow[t]{2}{*}{ Kuwait } & 720 & 103 & 181 & 3 & 200 & 6659 & 47802 \\
\hline & $(10.2)$ & (8) & $(15)$ & (3) & (1.) & $(8.2)$ & $(8.6)$ \\
\hline \multirow[t]{2}{*}{ Oman } & 751 & 86 & 183 & 8 & 1.51 & 1690 & 31737 \\
\hline & $(10.6)$ & (6) & (15) & (9) & (8) & $(2.1)$ & $(5.7)$ \\
\hline \multirow[t]{2}{*}{ Qatar } & 382 & 55 & 96 & 3 & 67 & 2322 & 22195 \\
\hline & $(5.4)$ & (4) & (8) & (3) & (4) & $(2.9)$ & (4) \\
\hline \multirow[t]{2}{*}{ KSA } & 2996 & 639 & 444 & 34 & 877 & 57042 & 282700 \\
\hline & $(42.3)$ & $(48)$ & (36) & $(37)$ & $(46)$ & $(70.1)$ & $(50.5)$ \\
\hline \multirow[t]{2}{*}{$U A \mathbb{E}$} & 1846 & 407 & 261 & 36 & 520 & 8362 & 148509 \\
\hline & $26.0)$ & $(30)$ & (21) & (39) & (27) & $(10.3)$ & $(26,6)$ \\
\hline $\mathrm{GCC}$ & 7088 & 1,344 & 1,223 & 93 & 1,896 & 81367 & 559352 \\
\hline
\end{tabular}

Note: Figures between brackets represent the share in total Gulf countries.

Sources: (a) Shiha, M. (2000) P.2I and (b) GOlC Industrial Data Bank (2000b)

Table 2.5 - Total mumber and distribution of establishments (factories), capiral investment and employment in the manufocturing industries in the Gulf counries 1998 (defined by industrial categorization)

\begin{tabular}{|c|c|c|c|c|c|c|}
\hline Industrial category & $\begin{array}{l}\text { Number } \\
\text { of fac- } \\
\text { tory }\end{array}$ & $\%$ & $\begin{array}{l}\text { Total Capital } \\
\text { investment (million } \\
\text { dollars) }\end{array}$ & $\%$ & $\begin{array}{l}\text { Total num- } \\
\text { ber of } \\
\text { workers }\end{array}$ & $\%$ \\
\hline $\begin{array}{l}31 \text { - Food, Bevertiges and } \\
\text { Tobacco. }\end{array}$ & 1048 & 14.8 & 6012 & 7.4 & 73471 & 13.4 \\
\hline $\begin{array}{l}\text { 32. Textile, Wearing, Apparel } \\
\text { and Leather. }\end{array}$ & 483 & 6.8 & 1103 & 1.4 & 56990 & 10.4 \\
\hline $\begin{array}{l}\text { 33-Wood Products Including } \\
\text { Fumiture. }\end{array}$ & 452 & 6.4 & 736 & 0.9 & 25587 & 4.7 \\
\hline $\begin{array}{l}\text { 34. Paper Products, Printing } \\
\text { and Publishing. }\end{array}$ & 455 & 6.4 & 1794 & 2.2 & 28853 & 5.3 \\
\hline $\begin{array}{l}\text { 35- Chemical, Petroleum, Coal } \\
\text { and Plastic Products. }\end{array}$ & 1314 & 18.5 & 49605 & 61.0 & 1.17805 & 21.6 \\
\hline $\begin{array}{l}\text { 36- Non-Metallic Mineral } \\
\text { Products }\end{array}$ & 1173 & 16.5 & 9.54 & 11.1 & 77645 & 1.4 .2 \\
\hline 37- Basic Metallic Industries. & 93 & 1.3 & 6013 & 7.4 & 18221 & 3.3 \\
\hline $\begin{array}{l}\text { 38- Fabricated Metal Products, } \\
\text { Machinery and Equipment. }\end{array}$ & 1891 & 26.7 & 6730 & 8.3 & 137769 & 25.2 \\
\hline $\begin{array}{l}\text { 39. Other Maunufacturing } \\
\text { Industries }\end{array}$ & 179 & 2.5 & 321 & 0.4 & 10011 & 1.8 \\
\hline Total & 7088 & 100 & 81368 & 100 & 546352 & 100 \\
\hline
\end{tabular}




\subsubsection{Oil and the challenges of developmen in the Gulf countries}

On the other hand, the heavy dependence on oil has created several serious challenges for development in the Gulf countries. One serious challenge following the discovery of oil is that the Gulf countries suffer from structural problems related to the Dutch Disease phemomenon. For instance, the World Bank (2004) indicates that despite massive efforts to promote industrialization in many of the MENA (including the Gulf) countries, the manufacturing share in employment and output was either stagnant or declining in 1970 s and 1980 s, a result of the Dutch Disease phenomenon.8. A general increase in expenditures and appreciation of the real exchange rate brought about by the oil windfall resulted in a boom in nontradables, adversely affecting the production of tradable goods (World Bank 2004: 104; Corden, 1984; Richards and Waterbury, 1998). The Dutch Disease or deindustrialization appears from the declining share of manufacturing and industry in total exports, GDP and employment - see Figures $2.2-2.4$ below.

In contrast to the World Bank (2004) argument presented above, a study by Goyal (2003) provides a conflicting argument against the Dutch disease and indicates that the UAE managed to avoid the Dutch disease. "Access to expatriate workers at internationally competitive wages also contributed to avoiding the consequences of a "Dutch disease" usually observed in oil (or other natural resource) rich economies like the UAE. In most of these economies, the formal or organized labor market comprises mainly national. Thus when the world price of oil rises, the wages of these nationals increase, making the non-oil export sector less competitive and encouraging the adoption of import substitution policies. In contrast, the UAE economy has been able to avoid "this disease" because it faces a highly elastic supply of foreign labor at competitive international wages and flexible contracts. In fact, the exogenous decline in real and relative wages of low-skilled expatriate workers over the 1990 s contributed to boosting employment and output growth by lowering relative labor costs. As a result, employment of low skilled workers was especially strong in that period, as was the growth of sectors such as trade and construction that use low-skilled workers more intensively" (cf. Goyal, 2003: 46).

\footnotetext{
According to the World Bank classification of world regions the Middle East and North Africa (MENA) region is composed of fourteen countries, including Algeria, Djibouti, Egypt, Iran, Iraq, Jordan, Lebanon, Libya, Morocco, Oman, West Bank and Gaza: Occupied Palestine Territories, Syrian Arab Republic, Tunisia and Yemen.
} 
Fingure 2.2- The shore of manufocturing in lold exports in the Gulf countries (1987-1998)

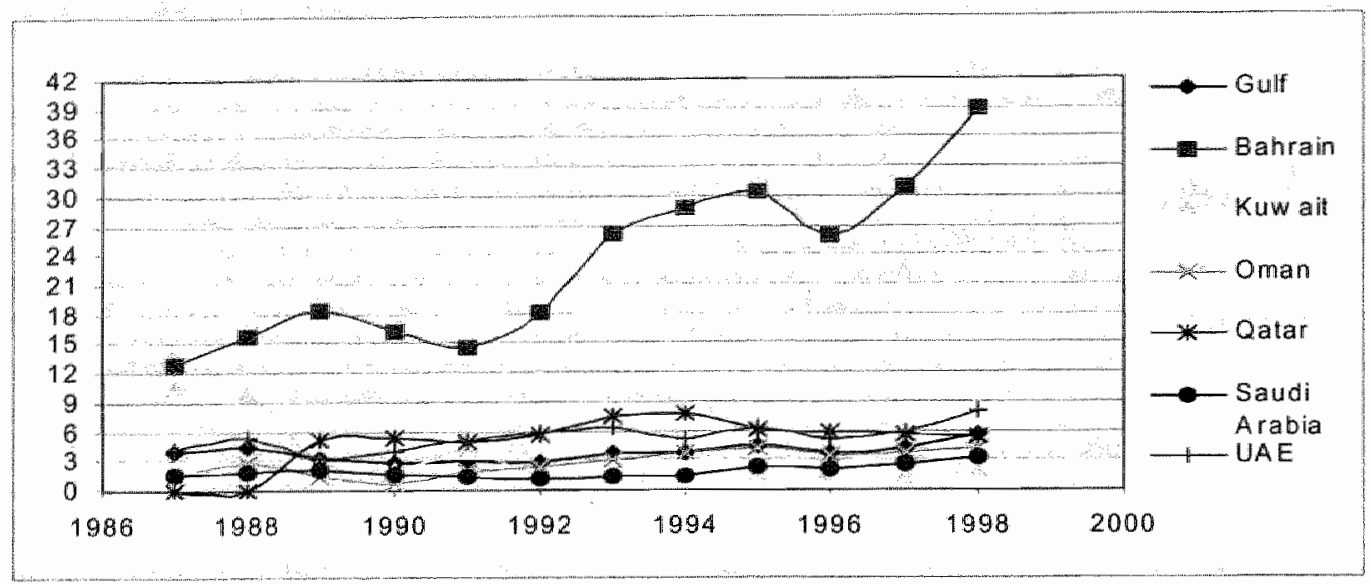

Source: Adapted from GOIC $(1998,2000 a)$

Figure 2.3 - The share of mamufachiring in GDP in the Gulf countries (1987-1998)

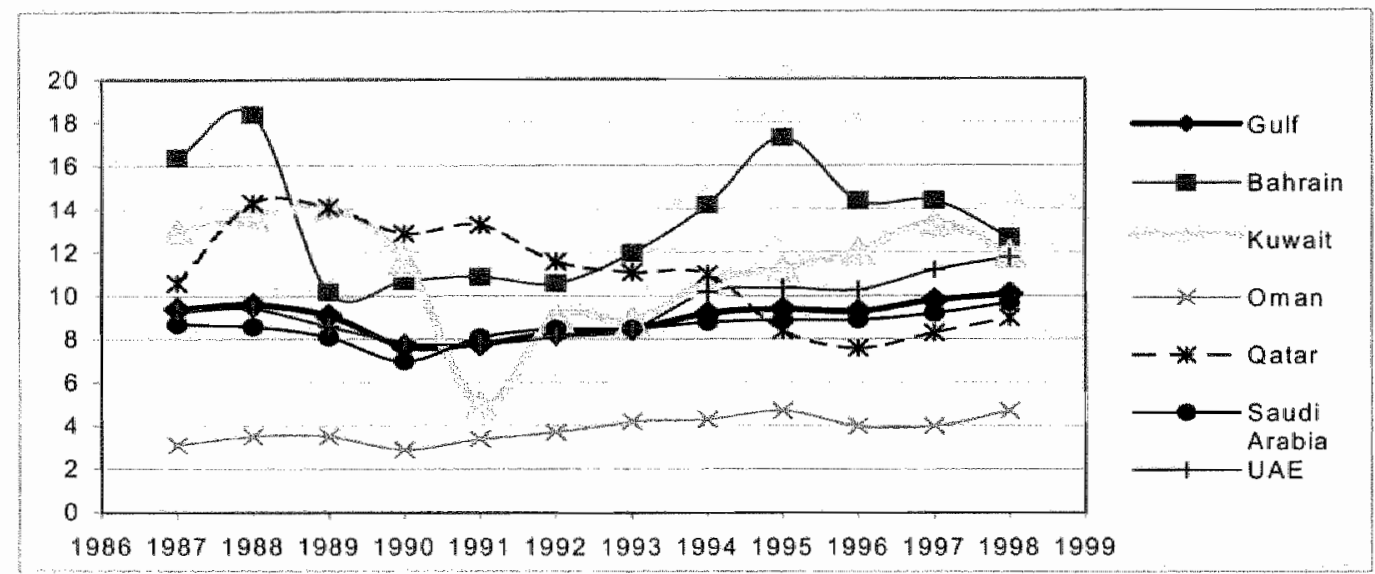

Source: Adapted from GOIC $(1.998,2000 a)$

Figure 2.4- The share of industry in total employment in the Gulf coumtries (1980-1999)

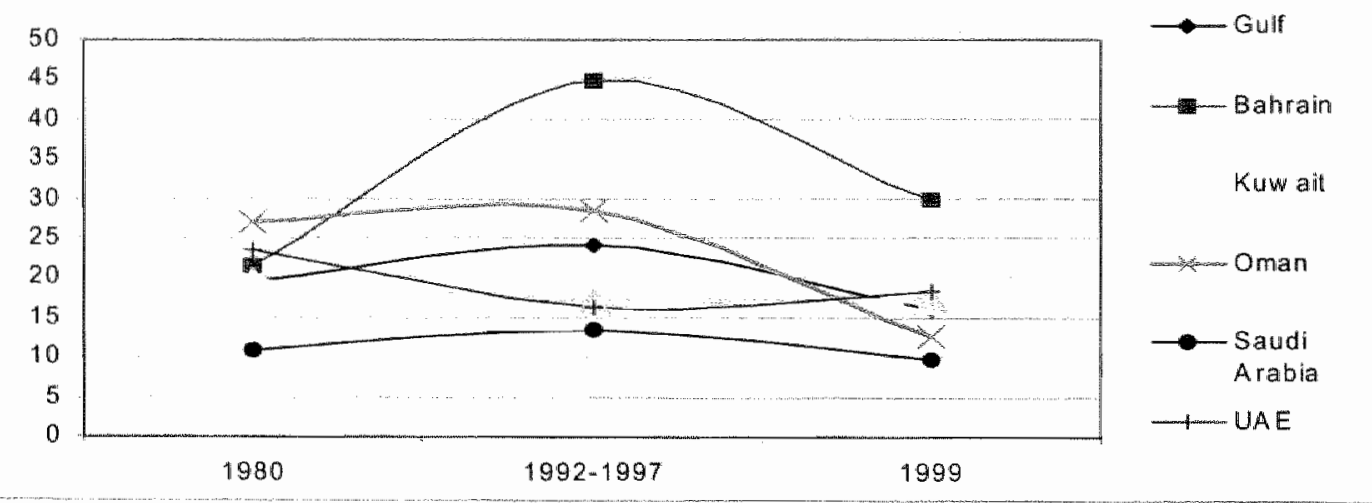

Sources: Adapted from ERF (2002) and the Joint Arab Economic Report (2001) 
Moreover, although oil has contributed to the enhancement of economic development in the Gulf, the general instability of oll prices in the world market and the extreme dependence on uncertain oil revenues lead to serious fluctuations and challenges confronting economio development in the Gulf region - see Figure 2.5 below. Hence, economic diversification in the Gulf becomes more pressing. The success of the diversification strategy is contingent upon availability of appropriate skills and human resources development.

Figure 2.5- The trend of total GDP in the Gulf countries at current prices (1980-2002) (Million USS)

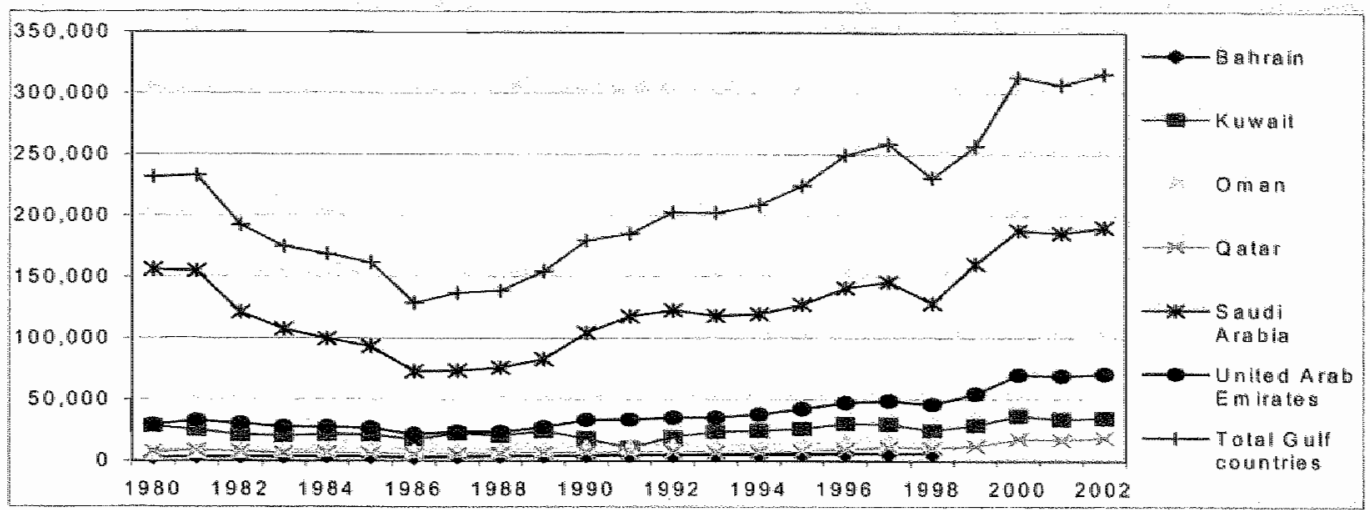

Sources: (a) GOIC Industrial Data Bank (2000b) and (b) OPEC (2002).

Table 2.6- Exports diversification index in the Gulf countries (1980-1990)

\begin{tabular}{lllll}
\hline Country & Including oill & \multicolumn{3}{c}{ Excludiug oill } \\
\cline { 2 - 5 } & Mid 1980 & Mid 1990 & Mid 1980 & Mid 1990 \\
\hline Bahrain & $\mathrm{n} / \mathrm{a}$ & 0.56 & $\mathrm{n} / \mathrm{a}$ & 0.55 \\
Kuwait & $\mathrm{n} / \mathrm{a}$ & 0.59 & $\mathrm{n} / \mathrm{a}$ & 0.63 \\
Onan & 0.91 & 0.74 & 0.33 & 0.27 \\
Qatar & 0.71 & 0.64 & 0.41 & 0.34 \\
Saudi Arabia & 0.77 & 0.75 & 0.57 & 0.57 \\
United Arab Emirates & $\mathrm{n} / \mathrm{a}$ & 0.36 & $\mathrm{n} / \mathrm{a}$ & 0.36 \\
Average Gulf countries & 0.7966 & 0.6066 & 0.43666 & 0.4533 \\
\hline
\end{tabular}

Source: ERF (2002: 53).

Furthermore, other serious problems facing the Gulf economies appear from the declining reserves of oil and natural gas. Table 2.3 above predicts that oil reserves are likely to last for a century only for a half of the Gulf countries, namely, Saudi Arabia, Kuwait and the UAE, whereas for the other half, Bahrain, Oman and Qatar, proven reserves are likely to be exhausted within the next two decades. In order to avoid the risks of over dependence on diminishing oil resources, the Gulf countries are determined to decrease their dependence on oil revenues and diversify their sources of income. A diversification strategy, mainly industrial diversification, is required to shift to non-oil industries to encourage the development of a wide range of manufacturing industries. Table 2.6 indicates that in the last decade the extent of economic diversification - measured by exports diversification index (excluding oil)-varies across the Gulf countries and shows only a relative success in both Oman and 
Qatar. However, in general, the average performance for all Gulf countries has declined over the same period of time (ERF, 2002)."

Our results presented above indicate that although the Gulf countries share many economic characteristics, there are important differences among these countries. For instance, the per capita income ranges from less than $\$ 13,000$ in Saudi Arabia to $\$ 22,420$ in the United Arab Emirates. The structure and composition of the economy and the degree of diversification also vary across the Gulf countries. For instance, the weight of the manufacturing sector has been growing very rapidly in Saudi Arabia, as with the trade and related activities sector in the United Arab Emirates, the banking and insurance sector in Bahrain, the natural gas sector in Qatar, and natural gas resources and tourism in Oman (cf. Fasano and Iqbal, 2003). Differences also remain in the degree of industrialization and the role of manufacturing sector. For instance, Figures 2.2-2.4 above indicate that Bahrain seems to be different from the other Gulf countries in terms of the share of industry in total employment (1980-1999) and the share of manufacturing sector in total exports and in GDP (19871998). Bahrain seerns to have opted to invest more in manufacturing to diversify the economy, probably because of the more sound institutional settings and policies that were adopted to increase industrialization, Bahrain being compelled to act by the fast depletion of its oill resources as compared to the other Gulf countries.

\section{2. 2. Structural problems of the labour market in the Gulf countries}

In addition to the challenges associated with the heavy dependence on oil, the structure of the labour markets in the Gulf countries shares several problematic features. One serious structural problem related to oil, and probably also to the Dutch disease, is the minor share of the manufacturing sector in total employment as the majority of the economically active population is employed by the services sectors. For instance, Figure 2.6 below illustrates that the services, construction, sales and trade sectors employ $73 \%$ of total economically active population, the government and social services sector alone accounts for $40.9 \%$, while the manufacturing sector absorbs only $9.1 \%$ of the total economically active population.

\footnotetext{
The exports diversification index is a measure of products diversification -it assigns a value of zero to the most diversified economies and a value of one to the least. It aims to widen the range of the exports products, to expand exports base and reduce the concentration in a few commodities such as agricultural or raw materials and minerals. For the Gulf countries, the exports diversification index especially defines the move away from primary exports or the dependency on oil exports (ERF, 2002: 53).
} 


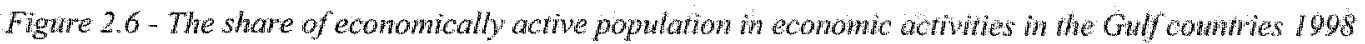

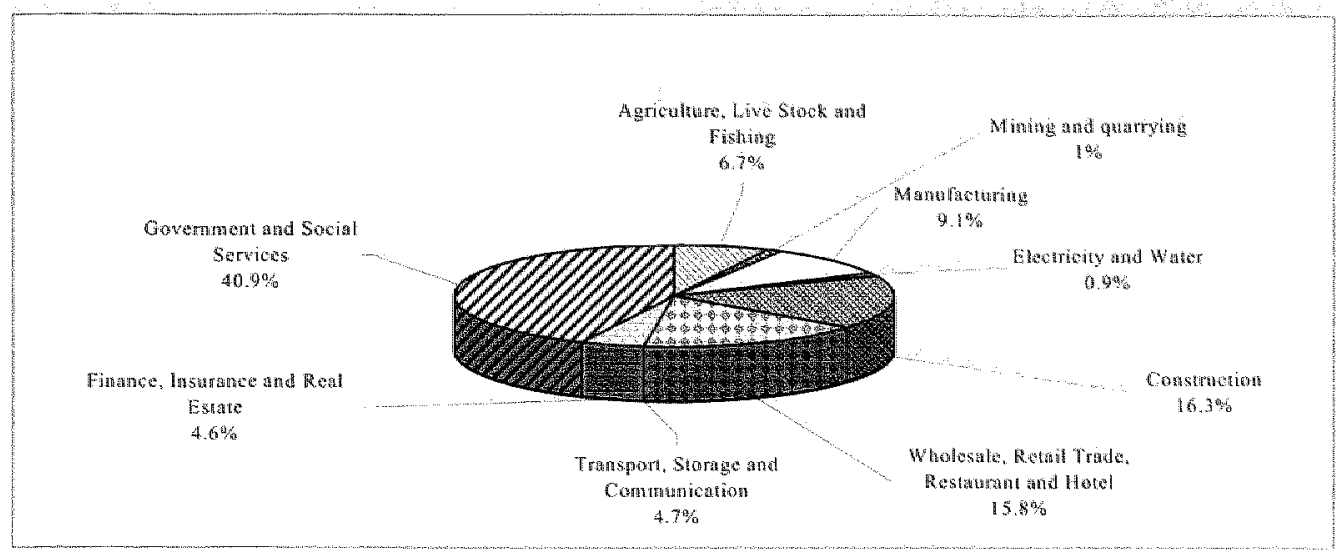

Source: GOIC Industrial Data Bank (2000b).

Moreover, the labour market in the Gulf countries is characterized by serious structural imbalances due to the minor and declining share of nationals workers in the total labour force when compared to foreign workers - see Table 2.7 below. ${ }^{10}$ Several studies (cf. Issawi, 1982; Serageldin et al., 1983; Haan, 1999; Gray, 1999) interpret the imballanced structure in both population and labour market as consequences of the low density of population, shortage of domestic workers, the influx of migrants and a heavy dependence on foreign workers. The migration to the Gulf countries during the last three decades was encouraged in response to the increasing demand for workers to support development projects established following the increasing wealth from oil revenues in the Gulf. The major implication of the dominance of foreign workers in the labour market is the increasing competition for employment opportunities available for national workers, particularly in the private sector of the economy in the Gulf countries. For instance, despite the high share of private sector workers in total employment in both Kuwait $(70 \%)$ and the UAE $(83 \%)$, the share of national workers in the private sector does not exceed $2 \%$ (Khorshid, 2000; 6, 3). ${ }^{11}$

\footnotetext{
${ }^{10}$ During 1975-1995, the percentage of national to total manpower has decreased in all Gulf countries except in Bahrain. "Available data indicate that the number of expatriate workers is about 7.8 milion in 1999, of whom 3.5 million are Arabs (or about 45 percent) and 4.3 million are Asians. The former group is dominated by workers from Egypt and, to a lesser extent, Palestine and Sudan. The latter group is made up primarily of workers from India and Pakistan and to a much lesser extent, Iran." ERF (2000: Chapter 5).

11 See Khorshid (1997, 2000) Gray (1999), Haan (1999) and Cohen (2000) respectively, Gray (1999) finds that the UAE is more dependent on non-national workers than its neighbours, particularly in the priwate sector. Private sector employers in the UAE are distinctive in their dependence on importing ready-made skills, rather than investing in training mationals in the requisite skills, the sector is currently staffed almost entirely by expatriate workers, with nationals comprising only $2 \%$ of its workforce (Gray, 1999: 5). The UAE Population Census data (1995) indicates that the non-national constitutes about $75.6 \%$ of total population and $90.9 \%$ of total work force.
} 
Table 2.7 - The shane of national and foregn labour in total laboum (owce wh the Gulfcoumies (1975-1995)

\begin{tabular}{|c|c|c|c|c|c|c|c|c|c|c|c|}
\hline \multirow[t]{2}{*}{$\begin{array}{l}\text { Country } \\
\text { Year }\end{array}$} & \multicolumn{4}{|c|}{$\begin{array}{l}\text { Share of foreign latbour in total } \\
\text { labour force }(\%)\end{array}$} & \multicolumn{3}{|c|}{$\begin{array}{l}\text { Share of national } \\
\text { labour in total labour } \\
\text { force }(\%)^{6}\end{array}$} & \multicolumn{2}{|c|}{$\begin{array}{l}\text { Annual } \\
\text { Growth rate } \\
\text { of national } \\
\text { labour }(\%)\end{array}$} & \multicolumn{2}{|c|}{$\begin{array}{l}\text { Amual } \\
\text { Growth rate } \\
\text { of foredgn } \\
\text { labour }(\%)\end{array}$} \\
\hline & 1975 & 1980 & 1985 & 1990 & 1975 & 1985 & 1995 & $\begin{array}{l}1975- \\
1985 \\
\end{array}$ & $\begin{array}{l}1985- \\
1995\end{array}$ & $\begin{array}{l}1975 \\
1985 \\
\end{array}$ & $\begin{array}{l}1985- \\
1995\end{array}$ \\
\hline Bahrain & 80.3 & 59.3 & 67.7 & 75.0 & 18.2 & 42.1 & 40 & 6.6 & 2.4 & 11 & 2.9 \\
\hline Kurwait & 69.8 & 78.1 & 81.1 & 82.0 & 18.2 & 14.3 & 16.6 & 5.6 & 6.2 & 8.2 & 4.6 \\
\hline Omant & 45.5 & 40.0 & 56.6 & 75.4 & 68.9 & 48.2 & 35.8 & 1.4 & 3 & 5.1 & 6.2 \\
\hline Qatar & 85.5 & 81,6 & 75.5 & 81.0 & 17 & 23.5 & 17.9 & 7.3 & 5.2 & 3.8 & 8.1 \\
\hline $\mathrm{KSA}$ & 25.2 & 58.3 & 64.2 & 78.6 & 74.8 & 37.5 & 36.5 & 1.2 & 1.4 & 8.5 & 4 \\
\hline UAE & 81.4 & 89.7 & 87.6 & 83.5 & 16 & 12.4 & 11.6 & 3.9 & 5.5 & 6.5 & 6.2 \\
\hline Weighted & 64.6 & 67.8 & 72.1 & 79.3 & 61 & 33.2 & 26.4 & 1.7 & 2.1 & 8 & 4.5 \\
\hline Average & & & & & & & & & & & \\
\hline
\end{tabular}

Notes: ${ }^{*}$ ) Data for Bahrain is in respect of census years 1971,1981,1985 (estimate) and 1991.

Sounces: (a) Figures through 1990 are from Gamelidin (1994). (b) Girgis (2000)

In addition, the heavy and increasing dependence on foreign workers, especially in the private sector, result in contrastung implications: on the one hand, the high skilled foreign workers have positive impacts on enhancing productivity and output in the private sector. On the other hand, one major drawback related to the heavy dependence on foreign workers is the leakage of foreign remittances away from the Gull countries, which results in a drain on the current account balance and GNP. For example, in 1990 the remittances from the foreign workers accounted for $20 \%$ to $66 \%$ of the total import bills of the Gulf countries (Girgis, 2000; Datta et al., 2000: 5). In addition, the excessive use of unskilled foreign workers leads to low skill levels and contributes to declining productivity of labour, as we will explain below and in Chapters 5 and 6.

Moreover, another common characteristic challenging the labour market in each of the Gulf countries is the dualistic feature that appears from the concentration of domestic workers in the public sector and foreign workers in the private sector. A fact that has been well documented in the Gulf literature is that the national workers lack incentives to work in the private sector and prefer to work in the public sector because the public sector offers higher salaries, subsidies, shorter working hours and other benefits. For instance, Gray (1999) finds that in the UAE, the private sector prefers to employ foreign workers, because they are mote productive, less expensive and accept flexible employment contracts. In contrast, the national workers are considered less productive, more expensive and do not possess the prerequisite skills. Both subsidy and wage premins offered to domestic workers lead to considerable variations in the distribution of average wages between domestic and foreign workers. Further evidence of the dualistic nature and differences in wage premiums and average working hours for both domestic and foreign workers in Kuwait appears from the results of Wadi"s study (2001). These results imply the duality and inequality characterizing the distribution of average wages in the Gulf countries.

Furthermore, Table 2.1 above indicates that the average rate of unemployment increased rapidly from 0.5 in 1990 to 7.2 per cent in 2001 . "The labour markets in the Gulf countries are experiencing serious growing trend of both structural and cyclical unemployment. The incidence of structural unemployment is related to discrepancy between the demand for and the supply of workers due to changes in the structure of the economy and the mismatch in both skills and wages premium for national workers. The major interpretation 
is related to the failure of the demand to respond to the recent increase in the supply of new national job seekers, (majority of whom do not posses the skill much in demand by private sector)" (ERF, 2000; Girgis, 2000; Khorshid, 2000). "The rapid increase in domestic work force of the Gulf nationals is attributed to the rapid growth in the domestic population, rising participation rates of female workers and projected increase in the share of the economically active population. For instance, during the period (1985-1995), the supply of national manpower in Kuwait, Qatar and the UAE grew by $6.2 \%, 5.2 \%$ and $5 \%$ respectively, while, the average growth rate of the national job seekers increased from $1.7 \%$ during the period (1975-1985) to 2.1\% during the period (1985 - 1995)" (Khorshid, 2000: 3, 6). Moreover, "the Gulf countries suffer from cyclical unemployment that attributed to economic slowdown caused mainly by the instability of the oil prices and revenues. That leads to decline in government spending and had caused serious reduction in the demand for workers and growth rate of employment, particularly in the public sector. The failure of the private sector to fill the gap, due to preference for hiring foreign rather than national workers in the sector created an open unemployment phenomenon especially among the national workers in the Gulf countries" (ERF, 2000: 118; Girgis, 2000; Khorshid, 2000: 3, 5 ).

Therefore, the Gulf countries need to restructure the labour market, to create more jobs to absorb the growing supply of workers, especially skilled national workers, reduce the unemployment rate and dependence on foreign workers. To that end, more attention needs to be paid to enhancing investment and incentives for public and private sector education and training, mainly tertiary and technical education, and training to promote adequate and appropriate local skills...

\subsubsection{The low skill levels in the Gulf countries}

Further to the challenges associated with the extreme dependence on oil and structure of labour market, other serious problem for economic development in the Gulf countries is the low skill levels or educational qualifications of both domestic and foreign population. ${ }^{12}$ As we will explain below and in the Chapters 5 and 8 , the low skill levels that appear from several indicators at both macro and micro levels can be attributed to both the deficient educational system and the excess supply of unskilled foreign workers in the Gulf countries. For instance, $67 \%$ of the UAE foreign population have educational qualifications below secondary schooling, $68 \%$ and $72 \%$ of Kuwait foreign workers were either unskilled or low skilled in 1989 and 1999 respectively (cf. UAE, 1998; 1999; Al-Tony, 2002). At the macro level, Table 2.8 indicates that the low skill levels in the Gulf when compared to World advanced countries are evident from several indicators, including the Harbison Myers Index, the technical enrolment index, the engineering index, the share of tertiary students in science, math and engineering, gross enrolment at tertiary education and school life expectancy. ${ }^{13}$ Skill indicators vary enormously across the Gulf countries, for instance, skill indi-

\footnotetext{
${ }^{12}$ Similar to other developing countries, the Gulf countries have low skill levels. The more specific feature of the Gulf countries is the low skill levels in a majority of foreign workers.

${ }^{13}$ We use many indicators to measure skill levels. For instance, the Harbison Myers Index is sum of secondary enrolment and tertiary enrolment times 5 , both as \% of age group. Technical enrolment index is tertiary total enrolment (times 1000) plus tertiary enrolment in technical subjects (times 5000), both as \% of population, Engineering skills index is the same as previous index, with tertiary enrolment in engineering instead of enrolment in technical subjects (Lall, 1999: 52). In addition, we use school life expectancy as another measure of skill; according to the UNESCO technical specifications, school life expectancy is one indicator on access to schooling, and is defined as "the total number of years of schooling which a child of
} 
ces and gross enrolment ratios in Kuwait and Saudi Arabia are higher than the UAE, while the opposite is true with respect to the share of tertiary students in science, math and engineering. In addition, school life expectancy is higher in Bahrain and Qatar compared to the UAE, Saudi Arabia and Kuwait.

Table 2.8 - Skall indicators in the Gull countries compared to World cowntries (1992-2000)

\begin{tabular}{|c|c|c|c|c|c|c|c|}
\hline \multirow[t]{2}{*}{ Counitry } & \multicolumn{3}{|c|}{ Skill indices (1995) } & \multirow{2}{*}{$\begin{array}{l}\text { Gross en- } \\
\text { rolment } \\
\text { ratio }(\%) \text { at } \\
\text { tertiary } \\
\text { education } \\
1998- \\
2002 / 2003^{c}\end{array}$} & \multirow{2}{*}{$\begin{array}{l}\text { Share tertiary } \\
\text { students in } \\
\text { science, math } \\
\text { and engineer- } \\
\text { ing } \\
1994-1997^{\circ}\end{array}$} & \multicolumn{2}{|c|}{$\begin{array}{l}\text { School life } \\
\text { expectancy }\end{array}$} \\
\hline & $\begin{array}{l}\text { Harbison } \\
\text { Myers } \\
\text { Index }\end{array}$ & $\begin{array}{l}\text { Technical } \\
\text { entrolment } \\
\text { index" }\end{array}$ & $\begin{array}{l}\text { Engineering } \\
\text { enrolment } \\
\text { index }{ }^{3}\end{array}$ & & & $1992^{c}$ & $2000^{\text {a }}$ \\
\hline Bahrain & $\mathrm{n} / \mathrm{a}$ & n/a & $\mathrm{n} / \mathrm{a}$ & 21 & $\mathrm{n} / \mathrm{a}$ & 13.5 & 13.0 \\
\hline Kenwait & 19.10 & 36.49 & 30.57 & 21 & 23 & 7.0 & 8.7 \\
\hline Oman & 8.95 & 5.35 & 4.44 & 7 & 30 & $\mathrm{n} / \mathrm{a}$ & 8.7 \\
\hline Qatar & $\mathrm{n} / \mathrm{a}$ & $\mathrm{n}^{\prime} \mathrm{a}$ & $\mathrm{n} / \mathrm{a}$ & 23 & $\mathrm{n} / \mathrm{a}$ & 11.8 & 13.1 \\
\hline $\mathrm{KSA}$ & 13.45 & 18.96 & 14.42 & 22 & 18 & 8.5 & $\mathrm{n} / \mathrm{a}$ \\
\hline UAE & 1220 & 7.51 & 5.70 & 10 & 27 & 10.6 & 10.7 \\
\hline Average Gulf & 13.425 & 17.0775 & 13.7825 & 17.33 & 24.5 & 10.3 & 10.8 \\
\hline Norway & 38.85 & 73.52 & 60.25 & 74 & 18 & $\mathrm{n} / \mathrm{a}$ & 17 \\
\hline Sweden & 34.45 & 64.50 & 49.94 & 62.3 & 31 & 13.7 & 16 \\
\hline USA & 50.25 & 88.10 & 68.98 & 81 & $\mathrm{n} / \mathrm{a}$ & 16.0 & 15 \\
\hline UK & 37.55 & 68.69 & 49.83 & 64 & 29 & 15.7 & 16 \\
\hline Japan & 30.05 & 63.54 & 63.54 & 49 & 23 & 13.3 & 14 \\
\hline Korea & 36.10 & 132.06 & 113.83 & 85 & 34 & 13.5 & 15 \\
\hline Singspore & 23.05 & 48.81 & 44.76 & $\mathrm{n} / \mathrm{a}$ & $\mathrm{w} / \mathrm{a}$ & $\mathrm{n} / \mathrm{a}$ & $\mathrm{n} / \mathrm{a}$ \\
\hline Mexico & 12.95 & 37.53 & 31.83 & 21 & 3.1 & $\mathrm{n} / \mathrm{a}$ & 12 \\
\hline Brazil & 10.15 & 19.87 & 15.50 & 18 & 22 & 10.7 & 15 \\
\hline
\end{tabular}

Sources: (a) L.all (1999) (b) UNDP (2002), Human Development Report (2002). (c) UNESCO (1996), (d)

UNESCO - UIS (2003): wWw unesco.org and (e) UNESCO- UIS (2004d) Educational statistics (1998-

2002/2003): most recent data on gross enrolment in tertiary education.

Moreover, Figure 2.7 illustrates the low skill levels - measured by occupational classification - as the share of white collar/high skilled class accounts for only $16.4 \%$ of total Gulf population, compared to $83.6 \%$ for blue collar/low skilled class. The occupational classification indicates the low share of skilled foreign and national workers; Khorshid (2000) finds that in both the UAE and Kuwait the share of skilled and semi skilled national workers in the total supply are below $5 \%$. The national workers are greatly biased towards clerical work, military occupations, teachers and non scientific professions, and senior mangers. For instance, in Kuwait the share of clerical and policemen; managers and super-

a certain age can expect to receive in the future, assuming that the probability of his or her being enrolled in school at any particular age is equal to the current enrolment ratio for that age". cf. the UNESCO web site. This indicator shows the overall level of development of an educational system in terms of the number of years of education that a child can expect to achieve. We observe that the data used for the estimation of the UNESCO school life expectancy refers to enrolment by age at all levels of education. For that reason, these figures are higher than those of Barro and Lee (2000), which have been used in the UNDP (2001) figures on mean/average years of schooling and refer to age 15 and above. For instance, the UNESCO school life expectancy accounts for 13 and 8.7 in both Bahrain and Kuwait respectively, while Barro and Lee (2000) and the UNDP (2001) mean years of schooling accounts for 6.1 and 6.2 in both Bahrain and Kuwait respectively. However, we use the UNESCO figures in our analysis because Barro and Lee (2000) and the UNDP (2001) figures are available only for Bahrain and Kuwait. 
visor professions; and teachers represent $41 \%, 17 \%$ and $13 \%$ of total labour force respectively, whereas the share in remaining professions does not reach $7 \%$. The national workers participation rates in four occupational groups: teachers, social scientists, managers and supervisors and clerical exceed $50 \%$ of the total number of workers. Similarly, the UAE shows a low share of national workers in most of occupational classifications except military occupations, where national represents $56 \%$ of the total workers (Khorshid, 2000: 6-7).

Figure 2.7 - The share of economically active population in the Gulf cowntries 1998 (defined by occupational level]

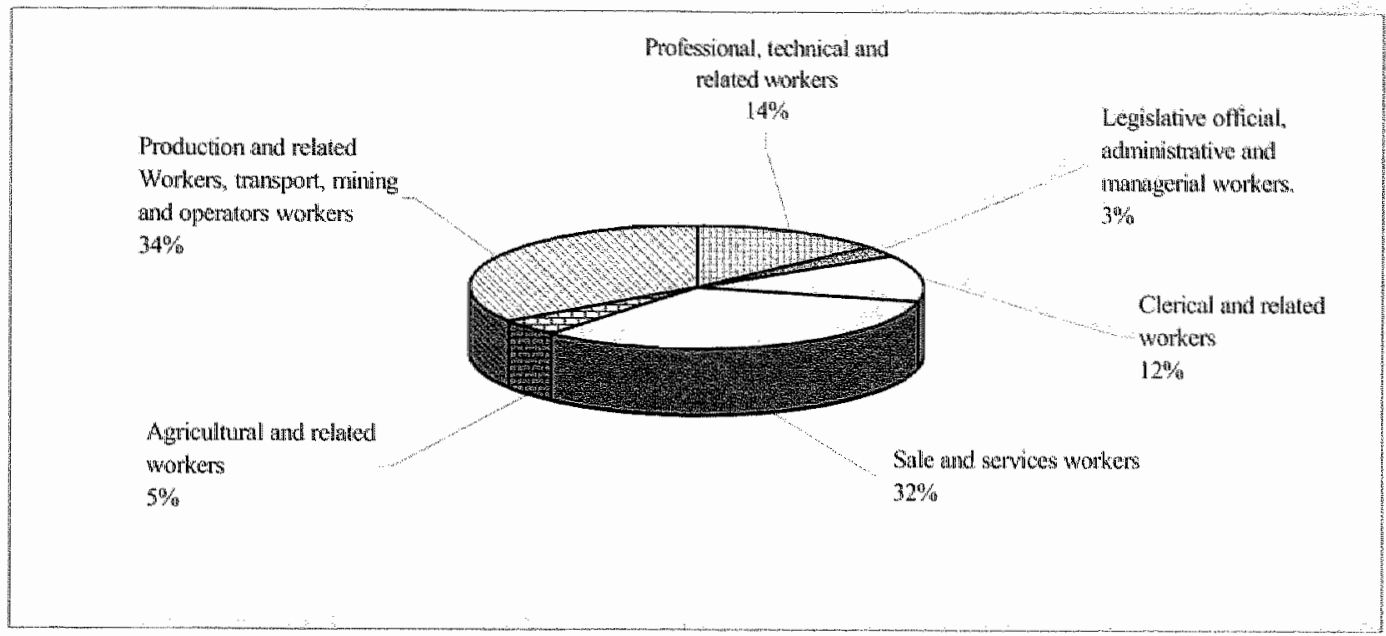

Source: GOIC Industrial Data Bank (2000b)

Therefore, these results highlight the need for reforming the educational and training systems in the Gulf in order to ensure more balanced occupational structure. As we elaborate below and in the next Chapters, the low skill level in the Gulf countries hinders the development of local technologies, productivity and hence economic growth. Since the supply of skills (as shaped by systems of education and training) has not responded fully to the rising demand, skill development has become even more pressing for enhancing productivity of labour, replacing foreign workers with domestic workers, reforming the labour market and developing local technologies.

\section{2. 4 The low technological level and technological gap in the Gulf coun- tries $^{14}$}

The low skill levels in the Gulf countries have resulted in poor technological performance and a wide technological gap or distance from the world's rapidly advanced countries such

\footnotetext{
${ }^{14}$ In recent years there is a growing body of literature focusing on technological capability building in the developing countries, for early references, see e.g. Fransman and King (1987), Lall (1987), Enos (1991), Hillebrand, Messner and Meyer-Stamer (1994), UNCTAD (1996) and Romiin (1999). Early studies on Trinidad and Tobago, Costa Rica and Iran have brief observations indicating that technological capability building is related to current resources based industries, and that governments work only on static capability building. Another earlier study on the Andean countries in 1979 contains a brief remark on multinationals discouraging capability building.
} 
as Singapore, Korea and Malaysia. ${ }^{15}$ Table 2.9 illustrates the poor technological performance and technological gap that is manifested in the percentage share of spending on R\&D in GDP, the number of scientists and engineers in R\&D, patent and population access to Internet, telephone and mobile. ${ }^{16}$ We observe that, due to the high GDP per capita income in the Gulf countries, both spending and use of ICT/access to Internet, telephone and mobile increased rapidly during the period 1990-2002. Moreover, technology indicators vary enormously across the Gulf countries, for instance, ICT indicators -access to Internet, telephone and mobile - are higher in the UAE than in Kuwait, Saudi Arabia and the other Gulf countries (cf. Nour, $2002 \mathrm{a}, \mathrm{b}$ ), whereas the percentage share of spending on R\&D in GDP, the number of scientists and engineers in $R \& D$ and patent are higher in both Saudi Arabia and Kuwait compared to the UAE and other Gulf countries.

Poor technological performance is closely related to low R\&D spending. More recently the UNESCO-UIS (2004a) indicates a remarkably serious weaknesses of investment in R\&D in the Arab (including the Gulf) countries when compared to the New Industrialized Economies of South East Asia, such as China and India, and also compared to Latin America. "Despite efforts to increase investment in $R \& D$, expenditures remain very low in developing countries. In 2000 , developing countries spent $0.9 \%$ of their GDP on R\&D, still falling short of the target of $1 \%$ mentioned in various S\&T policy documents and international declarations for over 30 years. ${ }^{17}$ Nevertheless, there is considerable variation across countries. .... both sub-Saharan African countries and the Arab states showed much lower levels of R\&D expenditures... To complete the picture, the Arab states show a very low level $(0.15 \%)$ of research intensity." (UNESCO-UIS, 2004a: 3 ).

Furthermore, the distribution of R\&D institutions indicates that most of the R\&D activities are carried out within the public $(49.4 \%)$ and university $(43.5 \%)$ sectors, while the private sector has only a minor contribution and accounts solely for $7 \%$ of total R\&D institutions in the Gulf countries - see Table 2.10 below. That also holds for the distribution of human resources available to R\&D institutions - defined by the number of full-time equivalent (FTE) ${ }^{18}$ researchers. For instance, Table 2.10 illustrates that the majority of FTE researchers are employed by public $(49.2 \%)$ and university $(49.3 \%)$ sectors, while the private sector absorbs onlly about $1.4 \%$ of total FTE researchers in the Gulf countries (cf. Nour, 2005). Therefore, these results imply that the private sector, and hence industry, makes only a minor contribution in both human resources (FTE researchers) and total R\&D activities,

\footnotetext{
${ }^{15}$ Several indicators have been used to measure the technological distance between nations. Such as the number of patent registrations; per capita expenditure on R\&D, or its share in GDP; the number of skilled persens engaged therein; or the ability of the country to master 'frontier' technologies such as, electronic, informatics, new materials, biotechnology, etc.). These measures are useful for indicating weaknesses in specifically defined areas and determining the need for new policies in specific sectors, but they have shortcomings in reflecting the differences in the degree of technological intensity, or of the efficiency of technological inputs. A broader indicator for a multi-ctimensional analysis of technological transformation includes the rate of growth of GDP, per capita GDP and productivity that also reflect changes in the structure of production and trade; domestic production of machinery; availability of advanced education; literacy rate, etc. (Patel, 1995).

${ }_{16}$ As in most other developing countries, the Gulf countries show poor technological performance In view of their high GDP per capita income, which is comparable to high-income countries, one would have expected a better performance in the Gult.

${ }^{7}$ For early references to R\&D expenditure target setting, of. United Nations (1970)"United Nations Science and Technology for Development, Proposals for the Second United Nations Development Decade," New York, 1970.

Is The concept of full- time equivalent researcher is adopted by UNESCO statistics on R\&D personnel.
} 
and lags behind most of the industrialized countries, in which more than half of R\&D expenditures are financed by industry. ${ }^{19}$

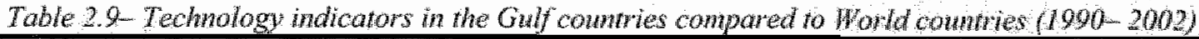

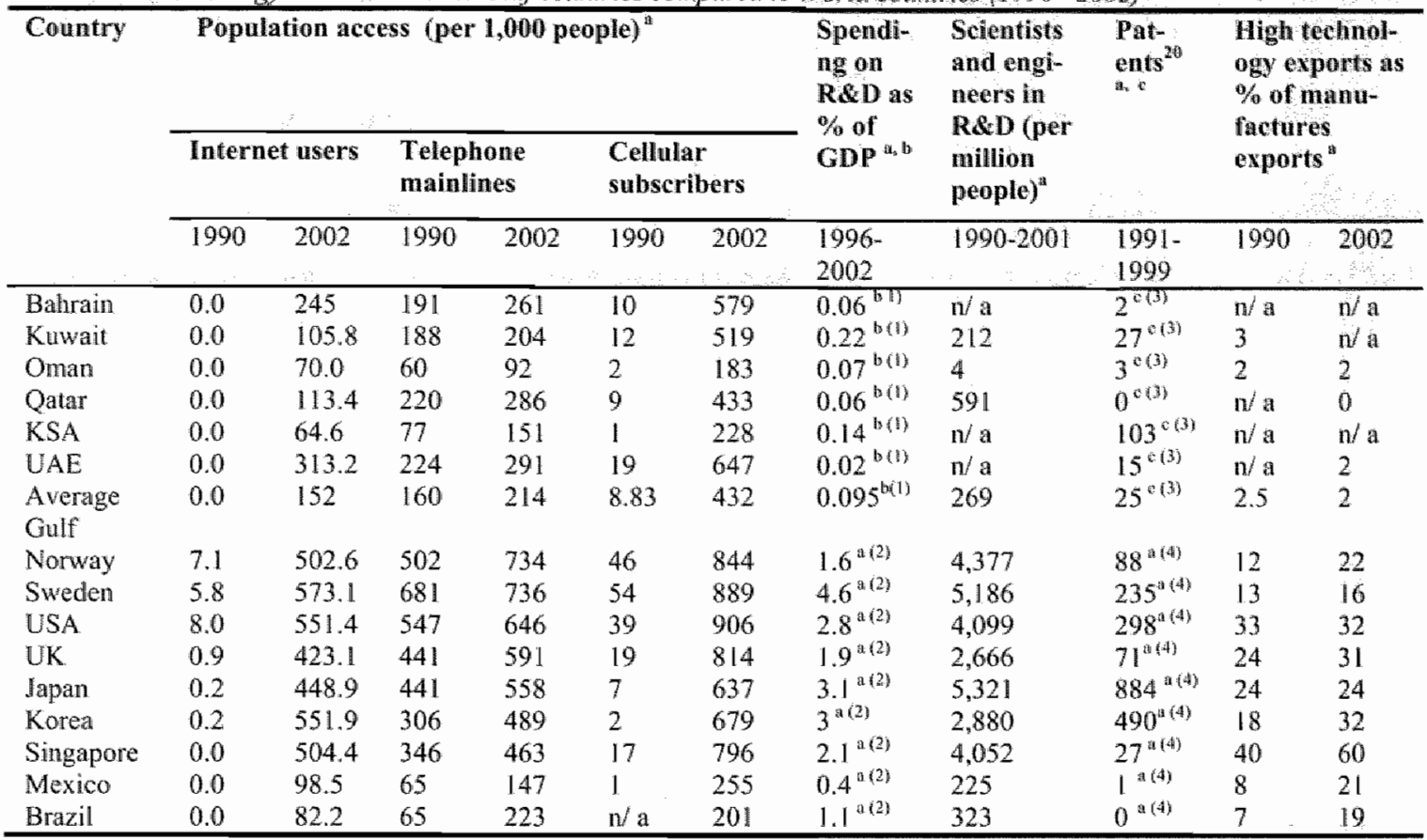

Notes: (1) Data refers to 1996, (2) Data refers to 1996-2002, (3) Data refers to 1991-1999, (4) Data refers to 2000 .

Sources: (a) UNDP Human Development Report (2004), (b) Calculated from Qasem (1998) and GOlC (2000a)

(c) US Patent and Trademark office web site: www uspto.govt.

Table 2. IO- Drstribution of R\&D instintional whits and full-time equivalen (FTE) researchers by type of RdD Jistivion in the Gwlf comtries 1996

\begin{tabular}{|c|c|c|c|c|c|c|c|c|}
\hline \multirow[t]{2}{*}{ Comblry/area } & \multicolumn{4}{|c|}{ Number of R\&D institutions } & \multicolumn{4}{|c|}{ Number of ITE Resentrehers } \\
\hline & Plublic & University & Private & Total & Public & University & Private & Total \\
\hline Bahrain & 3 & 1 & 0 & 4 & 27 & 59 & 0 & 86 \\
\hline Kuwait & 11 & 0 & 4 & 15 & 334 & 83 & 23 & 440 \\
\hline Oman & 6 & 0 & 0 & 6 & 56 & 26 & 0 & 82 \\
\hline Qatar & 0 & 6 & 0 & 6 & 4 & 30 & 0 & 3,4 \\
\hline Saudi Arabia & 19 & 28 & 2 & 49 & 308 & 538 & 0 & 846 \\
\hline UAE & 3 & 2 & 0 & 5 & 56 & 51 & 0 & 107 \\
\hline Totall & 42 & 37 & 6 & 85 & 785 & 787 & 23 & 1595 \\
\hline \% Distribution & 49.41 & 43.53 & 7.06 & 100 & 49.22 & 49.34 & 1.44 & $\$ 00$ \\
\hline
\end{tabular}

Soure: Adapted from ESCWA UNESCO. Research and Development System in the Arab States: Development of Science and Technology Indicators 1998/E/ESCWA/TECH/1998/3)

19 See the OECD Second European Report on S\&T (1997).

20 Patent data for Norway, Sweden, UK, US, Korea and Singapore, Japan, Mexico and Brazil obtained from UNDP (2003) and refers to patents granted to residents per million people in 1999. For all Gulf countries patent data obtained from US patent office during 1991-1999, it refers to the number of registered US patents (in which the inventor of the patent is a resident) that originated from the selected Gulf countries. One limitation of the comparison in our analysis is that we use patent data from two different sources: the scarcity of data and information covering all countries limited our attempt to use a unified source. 
In addition, the large technological gap between the Gulf countries and the world's rapidly advanced countries like Singapore, Malaysia and Korea is also apparent from the technological structure of manufactured exports, in particular the share of high technology exports as a percentage of total manufactured exports. For instance, in contrast to Singapore, Malaysia and Korea, both medium and high technology exports lag behind and constitute only a minor share in total Guf manufacturing exports. In addition, the Gulf countries show heavy concentration on primary and resources based manufactured exports, but serious negligence of medium and high technology exports. The average for Gulf countries allso shows a worsening status or declining share of high and medium technologies over the periods $1985-1997$ - see Table 2.11 below. Furthermore, the levels of net capital inflows and foreign direct investment indicate a large gap and weak competence of the Gulf countries to attract foreign investment for developing local technologies. For instance, the levels of net capital inflows and foreign direct investment in the Gulf countries fall below those of the rapidly advanced countries, namely Singapore, Malaysia and Korea (cf. UNDP, 2004). ${ }^{21}$

Table 2.11- Technological stwacture of manufactumed exports in the Gub and developing coumries (1985 1997) (og of "oral manufactured exports

\begin{tabular}{|c|c|c|c|c|c|c|c|c|c|c|}
\hline \multirow[t]{2}{*}{ Countries } & \multicolumn{2}{|c|}{$\begin{array}{l}\text { Primary } \\
\text { products }\end{array}$} & \multicolumn{2}{|c|}{$\begin{array}{l}\text { Resources } \\
\text { based mantu- } \\
\text { factures }\end{array}$} & \multicolumn{2}{|c|}{$\begin{array}{l}\text { Low technol- } \\
\text { ogy manufac- } \\
\text { tures }\end{array}$} & \multicolumn{2}{|c|}{$\begin{array}{l}\text { Medium } \\
\text { technology } \\
\text { manufactures } \\
\mathrm{w} ; \mathrm{b}\end{array}$} & \multicolumn{2}{|c|}{$\begin{array}{l}\text { High technology } \\
\text { manufactures }\end{array}$} \\
\hline & 1985 & 1997 & 1985 & 1997 & 1985 & 1997 & 1985 & 1997 & 1985 & 1997 \\
\hline Bahrain & 54.4 & 56.1 & 10.9 & 12.5 & 11.8 & 13.1 & 22.0 & 16.7 & 0.6 & 1.5 \\
\hline Kuwait ${ }^{\text {a }}$ & $\mathrm{n} / \mathrm{a}$ & $\mathrm{n} / \mathrm{a}$ & $\mathrm{n} / \mathrm{a}$ & $n d a$ & $\mathrm{n} / \mathrm{a}$ & $\mathrm{n} / \mathrm{a}$ & $n / a$ & $\mathrm{n} / \mathrm{a}$ & $\mathrm{d} / \mathrm{a}$ & $\mathrm{n}^{\prime} \mathrm{a}$ \\
\hline Oman ${ }^{a}$ & 93.8 & 76.9 & 0.7 & 5.7 & 0.4 & 2.6 & 3.3 & 11.8 & 1.2 & 1.6 \\
\hline Qatar $^{33}$ & 72.2 & 674 & 11.0 & 10.5 & 5.2 & 7.9 & 11.4 & 13.9 & 0.1 & 0.3 \\
\hline $\mathrm{KSA}$ & 82.7 & 74.5 & 13.6 & 18.0 & 0.6 & 1.6 & 2.9 & 5.7 & 0.1 & 0.2 \\
\hline UAE: & 22.3 & 35.6 & 15.0 & 14.9 & 16.1 & 33.4 & 33.0 & 15.7 & 5.6 & 0.3 \\
\hline Average Gulf & 65.08 & 62.1 & 10.24 & 12.32 & 6.82 & $\| 1.72$ & 14.52 & 12.76 & 1.52 & 0.78 \\
\hline World & $\mathrm{n} / \mathrm{a}$ & $\mathrm{n} / \mathrm{a}$ & $n / a$ & 13.7 & $n / a$ & 21.3 & $\mathrm{n} / \mathrm{a}$ & 37.2 & $\mathrm{~N} a$ & 27.7 \\
\hline Singapore & $\mathrm{n} / \mathrm{a}$ & $\mathrm{n} / \mathrm{a}$ & $n / a$ & 12.7 & $n / a$ & 7.9 & $\mathrm{~m} / \mathrm{a}$ & 14.0 & $\mathrm{n} / \mathrm{a}$ & 65.4 \\
\hline Malaysia & $n / a$ & $\mathrm{n} / \mathrm{a}$ & $\mathrm{n} / \mathrm{a}$ & 17.8 & $n / a$ & 13.1 & $\mathrm{~d} / \mathrm{a}$ & 8.7 & $\mathrm{n} / \mathrm{a}$ & 60.4 \\
\hline Korea & $n / a$ & wa & $n / a$ & 9.4 & $n / a$ & 28.4 & $\mathrm{n} / \mathrm{a}$ & 26.6 & $\mathrm{n} / \mathrm{a}$ & 35.7 \\
\hline Mexico bis & $n / a$ & $\mathrm{n} / \mathrm{a}$ & $\mathrm{l} / \mathrm{a}$ & 7.1 & $n / a$ & 20.9 & $n / 4$ & 352 & $n$ & 36.9 \\
\hline Brazil ${ }^{(6)}$ & $11 / \mathrm{x}$ & $\mathrm{n}^{\prime} \mathrm{a}$ & wa & 25.6 & $n / a$ & 31.8 & $\mathrm{n} / \mathrm{a}$ & 340 & $n / a$ & 8.6 \\
\hline
\end{tabular}

Note: (1) Data refers to 1996.

Sources: (a) Haddad (2001) and (b) Lall (1999) computations based on UNCOMTRADE data 2000 and 1996 respectively.

As a result of the poor technological performance and technological distance, the Gulf countries are facing the problem of strong dependence on foreign technologies, which is apparent from the trade balance in technological products. ${ }^{22}$ Muysken and Nour (2005) measure the dependence on foreign technology by the share of chemical, machinery,

21 FDI stimulates the development and dispersion of technology as foreign investors transfer techniques and skills to their local affiliates. These skills then generally spill-over to other companies and institutions in the local markets, and are often the missing resource that countries need to expand their access to international markets and to develop areas in which they have a comparative advantage. FDI also leads to the trans fer of important capital goods and internediate inputs. It can help a country develop new comparative advantages, as was the case with the electronic industry in Southeast Asia. In addition it also contributes to increasing output and/or productivity (Hafsi, 2001:41).

${ }^{22}$ This phenomenon of dependence on foreign technologies is similar to most other developing countries The Gulf countries, however, are also highly dependent on the import of technical skills to operate them. 
equipment and manufactured products in total imports (Lall, 1999, Patel, 1995). They observe that despite the significant contribution of oil to GDP, govemment revenues and total exports, the share of chemical, machinery, equipment and manufactured products in total mports remains high in most of the Gulf countries . The high share of crude oil and mineral fuel in total exports together with the strong dependence on foreign technologies indicates a failure to mamfacture oil domestically within the Gulf countries. They find that the heavy dependence on foreign technologies varies across the Gulf countries; however, in general, the average for all Gulf countries throughout the period 1989-1998 did not show a considerable change and remained above 70\% (GOIC, 2000). They attribute that to a lack of R\&D efforts, skills and scientific cooperation and to a poor technology infrastructure (Zahlan, 1999; Rasiah, 2002). Furthermore, the status of the Gulf countries according to the UNDP (2001) classification of world countries according to the technology achievement index $\left(\mathrm{TAI}^{23}\right)$ shows that none of the Gulf countries are classified as leaders, potential leaders or dynamic adopters of technologies in the world.

Since Muysken and Nour (2005) discuss only the demand side, using the demand for imported technology or dependence on foreign technologies, it may be interesting to complement their analysis by also examining the supply side. We measure the supply side by multiplying the manufactures/GDP ratio taken from Figure 2.3 above by walue added in machinery and transport equipment as \% of value added in total manufactures using WDI data, the result is value added in machinery and transport equipment/GDP, which we use as a measure of specialization in production related to technology. When using this measure, our results show a low technological specialization in the Gulf countries- see Table 2.1.2 below. ${ }^{24}$

${ }^{23}$ According to the UNDP (2001), the technology achicvement index (TAI) focuses on four dimensions of technological capacity that are important for reaping the benefits of the network age. TAl includes: (1) Creation of technology as measured by the number of patents granted per capita and receipt of royalty and licenses fees from abroad; (2) Diffusion of recent innovations as measured by diffusion of Internet and export of high and medium technology products as a share of all exports; (3) Diffusion of old innovations as measured by diffusion of telephone and electricity; and (4) Human skills as measured by mean years of schooling and gross enrolment ratio of tertiary students enrolled in science, mathematics and engineering (UNDP, 2001).

I4 Since the recent data from the WDI is available only for Kuwait and Oman, we therefore use an alternative set of indicators from GOIC in Table 2. 12.b. Alternatively, whe multiply the marufactures/GDP ratio from Figure 2.3 above by investment in fabricated metal, machinery and equipment/manufactures and we get investment in fabricated metal, machinery and equipment/GDP. This measure may have the advantage of increasing the consistency between supply and demand measures. However, it has a linitation and may also be inaccurate for our analysis since it does not reflect machinery and transportGDP separately. Rather, it tends to somewhat overestimate the actual value as the figures include fabricated metal in addition to machinery and equipment, which are combined together in one category. This is most probably because the only available data is based on the International Standard Industrial Classification of all economic activities according to ISIC 1968 rather than ISIC Rev 3. 
Table2.12. Demond for and supply of technologies wh Gulf cownmes (1989-1998) (\%)

\begin{tabular}{|c|c|c|c|c|c|c|c|c|c|c|c|}
\hline \multicolumn{2}{|c|}{ Contultry/ntems: } & 1989 & 1990 & 1991 & 1992 & 1993 & 1994 & 1995 & 1996 & 1997 & 1998 \\
\hline \multirow{2}{*}{ Batrain } & Demand " & 48.7 & 39.4 & 45.6 & 52.4 & 512 & 50.8 & 452 & 39.7 & 44.6 & 53.2 \\
\hline & Supply & $\mathrm{wa}$ & $\mathrm{N} / \mathrm{a}$ & nta. & $\mathrm{n} / \mathrm{a}$ & $n / a$ & $\mathrm{n} / \mathrm{a}$ & $n / a$ & nia & ra & $\mathrm{m} / \mathrm{a}$ \\
\hline \multirow{2}{*}{ Kuwait } & Derrend & 76.5 & 79.1 & 87.4 & 84.5 & 82.5 & 80.4 & 82 & 81.5 & 80.7 & 81 \\
\hline & Surpply ${ }^{b}$ & 28 & 23 & 15 & 63 & 53 & 53 & 34 & 36 & 40 & 48 \\
\hline \multirow{2}{*}{ Omant } & Demand $^{\text {" }}$ & 73.8 & 70.3 & 75.6 & $74: 7$ & 72.4 & 73.4 & 71.7 & 74.2 & 76.8 & 79 \\
\hline & Supply' & $\mathrm{n} /$ 敞 & $\mathrm{n} / \mathrm{a}$ & $\mathrm{n}^{\prime} \mathrm{a}$ & $\mathrm{w}^{i} \mathrm{a}$ & 8 & 13 & 14 & 16 & 24 & 24 \\
\hline \multirow{2}{*}{ Qatar } & Demand & 78 & 78.6 & 79.2 & 81.8 & 82.2 & 809 & 87.7 & 86.2 & 86.8 & 86.6 \\
\hline & Suppoly ${ }^{b}$ & $\mathrm{n} / \mathrm{at}$ & $n / a$ & $\mathrm{w}$ & $\mathrm{n}^{\mathrm{t}} \mathrm{a}$ & na & $\mathrm{n} / \mathrm{a}$ & $\mathrm{n} / \mathrm{a}$ & $\mathrm{n} / \mathrm{a}$ & $\mathrm{n} / \mathrm{a}$ & $\mathrm{n} / \mathrm{a}$ \\
\hline Saludi & Demand & 78 & 77.5 & 80.1 & 83 & 84 & 81.4 & 77.7 & 76.4 & 73.1 & 75.7 \\
\hline Arabia & Supply" & 32 & $\mathrm{n} / \mathrm{a}$ & $\mathrm{n} / \mathrm{a}$ & $\mathrm{wa}$ & $\mathrm{n} / \mathrm{a}$ & $\mathrm{n} / \mathrm{a}$ & $\mathrm{n} / \mathrm{at}$ & $\mathrm{n} / \mathrm{a}$ & $\mathrm{n} / \mathrm{a}$ & $\mathrm{n} / \mathrm{a}$ \\
\hline \multirow{2}{*}{ UAE } & Demund & 78.5 & 79.5 & 66.6 & 85.3 & 85.1 & 85.3 & 85 & 86.4 & 86.4 & 86.4 \\
\hline & Supply & $n+a$ & $\mathrm{n} / \mathrm{a}$ & $\mathrm{an} / \mathrm{a}$ & nía & $\mathrm{n} / \mathrm{a}$ & $\mathrm{n} / \mathrm{a}$ & $\mathrm{N} / \mathrm{a}$ & $\mathrm{m} / \mathrm{a}$ & $\mathrm{n} / \mathrm{a}$ & $\mathrm{w} / \mathrm{a}$ \\
\hline A verage & Demand & 75.6 & 74.7 & 74.3 & 81.4 & 81.5 & 80.2 & 78.8 & 78.3 & 78 & 79.8 \\
\hline Ciulli & Supply & 30 & 23 & 15 & 63 & 31 & 33 & 24 & 26 & 32 & 36 \\
\hline
\end{tabular}

Notes: The demand side refers to demand for imported technologies (or dependence on foreign technologies) and measured by the share of chemical, machinery, equipment and manufactured products in total imports. The supply side refers to technological specialization and is measured by the share of value added in machinery and irsusport equipment/GDP.

Sources: Calculated from (a) GOlC (1998, 2000a); (b) World Development Indicators database and GOIC (1998, $20000)$.

Table 2.12. b-Demand for and supply of technologies in the Gulfcountries (1996-1998) (\%)

\begin{tabular}{lllll}
\hline Items & Supply & & Demand & 1998 \\
\hline Couniry years & 1996 & 1998 & 1996 & 53.3 \\
\hline Bahrain & 61 & 71 & 39.7 & 81 \\
Kuwait & 22 & 11 & 81.5 & 79 \\
Oman & 24 & 32 & 74.2 & 86.6 \\
Qatar & 11 & 15 & 86.2 & 75.7 \\
Saudi Arabia & 71 & 88 & 76.4 & 86.4 \\
United Arab Emirates & 64 & 73 & 86.4 & 79.8 \\
Average Gulli & 42.17 & 48.33 & 78.3 & \\
\hline
\end{tabular}

Notes: The demand for imported technologies is measured by the share of chemical, machinery, equipment and manufactured products in total imports, the supply is measured by the share of investment in fabricated metal, machinery and equipment in GDP

Source: Calculated from GOIC (2000a)

Hence, the Gulf countries need to upgrade skills (enhancing education and training), in order to develop local technologies, reduce dependence on foreign technologies, narrow the technological gap, adapt appropriate foreign technologies and enhance economic development. Although the development of local technologies is indeed a costly process, this can be funded from the oil revenues and by offering further incentives to motivate private investment in skill, technology and technical education

\section{2.5 The dectining productivity of labour and economic growth in the Gulf countries}

In recent times, the Gulf countries are facing serious additional problems due to the declining productivity of labour, value added and economic growth. Table 2.1 above, indicates that the average real GDP growth rate in the Gulf declined from $5.1 \%$ in 2000 to $2.5 \%$ in 2001. In addition, the declining productivity of labour and value added can be interpreted as implications of low skill levels amongst both domestic and foreign workers. For instance, the UAE Reports (UAE MOP, 1998; UAE MOL, 1999) indicate that the UAE migrant population shows a quantitative increase rather than a qualitative improvement, which hinders the improvement of skill structure and the average productivity of labour. The reports 
also indicate that between 1985-1995 an increase in the UAE total labour force at $8.1 \%$, the GDP at constant prices at average annual rate of $7.0 \%$ and private sector employment at average annual rate of $3.2 \%$ during 1990-1995 resulted in an annual decrease in average productivity of labour by $3.8 \%$. This implies that the UAE was importing an excess supply of unskilled workers, particularly in the private sector, while the marginal productivity was below zero. ${ }^{25}$ Moreover, the UAE Ministry of Planning (2004) reported continuous annual decline in the productivity of labour in the period 1997-2002. In addition, Cohen (2000) provides evidence for the declining labour productivity and growth of labour productivity in the manufacturing sector in the UAE in the period 1993-1998. Further evidence of the declining growth rates and declining labour productivity in Kuwait and the UAE appear from the results of Wadi (2001) and Abdelkarim and Ibrahim (2001) respectively.

\section{3. Conclusions}

This chapter presents an introduction and background to motivate the research and explains some stylized facts, the research problem along with other strategic problems confronting economic development in the Gulf countries. We explain that oil has contributed to economic development in the Gulf countries. However, the heavy dependence on oil leads to serious challenges since oil is an exhaustible resource and also, because of the instability of oil prices, the revenue from oil is uncertain and volatile. Hence, economic growth and the sustainable development strategy in the Gulf depend on economic diversification, which is contingent upon availability of adequate and appropriate skills and technologies. Moreover, we present other serious structural problems in the Gulf countries that are related to the Dutch disease, structural imbalances in the labour market, duality between public and private sectors, growing unemployment, slowdown in economic growth, declining labour productivity and lack of incentives. We illustrate the low skill and technology indicators and the gap the Gulf countries exhibit when compared to rapidly advanced countries.

Hence, we show that the Gulf countries need to upgrade skill levels and motivate development of local technologies to narrow the technological gap and enhance economic development in the region. In our view, the upskilling of workers through enhancing the system of education and training will encourage R\&D activities and the adoption of appropriate foreign technologies and so motivate both the development of local technologies and the bridging of the technological gap. Moreover, skill upgrading will facilitate economic diversification, restructuring of the labour market, enhancing productivity of labour, and reducing dependence on foreign workers, duality and unemployment.

Therefore, our findings in this chapter confirm our first hypothesis in Scheme 1.1 Chapter 1 above: the Gulf countries need to promote the local skill and local technologies to face the challenges created by the depletion of oil resources. They also need to implement the three strategies of diversification, building local technological capacity and restructuring the labour market. Our results confirm part of the second hypothesis in Scheme 1.1 Chapter 1 above: in the short and medium term, the Gulf countries will be unable to rely on local skill and local technologies and remain heavily dependent on both foreign skills and foreign technologies at the macro level.

\footnotetext{
${ }^{25}$ See the UAE Ministry of Planning Report (1998: 31) and the UAE Ministry of Labour Report (1999: 14) respectively.
} 
PART II

CONCEPTUAL AND THEORETICAL FRAMEWORK 


\section{Chapter 3}

\section{Technological Change and Human Capital: Conceptual Framework, Theoretical and Empirical Literature}

\section{1 Introduction}

Technical progress has been essential for the creation, determination, acceleration and improvement of both quantitative and qualitative aspects of economic growth and welfare in any society. Economic growth theories often emphasize the importance of science and technology and the role of technological change in increasing, improving and sustaining the marginal productivity of capital accumulation and the per capita growth rate of the economy. The crucial role of technological change in economic growth has long received particular recognition amongst economists of different schools of thought, from classical, neoclassical, Schumpeterian, evolutionary to new growth theories. However, despite this consonance, both classical and neo-classical economic growth theories view technical progress as an exogenous or unexplained variable. The new growth or endogenous growth theory endogenizes technological progress in economic growth model and explicitly mentions technological progress as the main endogenous factor behind economic growth. Ever since, economists highlight the endogenous role of technical progress in stimulating economic growth and human welfare and identify industrial innovation as the engine of growth (Romer, 1990; Freeman and Soete, 1997).

Moreover, economic growth literature equally recognizes human capital as an important element for economic growth, and many recent theoretical and empirical studies conducted across countries include some proxies for human capital and emphasize the role of investment in human capital, particularly in the form of education. A higher educational attainment implies more skilled and more productive workers, who in turn contribute to enhancing innovative activities and absorption of advanced technologies. Endogenous growth literature explicitly reveals human capital as one major source of economic growth and acknowledges the endogenous role of human capital accumulation in aconomic growth. More recent literature finds that various measures of schooling are important determinants of per capita growth: an increase in the quantity of human capital per person leads to higher rates of investment in human capital, and so to higher per capita growth.

In light of this background and the findings in Chapter 2 above, it is therefore reasonable to highlight the need for improvement of education, skill upgrading and technological progress for economic development in the Gulf countries. Before starting the empirical analysis, it is useful in this chapter to briefly explain the concepts, measures and theoretical and empirical literature in relation to human capital (education), technological change and 
economic growth. We provide a background for the empirical analysis in the following chapters by surveying the theoretical and empirical literature that emphasizes the positive endogenous growth effects of technical change and human capital in increasing and sustaining economic growth.

The rest of this chapter is organized as follows: in Section 2 we define the concepts of technological change and human capital; the theoretical and empirical literature on the relationship between technological change, human capital and economic growth are presented in Section 3. Section 4 describes the measures of technological change and human capital; Section 5 discusses the role of public policies in supporting endogenous growth, and finally, Section 6 concludes.

\section{2 Conceptual Framework: definition of technological change and hu- man capital (human skills)}

Before presenting the theoretical and empirical literature, it is useful to begin with the definition of the concepts of technological change and human capital.

Distinction has been made between the term technology, technological change and the effect of technological change. The term technology refers to the branch of knowledge concerned with applied sciences and means the systematic treatment, study, use and application of scientific knowledge for practical purposes, such as in industry. Freeman and Soete (1997) define technology as a body of knowledge about techniques, but frequently used to encompass both the knowledge itself and the tangible embodiment of that knowledge in an operating system using physical production equipment. They use the expression 'technicall innovation' or simply 'innovation' to describe the introduction and spread of new and improved products and processes in the economy and 'technological innovation' to describe advances in knowledge. ${ }^{26}$

The rate of technological change is often defined by the rate of increase in the stock of knowledge and relates to the effect it introduces in shifting the production function, leading to either a new shift or an upward shift in the production function. Technological change can be neutral (unbiased) when it does not save any or leads to equal savings of all factors of production, but it can be biased when it results in increased using or saving of one factor rather than others. The classification of technical change into labour (capital) saving technical change implies that it increases the marginal productivity of capital (labour) more than it increases the marginal productivity of labour (capital). Another interpretation indicates that technological change can be equally capital and labour augmenting if it leads to an increase in the production due to either unchanged or equal increases in capital and labour inputs. However, technological change can be purely labour (capital) augmenting, if it leads to increase in effective labour (capital), while effective capital (labour) is constant.

Schumpeter (1934) discusses technological change in the form of innovation including the introduction of new products, services or methods of production; improvement in the quality of existing product or service; development of new markets; exploitation of new sources of supply; and reorganization of methods of operation. Product innovation refers to a substantially new product or an essential improvement to an existing product, while process innovation refers to the introduction of a new or essentially improved method
of production.

${ }^{26}$ See Freeman and Soete (1997: 24). 
Human capital refers to health and education that measured by many indicators, for instance, the amount of human capital embodied in people and their respective influence on productivity on the job are determined by skills, ability, edueation and training (cf. Schultz, 1961; Becker, 1962). In particular, skill is a broad concept and represents one important form of human capital and tacit knowledge: ${ }^{27}$ it refers to acquired and practiced ability or to qualifications needed to perform a job or certain tasks competently in the labour market. In addition, other indicators such as training, learning by doing and average years of experience are important components in the formation of skills and human capital.

\section{3 Theoretical Framework: technological change, human capital and economic growth}

Based on the above framework, in this section we show the theoretical and empirical literature on the relationship between technological change, human capital and economic growth. We explain that economic growth theories recognize and provide different perceptions and analytical frameworks for modelling the various effects of technical change, innovation and human capital on economic growth. The major differences arise because exogenous growth theories perceive and model technical progress and human capital as exogenous variables in growth accounting model, while, in contrast, the endogenous growth theory envisages and models technical progress and human capital as endogenous variables in determining growth process.

\subsubsection{Economic growth theory and exogenous technical change}

The classical economists, starting with Adam Smith (1776), observe the importance of the variable of technical progress in the form of invention (discoveries of new goods and methods of production), innovations, increasing specialization of labour and market expansion in the capitalist system. Despite the apparent recognition of the importance of technical progress in the classical growth theory, technical progress is assumed to remain exogenous variable in growth process.

Next, the neo-classical economists place more emphasis on the significance of technological change. For instance, Solow (1957) attributed $90 \%$ of the US growth rate during the period 1909-1949 to technical progress; Abramovitz (1956), Kendrick (1956) and Solow (1957) attributed almost all the change in output per hour worked in 1950 s to technological change. Subsequent analysis by Jorgonson, Gollop and Fraumeni (1987) showed the importance of technological change beside the increase in the effective labour force and the effective stock of capital in generating growth in output per worker. The neoclassical growth theory assumes an aggregate production function exhibiting constant returns in labour and capital; the only source of output growth being the increase of capital stock. While the rate of technological change is assumed exogenous variable, represented as a residual factor to measure the growth of TFP, thus in the absence of technological change

\footnotetext{
${ }^{23}$ In distinguishing between codified and tacit knowledge Freeman and Soete (1997) argue: "the codiffed knowledge implies that knowledge is transformed into information which can either be embodied in new material goods (machines, new consumer goods) or easily transmitted through information infrastructure. While, the tacit knowledge refers to that which cannot ensily transferred because it has not been stated or measured in an explicit form, one important kind of tacit knowledge is skill, which can be acquired through learning but often of a non-routine kind" (1997: 404-405).
} 
diminishing returns will eventually cause all economic growth to cease (cf. Solow, 1956 , 1957, Swan, 1956). ${ }^{28}$ Therefore, in order to compensate the diminishing returns of capital in the neo-classical framework long run and sustainable growth rate of output per capita assume to equal the continuous advances in the exogenous rates of technological progress in the form of new goods, new markets or new processes. The major limitation of the neoclassical growth theory is that the long run per capita growth is exogenous and determined entirely by the exogenous technical change or residuals factor, which is determined outside the model. This also called the black box problem since the residuals factor includes technical progress beside the contributions of many other variables such as human capital (education), organization, management, knowledge, new machines, etc. Moreover, although, technical progress is included in the neo-classical model, it is not treated as a production factor like capital and labour, and the effect of technical progress is viewed only as a shift in the production function (cf. Solow, 1956; 1957).

\section{3. 1. 2 Economic growth theory and endogenous technical change}

The neo-classical growth theory fails to explain persistent differences in growth rates across countries because it considers the rates of technological progress, which entirely determine the growth rate, as an exogenous variable and fails to deal with increasing returns in a dynamic general equilibrium framework.

The endogenous growth theory contributes to improving understanding of the interaction between technological change and economic growth and fills the gap in the neoclassical theory by recognizing the important endogenous effects of technological progress and innovation for creating and sustaining economic growth. In particular, the endogenous growth theory considers an endogenous technological change and innovation within a dynamic general equilibrium framework and avoids diminishing returns to capital. The endogenous growth theory assumes that technical change and human capital are the major sources of endogenous growth and the presence of increasing returns to scale and externalities prevent diminishing returns to accumulation of capital and so guarantee the steady state of growth in the long run.

An earlier attempt of the endogenous growth theory was made by Schumpeter (1934), who assumed that technological progress, innovation and their diffusion are driving forces and at the centre of the dynamics of the economic system. Schumpeter provides a pioneering theory of innovation that forms the basis for the subsequent thinking on the dynamic role of technological innovation in economic growth determination. Schumpeter considers innovation as an activity made by one or more workers (e.g. skilled workers), which produces an economic gain, growth and profit either by reducing costs or creating extra income.

A subsequent attempt by Arrow (1962) indicates that technology improvement and the growth of technical change become endogenous due to an unintended effect of learning

\footnotetext{
${ }^{25}$ The neo-classical Solow - Swan model assumes a general production function $Y(t)$, in which the flow of output produced at time $t$ and there are only two inputs, physical capital $K(t)$, and labour $L(t)$, the produc$Y(t)=F(K(t), L(t), t)$

The growth rate of the production function depends on time $t$, which reflects the effect of technological change. The long-run growth rate is determined entirely by exogenous elements such as the saving rate and
the level of technology.
} 
by doing. Other earlier endogenous growth models represent the major sources of growth by technical progress, which is viewed as a by-product of production and investment in human capital (cf. Uzawa, 1965; Nelson and Phelps, 1966). Uzawa (1965) interprets technical progress as representing human capital per worker, assuming that its growth required the use of labour services in the form of educational inputs and analyzed optimal growth paths. $^{29}$

Further efforts by Nelson and Winter $(1977,1982)$ attempt a search for a useful theory of innovation, and present an evolutionary theory of economic change that assumes economic change partially stems from innovation on the part of the firm. The ensuing attempt by Dosi, Freeman, Nelson, Silverberg and Soete (1988) contributes to an evolutionary theory of endogenous technical change by investigating the interaction between technical change and economic theory.

Since the mid 1980s, starting with the work of Romer (1986; 1989), Lucas (1988) and Rabelo (1991), which are based on the work of Arrow (1962) and Uzawa (1965), the endogenous growth theory explicitly recognizes the endogenous role of technical change and distinguishes between labour and human capital. The endogenous growth theory avoids the diminishing returns to the accumulation of capital and highlights the role of increasing returns and assumes that growth may proceed indefinitely due to the presence of human capital and endogenous technical progress. The endogenous growth theory also predicts that, in the long run, economic growth at the aggregate level is determined by endogenous sources of human capital, technical change, learning by doing, spillovers of knowledge, external effect of human capital and R\&D.

For instance, Romer (1986) and Lucas (1988) contributed to revitalizing the growth literature using Arrow's (1962) ideas to eliminate the tendency for diminishing returns by assuming that knowledge creation was a side product of investment and a positive effect of experience called learning by doing or learning by investing, but that the rate of technical change remains constant. Next, a major contribution by Romer (1990) presents a pioneering endogenous growth model where technical progress is defined by $R \& D$; assumes that nonhomogenous capital consists of a set of different intermediate goods; and new intermediate inputs are discovered when R\&D resources are devoted to the search process. Romer (1990) identifies two major sources of increasing returns to capital due to specialization or product differentiation, as in Romer (1987), and research spillovers, in which growth will accelerate indefinitely. Romer (1990) assumes knowledge about technology is a nonrival input and induces spillover effects.

Different from Romer (1990), Aghion and Howitt (1992) present an endogenous growth model that defines technical progress by both R\&D and accumulation of technological knowledge through the channel of industrial product and process innovations, which improve the quality of products. Aghion and Howitt's $(1990 ; 1992 ; 1998)$ framework differs from earlier models of endogenous growth (Romer, 1986; 1990; Lucas, 1988) in assuming a model of growth based on Schumpeter's (1.942) process of creative-destruction. Where growth results exclusively from technological progress, which has positive and normative implications for growth in creating losses as well as gains, by rendering obsolete skills, goods, markets and manufacturing processes. Innovation consists of "creativedestructions' rather than just new addlitions to production, and individual innovations are sufficiently important to affect the entire economy. Aghion and Howitt (1990) follow

\footnotetext{
29 See Aghion and Howitt (1998: 24).
} 
Romer (1990) in endogenizing technical change in producing endogenous growth, and follow Arrow (1962), Romer (1986) and Lucas (1988) in introducing learning by doing as a second source of growth beside innovation. They assume that the accumulation of learning by doing in the intermediary industry will introduce an increase in productivity in the consumption goods sector, and, in particular, intermediate firms will experience a complete spillover of their learning by doing, which also spills over into the research sector. Different from Romer (1986), the spillover of learning by doing in Aghion and Howitt (1990) leads to private economy growth: they assume that an increase in learning by doing will have a positive direct external effect on the average growth rate. Aghion and Howitt $(1992 ; 1998)$ assume that a stochastic economic growth is generated by random sequences of product innovations and quality-improving (or vertical) innovations that themselves result from (uncertain) research activities by firms. The average growth rate is determined by the interactions of spillovers or two externalities: positive effect, whereby the knowledge embedded in each innovation can be used by all future researchers to generate growth; and negative effects, namely the business stealing effects.

\section{3. 2 Human capital and economic growth}

Economists have long recognized the importance of human capital to the growth process. For instance, Adam Smith's writings at the beginning of the first industrial revolution recognized that human skills were already becoming more important than raw materials in the designed and manufactured machines. Endogenous growth theory fills the gap in earlier growth theories by assuming the accumulation of human capital is another source of endogenous growth. For instance, both Romer (1986) and Lucas (1988) present endogenous growth models where higher accumulation and an average level of human capital in a context of either increasing or constant returns lead to higher productivity of workers and a higher endogenous growth rate. The endogenous growth theory emphasizes the endogenous role of technology and human capital in economic growth, elaborates on the interaction between them and their central roles in determining the magnitude, speed and difference of growth rates across countries (cf. Abramovitz, 1986; Lucas, 1988; Romer, 1990; Aghion and Howitt, 1992). The literature discusses the relationship between human capital and economic growth following the pioneering approaches by Nelson and Phelps (1966) and Lucas (1988) and the contributions of Romer (1986, 1989, 1990) and Aghion and Howitt
(1992).

An earlier attempt of the endogenous growth model is the AK model, which assumes a constant return to scale in a broad aggregate capital including physical and human components "K", an improvement in the level of technology, raises the marginal and average product of capital and the growth rate. ${ }^{30}$ The AK model has the advantages of inclusion of physical and human capital, elimination of diminishing returns to accumulation of capital and creating endogenous growth; its limitations are the assumption of a fixed level of technology and the railure to explain long run balanced growth rate.

An earlier pioneering approach refers to an important contribution by Nelson and Phelps (1966), which assumes growth rates as being driven by the stock of human capital, which in turn affects a country's ability to innovate or catch up with more advanced coun-

\footnotetext{
${ }^{30}$ The $A K$ production function without diminishing returns and with a fixed level of technology $A$ is de-
fined by: $Y=A K$
} 
tries. Nelson and Phelps (1966) explain differences in growth across countries are primarily due to differences in human capital stocks and the abilities to generate technical progress. They assume that growth is primarily driven by the stock of human capital; but the effects of education and human capital are more important for producing technological change than for producing output under a given technology. Nelson and Phelps (1966) and, more recently, Benhabib and Spiegel (1994) assume that human capita ${ }^{31}$ is necessary for innovations (capacity to innovate) and for adapting to new technologies and thereby speeding up technological diffusion throughout the economy. A first implication of the Nelson- Phelps approach is that productivity growth and the rate of innovations should increase with the level of educational attainment, particularly with the enrolment in secondary and higher education, which best reflects the numbers of potential R\&D staff in a country. Recent empirical studies verify this result and show the significant impact of secondary and higher educational attainment level on the rate of productivity growth (cf. Barro and Sala-i-Martin, 1995; Benhabib and Spiegel, 1994). A second implication of Nelson and Phelps (1966) is that the marginal productivity of educational attainment is increasing in or with the rate of technological progress (including both innovation rate and speed of adapting to new technologies). Some studies verify this result and find that education induces a significant impact on productivity growth only when it is explicitly related to the rate of innovations and the speed of technological catch-up (cf. Bartel and Lichtenberg, 1987; Benhabib and Spiegel, 1994). A third interesting result of Nelson and Phelps (1966) is that education should permit the countries falling behind to learn more from advanced countries and thereby achieve a higher degree of productivity improvement when innovating. Recently, Benhabib and Spiegel (1994) support this result and indicate that the effect of past educational attainment levels on current growth rates is more obvious across countries that fall behind in terms of aggregate productivity, but growth is to be principally driven by technological catch-up. Thus, the inclusion of technical progress beside human capital substantiates the role of human capital in technological catch-up. ${ }^{32}$

A further interesting approach was introduced by Lucas (1988), based on Becker's (1964) theory of human capital, and on the idea that growth is primarily driven by the accumulation of human capital (education). ${ }^{33}$ The Lucas (1988) approach is a pioneering contribution to the endogenous growth literature: it regards human capital accumulation as the engine of growth, as an alternative (to technological change) and as a complementary source of sustained growth. ${ }^{34}$ Lucas (1988) adapts Uzawa (1965) and Rosen's (1976) formulation and assumes that growth rate is linearly related to human capital level and its accumulation over time. One implication of the Lucas model is that human capilal accumulation is a social activity, involving groups of people, in a way that has no counterpart in the accumulation of physical capital. Another implication is that economies with high human capital stock can easily produce more and can thus sustain a high growth rate. On the other hand, an economy beginning with low levels of human and physical capital will remain permanently below an initially better endowed economy.

Hence, in the Lucas model, differences in growth rates across countries are mainly attributable to differences in the rate at which those countries accumulate human capital over time, assuming that the rate of technical progress remains fixed or exogenous, while

\footnotetext{
"In Nelson-Phelps (1966) approach human capital is referring to education and the highly skilled workers.

${ }^{32}$ See Aghion and Howitt (1998): 339- 340

${ }^{33}$ Lucas (1988) defines human capital as general human skills that are produced and acquired by education.

${ }^{34}$ See Aghion and Howitt (1998: 327).
} 
Nelson and Phelps (1966) explain that differences in growth across countries are primarily due to differences in human capital stocks and the abilities to generate technical progress. Moreover, Lucas (1988) discusses the relationship between productivity growth and the rate of human capital accumulation, whereas Nelson and Phelps (1966) show that productivity growth and the rate of innovations should increase with the level of educational attainment and particularly so with the enrolment in secondary and higher education. Furthermore, Lucas (1988) assumes that the marginal productivity of education is determined and sustained only by the accumulation of human capital, while Nelson and Phelps (1966) assume the marginal productivity of educational attainment is increasing in the rate of technological progress (including both innovation rate and speed of adapting to new technologies). ${ }^{35}$

One feature of Lucas" (1988) model is the assumption of constant returns to scale and the accumulation of human capital, which implies that a diminishing return can be avoided when the production function includes both physical and human capital and both these grow at the same rate. Thus, in the steady state, rates of return remain constant and the economy can grow at a constant and sustained rate mainly due to endogenous growth from human capital accumulation, and without the need for external "engine of growth" or exogenous technological change. Barro and Sala-i-Martin's (1995) results indicate that the presence of human capital (as an alternative to improvements in technology as a mechanism to generate long-term growth) may relax the constraint of diminishing returns to a broad concept of capital and can lead thereby to long term per capita growth in the absence of exogenous technological progress.

Another interesting feature of Lucas' (1988) model is the introduction of human capital with externalities or spillovers effects of education between individuals. Lucas (1988) distinguishes between the internal effects of human capital, i.e. the effects of an individual's human capital on his own productivity, and the external effects of human capital that contributes to the productivity of all factors of production, including his or her own human capital. The external effects of human capital induce more rapid physical than human capital growth; the average skill level of a group of people is assumed to affect the productivity of each individual within the group. Both Lucas (1988) and Romer (1986) highlight the spillover effects or benefits from aggregate human capital, supposing that human capital can be passed down from generation to the next and can therefore grow without bound. Assuming that this special kind of knowledge is only produced as a side effect of other activities, investment in physical capital or investment in schooling respectively, while Romer $(1989,1990)$ allows this special kind of knowledge to be produced intentionally and not as a side effect. Azariadis and Drazen (1990) find that the existence of threshold externalities in education technology can lead to several steady state growth paths and explain existing continuous and perpetual differences in growth rates across countries due to unequal initial human capital endowments. ${ }^{36}$

Moreover, Lucas (1988) follows the theory of human capital and distinguishes between two main sources of human capital accumulation (or skill acquisition), namely education and learning by doing. Based on theory of human capital, Lucas assumes that the allocation of time over various activities in the current period affect productivity or affect the accumulation of human capital $h(t)$ level in future periods. Lucas identifies both the way the human capital level affects current production and the way the current time alloca-

35 See Aghion and Howitt (1998: 327,339)

"See Aghion and Howitt (1998: $331-333)$ 
tion affects the accumulation of human capital. Lucas assumes that a worker with skill level $h$ devotes the fraction of $u(h)$ of his non-leisure time to current production and the remaining $I-z(h)$ to human capital accumulation. So, the human capital equation in the Lucas model is defined by: $h=h(t) \delta(1-u(t)), \delta>0$ which spells out how current schooling time (1-u) affects the accumulation of human capital. If learning by doing rather than education is the primary source of human capital accumulation, the above equation should be replaced by the following equation: $\mathrm{h}=8 \mathrm{hu} .^{37}$

The subsequent contribution by Romer (1990) presents a growth model of endogenous technical change assuming long run growth is increasing in and driven primarily by both technological change (the accumulation of knowledge) and the stock of human capi$\mathrm{tal}^{38}$ rather than the total size of the labour force or the population. He emphasizes the central role of technological change, stock of human capital, externalities and increasing return associated with investments in human capital in the research sector and in determining the rate of growth. He finds that an economy with a larger stock of human capital will experience faster growth. Romer (1990) follows both Romer (1986) and Lucas (1988) in their assumption of external effects arising from knowledge spillover. Romer (1990) assumes that the final output is a function of physical labour, physical capital, human capital and an index of the level of technology. The application of more human capital to research leads to higher rate of production of new designs and stock of knowledge, which increases the productivity of engineers working in the research sector. ${ }^{39}$ The output of the design is a linear function of human capital and technology when the other variables are held constant. The marginal productivity of human capital employed in the manufacturing sector grows in proportion to technology. Unlike Lucas (1988), Romer (1990) follows Schumpeter's (1942) assumption that technological change drives growth and provides the incentive for continued capital accumulation, the growth rate is increasing in the stock of human capital. So, both capital accumulation and technological change account for much of the increase in output per worker.

The endogenous growth model proposed by Aghion and Howitt (1992) assumes that capital accumullation includes both physical and human components. They assume that both the average and the variance of the growth rate are increasing functions of the size of innovations, size of skilled labour and the productivity of research, which is measured by the effect of research on the Poisson arrival rate of innovations. They distinguish between three categories of labour: unskilled labour, which can be used only in producing consumption goods; skilled labour, which can be used either in research or in intermediate sector; and specialized labour, which can be used only in research. They assume that skilled labour has two uses: in the manufacture of the latest generation of intermediate goods and research aimed at discovering the next generation of these goods. An expectation of more research in the next period must correspond to an expectation of higher demand for skilled labour in research in the next period. They assume that research produces a random sequence of innovations, and that the Poisson arrival rate of innovations in the economy at any instant is

\footnotetext{
37 See Lucas (1988) and Aghion and Howitt (1998: 327, 329).

3 "Romer's (1990) definition of human capital includes activities such as formal education and on the job training.

${ }^{39}$ One implication of Romer's (1990) argument is that, despite having the same amount of human capital, an engineer working at current time has higher productivity than one who worked in the previous century because he acquires the advantages of all additional improvements and accumulation in knowledge since then.
} 
dependant on the current flow of skilled labour used in research. They assume that skilled labour is important factor in research, inmovations and economic growth, and that an increase in the endowments of skilled labour increases both the marginal benefit and reduces the marginal costs of research by reducing the wage of skilled labour.

Moreover, several recent empirical studies conducted across countries use many measures of human capital and find that human capital is important determinant of long rum economic growth or per capita growth. ${ }^{40}$

\section{3. 3 The relationship between technological progress, human capital (skill) and skill upgrading}

In this section, we show that the inclusion of technological change and human capital in growth accounting models motivates endogenous growth literature to postulate several explanations of the relationship between human capital and technical change. In particular, considerable debate arises around four issues regarding the complementary relationship between human capital and technical progress, skilled biased technical change, the role of technical progress in skill upgrading and the role of skill in skill upgrading.

The first hypothesis highlights the complementary relationship between technological progress and human capital. The interpretation of this hypothesis is that the high educated workers can adapt more and easier to changing technologies than the low educated workers. A large endowment of human capital facilitates the fast adaptation of technologies and induces positive impacts on economic growth, and faster technology driven growth in turn can induce more schooling by raising the rate of return on investment in schooling (cf. Nelson and Phelps, 1966; Benhabib and Spiegel, 1994). Moreover, human capital or skill is found to be more complementary with technology and capital (cf. Goldin and Katz, 1998; Mincer, 1989). Because the "embodiment" of technical change in both physical and human capital indicates that the improvement in their quality implies their complementarity with technological change (Bartel and Lichtenberg, 1987). In addition, more innovation stimulates human and physical capital accumulation by raising the marginal product of capital, while more capital accumulation stimulates innovation by raising the profit accruing to innovation (Aghion and Howitt, 1998). Furthermore, a high proportion of skilled workers in the labour force implies a large market size for skill-complementary technologies and encourages faster upgrading of the productivity of skilled workers (cf. Acemoglu., 1998).

Several studies use many different indicators to examine the technological progress and human capital complementary hypothesis. For instance, the increasing utilization of higher educated workers shows positive correlation with TFP growth (cf. Kahn and Lim, 1998), with physical capital, capital equipment or capital intensity (cf. Griliches, 1969; Bartel and Lichtenberg, 1987; Goldin and Katz, 1998), with R\&D (Acemoglu, 1998; Machin and Van Reenen, 1998) and with the use of new technologies (cf. Acemoglu, 1998), especially ICT (cf. Goldin and Katz, 1998; Bresnaham et al. 1999; Autor, Katz, and Krueger, 1998$)$.

\footnotetext{
40 For instance, Rebelo (1991), Barro (1991, 1996), Barro and Lee (1993, 1996, 2000), Benhabib and Spiegel (1994), Barro and Sala-i- Martin (1995), Mankiw, Romer and Weil (1992), and Kahn and Lim (1998) all find strong positive correlation between schooling and the growth rate or the subsequent growth rate of per capita GDP or TFP.
} 
The second hypothesis concerns the skill-biased nature of technical change. The rationale for this argument is that technical change has dual implications on employment and demand for skill, which is found biased against low skilled workers and lead to either unemployment /job mismatch (cf. Muysken, et al., 2002) or crowding out of low skilled workers (cf. Muysken and ter Weel, 1998).

Another interpretation is based on the argument that techmical changes induce creative- destruction effects on growth and employment. While it enhances productivity growth, stimulates demand and the creation of new jobs, it also destroys jobs because it is primarily labour saving through automation and skill obsolescence (cf. Aghion and Howitt, 1992; 1998).

In the recent literature two features have received particular attention: the first issue is that economic debate has become focused on the significant change in the composition of labour demand, particularly the increase in the demand for skilled workers and sharp decline in the demand for low skilled workers. The second issue is focused on the distributional aspects of technical change, particularly the implications of skill-biased technical change (SBTC) on the structure of employment and wages that has shifted against the low skilled workers, leading to either an increase in unemployment of low skilled workers or increasing wages divergence between high skilled and low skilled workers, which leads to greater inequality (cf. Autor, Katz, and Krueger, 1998; Acemoglu, 1998; Bound and Johnson, 1992).

The skill-biased technical change (SBTC) hypothesis has been verified both at the macro level across both developed and developing countries (cf. Berman, Bound and Machin, 1998) and at the micro level within industries (cf. Berman Bound and Griliches, 1994). SBTC is related to various measures of technical changes such as TFP growth (cf. Kahn and Lim, 1998), R\&D (cf. Berman Bound and Griliches, 1994; Acemoglu, 1998; Machin, and Van Reenen, 1998) and the use of IT or ICT (cf. Bound and Johnson, 1992; Berman Bound and Griliches, 1994; Freeman and Soete, 1994; Autor, Katz, and Krueger, 1998).

The third hypothesis explains the rolle of technical progress in skill upgrading. The interpretation of this hypothesis is that both the technology-human capital complementarity and skill-biased technical change hypotheses imply that a higher rate of technical progress should bring an increase or upgrading in skill level. Several studies in the literature use many indicators to show the role of technical progress (in the form of TFP, R\&D, ICT, IT or computer use, etc.) in skill upgrading. For instance, skill upgrading, defined by the increasing incidence of training, increases with the rate of technological change (cf. Mincer, 1989; Bartel and Sicherman, 1995 of productivity growth was higher (cf. Littard and Tan, 1986) or showing an increasing use of IT or computers (cf. Bresnahan, 1999). Skill upgrading, defined by the shift away from unskilled towards skilled employment or increase in the share of white-collar high skilled workers, is allso positively correlated to variables related to technological change, such as R\&D investment and growth in the number of patent (cf. Colecchia and Papaconstantinou,

4 Bartel and Sicherman (1995) find that on the job training will increase if technological change increases the productivity of human capital, reduces the costs of training or increases the value of time in training relative to work; and that the training gap between the highly educated and the less educated narrows, on average, as the rate of technological change increases. 
$1996^{42}$ ). In addition, skill upgrading, defined by the increase in the wage share of whitecollar workers, is positively related to two measures of technology: the level of investment in R\&D and computers (cf. Berman Bound, and Griliches, 1994). Furthermore, skill upgrading, as defined by the change in the share of educated workers in employment and return to schooling or wage rate, is positively correlated with the increase of R\&D intensity (cf. Machin, and Van Reenen, 1998). Moreover, skill upgrading, as defined by the share of high skilled workers, is positively correlated with TFP (cf. Garcia Cervero, 1997) or the use of computers, IT, ICT or computer-intensive industries (cf. Autor, Katz and Krueger, 1998; Bresnahan, 1999). Skill upgrading, decreasing motor skills and increasing cognitive skills accompany the diffusion of ICT, mainly through occupational change rather than educational improvement, and are also positively correlated with productivity growth (cf. Hwang, 2000).

The fotrth hypothesis deals with the role of human capital or skill acquisition in skill upgrading. Along with the debate on the relation between technological change and human capital and the positive effects of human capital/education on productivity and economic growth, theoretical and empirical literature highlight the role of human capital/education in skill upgrading through externalities and learning by doing. Educational attainment is important because skills acquisition from formal schooling lead to improvement in training and learning abilities and increase the accumulation of human capital through experience or "ly earning by doing", which in turn interact together and lead to improvements in workers productivity (cf. Autor, 2000) ${ }^{43}$. Theoretical literature highlights the role of human capital or skill in skill upgrading through externalities, spillover and learning by doing ( $\mathrm{cf}$. Lucas, 1988 ; Romer, $1986 ; 1989 ; 1990$ ). In addition, the average human capital tends to grow over time as human capital investments have a positive external effect on the human capital of the later cohorts (Stokey, 1991). Moreover, recent empirical literature shows that in the developed countries, particularly across the OECD countries, human capital may accumulate at a faster rate with the past intensive use of high skilled workers (cf. Colecchia and Papaconstantinou, 1996). Furthermore, empirical literature from the developing countries shows that in Singapore and Korea investment in human capital via the expansion and improvement of education and training systems, particularly the development of tertiary, vocational and technical education, leads to an improvement in the overall skill content or skill upgrading of the working population. This appears from the improvement in the educational attainment -defined by highest qualification attained-and skill levels, the rise in the share of high skilled workers, scientists and engineers and the fall in the share of low skilled workers. In addition, upgrading of the occupational structure has resulted from the large/rising share of the supply of high educated, white-collar and non-production workers and the small/falling share of blue-collar workers. ${ }^{44}$

\footnotetext{
42 Colecchia and Papaconstantinou (1996) find that a one percentage point R\&D intensity higher than avernge at the beginning of eighties has implied about twenty per cent higher than average upskilling per year.

${ }^{43}$ Autor (2000) argues that: first, training is more productive and therefore valuable to high ability workers; second, workers have some prior information about their ability that is not initially wisible to employers; and, third, firms are able to learn about ability through skills training.

* See Chealh (1997), Low (1998) and Cheon, (1999). In Singapore, the transfer of foreign technology and foreign skills stimulates the acquisition of knowledge and skills from abroad and induces positive spillover in upgrading the skill of domestic workers. This has been accompanied with technological upgrading to promote mechanization, computerization, automation, etc. In the Republic of Korea, the integration into global economy or exposure to foreign competition leads to skill upgrading of domestic workers in the
} 
These findings emphasize the importance of the endogenous effects of technical progress and human capital for enhancing economic growth. In particular, these explanations imply that next to the important endogenous effects of technical progress and human capital in economic growth, the complementary relationships between them and between them and skill upgrading are also important for enhancing economic growth.

\section{4 Measurement of technological change and human capital}

While it is admitted that technological progress and human capital are difficult to measure, the theoretical and empirical literature use many indicators to approximate their effects. It will be useful to illustrate the advantages and weakness of these measures in order to select some relevant measures for the empirical analysis in the subsequent chapters.

\section{4.1 Measurement of technological change}

The literature uses several indicators to measure the role of technical progress in economic growth and particularly distinguishes between input indicators, which include variables such as R\&D expenditures and human resources, and output indicators, which comprise variables such as patent, productivity growth, publication, etc. (cf. OECD, 1997). A comprehensive approach of technological progress should be based on integration of input and output indicators.

The traditional indicator used in the literature to measure the contribution of technical change in economic progress is represented by total factor productivity (TFP) (cf. Kahn and $\operatorname{Lim}, 1998)$. It is also known as Solow Residuals, as Solow $(1956,1957)$ was the one to find that the growth rate of technical progress emerges as the remaining unexplained variable or the residual parameter - defined as the factor of output that can not explained by the input factors. ${ }^{45}$ The use of TFP growth measure indicates the high significance of technical progress: for instance, Solow (1957) finds that around $90 \%$ of the growth in US output per worker during the period $(1909-1949)$ was due to the effect of the residual factor, which measures the effect of technical progress. Moreover, Abramovitz (1956), Solow (1957), Kendrick (1961) and Dension (1962) find that about half of the growth of the US economy up to the 1950s was attributed to technical progress measured by TFP. However, the TFP indicator has several drawbacks such as the lack of relevant and adequate data and the inaccuracy and broadness of the concept of TFP, which includes factors other than technological progress such as human capital (education), organization, management, knowledge, new machines, etc. According to Mincer (1989), productivity growth indicates the consequences of technical change, but is not a measure of it; TFP is a useful measure of technological change only if other factors affecting productivity growth are either unimportant or considered in the statistical applications. In addition, TFP growth measure may imply some measurement errors due to business cycles and economies of scale (cf. Mincer, 1989:4).

The major input indicator in measuring scientific and technological progress is often represented by the data relating to $R \& D$ expenditures, which have been widely used

manufacturing sector. Skill upgrading of domestic skills facilitates the adoption of foreign technologies and technological catching-up with the advanced countries.

${ }^{45}$ Productivity growth is calculated as the differences between the rate of growth of output and (an weighted measure of) the rate of growth of the capital and labour inputs (Mincer, 1989), or the differences in growth rates of the social product and the capital and labour production factors 
across the OECD countries due to their consistency and easier computation compared to output indicators in these countries. The R\&D expenditure data can be utilized to analyze the comparative development and breakdown of $\mathrm{R} \& \mathrm{D}$ activities according to sector and source of finance. However, R\&D expenditure data has several defects: for instance, that the data reflects only the recorded expenditures and the institutionalized aspects of technology aimed at increasing knowledge. It also does not include many activities that contribute to technological knowledge such as design, learning-by-doing, the indirect public spending on R\&D, etc. Moreover, R\&D data reflects only the effort put into research, and does not reflect the efficiency with which this effort leads to new knowledge, the quality of $R \& D$ work undertaken, the quality of the scientists performing the work, the cost of inputs of labour, equipment and materials, etc. Moreover, the definition of R\&D expenditure varies substantially across countries and is difficult to measure for a large number of countries, and does not reflect the effects of the international spillover of S\&T and variations across countries with respect to R\&D performance. In addition, it does not produce immediate results, making it difficult to establish direct relation between $R \& D$ performance and indicators of economic growth, because R\&D activities lead to knowledge creation, which may lead to improved performance only in the long run. ${ }^{46}$

The major output indicator is defined by the patent indicator, which is utilized in the literature to measure technological capacity and status of a country, sector or company. The literature uses patent data to measure the output of technological activities, to reflect the technological performance over time and across countries, to examine the technological specialization in key sectors of industry and to protect industrial property rights (cf. OECD, 1997). The patent indicator is often widely used in the measurement of technological change because it allows for international comparisons over a long period; it provides more accurate and specific analyses by sector and by technology; and allows for more focus on a company, institution and even single inventor or researcher. On the other hand, the patent indicator also has several limitations, such as: a lesser degree of reliability for countries or sectors with a small number of patents; and possible interruptions by reason of having to work with publication rather than priority dates. ${ }^{47}$ Further limitations lie in the difficulty in interpreting average annual growth rates per period due to unstable patent numbers at the end of a period, lack of exact measurements and the potential inconsistency between the required and actual measurements, the latter problem admittedly also applicable to other
indicators. $4 \$$

Numerous empirical studies use innovation surveys such as the survey of resources (R\&D) indicators, survey of direct progress (output) indicators and survey of indirect progress and impact indicators, which can be evaluated by questionnaires to measure technological change. A well-known example of this is the Community Innovation Survey (CIS). Distinction has been made between innovation surveys according to subject and object approaches. The subject approach focuses on the innovator or firm-level innovative activities, identifies both input and output indicators, includes small-scale incremental change, reflects economic indicators and permits for comparisons within industries or inter-firm comparison, but does not allow for comparison between different industries with different outputs.

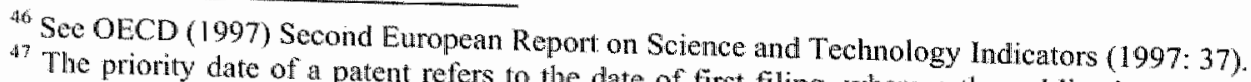

date on whicla the patent was published. This leads to a filing, whereas the publication date refers to the For example, in the European (EPO) system, patents to a time lag between the priority and publication year. 4" See OECD"s Second European Report on Science and Tublished eighteen months after first application.
} 
On the other hand, the object approach focuses on significant technological innovations (new product or process) or the objective output of the innovation process, on the technology itself. It allows for an external assessment of the importance of innovation independent of personal judgement and usually identified through expert appraisal or through new product announcement in trade journals or other literature. However, it has limitations as it is confined only to major innovations, neglects small incremental innovation and does not include an assessment of the economic significance of innovation. ${ }^{49}$

Some recent studies tend to measure technological change by using an index of use, investment or expenditures on ICT, IT, computers or computer equipment, which are also called the new general purposes technologies. These indicators are relatively easier to calculate and several studies provide strong results when using them to reflect the use and organization of technological innovation (cf. Autor, Katz and Krueger, 1998; Bresnahan, 1999). However, the utilization of computer use as a measurement of technological progress and innovation may lead to endogenity and measurement problems (cf. Sanders and ter Weel, 2000: 26).

For our macro-micro analysis we use R\&D, patent and ICT as more relevant measures of technical change at the macro-micro levels. Moreover, at the micro/firm level we use the innovation survey following the subject approach, as it appears more relevant for assessing only small incremental innovation at firm level. Our analysis will not include the object approach since it focuses on big (radical) innovations and seems inappropriate for measuring the small incremental innovations in our case studies in the Gulf. Other measures, such as the TFP measure, are not very relevant for our analysis and will not be included in our study due to a lack of relevant data and information to estimate these at both macro and micro levels. In order to measure these indicators, we will use the available relevant secondary data and information at the macro level and use the firm survey data at the micro level, as we will explain in Chapters 4 and 6 below.

\section{4. 2 Measurement of human capital (human skills)}

The most widely used measures of skill in the literature is educational attainment, as measured by the average years of schooling, occupation measure, the share of non-production workers in total employment and the share of non- production workers wages to total wages. In addition, the literature uses other measures of human capital such as school enrolment ratios, adult literacy rates and school quality measures.

School gross and net enrolment ratios reflect current flows of education that accumulate to create the future stocks of human capital and have been used in several studies (cf. Barro, 1991; Barro and Lee, 1993; 1996). ${ }^{50}$ However, they have several limitations: for instance, they only measure current flows of schooling and do not reflect the stock of human capital. In addition, they are susceptible to underestimation and overestimation meas-

\footnotetext{
49. See Simith (2000).

50 The UNESCO definition distinguishes between gross and net enrolment ratios. "Gross enrolment ratio defines the ratio of all persons enrolled in a given level of schooling to the population of the age group that would be enrolled at that level. While, net enrolment ratio modifies the numerator of the gross enrolment ratio to count only the students enrolled within the designated age group i.e. the ratio of students at a given level of schooling in the designated age group to the total population of the same age group. The net enrolment ratios vary between zero and one, whereas the gross enrolment ratios can exceed one" (Barro and Lee, 1993:4). For detailed definition, see also the UNESCO-UIS website: www. llis.unesco.org
} 
urement errors $^{5}$ : for instance, net enrolment ratios tend to underestimate the actual value of variables on both mortality and migration; gross enrolment ratios introduce errors related to repetition of grades and dropouts, which are widely observed in developing countries. Gross enrolment ratios overestimate the actual value because their calculation are based on annual surveys of educational institutions in each country and reflect registered number of students at the beginning of each school year rather than computing the actual number in attendance. In general, the net enrolment ratio is relatively more appropriate for measuring the accumulation of human capital, however, the gross ratio has been widely used because it is more often available for developing countries. ${ }^{52}$

The adult literacy rates have been frequently used in several studies to estimate the relationhip between human capital and economic growth (cf. Barro, 1991; Romer, 1989). They have an advantage over school enrolment ratios as they reflect the stock of human capital rather than the flow of investment. However, a major problem with adult literacy rates is that they measure only one component of the current stock of human capital or the first stage in the path of human capital formation, but do not reflect the skills that are obtained beyond the most elementary levels of schooling as well as many other important aspects of human capital and various types of technical knowledge, which are important for enhancing labour productivity and economic growth. The use of literacy to measure the stock of human capital implies that education beyond the most elementary level does not contribute significantly to productivity. ${ }^{53}$

The educational attainment or educational level is measured by average years of schooling to reflect the stock of human capital and allow for across countries or international comparison ${ }^{54}$ It has been widely used in the literature (cf. Barro and Lee, 1993; 1996) as an appropriate and accurate alternative measure to both school enrolment ratios and adult literacy rates. In recent literature, educational attainment is used to reflect the inflows of new school graduates to existing educational stocks across countries (cf. Barro and Lee, 2000). The rapid growth in average years of schooling led to double growth in the stock of human capital in the USA (cf. Mulligan and Sala-i-Martin, 1995), educational attainment or the average years of schooling has a significant contribution to the growth of total factor productivity (cf. Kahn and Lim, 1998). Although the average years of schooling measure is often widely used as the most popular measure of human capital in the new growth literature and comparisons across countries, it has some drawbacks, such as the assumption of constant elasticity of substitution across workers of different group, which

\footnotetext{
5ee and Barro (1997) use an adjusted enrolment ratio to overcome the problems of underestimation in $5_{22}$ enrolment atios and overestimation in gross enrolment ratios.

${ }^{52}$ See Barro and Lee (1993: 4-6).

Programe Barro and Lee (1993: 6). "The literacy rates have been used in the United Nations Development adult illiteracy rates to proxy for the per andex of human capital. Moreover, Barro and Lee (1993) use the gap in the availability of for the percentages of adult population who have no school attainment to fill website: www uns unesco.org

s4 The educational attaimment

the product of the number of years of sed the average years of schooling, which is computed by adding across school categories, "i.e. defined by the following formula:
}

Average Years of Schooling $=\Sigma_{j} \boldsymbol{Y} \boldsymbol{R}_{\dot{r}} \boldsymbol{H} \boldsymbol{S}_{j}$

Where $j$ is schooling level, $Y R_{j}$ is the number of years of schooling represented by the level $j$, and $H S_{j}$ is For detailed definition, faction for which the jth level is the highest value attained" Barro and Lee (1993. 7).

For detailed definition, see also the UNESCO-UIS website: www uis unesco.org 
implies that always and everywhere workers of each education category are perfect substitutes for workers in other categories. It assumes that productivity differentials among workers with different levels of education are proportional to their years of schooling, that always and everywhere a year of education adds a constant quantity of human capital and delivers the same increase in skill, whether undertaken by a primary pupil or a college student. It implies that always and everywhere a worker with 16 years of schooling is 16 times as productive as worker with one year of schooling, irrespective of the wage rate differentials. It does not consider differences in the fields of study and quality of schooling (quality of teachers and education infrastructure) and wage rate across countries. Moreover, the educational attainment does not directly measure the human skills obtained at schools, namely quality of schooling across countries, and it does not reflect the skills and experience gained by individuals after their formal education. ${ }^{55}$

Some studies use schooling quality measure or the quality of educational output to measure the impacts on various dimensions of cognitive skills that affect an individual's productive behaviour, and thereby the quality of the future labour force (cf. Hanushek and Kim, 1995; Lee and Barro, 1997). ${ }^{56,57}$ Although both the quality and the quantity of schooling are important ingredients of human capital, schooling quality measure has several disadvantages as it varies substantially across countries and is difficult to measure for a large number of countries (Lee and Barro, 1997: 1).

The occupation measure or classification is based on the definition of employment structure and the relative shares of educated and non-educated workers in total employment. In particular, the ILO International Standards Classification of Occupations (ISCO) ${ }^{58}$ is a widely used measure for measuring skill composition in the literature (cf. Colecchia and Papaconstantinou, 1996; Hwang, 2000 59 . According to the ISCO classification, only WCHS is referred to as "high-skilled", with all other groups regarded as low skilled. The advantage of the occupation measure is that the change in occupational distribution of employment provides more information on the skills required and measures the change in

\footnotetext{
55 See Mulligan and Sala -i - Martin (1995: 2) and Barro and Lee (2000: 12).

56. The definition of this measure includes the pupils/teacher ratios, spending per pupil at primary and secondary schools as a percentage of GDP, and also estimates average salaries of primary sehool teachers to per capita GDP.

${ }^{3}$ Hanushek and Kim (1995) find that cognitive skills are an important component of relevant variations in human capital, reinforcing the attention to school quality found in many countries today. Their results indicate that quallity of labour force has a consistent, stable and strong influence on economic growtly, the impact of quality indicates that one standard deviation in mathematics and science skills transiates into one percentage point in average annual real growth. This growth effect is larger than would be obtained from over eight years in average schooling.

5* The ILO International Standards Classification of Occupations (ISCO) are aggregated in the following way:

White-Collar high-skilled (WCHS) includes legislators, senior officials, managers, professionals, technicians and associate professionals.

White-Collar low-skilled (WCLS) includes clerks, services workers, shop and market salles workers.

Blue-Collar high-skilled (BCHS) includes skilled agricultural and fishery workers, craft and related trade workers.

Blue-Collar low-skilled (BCLS) includes plant and machine operators and assemblers and elementary occupations.

59 Hwang (2000) finds that skill upgrading, decreasing motor skills and increasing cognitive skills are accompanying the diffusion of ICT, mainly through occupational change rather than educational improvement.
} 
skills structure. But it has the drawback that it does not necessarily take into accounts onthe-job learning and, in particular, skills associated with the use of new technologies. ${ }^{60}$ It also fails to account for the changing nature of skills under an occupational title. ${ }^{6}$

The share of non-production workers to total enployment measure is defined by the ratio of the non-production workers to total employment and has been usually used in the literature (cf. Kahn and Lim, 1998; Cheon, 1999). However, it has several limitations: for instance, it does not exactly reflect change in relative demand for non-production workers, and it may over-represent the shift in demand for non-production workers. Moreover, the definition of non-production workers includes a lot of low-skilled service jobs such as janitors, cleaners or simple clerical jobs, and various liberal occupations, while excluding production supervisors, foremen and skilled workers that are of considerable importance in manufacturing sector of developing countries (Cheon, 1999: 12-13). ${ }^{62}$

The share of non-production workers ' wages in total wages is measured by the ratio of non-production workers wages to total wages, and has been used in several empirical studies (cf, Kahn and Lim, 1998). Its advantage is that the changes in the non-production share in the wage bill provide a better measure of the demand shift toward non-production workers, provided that the elasticity of substitution between production and non-production workers is above one (cf. Berman, Bound and Griliches, 1994; Cheon, 1999). However, it has several limitations: for instance, the measure is originally based on the definition of non-production and production workers for skill and unskilled workers and may suffer the same measurement errors related to the definition of non-production and production workers as we explained above. Moreover, the wage measure is applicable only when the elasticity of substitution between production and non-production worker is above one. Furthermore, it may be inaccurate to reflect the movement in the stock of human capital when the relative wages change for reasons other than changes in human capital and technological stocks (e.g. due to price change). So, the wage measures may induce some measurement errors (cf. Cheon, 1999; Goldin and Katz, 1998; Machin, and Van Reenen, 1998). ${ }^{63}$

For our analysis at the macro level we use the measures of school enrolment ratios, literacy rates, educational attainment, school quality measures and occupational classification to assess skill levels, based on information and data from many relevant sources (e.g. the UNESCO, UNDP, etc.). In addition, in our analysis at the micro/firm level, we use two more relevant measures of skill, namely, educational attainment and occupational classification, based on data obtained from the firm survey as we will explain in Chapters 4,5 and 6 . Our analysis will not include other indicators such as the share of non-production workers in total employment and the share of non-production workers wages in total wages due to a lack of relevant data to estimate these. Instead, we use the share of high-skilled in total employment and the share of high-skilled wages to low-skilled wages according to education and occupation definitions.

\footnotetext{
${ }^{60}$ See Colecchia and Papaconstantinou (1996: 8).

${ }^{61}$ See ILO (1998) World Employment Report (1998/1999: 35).

${ }^{62}$ See Kalm and Lim, (1998) and Cheon, (1999: 12-13).

${ }^{69}$ See Cheon (1999: 12-13), Goldin and Katz (1998) and Machin, and Van Reenen (1998).
} 


\subsection{Endogenous Growth and Public Policy}

We mentioned in Section 3 that endogenous growth literature revealed several robust facts and interesting implications that paved the way for growth, it is convenient in this section to explain that it also provided some insights for a possible role for government policy. We explain below the literature and arguments for government intervention to promote the accumulation of technology, human capital and hence growth rate.

The most popular view in the literature is that the rationale for government intervention is basically related to the idea that knowledge (in the form of technical progress or accumulation of human capital) is a public good, which is non-rival and partially excludable. As in Romer (1990) and Barro and Sala-i-Martin (1995), these two features imply an unbounded growth and incomplete appropriability of knowledge and raise the possibility of knowledge spillovers across firms and hence the whole economy. While the feature of spillovers of knowledge supports endogenous growth, it also creates a form of externality and implies that private investments generate a positive external effect and the private returns from investment tend to be lower than the social returns. The outcomes tend not to be Pareto optimal but sub optimal and require govertment intervention to correct the distortion. The social optimum can be achieved by many instruments such as providing subsidies (which can be financed by taxation) to improve the accumulation of technology and human capital, incentives and returns from investment for private investors.

In the endogenous growth literature some studies explicitly model the importance of technology and human capital for endogenous growth, but only implicitly indicate a role for public policy. For instance, while the Lucas (1988) model emphasizes investment in human capital, it only implicitly allows for a role for public policy through subsidies (Haslinger and Ziesemer, 1996: 230). Moreover, the Arrow (1962) learning-by-doing and Romer (1986) models imply an indirect intervention: an investment tax credit that increased the accumulation of capital necessarily also increased the accumulation of technology (Romer, 1990: 994).

According to Ziesemer's (1987) interptetation, T.W. Schultz (1964) presents a pioneering theoretical justification for a centrall role for government interference to promote public investment and emphasis their long-run effects on growth and development. Schultz's (1964) theory reveals that the provision of public factors, such as basic education and basic scientific research, is necessary for human capital formation and this would drive technical progress. Therefore, technical progress depends on human capital, and the production of human capital in turn requires public factors such as basic education and basic scientific research. It is assumed that the public goods are financed through a linear income tax rate: the lower the level of public goods and tax rate, the higher is the price of human capital and less human capital is supplied. If the rate of technical progress depends upon human capital, then technological progress is dependent upon taxation and public goods. The contribution by Shell (1967) involves public investment and assumes a public, non-rivalrous stock of technology; a flat-rate income tax is raised to finance the change in the stock of 
knowledge. Tax has two effects: it increases growth, but also decreases the returns from investment and negatively affects private capital formation. ${ }^{64}$

Ziesemer $(1990 ; 1991 ; 1995)$ formulates Schultz"s (1964) ideas that public factors - basic education and basic scientific research - are held as necessary for the formation of human capital and the development process. Ziesemer (1990) argues for an essential role of public factors, which are provided by the government and in turn financed by a simple flatrate income tax to introduce an outstanding role of economic policy in economic development. Ziesemer (1991) assumes that, in a growth model with endogenous technical progress, if an externality arises at the firm's level, government intervention is needed to obtain the optimum and perfectly competitive market structure. Hence, a tax subsidy system is introduced to influence the rate of technical progress and brings it to the optimal level of growth. Ziesemer's (1995) model inclicates that public factors are used in the formation of human capital and human capital, in turn, is necessary for the production of technical progress. If public factors are financed by a flat-rate income tax, then a higher rate of taxation or shares of public expenditure on education in the GDP will lead to a higher level of public factors, a higher rate of technical progress and will also lead to a higher growth if steady states are stable. In Ziesemer's (1991) model the optimal policy is a technology stock subsidy to reward firms and to provide an incentive for the spillovers of technology formation to the human capital schooling process. In Ziesemer's $(1990,1995)$ models the optimal policy is a tax financed by government spending on the provision or creation of public knowledge (basic education and basic scientific research). The share of GDP raised and spent on the provision of public factors has an impact on the level of GDP per capita or its growth rate respecively. ${ }^{65}$

One assumption in Romer's (1990) model of endogenous technological change is that technological change arises in response to market incentives, and the latter play an essential role in the model. Romer (1990) assumes that in a growth model with spillover effects, the social optimum can be achieved by subsidizing the accumulation of technology. A subsidy to R\&D works to compensate R\&D firms for the learning-by-doing and the positive external effects they spillover to other R\&D firms; in the absence of R\&D, a subsidy creates further incentives for firms to gain entry. Although all the research is embodied in capital goods, a subsidy to physical capital accumulation may be a very poor substitute for direct subsidies that increase the incentives to undertake research. In the absence of feasible policies that can remove the divergence between the social and private returns to research, a second-best policy for a government would be to subsidize the accumulation of human capital. A subsidy to employment in research sector that is financed through lump-sum taxes has the same effects on growth as an increase in the productivity parameter: in the long run, a subsidy will cause an increase in the growth rate (Romer, 1990: \$72, S74, S93, S98-\$99).

Barro and Sala-i-Martin (1992) allow for the effects of fiscal policy on long-term growth and discuss the role of tax policy in various models of endogenous economic growth. In their view, in growth models with learning-by-doing and spillover effects, the social optimum can be attained by financing government consumption purchases with an income tax, and monopoly pricing of new types of capital goods. The tax policies that en-

\footnotetext{
${ }^{64}$ See Ziesemer (1987: 107-108, 112.115) and Haslinger and Ziesemer (1996:230, 232). Ziesemer (1987) summarises T.W. Schultz's (1964) view and indicates that the latter uses Nelson (1959) idea that both basic

edtucation and basic scientific research should be viewed as a public good.
See Ziesemer (1990: 268-280); Ziesemer (1991: 47-68), and Ziesemer (1995: 1-19).
} 
courage investment can raise the growth rate and thereby increase the utility of the representative household. In growth models that incorporate public services, the optimall tax policy depends on the characteristics of services. If the public services are publicly provided private goods, which are rival and excludable, or publicly provided public goods, which are non-rival and excludable, then lump-sum taxation is superior to income taxation (Barro and Sala-i-Martin, 1992: 645, 660).

In many models of endogenous growth (e.g. Romer, 1987; 1990; Grossman and Helpman, 1991), technological progress corresponds to an expansion in the number of types of capital goods, inventions require active R\&D, and firms are compensated through the retention of monopoly power over the use of their inventions. Therefore, the models involve elements of imperfect competition as the excess of the monopoly price over the competitive one implies that the private rate of return on investment falls short of the social retum, and, hence, that the steady-state growth rate is below the socially optimal rate. A common feature in all three types of models - learning-by-doing with spillovers, taxation of income from capital (in models where government services are not subject to congestion) and varieties of capital goods under imperfect competition - is the shortfall of the private rate of return on investment from the social one. This implies that the Pareto optimum can be attained in each model if the government raises the private rate of return on investment to the social one without introducing other distortions. This outcome can be achieved either by subsidizing the purchase of capital goods or by subsidizing the income on capital. Another measure is to subsidize research to raise the private rate of return to the social rate and to provide further incentive to private producers to create new types of capital goods. ${ }^{66}$

Barro and Sala-i-Martin (1995) combine the Arrow (1962) and Romer (1986) assumptions of learning-by-doing and knowledge spillovers. In their model, the social optimum can be attained in a decentralized economy by providing various forms of subsidies that work to raise the private rate of return to investment and thereby tend to eliminate the excess of social over private returns. For instance, the government could induce the private sector to attain the social optimum if it provided subsidies to the purchases of capital goods (an investment-tax credit), financing it through a lump-sum tax. Further options open to the government are: providing subsidies to the purchase of intermediate goods, incentive to expand over time using a lump-sum tax to finance a subsidy, subsidies to final output so that producers receive units of revenue for each unit of good produced, or a direct subsidy to $R \& D$ spending to raise the private rate of return on R\&D and provide a sufficient incentive for research. Therefore, two policy instruments are needed: one that encourages production of the monopolized intermediates and another that stimulates R\&D. ${ }^{67}$

Aghion and Howitt (1998) argue for a role for public intervention to support innovative activities either through the design and use of subsidies (direct targeted or untargeted subsidies) or the design of property rights and patent legislation. They suggest that the R\&D investments should be subsidized whenever positive external effects dominate and as a result growth under laissez-faire is suboptimal, but that R\&D investment should be taxed if too much "business-stealing" or creative destruction takes place under laissez-faire. They distinguish between targeted and untargeted subsidies, the choice between them depends essentially on availability of information to the government. Targeted R\&D subsidies are direct government subsidies that are deliberately aimed at particular sectors (e.g. defence),

66 See Barro and Sala-1- Martin (1992: 651-652, 654-655).

${ }^{67}$ See Barro and Sala-1- Martin (1995: 146, 147, 150-151, 222, 223, 226, 229-230). 
industries or firms. It may take the forms of public investments in state owned laboratories, research grants, participation in R\&D funds, subsidies to enterprises (e.g., input subsidies), credit guarantees, and public investment in high-technology industries. Untargeted subsidies is another important instrument of direct policy intervention in the R\&D sector, offered on a non-discriminatory basis according to market decision, without targeting particular firms, industries or projects; untargeted subsidies take the form of research tax credits, tax deductions, credit guarantees, subsidized insurance for risky capital investments, etc. Aghion and Howitt (1998) indicate other forms of government intervention to increase incentives/ subsidies for R\&D efforts: through the government's buying up or reducing of the outside investors' share or equity in independent research units and turning it over to R\&D firms. Finally, they show that the government has a vital role in enforcing property rights by allowing firms involved to earn monopoly rents as a reward for innovation. ${ }^{68}$

Jones (1998) indicates that many models in the endogenous growth literature have the implication that changes in government policies, such as subsidies to research or taxes on investment, have level effects but no long-run growth effects. For instance, a government subsidy that increases the share of labour in research will typically increase the growth rate of the economy, but only temporarily, as the economy transits to a higher level of income. ${ }^{69}$

Several studies emphasize a role for government intervention and the positive impact of public provision of education and training. For instance, Azariadis and Drazen (1990) suggest a role for government intervention in the education sector (through education subsidies) to avoid low-development traps and thereby promote high sustained growth. Otani and Villanueva (1990), and Barro and Sala-i-Martin (1995) illustrate, for a cross section of countries, a positive impact of government interventions on growth rates coming from the expenditure side (i.e. the share of public expenditure on education of the GDP). Barro and Sala-i-Martin (1995) find that public spending on education has a significant positive effect on growth: a 1.5 per cent increase of the ratio of public education spending to GDP during the period 1965-1975 would have raised the average growth during the same period by 0.3 per cent per year. Aghion and Howitt (1998) indicate that centralized funding of education will always favor human capital accumulation and therefore growth in the long run, even though local funding may sometimes be growth-enhancing in the short run. ${ }^{70}$ Trostel (2002) suggests that public provision of education through subsidy has the potential to be the most efficient educational policy because it provides incentives and stimulates investment in and accumulation of human capital. A recent report by the UNESCOUIS/OECD (2003) stresses the role of public finance in enhancing investments and returns from education in a number of selected countries. Chatterji (1995) presents a growth model based on Lucas" (1988) model to explore a potential role for government intervention by subsidizing training to compensate private sector for the positive externalities they generate and to provide more incentives for more investment in the accumulation of skills. The model assumes two possible sources of growth: exogenous technical progress and endogenously produced skills growth. The optimal subsidy on training rises with the rise/strength of the externality generated by the average skill level in output production; it also depends

\footnotetext{
${ }^{68}$ See Aghion and Howitt (1998: 474, 489).

${ }^{69}$ See Jones (1998: 147, 112).

7a) Otani and Villanueva (1990) is cited in Haslinger and Ziesemer (1996: 236). Azariadis and Drazen (1990) and Barro and Sala-i-Martin (1995) respectively are cited in Aghion and Howitt (1998: 333, 328). See also Aghion and Howitt (1998: 338).
} 
on macroeconomic variables such as the extent of productivity growth from other soures an the economy. ${ }^{71}$

One interesting observation by Aghion and Howitt (1998) indicates that the finding with respect to the complementarity between educational attainment and R\&D activities has in turn many interesting policy implications. First, it suggests that "macroeconomic policies which affect rates of innovation and investment will affect the relative demand for workers classified by education, and hence the aggregate skill distribution of employment and earning. (Bartel and Lichtenberg, 1987)". In other words, governments will increase the average level of education not only directly through education policy, but also indirectly by actively supporting R\&D activities. Conversely, government subsidies to education will increase the profitability of research and development activities, and thereby speed up technological progress (Aghion and Howitt, 1998: 339-340).

Few studies examine the practical relevance of the models of growth enhancing policies, particularly for the developing countries. For instance, Haslinger and Ziesemer (1996) indicate that most of the models of publicly financed investment in human capital are basically intended for industrialized and not for developing countries. In their view, in the developing countries, raising the publicly financed investment is hampered by the lack of a well-developed institutional setup to use the instruments of taxation, mainly because of substantial engagement in non-monetised activities, a large informal sector, extreme poverty and different effects from the prevalent regressive trade tax (Haslinger and Ziesemer, 1996: 240-241). ${ }^{72}$

Apart from these practical limitations for the developing countries, in the recent years there is a growing body of literature on the role of public policies and government intervention to promote human capital and technological capabilities in the developing countries. For instance, Lall (1999) discusses strategies to develop skills and capabilities in developing countries and argues that there is a valid case for policies to coordinate, guide and subsidize learning; and to develop such factors as skills and technology where externalities and information failures are particularly pervasive. He identifies two broad successful strategies in the developing world to promote skills and learning for competitiveness. First, autonomous strategies to accelerate and guide learning by domestic firms by promoting infant industries, coordinating investments in related activities, overcoming externalities, directing credit, and developing specific skills and institutions. Second, foreign direct investment (FDI) dependent strategies that rely on Transnational Corporations (TNCs) to lead export growth and upgrading, which has two subsets of strategies: those based on targeting TNCs and using industrial policy to guide them in more technology intensive activities; and more passive strategies that rely on market forces to attract and upgrade activities. Korea and Taiwan are leading example of national-led strategy, Singapore and Malaysia of the FDI-led targeted strategy, and Mexico and Thailand of the FDI-led market-led strategy (Lall, 1999: 9-10).

\footnotetext{
${ }^{1}$ See Chatterji (1995: 274-282).

72 In the case of the Gulf countries, the extent of both the 'non-monetised' activities and informal sector is tess clear. However, different from other developing countries, in the Gulf countries both the prevalence of the welfare states- absence of extreme poverty (cf. UNDP, 2004)- and the recent structural relom of fiscat and monetary policies and labour market (cf. Fasano and Iqbal, 2003) may imply a promising role for govertament intervention.
} 


\section{6 Conclusions}

In this chapter we provide a background for the empirical analysis in the following chapters by surveying the theoretical and empirical literature that emphasize the positive growth effects of human capital and technological progress in increasing and sustaining economic growth. We explain that economic growth theories recognized and provided different perceptions and analytical frameworks for modelling the various effects of technical change, innovation and human capital on economic growth. The major differences arise because the exogenous growth theories perceive and model technical progress and human capital as exogenous variables in growth accounting model, whereas the endogenous growth theory envisages and models technical progress and human capital as endogenous variables determining the rates and differences of economic growth across countries. The endogenous growth theory contributes to improve understanding of the interaction between technological change, human capital and economic growth and fills the gap in earlier growth theories by considering the important endogenous effects of human capital, technological progress and innovation. The endogenous growth theory predicts that in the long run economic growth at the aggregate level is determined by endogenous sources of technological change, human capital, learning by doing, spillovers of knowledge and external effects of human capital. The presence of increasing returns to scale and externalities prevent diminishing returns to accumulation of capital, and so ensure the long run steady state of growth within a dynamic general equilibrium framework. We illustrate that the inclusion of human capital and technological change in growth accounting models motivate endogenous growth literature to provide several interesting explanations of the relationship between human capital and technical change. In particular, it stimulates considerable debate about the complementary relationship between human capital and technical progress, skilled biased technical change, the role of technical progress in skill upgrading and the role of skill and improvement in the accumulation of human capital in skill upgrading. These explanations imply that next to the important endogenous effects of technical progress and human capital for economic growth, the complementary relationships between them and between them and skill upgrading are also important for enhancing economic growth. Finally, we show the advantages and limitations of several measures of technological change and human capital that have been used in theoretical and empirical literature, some of these measures are relevant for the empirical analysis in the next chapters according to availability of data. 
PART III

EMPIRICAL APPLICATION 
the technology indicator, as measured by expenditures on R\&D as a percentage of GDP over the period 1996-2002, Kuwait shows high performance followed by Saudi Arabia, while Oman, Bahrain and Qatar respectively show medium performance, and the UAE only shows poor performance. In terms of technology indicator, as measured by application to patents over the period 1991-1999, Saudi Arabia shows high performance, Kuwait and the UAE respectively show medium performance, whereas Qatar and Bahrain respectively show poor performance- cf. Table 2.9. Probably, the only exception to the lack of coherence appears from the use of ICT in relation to income level. For instance, the high income Gulf countries (UAE, Kuwait, Bahrain and Qatar) achieve growth in the use of ICT that is higher than medium income Gulf countries (Oman and Saudi Arabia) - cf. Table 2.9 above. In terms of Internet users in the Gulf countries in 2000 and 2001 , the UAE ( $53 \%$ and $42 \%)$, Kuwait $(15 \%$ and $13 \%)$ and Bahrain $(12 \%$ and $28 \%$ ) had high shares; Qatar $(10 \%$ and $9 \%)$ and Oman $(9 \%$ and $6 \%)$ each had a medium share, whereas Saudi Arabia $(2 \%$ and $2 \%)$ only had a low share.

The firm survey covers medium and large size firms engaged in two industries in the manufacturing sector: the chemical and metal industries. ${ }^{75}$ The selection of both industries was based on the following reasons: First, the argument in favour of both upskilling and technological upgrading is promising in both sectors and can be used to reduce the dependence on foreign workers. Second, both sectors have strategic importance in creating forward and backward linkages and spin-off effects to other sectors/industries. Third, both sectors have the potential to produce energy-intensive use products benefiting from the comparative advantage of the cheapest energy sources, particularly petroleum and natural gases available in the UAE and the Gulf region. Fourth, the potential for product diversification in both sectors is promising. Fifth, the important contribution of both sectors in the manufacturing sector, for instance, in the year 2000 , the contribution of both sectors together was around $29.8 \%$ of total labour force, $18.7 \%$ of capital investment and $33.3 \%$ of the total number of industrial establishments in the manufacturing sector. In particular, the shares of the chemical sector accounted for $10.7 \%, 10.7 \%$ and $16.59 \%$, while that for the metal sector accounted for $19.17 \%, 7.98 \%$ and $16.67 \%$ respectively. ${ }^{76}$ This implies that the contribution and distribution of both sectors enable us to compare between the chemical as a capital-intensive sector and the metal as a labour-intensive sector. Table 4.1 illustrates the distribution of both chemical and metal industrial establishments according to the size/share of employment in the UAE and the Gulf countries. Sixth, both basic metal and chemical industries have approached high levels in terms of both technological intensification and full automation in the UAE in the period 1991-1995 (cf. Cohen, 2000).

\footnotetext{
${ }^{73}$ In the firm survey, the chemical sector includes manufactures of basic industrial chemicals, fertilizers and pesticides, synthetics, resin and related materials, paints, varnishes and lacquers. In addition, petrochemicals, pharmaceuticals, drugs and medicines, soap and cleaning preparations, chemical products, petroleum refineries, miscellaneous petroleum and coal products, tyre and tube industries, rubber products and plastics product are also included in this sector. The metal sector includes basic metal products, fabricated metal produets, machinery and equipment; however, the firm survey covers only the fabricated metal industries represented by aluminium and iron-steel because of their significant share in employment, capital and number of industrial establishments, as explained in this section.

${ }^{76}$ See for instance the GOIC (1996) Data and Statistics.
} 


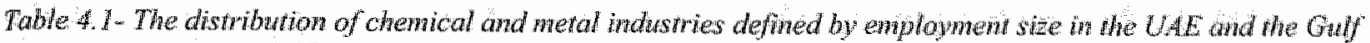
comtries $(1998-2000)$.

\begin{tabular}{|c|c|c|c|c|c|c|}
\hline Industry & \multicolumn{2}{|c|}{ Chemical } & \multicolumn{2}{|l|}{ Metal } & \multicolumn{2}{|c|}{ Total manufacturing industries } \\
\hline $\begin{array}{l}\text { Eimployment } \\
\text { size: } N\end{array}$ & $\mathrm{UAE}^{\text {עl }}$ & $\begin{array}{l}\text { Total Gulf } \\
\text { countries b }\end{array}$ & $\mathrm{UAE}^{\mathrm{a}}$ & $\begin{array}{l}\text { Total Gulf } \\
\text { countries }\end{array}$ & $\mathrm{UAE}^{\mathrm{a}}$ & $\begin{array}{l}\text { Total Gulf coun } \\
\text { tries }^{b}\end{array}$ \\
\hline $\begin{array}{l}\text { Small: } \\
N<50\end{array}$ & 283 & 521 & 374 & 749 & 1298 & 2766 \\
\hline Medium: & $(14 \%)$ & $(40 \%)$ & $(63 \%)$ & $(38 \%)$ & $(60 \%)$ & $(38 \%)$ \\
\hline $50 \leq \mathrm{N} \leq 100$ & $15 \%$ & 3210 & 120 & 472 & 382 & 1659 \\
\hline Large: & 43 & 466 & $(20,0)$ & & $(18 \%)$ & $(24 \%)$ \\
\hline$N>100$ & 1000 & 7000 & 104 & 703 & $4 / 3$ & 2665 \\
\hline Total & 383 & 1314 & 598 & 1984 & 2153 & 7088 \\
\hline
\end{tabular}

Sources: (a) UAE Ministry of Industry and Finance Industrial Statistical Book (2000), (b) GOIC Industrial Data Bank (1998)

Other important reasons for the selection of the chemical industry are the strategic importance of this industry in the international market, and the diversified nature of the chemical sector in the Gulf. For instance, data and statistics from GOIC (1996) and the UAE Ministry of Industry (1998) indicate that, in the years 1995 and 1998, with the inclusion of the manufacture of refined petroleum products to the petrochemical, chemical and plastic sector, the whole sector tended to be capital-intensive. In the years 1998 and 1999, with the exclusion of the manufacture of refined petroleum products, the petrochemical, chemical and plastic sector alone show more intensity in terms of labour than capital. In the year 2000 the petrochemical, chemical and plastic sector shows similar/equal intensity of both labour and capital, which may indicate similar capital/labour and output/capital ratios. Further strategic importance of this industry is the significant contribution of oil in oil and related industries in the Gulf economy.

Other reasons for the selection of the fabricated metal (aluminium, iron and steel) industry are the significant contribution of both aluminium and iron-steel as sub sectors in the fabricated metal products sector. For instance, in the year 1995 , both sub-sectors together accounted for $52.2 \%$ of total employment, $61.4 \%$ of total capital investment, and $54.2 \%$ of total number of industrial establishments in the fabricated metal products sector. ${ }^{77}$ In addition, aluminium is a significant industry in the UAE: for instance, Dubai Aluminium company is the largest single site aluminium smelter in the western world. ${ }^{78}$ Furthermore, the aluminium industry could have a wider utility in the region, given the potential increase in the demand for aluminium products due to the possible wider use of aluminium, owing to the natural characteristics of aluminium as a metal with thin weight and high degree of purification and flexibility, to replace/substifute other metals (such as iron) in industry (GOIC, 2000b: 99).

\section{2 The selection of the sample and composition of the surveys}

The sample in the firm survey was drawn from the medium and large size firms active in the chemical and metal industries, which are located in three emirates of Abu Dhabi, Dubai

\footnotetext{
${ }^{77}$ See the GOIC (1996) Data and Statistics (1996: 123).

78. See the Dubai Aluminium company (DUABL) web site: www dubal.ae
} 
and Sharjah. ${ }^{79}$ The selection of these emirates was based on their significant average share in total employment $(87 \%)$, capital investment $(86.4 \%)$ and total number of factories $(82.6 \%)$ in the chemical and fabricated metal industries in the UAE - cf. Table 4.2 below. Moreover, the selection of medium and large size firms was based on their share in total employment; which accounted for $23.62 \%$ of medium and large size enterprises working in the manufacturing sector (28.53\% of medium size and $19.66 \%$ of large scale enterprises) in these three emirates. Our sample drawn from these three emirates is quite representative, since the coverage of firms in the sample and survey represents $81 \%$ and $35 \%$ of the chemical and metal industries respectively and $62 \%$ and $44 \%$ of the large and medium size firms respectively. We employed the recent secondary data published by the UAE Ministry of finance and industry "The Industrial Statistics Book (2000)" in selecting a sample of the firms in the survey.

Table 4.2 - The average percentage shave of emirates of Abu Dhabi, Dubai and Sharjah in toral number of factaries. Lobour, capiral and medium and large size firms in the chemical and metal industries (2000)

\begin{tabular}{|c|c|c|c|c|c|c|c|}
\hline \multirow[t]{2}{*}{ Industry } & \multirow[t]{2}{*}{$\begin{array}{l}\text { Number of } \\
\text { factories }\end{array}$} & \multirow[t]{2}{*}{$\begin{array}{l}\text { Share of } \\
\text { capital } \\
(\%)\end{array}$} & \multirow[t]{2}{*}{$\begin{array}{l}\text { Share } \\
\text { of } \\
\text { labour } \\
(\%)\end{array}$} & \multicolumn{2}{|c|}{$\begin{array}{l}\text { Employment size: } \% \\
\text { of enployment in } \\
\text { medium and large size } \\
\text { establishments in the } \\
\text { manufacturing sector }\end{array}$} & \multicolumn{2}{|c|}{$\begin{array}{l}\text { Total employment in } \\
\text { medium and large size } \\
\text { establishments in the } \\
\text { manufacturing sector }\end{array}$} \\
\hline & & & & Medium & Large & Mediun & Large \\
\hline $\begin{array}{l}\text { Chemicril } \\
\text { Products }\end{array}$ & $80.75 \%$ & $83.30 \%$ & $83.25 \%$ & $11.25 \%$ & $7.40 \%$ & 43 & 35 \\
\hline $\begin{array}{l}\text { Metal } \\
\text { Products }\end{array}$ & $84.5 \%$ & $89.5 \%$ & $90.8 \%$ & $17.28 \%$ & $12.26 \%$ & 66 & 58 \\
\hline $\begin{array}{l}\text { Averige } \\
\text { Total }\end{array}$ & $82.6 \%$ & $86.4 \%$ & $87 \%$ & $28.53 \%$ & $19.66 \%$ & 109 & 93 \\
\hline
\end{tabular}

Source: UAE Ministry of Industry and Finance Industrial Statistical Book (2000)

The questionnaire on "Technological Change and Skill Development" was circulated amongst 106 of the chemical and metal medium and large size enterprises in the UAE. It aimed at collecting micro qualitative and quantitative data, and covered the medium and large size firms engaged in both the chemical and metal industries in the UAE. Table 4.3 below presents the composition of the firm survey. The response rate varied according to firm size and industrial activity: for the chemical industry the total response rate was $40 \%$, and the weighted response rates by employment size was $44 \%$ and $37 \%$ for medium and large size firms respectively. For the metal industry the total response rate was $44 \%$, and the

\footnotetext{
${ }^{74}$ For the purpose of this study, firm size is defined by employment size $N$. The small size firms are firms with $N<50$. the medium size tirms those with $49<N<100$, and the large size firms those with $N \geq 100$
workers.

sio These emirates also have strategic importance in the UAE: for instance, Abu Dhabi accounts for more than half of the country's total GDP. close to $40 \%$ of the population, and $90 \%$ of oil and natural gas resources. Dubai contributes one-fourth of the country's total GDP and has been at the forefront of developing non-oil activities. Sharjah currently accounts for 45\% of UAE manufacturing (cf. Fasano, 2002: 330).

pared to metal ind firms in the sample is based on two facts: the great diversity of the chemical commedium size firms.
} 
weighted response rates by employment size were $47 \%$ and $41 \%$ for medium and large size firms respectively. ${ }^{82}$

Table 4.3-Composition of the firm survey in the UAE, 2002

\begin{tabular}{llllllll}
\hline Industry & $\begin{array}{l}\text { Employment } \\
\text { size }\end{array}$ & $\begin{array}{l}\text { Share of } \\
\text { employ- } \\
\text { ment in } \\
\text { sample }\end{array}$ & $\begin{array}{l}\text { Share of } \\
\text { capital in } \\
\text { samplle }\end{array}$ & $\begin{array}{l}\text { Share } \\
\text { of firms } \\
\text { in } \\
\text { samplle }\end{array}$ & $\begin{array}{l}\text { Number } \\
\text { of firms } \\
\text { in the } \\
\text { sample }\end{array}$ & $\begin{array}{l}\text { Number of } \\
\text { the respon- } \\
\text { dent firms }\end{array}$ & $\begin{array}{l}\text { Response } \\
\text { rate }\end{array}$ \\
\hline Chemical & Medium & $57 \%$ & $87 \%$ & $26 \%$ & 25 & 11 & $44 \%$ \\
& Large & $59 \%$ & $17 \%$ & $33 \%$ & 38 & 14 & $37 \%$ \\
\multirow{5}{*}{ Metal } & Total & $59 \%$ & $20 \%$ & $59 \%$ & 63 & 25 & $40 \%$ \\
& Medium & $42 \%$ & $14 \%$ & $22 \%$ & 19 & 9 & $47 \%$ \\
& Large & $40 \%$ & $83 \%$ & $19 \%$ & 24 & 10 & $41 \%$ \\
& Total & $41 \%$ & $80 \%$ & $41 \%$ & 43 & 19 & $44 \%$ \\
Grand total & & $100 \%$ & $100 \%$ & $100 \%$ & 106 & 44 & $42 \%$ \\
\hline
\end{tabular}

The macro survey on "Skill Creation, Human Resources Development and Policy Intervention" provides primary macro qualitative data. The questionmaire was sent to 40 policy makers in government and experts in 14 public, university and educational institutions in the UAE. It aimed to collect macro qualitative data to reflect the opinions of policy makers and experts with respect to assessment of skill upgrading efforts and the causes and consequences of deficient educational system, provision of training, transfer of knowledge and technological upgrading. It was also intended to provide insights to help to generate policies to enhance them by implementation of short and long terms plans at the macro level. The selection of both institutions and policy makers and experts was based on their experience and potential contribution to enhance upskilling process. The advantage of the macro survey is that it examines these problems after integrating two different perspectives of policy makers and experts. Moreover, due to their close association to educational and training institutions, the approached policy makers and experts provided some useful information from both the analytical and policy perspectives. Table 4.4 below presents the composition of the macro survey, and indicates a total response rate of $75 \%$; the shares of universities, ministries and other public institutions are quite representative and yield different response rate. $^{84}$

${ }^{2}$ For the implementation of the firm survey, a team of part-time researchers from the National Human Resources Development and Employment Authority (TANMIA)- UAE Ministry of Labour and Social Affairs were hired to make direct personal contact, determine the contact address, then handle, distribute and collect the survey from firms. On request from some of the approached firms, an additional copy of the survey was sent by fax to accelerate and increase the response rates.

${ }^{83}$ The term respondent firms in Table 4.3 refers to all firms that retumed the questionnaire, including the firms. who did not answer/respond to some questions. This implies that response rates vary enormously across firms as some firms did not respond to all questions - - see Table 4.5 below. This maly constitute further limitations, as we explain below.

${ }^{84}$ For the implementation of the macro survey, we established direct personal contact to handle and accelerate the distribution and collection of the survey. On request from some of the approached officials, an additional copy of the survey was sent by fax to accelerate and increase the response rates. The translated Arabic version of the macro survey was distributed along with the English version. 


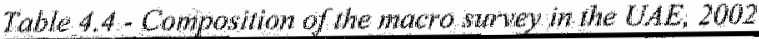

\begin{tabular}{llllccc}
\hline Representation & Institutions & \multicolumn{4}{c}{ Individuals } \\
\cline { 2 - 7 } & $\begin{array}{l}\text { Number in } \\
\text { sample }\end{array}$ & $\begin{array}{l}\text { Total re- } \\
\text { sponse }\end{array}$ & $\begin{array}{l}\text { Response } \\
\text { rate }(\%)\end{array}$ & $\begin{array}{l}\text { Number } \\
\text { in sample }\end{array}$ & $\begin{array}{l}\text { Total } \\
\text { response }\end{array}$ & $\begin{array}{c}\text { Response } \\
\text { rate }(\%)\end{array}$ \\
\hline Universities & 5 & 2 & 40 & 12 & 6 & 50 \\
Ministries & 5 & 5 & 100 & 15 & 11 & 73 \\
$\begin{array}{l}\text { Other Public centres } \\
\text { and authorities }\end{array}$ & 4 & 4 & 100 & 13 & 13 & 100 \\
Total & 14 & 11 & 79 & 40 & 30 & 75 \\
\hline
\end{tabular}

The data from the surveys is supported by ten face-to-face interviews with firm managers and five interviews with policy makers and experts. The purpose of these interviews was to obtain more information to support the findings from the macro survey concerning the failure of upskilling efforts, the deficiency in educational and training systems, and the implications on skills mismatch, transfer of knowledge, R\&D efforts and development of the local technologies, as well as the policies and plans of government and private sector to enhance the upgrading of local skills and local technology, the R\&D efforts, networks and transfer of knowledge.

\section{3 Structure and design of the questionnaire}

We present the general structure and design of the questionnaire of the macro and firm surveys in Table 4.5. The questionnaire in the macro survey was composed of six sections, and the average response rate ranked in a descending (downward) way, i.e. generally higher for the first four sections, moderate for the fifth section and low for the sixth section. ${ }^{85}$ Each of the six sections in the macro survey was designed to request specific information. Section 1 requested general assessment of upskilling efforts from the perspectives of policy makers and experts. Section 2 inquired the relevant policies and important factors contributing to enhance skill upgrading, education, training and the transfer of knowledge. Section 3 investigated the causes of low skill, deficient education, training, external effects of schooling, transfer of knowledge and skills mismatch. Section 4 examined both currently implemented plans and suggested future short and long run plans and policies for skill upgrading and determined the role of skill upgrading and technological upgrading in fulfilling the socioeconomic development objectives. Section 5 sought information to check the incidence of external effects of schooling/ the transfer of knowledge and the important factors hindering and those contributing toward enhancing the external effects and the transfer of knowledge. Finally, section 6 requested further recommendations for skill upgrading in the UAE.

\footnotetext{
${ }^{35}$ The design of the questionnaire in the macro survey includes three types of questions: nominal (Yes/No), scalar or categories, and open questions. The distribution of question types and their corresponding average response rate are identical, for instance, majority of questions are of scalar type, which allso receives higher average response rate, followed by nominal and open questions respectively.
} 
Table 4.5-Structure, aims and conerage response rate of the questionnaine in the firm and macro swrveys the U.A. 2002

\begin{tabular}{|c|c|c|c|c|}
\hline \multirow{2}{*}{$\begin{array}{l}\text { Sect } \\
\text {-ion } \\
\text { No. }\end{array}$} & \multicolumn{2}{|l|}{ Macro survey } & \multicolumn{2}{|l|}{ Firm survey } \\
\hline & Ain of the section & $\begin{array}{l}\text { Average } \\
\text { Response } \\
\text { Rate }(\%)\end{array}$ & Aim of the section & $\begin{array}{l}\text { Average } \\
\text { Response } \\
\text { Rate }(\%)\end{array}$ \\
\hline II & $\begin{array}{l}\text { Request general assess- } \\
\text { ment of upskilling ef- } \\
\text { forts. }\end{array}$ & $99 \%$ & $\begin{array}{l}\text { Request general background information about } \\
\text { the structure, identification and characteristics } \\
\text { of the firms. }\end{array}$ & $82 \%$ \\
\hline 2 & $\begin{array}{l}\text { Investigate the relewant } \\
\text { policies to enhance skill } \\
\text { upgrading, education, } \\
\text { training and transfer of } \\
\text { knowledge }\end{array}$ & $97 \%$ & $\begin{array}{l}\text { Investigate the use, level, transfer and depend- } \\
\text { ence on foreign technology, value and trend of } \\
\text { ICT expenditures. Technology indicators, } \\
\text { patent, R\&D, ICT and product process inno- } \\
\text { vations. }\end{array}$ & $60 \%$ \\
\hline 3 & $\begin{array}{l}\text { Examine the causes of } \\
\text { low skill, deficient edu- } \\
\text { cational system and the } \\
\text { consequences on training } \\
\text { provision, external } \\
\text { schooling effect transfer } \\
\text { of knowledge and skills } \\
\text { mismatch. }\end{array}$ & $94 \%$ & $\begin{array}{l}\text { Measure human capital (skill) indicators: } \\
\text { distribution of workers by skill lovels, eduea- } \\
\text { tional attainment average schooling years, } \\
\text { occupational level, average years of experi- } \\
\text { ence, required qualifications and average } \\
\text { wages. Assess the effect of skilled workers } \\
\text { and their shortage on firm product, the factors } \\
\text { hindering and other enhancing the incidence } \\
\text { and transfer of knowledge/ external effects of } \\
\text { schooling and firm upskilling platn. }\end{array}$ & $45 \%$ \\
\hline 4 & $\begin{array}{l}\text { Examine the short and } \\
\text { long- term mechanisms } \\
\text { for skill upgrading, their } \\
\text { effect on technological } \\
\text { upgrading and fulfilling } \\
\text { socio-economic aims. }\end{array}$ & $93 \%$ & $\begin{array}{l}\text { Examine the use of technology and the mplim } \\
\text { cations on upgrading skill level and the past } \\
\text { and future demand for skilled and unskilled } \\
\text { workers. The effect of upskilling on techno- } \\
\text { logical upgrading and self-reliance on local } \\
\text { skillls. }\end{array}$ & $67 \%$ \\
\hline 5 & $\begin{array}{l}\text { Investigate the incidence } \\
\text { of external effects of } \\
\text { schooling and transfer of } \\
\text { knowledge, their hinder- } \\
\text { ing and promoting factors }\end{array}$ & $74 \%$ & $\begin{array}{l}\text { Examine the relative importance of firm train- } \\
\text { ing and short and long run skill upgrading } \\
\text { mechanisms. The information, coverage, } \\
\text { resources and support to firm training, the } \\
\text { factors lindering and other promoting the } \\
\text { provision of training. }\end{array}$ & $54 \%$ \\
\hline 6 & Conclusions & $43 \%$ & & \\
\hline
\end{tabular}

The questionnaire in the firm survey was composed of five sections; the average response rate was higher for the first section, moderate for the second and fourth sections and low for the third and fifth sections. ${ }^{86}$ Each of the five sections in the firm survey aimed to request particular information. Section 1 requested general background information about the structure, identification and characteristics of the firms, it also requested (interval) economic quantitative data on the value and trend of firm production and performance indicators, including: employment, net worth (capital), profit, sale, output and product diversification by sale and employment. Section 2 examined the use of technology, level, transfer and dependence on foreign technologies. It assessed technology indicators, patent applications, spending on R\&D, and product and process innovations, the use of ICT, firm production and demand for high skilled and also requested quantitative data on the value and trend of

\footnotetext{
${ }^{86}$ The design of the questionnaire in the firm survey includes four types of questions: nominal (Yes/No), scalar or categories, open and interval questions. The distribution of the questions and their corresponding average response rates vary. Most of the questions are of scalar type, followed by nominal, interval and open questions respectively; and the corresponding average response rate is higher for nominal questions, followed by scalar, open and interval questions respectively.
} 
ICT expenditure. Section 3 requested quantitative data to measure human capital/skill indi. cators, defined by the distribution of workers by skill level, educational attainment (average year of schooling), occupational levels, average years of experience, attained and required education and average wages. This section also examined the effect of skilled workers on firm production, the incidence of external effects of schooling, the factors hindering and others contributing toward enhancing the transfer of knowledge at the firm level, firm upskilling plans and their various effects. Section 4 inquired into the implication of technology use on both upgrading skill levels and on the past and future demand for skilled and unskilled workers, and also examined the effect of firm upskilling plans on technological upgrading and self-reliance on local skill. Section 5 investigated the relative importance of the effort of training, the short and long run skill development mechanisms, the coverage, resources and support offered to firm training, the factors hindering and other contribute toward promoting the success of training at the firm level.

\section{4 Conclusions}

The data from the firm and macro surveys provides us with the required information, which is particularly useful for presenting a macro-micro comparative analysis to identify the causes and consequences of the skills problem, and the plans and policies for skill development from the macro-micro perspectives. The results of the macro survey seem quite representative, since the selection covers government, universities, and educational and training institutions. One advantage of the macro survey is that it examines the problem after integrating two different perspectives of policy makers and experts. Another advantage is that, due to their close association to educational and training institutions, the approached policy makers and experts provided some useful information, particularly from both the analytical and policy perspectives. Moreover, the data evaluates upskilling efforts, examines the causes and consequences of a deficient educational system, training provision, skills mismatch and transfer of knowledge; and also suggests relevant short and long run plans and policies for the enhancement of skill level, education, training, transfer of knowledge and technological upgrading. The main limitation of the macro survey is the low response rate from the university sector, probably because some of the academics lacked adequate information to enable them to contribute to a critical analysis of the causes and consequences of low skill levels.

The results of the firm survey are quite representative, since the selection and coverage of firms in the survey include a broad range of firms working in the chemical and metal industries, which provides us with relevant data and information that of considerable use in our analysis. Such coverage also has the advantage of enabling us to compare between firms according to two criteria, i.e. the size of employment and industrial activity. Moreover, the firm survey presents some background information, which is also quite useful for a further analysis of firms based on other characteristics such as the geographical location, sector (public-private), net worth (capital), ownership and nationality of owner (government, foreign, mixed) and foreign orientation or affiliation to multinational corporation $(\mathrm{MNC} / \mathrm{TNC})$. Another advantage of the firm survey is that it presents more specific but also quite comprehensive data and information that allow us to use a wide range of quantitative data and information for measuring skill and technology indicators and the link between them at the micro level/ across firms. In addition, the survey data allows us to approximate and examine the importance of tacit knowledge, and enables us to compare be- 
tween attained and required education and to measure the skills mismatch across firms. At the micro level, realizing the differences in both tacit knowledge and technologies used across chemical and metal industries when comparing their effects and interaction, we define tacit knowledge by the share of high skilled workers in total employment and technology by the share or total spending on ICT.

One major limitation with respect to firm survey is the low response rate for some questions, especially where the answers or data required quantitative measurement. Such problems arose because some of the respondents firms were unwilling to provide complete and reliable quantitative data or some of the respondents firms offered somewhat selective answers. For example, some firms seemed hesitant to provide information about training and skill upgrading efforts - see Table 4.5 above. An intensive follow-up with firms often improved the quality and quantity of the response rate. However, the hesitance of some firms compelled us to exclude them when their observations were incomplete, missing and unreliable. Therefore we used only completed and reliable observations in our estimation and analysis in the next chapters. Apart from this limitation, the data from the firm and macro surveys remains useful from both the analytical and policy perspectives and is suitable to use in the empirical investigation in Chapters 5 to 7 and also for the policy analysis and recommendations in Chapter 8 . 


\section{Chapter 5}

\section{Assessment of Skill and Technology Indicators}

\section{Introduction}

In this chapter we use the data and results of the firm and macro surveys set out in Chapter 4 to examine the third hypothesis in Chapter 1 about the serious implications of the interaction between the deficient educational system and the high incidence of unskilled foreign workers. In particular, we use the results of the macro survey to show the causes of the deficient educational system and consequences on low skill levels, poor provision of training, skills mismatch and low transfer of knowledge at the macro level. In addition, we use the results of the firm survey to illustrate that the high incidence of unskilled foreign workers leads to low skill level, poor provision of training, skills mismatch, poor technology indicators and a heavy dependence on foreign technologies. The rest of this chapter is organized as follows: Section 1 shows the causes and consequences of the deficient educational system and the high incidence of unskilled foreign workers and their implications on low skill levels, poor provision of training, skills mismatch, lack of knowledge transfer, low level of local technology and heavy dependence on foreign technology. Section 2 presents the micro-macro views about the upgrading of skill and technology and their potential implications. Section 3 provides the conclusions. The main ideas discussed in this chapter are summarized in Scheme 5.1 below. 
Scheme 5.1 - The Causes and Consequences of the Deficien Educational Systen and the Excessive Use of Low Educated Foreign Worker

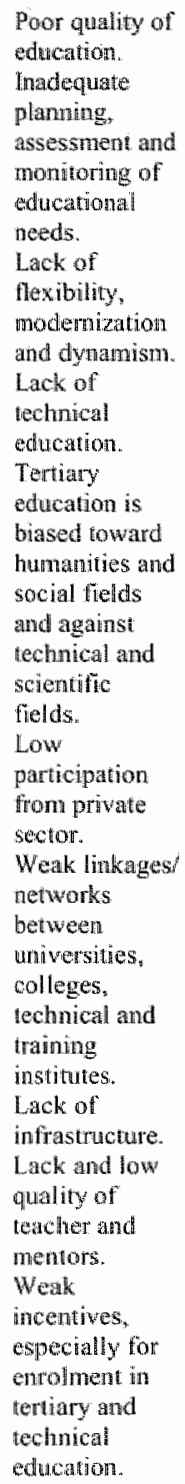

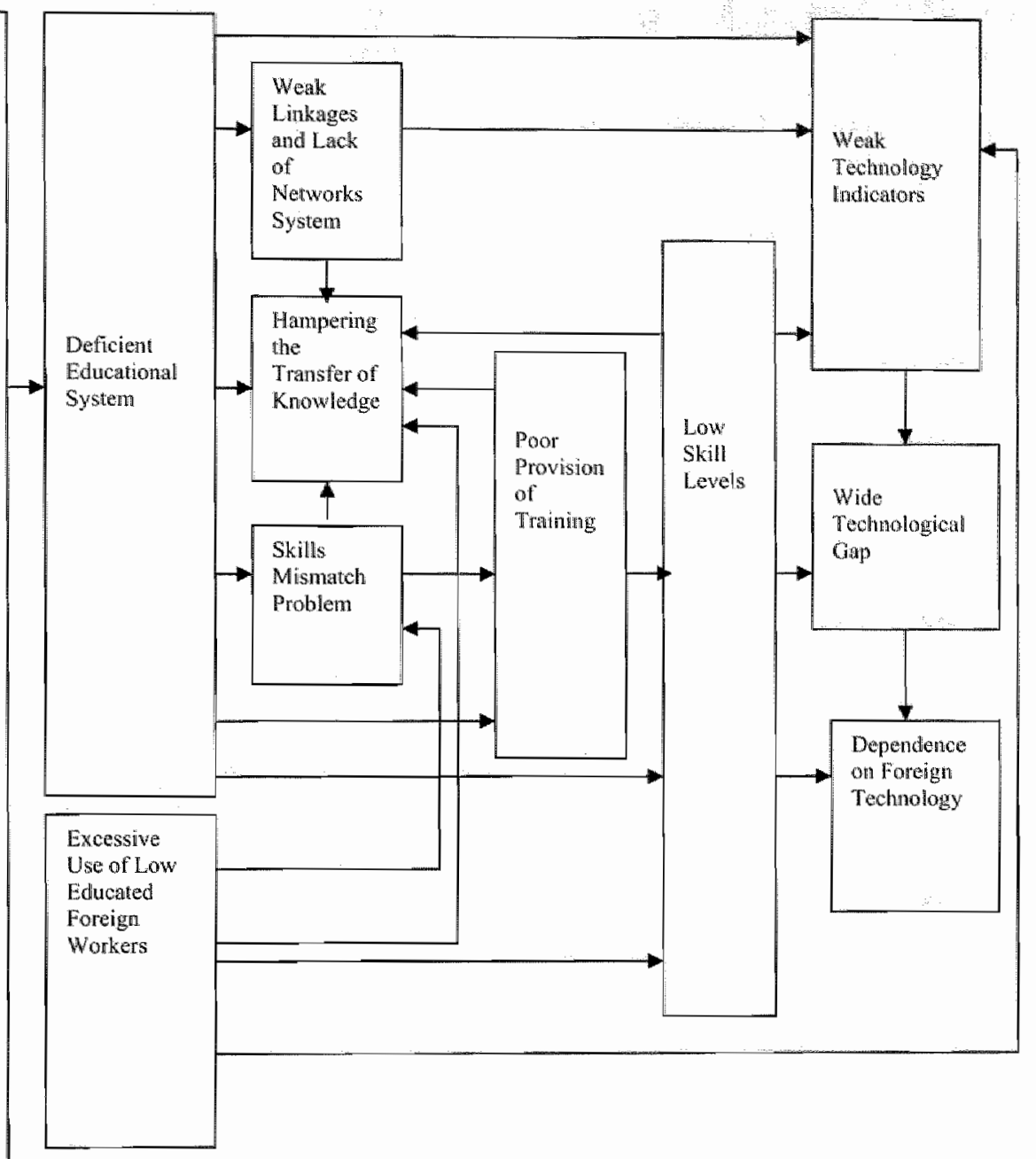




\section{1 Causes and consequences of deficient educational system}

The results of the macro survey indicate that, at the aggregate level, the official efforts to promote and upgrade the levels of local skill have been relatively successful only in some sectors ${ }^{87}$ In general, there has been a serious failure and shortcoming of the upskilling process, which is mainly attributed to: (1) inadequate training provision; (2) the deficient educational system; (3) misallocation of resources; and (4) failure of educated and trained workers to transfer knowledge.

We begin our discussion by the second reason i.e. the deficient educational system, because we want to argue that both inadequate training provision and the failure of educated and trained workers to transfer knowledge are direct implications of deficient education, while the misallocation of resources is indicated as one cause of both deficient education and the poor provision of training.

\section{A. Causes of deficiency in the educational system}

With respect to the second cause, Table 5.1 shows that the deficiencies of the educational system appear in both the basic and tertiary educational systems. Major causes are the inadequate assessment and monitoring of educational needs, low quality and internal efficiency of the educational system, and inadequate planning. Other important factors are the weak linkages/networks between universities, colleges, technical and training institutes, the lack of flexibility of educational institutions, the weak incentives for enrolment in technical education and the lack of modernization and dynamism. Finally, the low involvement and spending by the private sector and the low spending in technical education are also mentioned, but are of somewhat less importance. That also holds good for the lack of infrastructure (due to inadequate investment/public spending on education) and the lack of teachers and mentors. For instance, the share of public spending on education in GDP in the UAE $(1.9 \%)$ is low compared to other Gulf countries like Saudi Arabia $(9.5 \%)$ and other advanced Asian countries such as Korea (3.6\%) and Malaysia (7.9\%) (The UNDP, 2004) see our discussion of the supply side of educational policies in Chapter 8 . Moreover, according to the twin-peaks analysis in Ziesemer (2004), which compares the distribution of public spending on education across countries, the UAE's less than $2 \%$ public spending on education falls below the average $4.6 \%$ of public spending on education to improve the accumulation of human capital in 1998.

We observe that, according to $82 \%$ of the respondents to the macro survey, the low quality and efficiency of the educational system appears from the low quality at basic, secondary and tertiary education relative to international standards. Impontant causes are the low rates of accomplishments and motivation at higher secondary and tertiary education levels relative to international standards, but the problem is somewhat less at the basic education level. Another serious problem is the low quality of teachers and mentors, ${ }^{89}$ while less important causes include, the high pupil/teacher ratios, the low public current expenditure per pupil, the low survival rates and high drop-out and the high repetition rates. ${ }^{90,91}$

\footnotetext{
As reported by $63 \%$ of the respondent policy makers and experts to the macro survey.

$8 \%$ As indicated by $97 \%, 83 \%, 70 \%$ and $70 \%$ of the respondent policy makers and experts respectively.

\$9 As reported by $79 \%$ of the respondent policy makers and experts to the macro survey.

As indicated by about $61 \%, 54 \%, 50 \%$ and $50 \%$ of the respondent policy makers and experts to the macro survey respectively.

91 We observe that the presence of high drop-out levels in the transition from schooling education to university education, which implies the lack of social awareness of the importance of tertiary education or
} 
Table 5.1-The Causes of deficient edncarional system in the UAE, 2002

\begin{tabular}{|c|c|c|c|}
\hline Causes of Deficiency & $\begin{array}{l}\text { General educa- } \\
\text { tional system } \\
\text { (basic + tertiary) } \\
(\%)\end{array}$ & $\begin{array}{l}\text { Basic } \\
\text { educa- } \\
\text { tion } \\
(\%)\end{array}$ & $\begin{array}{l}\text { Tertiary } \\
\text { education } \\
(\%)\end{array}$ \\
\hline Inadequate assessments and monitoring of educational needs. & $84.5 \%$ & $83 \%$ & $86 \%$ \\
\hline Low quality / efficiency of educational system. & $82.5 \%$ & $79 \%$ & $86 \%$ \\
\hline Inadequate planning for educational needs. & $82.5 \%$ & $79 \%$ & $86 \%$ \\
\hline Lack of flexibility of educational institutions. & $77.5 \%$ & $76 \%$ & $79 \%$ \\
\hline Weak incentives for enrolment in technical education. & $75.5 \%$ & $76 \%$ & $75 \%$ \\
\hline Lack of modernization and dynamism. & $73.5 \%$ & $76 \%$ & $71 \%$ \\
\hline Low involvement and spending by private sector. & $70 \%$ & $72 \%$ & $68 \%$ \\
\hline Low spending in technical education. & $68.5 \%$ & $69 \%$ & $68 \%$ \\
\hline $\begin{array}{l}\text { Weak linkages [networks] between universities, colleges, } \\
\text { technical and the training institutes. }\end{array}$ & $79 \%$ & - & $79 \%$ \\
\hline $\begin{array}{l}\text { Lack of infrastructures due to Inadequate investment (public } \\
\text { spending on education). }\end{array}$ & $58 \%$ & $55 \%$ & $61 \%$ \\
\hline Lack of teachers and mentors. & $54.5 \%$ & $55 \%$ & $54 \%$ \\
\hline
\end{tabular}

Source: Own calculation based on the macro survey (2002).

\section{B. Consequences of the deficient educational system}

\section{a. mismatch between the output of education and the market needs}

We find that both the deficient basic (primary and secondary) and tertiary educational systems together lead to serious mismatch between the output of education and the market needs. In particular, about $96 \%$ of the respondents to the macro survey reported that the mismatch is mainly attributed to deficiency of both tertiary and basic education. Moreover, the follow-up interviews with policy makers and experts show that the mismatch is attributed to the deficient educational system ${ }^{92}$, the lack of coordination and planning to meet the critical skill needs and the cultural/social reasons: preference for white-collar jobs and biased against technical education and technical jobs. For instance, the deficiency of tertiary educational system is caused by the inconsistent structure: the share of students enrolled in the UAE between 1994-1997 in all social sciences, humanities and art faculties (73\%) was much higher than those of sciences, math and engineering $(27 \%)$. The share of students enrolled in sciences, math and engineering in the UAE is also low compared to both Korea $(34 \%)$ and China (53\%) (The UNDP, 2002; 2003) - cf. our discussion on the demand for education in Chapter 8.3

preference of more certain short term return to available jobs than long term investment in education and skills.

${ }^{22}$ As in most other developing countries, the mismatch is attributed to deficiency in the educational system. Another interpretation in the Gulf countries attributes this to culture: i.e. preference for white-collar jobs.

${ }^{93}$ These results are allso consistent with the findings of both EI Sabaa (1997) and Haan (1999) respectively. "Reviewing the numbers of student enrolled in the UAE University shows that the total number of enrolled students in engineering, science, agriculture and medicine faculties in 1994 was nearly $24 \%$ of the total number of the enrolled students. While the number of other theoretical faculties, mainly, literature, economics, education, and law in the same year were accounting for $76 \%$ of the total number of enrolled students. The other foreign and private faculties operating in the UAE are stressing on the theoretical branches of education. Similarly, the Higher Faculties of Technology are also allocated the larger part of its studies to business management at the expense of other technological and engineering branches. This leads to imbalanced distribution of graduates and the limited contribution of researchers, technologists and engineering to the local manpower: It is noticeable that the larger segment of local manpower tends to prefer 


\section{b. lowering skill levels}

From the UAE population census data (1995) and the educational matrix for the period 1985-1995 set out in Table 5.2, we observe the low skill levels - defined by educational level of total population. The share of low educated $(71 \%-66 \%)$ is much higher than that of high educated $(10 \%-12 \%)$ in total population. That also indicates a minimal skill upgrading, defined by the relative rise in the share of high educated population and the relative decline of the share of low educated population cluring the period $1985-1995 .^{94}$ In addition, the UAE Ministry of Planning Statistical data (1995-1997) on the distribution of economically active population by occupational classification (1985-1995) shows the low skill level defined by occupational levels, for instance, the share of unskilled population $(86-81 \%)$ is much higher than that of high skilled population (13-18\%). That also implies a slight improvement in skill upgrading defined by the increasing share of high skilled and a falling share of unskilled during the period (1985-1995). Furthermore, as we explain below, the low skill levels at the macro level is consistent with that at the micro level.

Table 5.2. The UAE educational matrix: The distribution of Population by educational level (1985-1995)

\begin{tabular}{lllllll}
\hline 1985 & & Low & Medium & High & Not stated & Total \\
\hline \multirow{2}{*}{ Native } & Male & 0.079314 & 0.009192 & 0.005544 & 0.000012 & 0.094062 \\
& Female & 0.001677 & 0.002463 & 0.001705 & 0 & 0.005845 \\
& Total & 0.080991 & 0.011655 & 0.007249 & 0.000012 & 0.099907 \\
Non-native & Male & 0.585299 & 0.143734 & 0.081035 & 0.000209 & 0.810277 \\
& Female & 0.044652 & 0.02966 & 0.015462 & 0.000042 & 0.089815 \\
Total population & Total & 0.629951 & 0.173394 & 0.096497 & 0.000252 & 0.900093 \\
\hline 1995 & & 0.710942 & 0.185049 & 0.103746 & 0.000263 & 1 \\
\hline \multirow{2}{*}{ Native } & Low & Medium & High & Not stated & Total \\
& Female & 0.052143 & 0.017576 & 0.00929 & 0.00001 & 0.07902 \\
& Total & 0.05406 & 0.021907 & 0.014816 & 0.000012 & 0.011774 \\
Non-native & Male & 0.557998 & 0.150259 & 0.093477 & 0.002628 & 0.804362 \\
& Female & 0.05228 & 0.032108 & 0.020365 & 0.000091 & 0.104844 \\
Total population & Total & 0.610278 & 0.182367 & 0.113841 & 0.00272 & 0.909206 \\
\hline
\end{tabular}

Source: Own calcutation from the population consus data $(1985-1995)$

managerial and commercial domains. Thus, the number of theoretical faculties graduates has been much more than the vacancies available in managerial careers and government services" (EI Sabaa, 1997: 20-21). "While the UAE has in recent years made progress in developing its human resource base, its educational system is still largely geared towards general education and most of the students in higher education are found in humanity and similar studies. Technical skills are lacking and technical education and training, which historically does not enjoy much status in society, are lagging far behind. For instance, from the HCTs, the lirst one of which only opened their doors in the late $1980 \mathrm{~s}$, have so far graduated only 264 engineers, some of these graduates still lack a great deal of field practice. Moreover, most of the qualified people with techmical skills still end up working in the government and white collar work in general reflecting the bias against technical and manual work in particular, very, very few actually work in practical jobs in private firms and other jobs which would require them to work in the field" (Haan, 1999: 37).

94 At the aggregate level, the educational matrix implies the distribution of population according to educational level: low level of education refers to illiterate, literate, primary and preparatory school; medium level of education includes secondary, post-secondary and below university; and high level of education includes university and postgraduate levels. 


\section{c. hampering transfer of knowledge}

Our results in Table 5.3 show that the low quality of education hindered the easy transfer of knowledge and external schooling effects. According to the macro survey, only $42 \%$ of the respondent policy makers and experts reported that the incidence of knowledge transfer/external schooling effect is successful, while around $58 \%$ reported that the transfer of knowledge/ the external schooling effects are constrained by several factors. The major important factors include: the low quality of education, the low quality of training, prevailing conditions in the firm do not encourage external effects, failure of skilled workers to deliver knowledge to unskilled workers and failure of unskilled workers to acquire knowledge from skilled workers. ${ }^{95}$

In strong contrast to this view, the results of the firm survey show that, at the mi$\mathrm{cro} / \mathrm{firm}$ level, the incidence of knowledge transfer/external schooling effect is successful among $95 \%$ of the respondents firms. It is only unsuccessful within two firms because of the following: the low quality of education, the low quality of training, the prevailing conditions in the firm do not encourage the external effects and the fallure of unskilled workers to acquire knowledge from skilled workers. ${ }^{96}$

Table 5.3 - The factors constrained the fransfer of knowledgel extemal schooling effect in the UAE, 2002

\begin{tabular}{ll}
\hline Factors constrained the transfer of knowledge / External Effect of Schooling & Officials \\
\hline Low quality/retum from education & $95 \%$ \\
Low return form/ quality of training compared to international standard & $95 \%$ \\
Prevailing conditions in the Firm conditions do not encourage the external effect & $95 \%$ \\
Failure of skilled workers to deliver their knowledge and experiences to benefit unskilled & $90 \%$ \\
workers. & \\
Failure of unskilled workers to acquire the knowledge and experience from skilled workers & $90 \%$ \\
\hline
\end{tabular}

Source: Own calculation based on the macro survey (2002)

This contradicting optimistic-pessimistic views at the micro and macro levels regarding the incidence and success of knowledge transfer/external schooling effect implies that the transfer of knowledge/ the external schooling effects is probably successful within firms but unsuccessful between firms and within society at large. This is consistent with our observations from the follow-up interviews that the transfer of knowledge is hindered by both the low quality of education and the lack of cooperation with university sector due to inadequate awareness and lack of social partnership between public sector, private sector, university sector and society. The weak linkages and lack of networks between universities, colleges, technical and training institutes and the productive sectors is mentioned by $79 \%$ of the respondents to the macro survey as factor that constrains the efficiency of educational system - it probably also constrains the transfer of knowledge. An additional factor is that the transfer of knowledge within society at large is probably hindered by the imbalanced

\footnotetext{
95 The transfer of knowledge and external schooling effects refers to knowledge transferred from knowledge holders (high skilled workers/people) to knowledge recipients (low skilled workers/people) - cf. Cowan, Soete and Tchervonnaya (2001: 9). Knowledge in this sense refers to know how or tacit knowledge embodied in people, and is different from the broad definition of technology, which refers to both embodied and disembodied knowledge.

9 Another possible explanation for the low transfer of knowledge can be interpreted in relation to the prevailing conditions within private firms. Since within private firms most of the highly skilled posts as well as most of the low skilled posts are held by foreigners, there may be less incentives for the incidence of transfer of knowledge from high to low skilled workers.
} 
structure of population and labour market. Mainly due to the excessive share of foreign workers with different nationalities, cultures, languages, etc. that probably hindered their sufficient integration and interaction with local workers and local population. ${ }^{97}$ This is probably atso due to a lack of incentives at the aggregate level. ${ }^{98}$

Finally, the macro survey indicates that the contribution of both educated and trained population to promote the local skills is constrained by several causes. Major causes are the lack of interaction to market needs (nismatch) and the lack of information on educational and training needs in the productive sectors and their demand for graduate students." Other important causes are: risk aversion, i.e. the preference of more certain short term returns to available jobs than long term skill investments; the uncertainties about future skill needs; the lack of a system of certification of skilled acquired; and inadequate incentives for trainers. ${ }^{100}$ Relatively less important causes include the uncertainties about the future value of investment in education and training and the high costs to finance education and training. ${ }^{101}$ These factors probably also contribute to hinder the transfer of knowledge within sociery at large.

\section{d. poor provision of training}

Both the deficient educational system and the excess supply of low skilled foreign workers lead to a low skill level and hinder the provision of training. Table 5.4 shows that both the policy makers and experts (officials) and firm managers mentioned the low educational qualifications of workers among the important factors constraining the provision of training. Other important factors are the lack of appreciation/ information about training, inadequate assessment and planning for training programmes and the mismatch problem.

\footnotetext{
"This result is consistent with the findling of EI Sabaa (1997), who notes: "It is widely observed that industrial entrepreneurs in the technically advanced projects are strictly against leakage of their technologies oulside their fatotories. Thus, they minimally contribute to developing the technology enviromment in the country. This adverse impact has been amplified by the unwillingness of foreign as well as local entrepreneurs to employ local manpower, to train them in their factories, either because they doubt their capabilities, or for fear to leaking their technology secret to other competitors. The limited supply of local industriul manpower, coincided with the unwillingness to employ them in both foreign and local industries applying advanced technologies, resulted in constricting the role supposed to be played by expatriate manpower in ransferring technology to the industrial sector in the Gulf region. Moreover, the large scale industries despite using more sophisticated advanced technologies, however, they minimally contribute to elevare the technology transfer to the local industrial sector, as they strictly keep their operational and managerial techniques as top confidential secrete and prevent their leaking outside their units. To some extent, the chance of their flow to the rest of the operating factories seems better in the medium size factories" (E)
Sabas, 1997: 22, 24-25).

The lack of transfer of knowledge can be interpreted as a lack of absorptive capacity, mainly related to

deficiencies of education and continued dependence on imported technologies.
${ }_{99}$ As indicated by $82 \%$ and $79 \%$ of the respondent policy makers and experts respectively.

100 As reported by $75 \%$ of the respondent policy makers and experts.

As indicated by $71 \%$, and $61 \%$ of the respondent policy makers and experts respectively.
} 
Table 5.4-The factors constrained the prowision of waining in the $U A E_{n} 2002$

\begin{tabular}{|c|c|c|c|c|c|c|}
\hline Fictors constrained the provision of training & $\begin{array}{l}\text { Offi } \\
\text { cial }\end{array}$ & $\begin{array}{l}\text { All } \\
\text { firms }\end{array}$ & $\begin{array}{l}\text { Chemi } \\
\text { cal }\end{array}$ & Met & $\begin{array}{l}\text { Me- } \\
\text { dium }\end{array}$ & Larg \\
\hline Inadequate planning for training progranme & $93 \%$ & $42 \%$ & $43 \%$ & $40 \%$ & $50 \%$ & $25 \%$ \\
\hline Inadequate assessment of training needs. & $93 \%$ & $50 \%$ & $57 \%$ & $40 \%$ & $63 \%$ & $25 \%$ \\
\hline $\begin{array}{l}\text { Mismatch between training programme and changing } \\
\text { technical needs }\end{array}$ & $96 \%$ & $33 \%$ & $29 \%$ & $40 \%$ & $38 \%$ & $25 \%$ \\
\hline $\begin{array}{l}\text { Mismatch between training programmes and changing } \\
\text { skill needs }\end{array}$ & $96 \%$ & $33 \%$ & $29 \%$ & $40 \%$ & $38 \%$ & $25 \%$ \\
\hline Low quality of trainers and mentors & $82 \%$ & $33 \%$ & $43 \%$ & $20 \%$ & $38 \%$ & $25 \%$ \\
\hline Low educational qualifications of workers & $79 \%$ & $58 \%$ & $43 \%$ & $80 \%$ & $50 \%$ & $75 \%$ \\
\hline Lack of trainers and mentors & $79 \%$ & $33 \%$ & $43 \%$ & $20 \%$ & $38 \%$ & $25 \%$ \\
\hline Lack of appreciation/ information about training & $75 \%$ & $50 \%$ & $57 \%$ & $40 \%$ & $63 \%$ & $25 \%$ \\
\hline Lack of specialized training institutions & $79 \%$ & $33 \%$ & $29 \%$ & $40 \%$ & $50 \%$ & \\
\hline $\begin{array}{l}\text { Lack of full appropriability of the return from training } \\
\text { investment. }\end{array}$ & $71 \%$ & $33 \%$ & $29 \%$ & $40 \%$ & $50 \%$ & \\
\hline $\begin{array}{l}\text { Lack of interactions between training institutions and } \\
\text { firms }\end{array}$ & $71 \%$ & $33 \%$ & $29 \%$ & $40 \%$ & $50 \%$ & \\
\hline Lack of finance to cover the cost of training & $68 \%$ & $33 \%$ & $29 \%$ & $40 \%$ & $50 \%$ & \\
\hline Lack of training materials and equipment & $68 \%$ & $33 \%$ & $29 \%$ & $40 \%$ & $38 \%$ & $25 \%$ \\
\hline $\begin{array}{l}\text { High rate of mobility of trainers to move for better } \\
\text { paid jobs after training }\end{array}$ & $68 \%$ & $33 \%$ & $29 \%$ & $40 \%$ & $50 \%$ & \\
\hline $\begin{array}{l}\text { Lack of a system of training certification of skills } \\
\text { acquired }\end{array}$ & $71 \%$ & $8 \%$ & $14 \%$ & & $13 \%$ & \\
\hline Total response & 28 & 12 & 7 & 5 & 8 & 4 \\
\hline
\end{tabular}

Source: Own calculation based on the macro survey (2002) firm survey (2002)

Moreover, the results of the firm survey illustrate that the low provision of training appears from the following: (1) The lack of an in house training unit -only $23 \%$ of the respondent firms have an in house training unit; (2) The complete absence of public financial support: for instance, none of the respondent firms received any government subsidies to support training provision; (3) The selective training provision: in the year 2001, the priority for training among the respondent firms was mostly given to production workers, production engineering staff, management staff and services workers; ${ }^{102}$ (4) The limited type of training: most of training provision is focused on the job training, and on the job and off the job combined, which are preferred by $87 \%$ and $91 \%$ of the respondent firms respectively. The other types of training such as: off the job within the firm (training centre), off the job outside the firm (outside the country) and (specialist training centre inside the country) are very limited. ${ }^{103}(5)$ The limited sources of information about training opportunities, as most of the information about training opportunities is provided by private trainers (local and foreign companies) and the chambers of commerce. Few firms find information from public educational institutions/ universities, other firms working in the same sector, and government and semi government units. ${ }^{104,105}$

\footnotetext{
102 As reported by $68 \%, 54 \%, 43 \%$ and $35 \%$ of the respondent firms respectively.

${ }^{103}$ As indicated by $55 \%, 27 \%$ and $27 \%$ of the respondent firms respectively.

${ }_{104}$ As reported by $65 \%, 42 \%, 35 \%, 29 \%$ and $26 \%$ of the respondent fims respectively.

105 These results seem consistent with the findings of the earlier studies conducted by the UAE University (1994; 1997), Gray (1999) and Abdelkaraim and Haan (2002). For instance, the UAE Education Assess ment Report (1994) shows that both technical and vocational education and training prowision are unregulated, uncoordinated and unplanned, while the results of the UAE University (1997) show the limited contribution to private sector training provision by both the public and government sectors. Moreover, the
} 


\section{Consequences of the low educational qualifications of foreign work- ers at the micro/firm level}

In Chapter 2 we explained that one well-known fact about the Gulf countries is the high share of foreign workers in total employment. In this section we show that next to the consequences of the deficient educational system at the macro level, the high incidence of unskilled foreign workers also causes several serious implications at the micro/firm level.

\section{a. Low skill level and skills mismatch at the micro/firm level ${ }^{106}$}

From the demand perspective, the results of the firm survey can be used to argue that firm demand for low skilled workers leads to an excessive share of low skilled workers. On the other hand, from the supply perspective, our findings from the firm survey show that the excessive share of low skilled foreign workers has direct implications in lowering skill levels at the micro/ firm level. For instance, Table 5.5 below shows that across firms the average percentage share of low skilled workers $(71 \%$ and $75 \%$ ) is much higher than that of high-skilled workers ( $29 \%$ and $25 \%$ ) defined by both educational and occupational classifications respectively. Moreover, Tables 5.4 and 5.5 show that the poor educational qualifications of foreign workers lead to poor provision of training - see our discussion above - and a serious skills mismatch across firms, as we will explain in detail in the next chapter. ${ }^{107}$

findings of Gray (1999) show that only $30 \%$ of the respondent firms provide systematic training. The provision of training is selective in most cases - focused on some occupational groups, but not others - and for two-thirds of the respondent firms, the provision of training was limited to on-the-job training. The study concluded that the UAE does not have a training-led employment culture. Employers have become used to bringing in their workers from outside the country with readymade skills and replacing them with similarly skilled workers. There has been little incentive to provide skill upgrading except in response to immediate needs such as the introduction of new technology. The local training industry has suffered from the uncoordinated nature of provision and the very limited contribution by public sector organisations and higher education institutions to this variety of provision. Most of training provision has been in low-investment, low-cost and quick-profit areas such as marketing, public relations, sales, computer awareness and management development. The private sector training is relatively undeveloped and un-coordinated and has limited market due to both limited demand and limited supply. Moreover, the provision of public sectot training is constrained by the inadequate involvement of public education institutions. For instance, the Higher Colleges of Technology (HCTs) had little involvement in the important area of adult technical education, including vocational training and retraining (Gray, 1999: 15, 33-34,43). Additionally, the findings of Abdelkaraim and Haan (2002) show that the UAE public sector training is still limited due to less attention, awareness and resources (Abdelkaraim and Haan, 2002: 15).

106 It is convenient in this chapter to briefly indicate the consequences with respect to low skill and skills mismatch at the micro level and to discuss this more fully later in Chapter 6 . That serves our aim in this chapter to compare and integrate the macro-micro consequences of low skill level - cf. Scheme 5.1. above. This brief discussion in this chapter also substantiates the third hypothesis in Chapter 1 above about the interaction between the deficient educational system at the macro level and the high incidence of unskilled foreign workers at the micro level and the serious implications on low skill levels and skills mismatela. It is appropriate to discuss the skills mismatch problem more extensively later in Chapter 6 , where we provide a broader, more in-depth and coherent analysis of skill problem and the implications of the prevalence of lows-skilled foreign workers at the micro/firm level.

${ }_{107}$ We define the mismatch as the differences between the required and actual education. Actual education refers to high (university and above), medium (secondary) and low (below secondary) levels of attained years of education that represent the supply of skills. We define the required education by the required the demand for skills. We observe that the inconses translated into average years of schooling that represent 


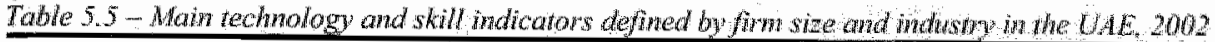

\begin{tabular}{|c|c|c|c|c|c|}
\hline \multirow[t]{2}{*}{ Indicator } & \multirow{2}{*}{$\begin{array}{l}\text { All } \\
\text { firms }\end{array}$} & \multicolumn{2}{|l|}{ industry } & \multicolumn{2}{|l|}{ silize } \\
\hline & & Chernical & Metal & Lange & Medium \\
\hline \multicolumn{6}{|l|}{ Skill and skills mismatch indicators } \\
\hline Share of high skilled (education) (\%) & $29 \%$ & $35 \%$ & $23 \%$ & $33 \%$ & $27 \%$ \\
\hline Share of high skilled (occupation) $(\%)$ & $25 \%$ & $28 \%$ & $21 \%$ & $21 \%$ & $28 \%$ \\
\hline Share of low skilled (education) (\%) & $71 \%$ & $65 \%$ & $77 \%$ & $67 \%$ & $73 \%$ \\
\hline Share of low skilled (occupation) (\%) & $75 \%$ & $72 \%$ & $79 \%$ & $79 \%$ & $72 \%$ \\
\hline Share of firm conducting $R \& D(\%)$ & $37 \%$ & $47.8 \%$ & $26.3 \%$ & $47.8 \%$ & $26.3 \%$ \\
\hline high skilled wages /low skilled wages & 7.5 & 6.9 & 8.1 & 6.3 & 8.4 \\
\hline \multicolumn{6}{|l|}{ Share of firm with skills mismatch $(\%)$} \\
\hline The high skilled group $(\%)$ & $29 \%$ & $28.6 \%$ & $30 \%$ & $35.7 \%$ & $20 \%$ \\
\hline The mediunn skilled group $(\%)$ & $72 \%$ & $69.2 \%$ & $75 \%$ & $83.3 \%$ & $55.6 \%$ \\
\hline The low skilled group $(\%)$ & $66 \%$ & $60 \%$ & $71.4 \%$ & $72.7 \%$ & $50 \%$ \\
\hline \multicolumn{6}{|l|}{ Technology indicators } \\
\hline $\begin{array}{l}\text { Share of R\&D expenditure/total output (sales value) } \\
(\%)\end{array}$ & $0.01 \%$ & $0.0115 \%$ & $0.005 \%$ & $0.017 \%$ & $0.014 \%$ \\
\hline $\begin{array}{l}\text { Average R\&D expenditure ( } x \text { I million UAE Dir- } \\
\text { ham) }\end{array}$ & 0.9 & 1.5 & 0.2 & 1.4 & 0.5 \\
\hline Number of R\&D employees (R) & $1 \leq \mathbb{R} \geq 11$ & $1 \leq \mathrm{R} \geq \mathrm{ll}$ & $1 \leq \mathrm{R} \leq 10$ & $1 \leq \mathrm{R} \geq \mathbb{1}$ & $1 \leq \mathrm{R} \leq 5$ \\
\hline Number of full time R\&D employees & $1-11$ & $1-11$ & $1-5$ & 1.11 & 1.5 \\
\hline Number of part time R\&D employees & $6 \leq \mathrm{R} \geq 11$ & $6 \leq \mathrm{R} \geq \mathrm{B}$ & $6-10$ & $6 \leq R \geq 1$ & 0 \\
\hline Share of firm applying for patents (\%) & $13 \%$ & $13 \%$ & 0 & $12 \%$ & 0 \\
\hline Share of firm in total spending on $I C T(\%)$ & $100 \%$ & $88 \%$ & $12 \%$ & $95 \%$ & $5 \%$ \\
\hline Share of firm in total spending on ICT training (\%) & $100 \%$ & $86 \%$ & $14 \%$ & $94 \%$ & $6 \%$ \\
\hline Share of firm in total spending on ICT $(\%)$ & $69 \%$ & $67 \%$ & $72 \%$ & $73 \%$ & $65 \%$ \\
\hline Share of firm with spending on ICT training (\%) & $52 \%$ & $50 \%$ & $56 \%$ & $68 \%$ & $35 \%$ \\
\hline $\begin{array}{l}\text { The degree of automation/use of sophisticated } \\
\text { technologies }{ }^{\text {os }}(\%)\end{array}$ & $40 \%$ & $54.5 \%$ & $26.3 \%$ & $45.5 \%$ & $36.8 \%$ \\
\hline Dependence on foreign technology $y^{10 \%}(\%)$ & $90 \%$ & $96 \%$ & $84 \%$ & $91 \%$ & $90 \%$ \\
\hline Share of firm providing training $(\%)$ & $23 \%$ & $32 \%$ & $8 \%$ & $24 \%$ & $22 \%$ \\
\hline Incidence of external schooling effect $(\%)$ & $95 \%$ & $95 \%$ & $94 \%$ & $94 \%$ & $95 \%$ \\
\hline
\end{tabular}

Source: Own calculation based on the firm survey (2002).

$b$. weak technology indicators

From the demand perspective, the results of the firm survey can be used to argue that weak technology indicators lead firms to demand and rely heavily on low skilled workers. On the other hand, from the supply perspective, the excessive share of unskilled foreign workers leads to weak technology input-output indicators across firms. From Table 5.5 above, we observe that a weak R\&D indicator appears from the following: (a) "The limited R\&D activities/efforts performed continuously or occasionally amongst only $37 \%$ of all the respondents firms; (b) The limited R\&D activities and expenditure particularly devoted/aimed at

inconsistency between demand for and supply of skillls, which we interpreted as skills mismatch - cf. the detailed discussion in Chapter 6 below.

108. We measure the degree of automation/ sophisticated technologies qualitatively, we asked firms about their own appreciation or evaluation of the level of technologies they are using in their production.

109 We measure the dependence on foreign technologies qualitatively, we asked firms if they have an adequate capacity/ability to produce and develop local technologies and if they have purchased equipment, machines and techniques from abroad. Our definition also include quantitative measurement of the value of imported capital equipment to total capital equipment, the percentage value of capital equipment to total capital equipment that has been build by foreign companies. Finally technology transfer is also an indicator of dependence on foreign technologies- see Table 5.7 below. 
improving firm product and to produce a new product; (c) The low R\&D expenditures and R\&D expenditures as percentage of total output expenditures. For instance, amongst all the respondent firms, average $\mathrm{R} \& \mathrm{D}$ expenditure was around 0.9 million Dirhams, ${ }^{110}$ while the average $\mathrm{R} \& \mathrm{D}$ expenditures as a percentage of total output (sales value) amongst all the respondents firms accounted for only $0.01 \%$; (d) The low number of both full time and part time R\&D employees. For instance, a large majority $(87.5 \%)$ of the respondents firms with R\&D activities have a low number (1-5) of full time research employees. Only two of the large chemical firms have more than eleven full and part-time research employees and only one large metal firm has 6-10 part time research employees. For instance, the contribution of research units in adapting the imported technologies is constrained by a shortage of skilled and qualified workers amongst $86 \%, 82 \%, 100 \%, 80 \%$ and $89 \%$ of all firms, chemi$\mathrm{cal}$, metal, medium and large firms respectively, see Table 5.8 below. "Moreover, the follow-up interviews with the officials and firms managers revealed that R\&D activities are constrained by several factors such as high costs and low public and private spending, lack of information systems, and the absence of a R\&D culture due to inadequate awareness and concern. Additional constraints relate to the poor coordination between the institutions engaging in R\&D activities, either due to the absence of explicit government policy or the ineffective role of a central body (e.g. government) to coordinate and promote R\&D efforts and motivate collaborative research efforts between the firms sector and university sector. In addition to weak network systems, R\&D efforts, in particular, are limited across firms because of weak contact and collaboration with the university sector, this is probably attributable to the fact that the university sector is lacking resources or concern and interest to conduct joint research with the firms sector. ${ }^{112}$

110 The value is measured in the UAE local currency: Dirham, which equalled 3.67 US Dollars when the survey was held (2002).

$1: 1$ We measured the contribution of a research unit to adapt the imported technologies qualitatively, by asking firms how the research unit contributed to adapting imported rechnologies. In addition to a lack of qualified workers, there may also be other factors such as a lack of incentives or pressure to adapt or master imported technologies as firms can always opt to buy the required technologies or techniques.

112 "This can also be interpreted as a lack of demand-pull since firms can buy sill technologies or techniques. Our findings are consistent in some respects with the findings of Haan (1999) "R\&D capacity in the UAE is presently very limited. While some research is taking place at the University and other institutes of higher education, it is -as usual in such institutions- more geared towards pure science and tend to have only limited relevance for the productive sector. While the Higher Colleges of Technology place enyphasis on more practical training, hardly any R\&D takes place, only as a by-product of the training. Within the private sector in the UAE likewise very few R\&D activities are going on. Most manufacturing and other lirms tend to rely on imported technologies (both in terms of hardware and software), as well as imported materials and even expatriate manpower. There is very little interest in carrying out research, and the R\&D activities are small-scale in nature and mostly only concern -minor-adaptations to the companies' own products. In all it is estimated that less than $1 \%$ of turnover is used for this purpose. The parastatel sector, in which a number of large basic industries are operating, will do better. There is also some agricultural research ongoing. Without such R\&D facilities and efforts, the UAE is almost completely dependent on imported technologies. And without the necessary adaptations to local conditions (e.g temperatures, effects of dust and sand winds, special cultural aspects, the country's socio-political system, etc.), even these technologies cannot be optimally applied. Moreover, a genuine technology culture to motivate the inwolvement in R\&D and promotion of local technology is now absent in the UAE. The UAE society is geared more predominantly to non-technical education, traning and employnent. Technical qualifications and occupations are not rated very high by its social values and cultural traditions. The UAE only has a himited industrial tradition (e.g. trade), and lacks explicit policies to stimulate and direct technological development" (Haan, 1999: 37-38). 
Moreover, Table 5.5 above shows the weak technology output indicator as measured by patent applications. For instance, in the year 2001 , only $13 \%$ of all respondent firms applied for a patent; the low degree of patenting may be attributable to low R\&D efforts.

In addition, a lack of R\&D efforts may hinder innovative activities across firms. The increasing uses of technology has encouraged the incidence of product and process innovations, in particular, the incidence of incremental product innovation, namely, improwement of product quality amongst $88 \%$ of all respondent firms. It has also encouraged the incidence of new process, new method of production and new combination of old output and new product. ${ }^{13}$ But it has only slight effect on reducing total costs and increasing total sales and total profits - see Table 5.6 below. ${ }^{114}$

Table 5.6 - The effects of increasing use of technology product and process whovarions across firms in the UAt, 1999.2001

\begin{tabular}{llllll}
\hline Product / process innovation (1999-2001) & All & \multicolumn{2}{l}{ Firn industry } & \multicolumn{2}{l}{ Firm size } \\
\cline { 3 - 5 } & firms & Chemical & Mletal & Medium & Large \\
\hline Improwement of product quality. & $88 \%$ & $88 \%$ & $90 \%$ & 100 & $82 \%$ \\
Production of a new method of production. & $69 \%$ & $63 \%$ & $80 \%$ & $78 \%$ & $65 \%$ \\
Production of a new combination of old output. & $69 \%$ & $75 \%$ & $60 \%$ & $78 \%$ & $65 \%$ \\
Production of a new process. & $73 \%$ & $75 \%$ & $70 \%$ & $67 \%$ & $76 \%$ \\
Production of a new product. & $62 \%$ & $63 \%$ & $60 \%$ & $44 \%$ & $71 \%$ \\
Production of new organizational method. & $58 \%$ & $50 \%$ & $70 \%$ & $44 \%$ & $65 \%$ \\
Improvement of training within the firm. & $50 \%$ & $44 \%$ & $60 \%$ & $44 \%$ & $53 \%$ \\
Improvement of communication within the firm. & $54 \%$ & $50 \%$ & $60 \%$ & $44 \%$ & $59 \%$ \\
Production of more output with low cost. & $58 \%$ & $50 \%$ & $70 \%$ & $56 \%$ & $59 \%$ \\
Production of the same output with llow cost. & $38 \%$ & $38 \%$ & $40 \%$ & $56 \%$ & $29 \%$ \\
Open of a new nuarket. & $46 \%$ & $44 \%$ & $50 \%$ & $33 \%$ & $53 \%$ \\
Reduction in per unit material costs. & $27 \%$ & $25 \%$ & $30 \%$ & $33 \%$ & $24 \%$ \\
Reduction in per unit energy costs. & $27 \%$ & $25 \%$ & $30 \%$ & $33 \%$ & $24 \%$ \\
Rediuction in total cost. & $35 \%$ & $25 \%$ & $50 \%$ & $44 \%$ & $29 \%$ \\
Increase in total sales. & $38 \%$ & $19 \%$ & $70 \%$ & $33 \%$ & $41 \%$ \\
Increase in total profit. & $27 \%$ & $6 \%$ & $60 \%$ & $33 \%$ & $24 \%$ \\
Total response & 26 & 16 & $10 \%$ & 9 & 17 \\
\hline
\end{tabular}

Source: Own calculation based on the firm survey (2002).

\section{c. dependence on foreign technology}

From the demand perspective, the results of the firm survey can be used to argue that the dependency on foreign technology leads firms to demand and rely heavily on low skilled workers. On the other hand, from the supply perspective, the deficient educational and training system and a high supply of low skilled foreign workers lead to low skill levels, lack of knowledge transfer and low capability to build and promote the local technology. The results of the firm survey show that this condition leads to weak technology indicators and dependence on imported technology that appears from the following: (1) The high dependence on the imported equipment, machines and techniques among $90 \%$ of the respondent firms. (2) The high percentage value of capital equipment to total capital equipment that has been built by foreign companies $(70 \%)$ among the respondent firms. (3) The considerable percentage value of imported capital equipment to total capital $(40 \%)$ among the respondent firms in the year 2001. (4) The short run plan for $46 \%$ of the respondent firms is

${ }^{113}$ As reported by $73 \%, 69 \%, 69 \%$ and $62 \%$ of all respondent firms respectively.

114 The terms new product and new process refers to new products and processes intended even just for local firm or for local market and not necessarily for the international market. 
based/ depends on imported technology. ${ }^{115}$ The main reasons for the dependence on foreign technology are the lack of local technology from local suppliers, better price and better quality of foreign technology in that order. ${ }^{11 / 3}$ Due to the high dependency on imported technologies, it is not surprising that the level of technology used is similar to international standards amongst all the respondent firms. However, a high degree of automation through the use of sophisticated and advanced technology is limited only within $40 \%$ of all the respondent firms- see Table 5.5 above. The degree of automation/ sophisticated use of advanced technologies is determined by both firm size and industry/activity. ${ }^{117}$

The dependence on foreign technologies also appears from the reported information on the transfer of foreign technology that is made through different channels. For instance, Table 5.7 below illustrates that strategic alliances, hiring foreign skills/ technologically advanced workers/ consultants and joint ventures are more common channels of technology transfer, while FDI and technology licensing are less preferred channels. The transfer of technology, mainly the transfer of technologically advanced workers/consultants, has induced important effects in enhancing firm production but has had only slight effects in enhancing the capacity to develop the local technologies. ${ }^{118}$

In the firm survey questionnaire the question on the channels of technology transfer allows for multiple answers, assuming that firms may choose more than one channel to transfer technology. ${ }^{119}$ Our results indicate that chemical firms are less interested in transferring technologies through formal licenses. These may not be often requested, probably

115 Short, medium and long run refers to next three years, next three to five years and next ten years respectively.

1116 As reported by $84 \%, 37 \%$ and $34 \%$ of the respondent firms respectively.

117 These results are consistent with the findings of El Saba (1997) "The adoption of different approaches in transferring technology differs acconding to certain criteria, such as: the scale of industry and its activity. Large size and some specific sectors, namely chemical and petrochemicals industries have better use of sophisticated advanced technologies" (El Sabaa, 1997: 21-22).

118 "These results are consistent in some respects but differ in others with the findings of El-Sabaa (1997) and Haan (1999) respectively. "The major channels of technology transfer are: joint ventures, and industrial foreign projects, the latter accounts for the first source of technology transfer. The turn-key projects are preferred channel of technology transfer in the Gulf region mainly because of the keenness to avoid defects of execution and to guarantee the maximum consistency of the project's design, lines of production, quality of the procluets. facilities of training, etc. But it has very limited role in transferring technology to local industry, because it is confined to their plants, with no minimum leakage allowed. Thus they contribwe nothing to implant advanced technologies in the country. "Technology transfer to the UAE has obviously contributed to accelerating industrial and economic growth, elevating the standard of national products both quality- wise and quantity-wise. In particular, the transfer of technology contributed to rapid growth of local industrial sector. However, a number of negative factors are still adversely affecting the transfer of technology, the technologies transferred could hardly approach its target of constituting an autonomously developing local technological base, similar to those in the Far East industrial countries. Because of: the inadequate awareness of the end target of technology transfer, the lack of a constitutional framework or comprehensive plan for transferring technology, the insufficient local base of technological data, the lack of qualified local manpower necessary for transferring technology and the contracts of technology transfer" (EI Sabaa, 1997: 23-26) ........ The UAE is almost completely dependent on imported technologies. And without the necessary adaptations to local conditions (e.g. temperatures, effects of dust and sand winds, special cultural aspects, the country"s socio-political system, etc.), even these technologies cannot be optimally applied" (Haan $1999: 38$ ).

110 Our assumption and respective findings are plausible and consistent with the results of EI Sabaa (1997), which indicate numerous different channels of technology transfer to the UAE, such as: foreign industrial investments, offset programs, training missions, technological imports, industrialization licenses, patents, technological products, foreign manpower and industrial consulting offices (El Sabaa, 1997: 26). 
because of more liberalized and open market policies that led to considerable presence of foreign capital investment and allowed for foreign and mixed ownership - cf. Table 6.1 Chapter 6 below. ${ }^{120}$

Table 5.7- The chawnels of technology transfer and then fects an finm production and dewelopment of local technology across fins in the UAE 2002

\begin{tabular}{|c|c|c|c|c|c|}
\hline (a) Channels of technology transfer (1999-2001) & $\begin{array}{l}\text { All } \\
\text { firms }\end{array}$ & Chemical & Metal & Medium & Large \\
\hline Strategic alliance & $42 \%$ & $33 \%$ & $57 \%$ & $43 \%$ & $42 \%$ \\
\hline $\begin{array}{l}\text { Hiring foreign skills/technologically advanced work- } \\
\text { ers/ consultants }\end{array}$ & $32 \%$ & $42 \%$ & $14 \%$ & $43 \%$ & $25 \%$ \\
\hline Joint wentures. & $32 \%$ & $25 \%$ & $43 \%$ & $43 \%$ & $25 \%$ \\
\hline FDI & $21 \%$ & $33 \%$ & 0 & $29 \%$ & $17 \%$ \\
\hline Licensing & $16 \%$ & $8 \%$ & $29 \%$ & $14 \%$ & $17 \%$ \\
\hline $\begin{array}{l}\text { Others (e.g. in house technology development by } \\
\text { hiring technologically advanced persons) }\end{array}$ & $8 \%$ & $8 \%$ & 0 & 0 & $8 \%$ \\
\hline Total response (1999-2001) & 19 & 12 & 7 & 7 & 12 \\
\hline $\begin{array}{l}\text { (b) The effects of technology transfer in (1999- } \\
\text { 2001) }\end{array}$ & $\begin{array}{l}\text { All } \\
\text { firms }\end{array}$ & Chemical & Metal & Medium & Large \\
\hline Enhancing firm production & $87 \%$ & $72 \%$ & $47 \%$ & $77 \%$ & $50 \%$ \\
\hline $\begin{array}{l}\text { Enhancing the capacity to develop the local tech- } \\
\text { nologies }\end{array}$ & $48 \%$ & $44 \%$ & $20 \%$ & $38 \%$ & $30 \%$ \\
\hline Total response $(1999-2001)$ & 23 & 18 & 15 & 13 & 20 \\
\hline $\begin{array}{l}\text { (c) The effects of technologically advanced work- } \\
\text { ers in }\end{array}$ & $\begin{array}{l}\text { All } \\
\text { firms }\end{array}$ & Chemical & Metal & Medium & Large \\
\hline Enhancing firm production & $47 \%$ & $63 \%$ & $29 \%$ & $50 \%$ & $45 \%$ \\
\hline $\begin{array}{l}\text { Enhancing the capacity to develop the local tech- } \\
\text { nologies }\end{array}$ & $33 \%$ & $26 \%$ & $41 \%$ & $25 \%$ & $40 \%$ \\
\hline Totzl response (1999-2001) & 36 & 19 & 17 & 16 & 20 \\
\hline
\end{tabular}

Source: Own calculation based on the firm survey (2002).

These findings on weak technology indicators and dependence on foreign technologies at the micro level are consistent with those at the macro level and the interaction of these findings lead to a large technological gap - see also our earlier discussion in Chapter 2 above. Our results in this chapter and Chapter 2 above verify the second hypothesis in Scheme 1.1 in Chapter 1 above that, in the short and medium term, the Gulf countries are unable to rely on local technologies and remain heavily dependent on foreign technologies.

Our findings from the firm survey show that both skil\| and technology indicators, product and process innovations, the channels of technology transfer and their respective effects vary enormously across firms and seem determined by both firm size and industry level. For instance, Table 5.5 above shows that skill levels, technology input-output indicators (R\&D and patent), the provision of training (upskilling), the dependence on imported technology, the degree of automation and the use of sophisticated and advanced technology wary across firms and increase with firm size and industry level. Moreover, the use of ICT and provision of ICT training increase with firm size, while the transfer of knowledge/ external effects of schooling increase with industry level.

${ }^{120}$ For instance, Fasamo (2002) indicates that other than Abu Dhabi, the emirates have established free zones that allow 100 per cent foreign ownership of companies. These zones are particularly important in Dubai, where they have attracted a large number of foreign companies (Fasano, 2002: 331). El Sabaa (1997) finds that the adoption of open market philosophy, supported by the existence of nine free zones in the seven emirates and the advantage of $100 \%$ foreign ownership and control, encourages foreign industrial investors to set up their projects and to promote technology transfer to the UAE (E1 Sabaa 1997: 23). 


\section{d. Shortage of skilled workers and weak adaptation of imported tech-} nologies

From the demand perspective, the results of the firm survey can be used to argue that low supply of skilled workers lead firms to demand and rely heavily on low skilled workers. On the other hand, from the supply perspective, our findings show that the excessive share (supply) of low skilled foreign workers and low supply of high skilled workers lead to some shortage of skilled workers, since firms are experiencing increasing demand for skilled workers, see Figure 5.1 below. We find that the increasing demand for high skilled workers is related to increasing use of new technologies, which has not only raised the demand for these workers in the past few years, but has also encouraged firms to predict a future/long run increase in this demand. For instance, Figure 5.1 identifies and compares past and future trends of the demand for skilled workers, which vary enormously across firms according to size and industry level. According to $61 \%$ of the respondent firms, the interpretations of the predicted long run increase in the demand for skilled workers are related to expansions of production, project plans, increasing $R \& D$ activities, implementation of new processes, output technologies, advanced control systems and purchases of new machines and equipment. Additional reasons for the rising demand are the increasing adoption of international standards and enhancement of production, product diversification, market share, turnover, sales, shortage of manpower, competition, increasing motivation to reduce costs, increasing production, achieving high standard precision work and improving productivity and quality of work and demand for more specialized skills in IT. On the other hand, the major explanations for the predicted long run stability in the demand for skilled workers across $39 \%$ of all respondent firms is related to the stability in quantity of production, sales, business, demand and market; as well as to the lack of a plan for critical expansion of product operations, potential stability in substituting and replacing the outgoing skilled worker in any field, the use of automated technology and the dependence on the policy of parent company-MNC and its affiliated research group.

We observe that the expected future rise in the demand for high skilled workers across firms is reasonable since increased use of skilled workers in the past has had significant effects. In particular, there have been improvements in firm production, the level of competitiveness in the local market, faster adaptation of foreign technology, utilization of technology and product quality. ${ }^{121}$ On the other hand, our results from the firm survey indicate that the relative shortage of skilled workers amongst $32 \%$ of the respondent firms leads to serious delay, slight abolishment/cancellation of project implementation and constrains the R\&D units in adapting imported technologies - see Table 5.8 below. ${ }^{122}$

121 As indicated by $90 \%, 90 \%, 80 \%, 75 \%$ and $60 \%$ of the respondent firms respectively
122 As indicared by $43 \%, 15 \%$ and $86 \%$ of the respondent firms respectiwely. 
Figure 5.1-Past and futwe trends (increase or stabutin) in the demand for skilled workers across firms

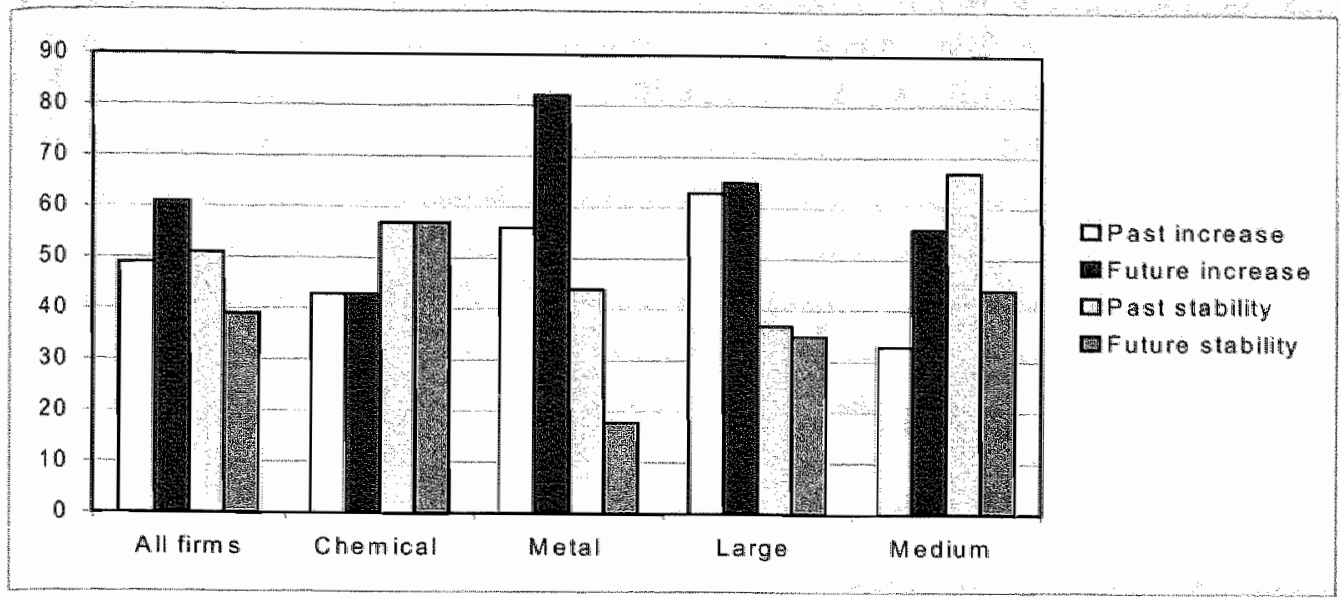

Source: Firm survey (2002)

Table 5.8 - The shoriage of skilled workers and effects across firms in the UAE, (1999-2001)

\begin{tabular}{llllll}
\hline $\begin{array}{l}\text { Shortage of skilled workers and effects on firm } \\
\text { projects }\end{array}$ & $\begin{array}{l}\text { All } \\
\text { firms }\end{array}$ & Chemical & Metal & Medium & Large \\
\hline Shortage of skilled workers & $32 \%$ & $19 \%$ & $47 \%$ & $16 \%$ & $47 \%$ \\
\hline Effects of shortage of skilled workers on firm projects & & & & & \\
\hline Serious delay of firm project & $43 \%$ & $31 \%$ & $63 \%$ & $50 \%$ & $38 \%$ \\
Abolishment/ Cancellation of firm project & $15 \%$ & $16 \%$ & $13 \%$ & 0 & $23 \%$ \\
Constrained the R\&D units to adapt the imported & $86 \%$ & $82 \%$ & & $80 \%$ & $89 \%$ \\
lechnologies & & & $100 \%$ & & 13 \\
Total response & 21 & 13 & 8 & 8 & 13 \\
\hline
\end{tabular}

Source: Own calculation based on the firm survey (2002).

Our analysis of the shortage in skilled workers is based on the economic interpretation and definition of 'skilled shortage' as scarcity or lack of sufficient skilled workers needed, mainly because the supply of skills (as shaped by systems of education and training) has not responded fully to the rising demand across firms. However, managers may have a different interpretation and understand this as a lack of sufficient skilled workers in conjunction with wages constraints, due to limitations on their ability to pay higher wages for the high skilled workers they demand. This may constitute a limitation and appropriate caution should be exercised in interpreting our results with respect to skilled shortage, mainly because the firms answered the questionnaires do not really make it very clear bow they have perceived the shortage of skilled workers and their further consequences.

\subsection{The impacts of skill upgrading and technological upgrading: Micro- Macro views}

In view of the above findings and our results in Chapter 2 above on poor skill and technology indicators, it is therefore essential to recommend further incentives to upgrade both skill and technology levels at both micro and macro levels. From that perspective, our findings in Table 5.9 below show that at the micro level the upskilling plan amongst $55 \%$ of the respondent firms induced significant effect in enhancing firm production and facilitating the 
effective uthization and upgrading of technologies. But it has only a slight effect on restructuring the imbalances of labour market via hing more skilled national workers, upskilling national workers in the firm, reducing future demand for foreign workers and reinforcing the employment of national skills. Moreover, technological upgrading induced significant effects in enhancing firm production, raising skill levels and reinforcing firm ability to promote the local technology, but it has only a slight effect on both upskilling and hiring more skilled national workers.

Table 5.9. The effer of wowhing plan and rechnological upgrading across fim in the UAE, 2002* Micro view

\begin{tabular}{|c|c|c|c|c|c|}
\hline $\begin{array}{l}\text { (a) Upskilling plan and its impacts, self-reliance } \\
\text { strategy }\end{array}$ & $\begin{array}{l}\text { All } \\
\text { firms }\end{array}$ & Chemical & Metal & Medium & Large \\
\hline General Upskilling plan & $55 \%$ & $48 \%$ & $65 \%$ & $47 \%$ & $63 \%$ \\
\hline Upskilling plan specially for national workers & $19 \%$ & $21 \%$ & $17 \%$ & $10 \%$ & $27 \%$ \\
\hline $\begin{array}{l}\text { Self-reliance strategy: Special training programs } \\
\text { for upskilling national workers }\end{array}$ & $52 \%$ & $59 \%$ & $42 \%$ & $40 \%$ & $64 \%$ \\
\hline Self- reliance on national skills & $15 \%$ & $17 \%$ & $13 \%$ & $11 \%$ & $20 \%$ \\
\hline \multicolumn{6}{|l|}{ (b) The effect of general upskilling on } \\
\hline Enhancing firm production & $96 \%$ & $92 \%$ & $100 \%$ & $90 \%$ & $100 \%$ \\
\hline $\begin{array}{l}\text { Facilitating effective urilization and upgrading of } \\
\text { technologies }\end{array}$ & $73 \%$ & $61 \%$ & $87 \%$ & $67 \%$ & $80 \%$ \\
\hline Hiring more skilled national workers. & $48 \%$ & $62 \%$ & $33 \%$ & $50 \%$ & $47 \%$ \\
\hline Upskilling national workers in the firm. & $48 \%$ & $54 \%$ & $42 \%$ & $50 \%$ & $47 \%$ \\
\hline Redwaing future demand for foreign workers. & $52 \%$ & $58 \%$ & $44 \%$ & $40 \%$ & $64 \%$ \\
\hline $\begin{array}{l}\text { Reinforcing the employment of national skill } \\
\text { workers. }\end{array}$ & $36 \%$ & $33 \%$ & $40 \%$ & $33 \%$ & $40 \%$ \\
\hline \multicolumn{6}{|l|}{ (c) The effects of technological upgrading in: } \\
\hline Enhancing firm production & $89 \%$ & $90 \%$ & $88 \%$ & $89 \%$ & $90 \%$ \\
\hline Raising skill level & $79 \%$ & $81 \%$ & $76 \%$ & $78 \%$ & $80 \%$ \\
\hline $\begin{array}{l}\text { Reinforcing firm ability to promote the local } \\
\text { technology }\end{array}$ & $68 \%$ & $62 \%$ & $76 \%$ & $61 \%$ & $75 \%$ \\
\hline Total response & 38 & 21 & 17 & 18 & 20 \\
\hline Upskilling national workers in the firm. & $45 \%$ & $47 \%$ & $43 \%$ & $40 \%$ & $50 \%$ \\
\hline Hiring more national skill workers. & $48 \%$ & $58 \%$ & $36 \%$ & $33 \%$ & $61 \%$ \\
\hline Total response & 25 & 13 & 12 & 10 & 15 \\
\hline
\end{tabular}

Source: Own calculation based on the firm survey (2002).

At the micro level, Figure 5.2 below compares the plans of public and private firms to depend on national skils. It predicts a great disparity between private and public firms that appears from the potentiall strong commitment to rely on national skills in the short, medium and long run plans in the large public firm. While our results from the firm survey and Figure 5.2 below show that managers of private firms have a somewhat pessimistic view regarding the self-reliance on local skills and the potential role of both technological upgrading and upskilling in reinforcing the self-reliance strategy. For instance only $19 \%$ of the respondent firms provide special training programmes for upskilling national workers and only $15 \%$ of the respondent firms have plans to rely on national skilled workers even in restricted fields. Amongst all the respondent private firms the plan for depending on the national skills over the long run will not exceed $20 \%$ of the total skilled workers. 
Figure 5.2- Short, mediun and long run plans of self-reliance on national skills across wublic and private finms

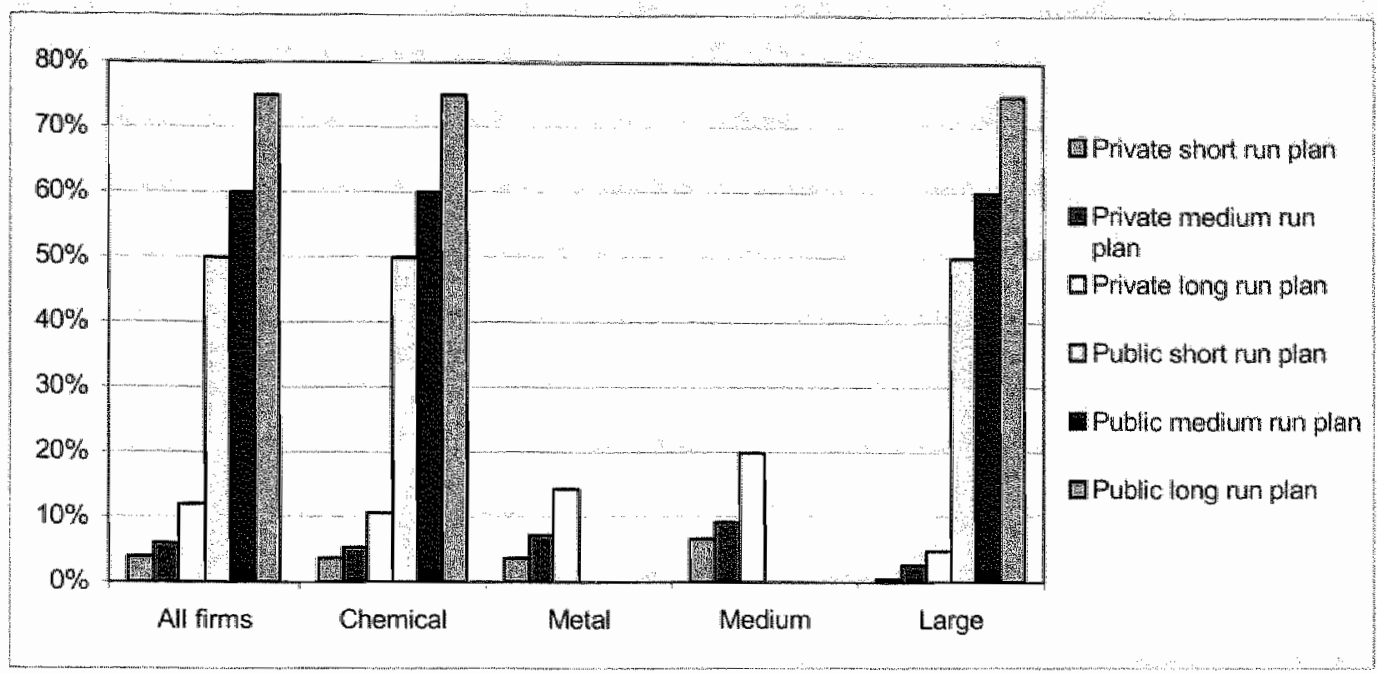

Source: Firm survey (2002)

In strong contrast to the above view, the macro survey shows that the respondent policy makers and experts are highly optimistic regarding the interactions between technological upgrading and upskilling and their roles in reinforcing economic growth, self-reliance on locall skills and restructuring the labour market at the aggregate/ macro level. For instance, Table 5.10 below shows that all the respondent policy makers and experts predict strong linkages between both upgrading of technollogy and upskilling of labour force to reinforce each other and to have a similar effect on reinforcing the self-reliance strategy and reducing unemployment rate. The official view predicts that the effect of upskilling is stronger than the effect of technological upgrading in both reinforcing economic growth and solving the imbalances in the labour market and so reducing the future demand for foreign skilled workers.

Table 5.10 - The effects of technological upgrading, skill upgrading at the aggregate level in the UAE, 2002: Macro view

\begin{tabular}{|c|c|c|c|}
\hline The effects of technological upgrading & $\%$ & The effeets of skill upgrading & $\%$ \\
\hline Enhancing / accelerating upskilling. & $100 \%$ & $\begin{array}{l}\text { Enhancing/accelcrating technologicul up- } \\
\text { grading }\end{array}$ & $100 \%$ \\
\hline Increasing/reimforcin & \multirow{4}{*}{$\begin{array}{l}96 \% \\
89 \% \\
86 \%\end{array}$} & Increasing/reinforcing economic growth. & $100 \%$ \\
\hline Reinforcing self-reliance strategy. & & Reinforcing self-reliance strategy. & $89 \%$ \\
\hline $\begin{array}{l}\text { Solving the imbalances in the labour } \\
\text { market: Reducing the future demand for } \\
\text { foreign skilled workers. }\end{array}$ & & $\begin{array}{l}\text { Solving the inbalances in the labour market: } \\
\text { Reducing the futture demand for foreign } \\
\text { skilled workers. }\end{array}$ & $93 \%$ \\
\hline Reducing unemployment rate. & & Reducing unemployment rate. & $82 \%$ \\
\hline
\end{tabular}

Source: Own calculation based on the macro survey (2002)

This contradicting optimistic-pessimistic views at the macro and micro levels, regarding the self-reliance on local skills and the role of both technollogy and upskilling in reinforcing it, imply that the self-reliance strategy is probably a preferred government strategy, but not necessarily favoured by firms. This is consistent with the observation that $96 \%$ of the re- 
spondent firms are private fimms dominated by foreign workers and probably lack the incentives/nterests to rely on national workers, mainly due to low skill and high salary requirements - see also our earlier discussion in Chapter 2 above. The respondent firms, which are costs minimizers/profits maximizers, are probably willing to continue hiring cheap readymade skilled foreign workers instead of hiring, training and upskilling expensive national workers.

\section{3 Conclusions}

This chapter uses the results of the macro and firm surveys to show the interaction between the deficient educational system and the high incidence of unskilled foreign workers and their implications.

Our results confirm a part of the second hypothesis in Scheme 1.1 Chapter 1 above: that in the short and medium term, the Gulf countries are unable to rely on local skills and local technologies and remain heavily dependent on both foreign skills and foreign technologies at the micro level. The major reasons are low levels of both skill and technology due to the deficient educational system and the high incidence of unskilled foreign workers and their implications.

On the one hand, from the demand perspective, the results of the firm survey can be used to argue that firm demand for low skilled workers, weak technology indicators and dependency on foreign technology led firms to demand and rely heavily on low skilled workers. On the other hand, from the supply perspective, our findings in Section I show that the deficient educational system - due to low quality of education - and the excessive share of unskilled foreign workers led to low skill levels, poor provision of training, serious skills mismatch, weak linkages, lack of a networks and hindered the transfer of knowledge. These factors interacted with each other and led to poor technology indicators, poor indigenous capability to build the local technology and a heavy dependence on foreign technology. These results prove hypotheses $3 . \mathrm{a}-3 . \mathrm{b}$ in Scheme 1.1 in Chapter $\mathbb{l}$ above concerning the low skill and technology indicators at the micro-macro levels: the serious implications of the interaction between the causes and consequences of the deficient educational system and the high use of unskilled foreign workers. We confum hypothesis 3.c. in Scheme 1.1 in Chapter I above that the major causes of low level of local technology are low/ a lack of R\&D activities due to a lack of skils, transfer of knowledge, networks and collaborations between universties and industry/firms.

Our findings show two surprising contradicting macro-micro views. The first contradicting optimiste - pessimistic micro and macro views regarding the incidence and success of knowledge transfer external schooling effect implies that probably the transfer of knowledge/ the external effects of schooling is successful within firms but is unsuccessful within society at large. This is probably because the transfer of knowledge is hindered by: low quality of education; the weak linkages and lack of networks between universities, colleges, technical and training institutes and the productive sectors; and the imbalanced structure of population and labour market. We show that the major cause behind the low transfer of knowledge/external schooling effect is low educational qualifications, and deficient educational and training systems. The major consequences are the lack of networks and collaboration between universities and firms, low R\&D efforts and low technology indicators. These results prove part of the sixth hypothesis in Scheme 1.1 in Chapter 1 above with respect to the failure and the factors hindering the transfer of knowl- 
edge/external schooling effect at the macro level. But, on the other hand, our findings surprisingly reject a part of the sixth hypothesis in Scheme 1.1 in Chapter 1 above concerning the failure of the transfer of knowledge/external schooling effect at the micro level.

Our observation of the second contradicting optimistic-pessimistic macro and micro views concerning the self-reliance on local skills, and the role of both technological upgrading and upskilling in reinforcing it, implies that the self-reliance strategy is probably a preferred government strategy, but is not necessarily one followed by private firms. Driven by profit-maximizing considerations, private firms are likely to continue in hiring cheap readymade skilled foreign workers rather than hiring, training and upskilling expensive national workers. From these observations, our results reject hypothesis 8.c. in Scheme 1.1 in Chapter 1 above about the consistency of upskilling and transfer of knowledge at the macro-micro levels. 


\section{Chapter 6}

\section{Relationship between Skill, Technology and Input-Output Indicators}

\section{Introduction}

Earlier findings in Chapter 5 show the serious implications of the deficient educational system and excessive use of low educated workers, and illustrate two surprising contradicting macro-micro views regarding the transfer of knowledge/external schooling effects and upskilling plans. These surprising results from Chapter 5 motivate our research to attempt a more comprehensive analysis of skill problem and implications of unskilled foreign workers at the micro level/across private firms. Hence, the aim of this chapter is to broaden our earlier analysis in Chapter 5 by providing an in-depth analysis of skill and technology indicators and the relationship between them and the implications of the prevalence of low-skilled foreign workers at the micro level. In addition, we examine the relationships between; skill indicators (education/actual education and occupation/required education respectively and experience) and average wages; between skill, upskilling (spending on ICT training) and technology (spending on JCT); and between technology (spending on ICT) and input-output indicators across firms. We also compare the relevance of our results to the theoretical framework in Chapter 3 and the findings concerning these relationships in the new growth literature.

The rest of this chapter is organized as follows: Section 1 defines the variables used in our analysis and the general characteristics of firms. Section 2 presents our hypotheses and discusses differences in prevalent skill levels and requirements and the implications of low skill levels on skills mismatch, public-private duality and productivity decline across private firms. Section 3 examines the relationships between actual and required education, experience and wages. Section 4 shows the relationships between skill, technology (spending on ICT) and upskilling (spending on ICT training) and between technology (ICT) and input-output indicators. Section 5 concludes.

\section{1. Data, definition of variables and general characteristics of firms}

Before commencing with the empirical analysis, it will be useful to briefly explain the data used in our analysis and the general characteristics of firms. 


\subsubsection{Data and definition of variables ${ }^{123}$}

Our analysis in this chapter uses the data from the firm survey (2002), which provides us with three sets of micro variables. The first set includes skill variables, while the second and third sets include both technology and input-output related variables respectively. We define skill variables by educational attainment, occupational level (measured by the required qualifications/schooling years) and average years of experience. ${ }^{124}$ We use the total spending on ICT ${ }^{125}$ to define "technology", the share of spending on ICT training as a percentage of total spending on ICT to define "upskilling", total sales value to define "output", total profit to define "performance", total employment and net worth to define "labour" and "capital" inputs, respectively. ${ }^{126}$

We use the first set of skill variables in Section 2 to discuss hypotheses 3.b and 4.a. in Scheme 1.1 Chapter 1 above regarding the implications of unskilled foreign workers across firms. We use input-output indicators to illustrate the decline in productivity, output/labour and capital/labour ratios. Next, in Section 3, we test hypothesis 4.b. in Scheme 1.1 Chapter 1 above about the relationships between actual and required education and experience and wages. In Section 4, we use the first and second sets of variables including skill, ICT and the share of spending on ICT training to test hypothesis 4.c. in Scheme 1.1 Chapter 1 above regarding the relationship between skill, technology (ICT) and upskilling. Next, we use the second and third sets of technology and input-output variables to test the fifth hypothesis in Scheme 1.1 Chapter 1 above about the relationship between technology (ICT) and input-output indicators. ${ }^{12}$

\subsubsection{General characteristics of firms}

Table 6.1 presents the main general characteristics of firms and economic indicators such as the share of firms in total employment, capital, profit and output (total sales value), and

${ }^{123}$ All data, information and analysis in this chapter are based on the results covering 26 firms obtained from the firm survey (2002).

${ }_{124}$ We classify the educational qualifications of workers into three groups: high skilled $(\mathrm{H})$ with postgraduate. university and diploma degree (more than welve years of schooling), medium skilled (M) with secondary education (twelve years of schooling) and low skilled (L) with less than secondary education (less than twelve years of schooling). We define the oceupational status according to five categories, including white-collar high (managers, professionals, management executives, scientists, technicians and engineers); white-collar low (clerical and administrative); blue collar high (skilled craftsmen); blue-collar low (plant machinery operators, assemblers and elementary occupationj and other workers. We define the required qualifications by required years of schooling including: postgraduate/ Ph.D. (19-20 years); professional, MSc/ postgraduate (18 years); university graduate (16 years); diploma (14 years); higher secondary schooling (12 years); and less than secondary schooting (less than 12 years). We measure the average wages by average monthly wages (in Dirhams, the UAE national currency), and average years of experience by both actual and required average years of experience for both educational and occupational definition respectively.

125 ICT is the sum of total expenses on computers, telecommunications, training, maintenance and other related items.

126 We measure output by the total sales value because the messurement units of sales value is unified (in local currency) across firms, while the measurement units of output in physical terms (tonne, litre, etc.) varies across firms.

${ }_{127}$ We use few observations in the estimated equations, due to limited availability of reliable dlata covering these indicators, because some of the respondent firms were particularly reluctant to provide adequate reliable quantitative data covering these indicators. 
their differences defined by firm size and industry level. We observe that the market size or structure - defined by the share in total employment, capital, output (total sales value) and profit - seems biased toward large size and chemical firms. For instance, on average, the large size and chemicall firms respectively employ $89 \%$ and $75 \%$ of total workers, absorb $92 \%$ and $87 \%$ of total capital, and constitute $93 \%$ and $89 \%$ of total output (total sales value) and $71 \%$ and $56 \%$ of total profit. These differences in market size leads to several implications, as we explain below and in the next sections.

From Table 6.1 we observe the limited contribution of public sector and high share of private sector in the chemical and metal industries. We also note the high share of local ownership and also a considerable share of foreign and mixed ownership, which implies the dependency on foreign capital and foreign workers. But despite the presence of foreign capital, there is limited contribution of multinational companies; however, such contribution is diversified as the sources of foreign capital of multinational companies originate from different countries and increases with industry level, but decreases with firm size. We also observe limited changes in the general structure of firms during the period 1999-2001, which may indicate a lack of dynamism, particularly with respect to the distribution of economic indicators, i.e. total employment, capital and output/sales value across firms. The reported change since establishment and in ownership, nationality of main owner and length of year in operation (age) vary across firms and generally are increase with firm size and industry level. In addition, the geographical distribution of firms indicates that most of firms are clustered in two main locations and only some have branches in cities other than the main location, though the probability of both clustering and having branches increases with firm size and industry. Moreover, we realize the limited scope for diversification as measured by sales and employment indices across firms. ${ }^{128}$ The average diversification index increases with industry but decreases with firm size: this implies that large size firms have more interest in specialization/concentration, whereas medium size firms have more interest in diversification. As expected, chemical firms reported more interest in diversification than metal firms.

\footnotetext{
${ }^{128}$ We use a modified definition of the diversification index developed by Utton (1979). We define the diversification index by output/ sales diversification $\mathrm{Di}=[\mathrm{P} 1+2 \mathrm{P} 2+3 \mathrm{P} 3+4 \mathrm{P} 4]-1 / 2]$, where $\mathrm{Pi}$ refers to the percentage share of diversified sale product in total sale products within firms. Ranked from large to small, when $\mathrm{Di}=1, \mathrm{Di}=4$ and $\mathrm{L}<\mathrm{Di}<4$, it implies complete specialization, complete diversification and some degree of diversification respectively. We apply the same definition for employment diversification index (cf. Utton, 1979: 15-16, 104-105).
} 
Table 6. - Main characteristics of finms in the UAE (1999-2001)

\begin{tabular}{|c|c|c|c|c|c|c|}
\hline \multicolumn{2}{|c|}{ Main indicators (1999-2001) } & $\begin{array}{l}\text { No. of respondent } \\
\text { firms }\end{array}$ & Chemical & Metal & Large & Medinim \\
\hline \multirow{4}{*}{$\begin{array}{l}\text { Share in employ- } \\
\text { ment }(\%)\end{array}$} & 1999 & 28 & 74 & 26 & 89 & 11 \\
\hline & 2000 & 28 & 75 & 25 & 89 & 11 \\
\hline & 2001 & 30 & 75 & 25 & 89 & 11 \\
\hline & average 19992001 & 28 & 75 & 25 & 89 & 11 \\
\hline \multirow{4}{*}{ Share in capital $(\%)$} & 1999 & 20 & 85 & 15 & 92 & 8 \\
\hline & 2000 & 19 & 88 & 12 & 92 & 8 \\
\hline & 2001 & 19 & 89 & 11 & 92 & 8 \\
\hline & average $1999-2001$ & 19 & 87.3 & 12.7 & 92 & 8 \\
\hline \multirow{4}{*}{ Share in profit $(\%)$} & 1999 & 23 & 39 & 61 & 79 & 21 \\
\hline & 2000 & 22 & 60 & 40 & 68 & 32 \\
\hline & 2001 & 22 & 68 & 32 & 66 & 34 \\
\hline & average $1999-2001$ & 22 & 56 & 44 & 71 & 29 \\
\hline \multirow{4}{*}{$\begin{array}{l}\text { Share in ontput } \\
\text { (total sales } \\
\text { value) }(\%)\end{array}$} & 1999 & 29 & 85 & 15 & 93 & 7 \\
\hline & 2000 & 28 & 92 & 8 & 94 & 6 \\
\hline & 2001 & 28 & 91 & 9 & 93 & 7 \\
\hline & average 1999-2001. & 28 & 89.3 & 10.7 & 93.3 & 6.7 \\
\hline $\begin{array}{l}\text { Share in spending } \\
\text { on } 1 C T(\%)\end{array}$ & Average 1999-2001 & 26 & 76 & 24 & 98 & 2 \\
\hline $\begin{array}{l}\text { Share in spending } \\
\text { on ICT tranning }(\%)\end{array}$ & Average 1999-2001 & 14 & 94 & 6 & 98 & 2. \\
\hline $\begin{array}{l}\text { Share of private } \\
\text { firms }(\%)\end{array}$ & 2001 & 40 & 92. & 100 & 92 & 100 \\
\hline \multirow{2}{*}{$\begin{array}{l}\text { Share of ownership } \\
(\%)\end{array}$} & Local-2001 & 34 & 70 & 69 & 75.2 & 61.3 \\
\hline & Foreign- 2001 & 22 & 30 & 31 & 24.8 & 38.7 \\
\hline \multirow{3}{*}{$\begin{array}{l}\text { Share of main } \\
\text { owners }(\%)\end{array}$} & Local -. 2001 & 19 & 48 & 37 & 58 & 25 \\
\hline & Foreign -2001 & 13 & 32 & 26 & 25 & 35 \\
\hline & Mixed - 2001 & 12 & 20 & 37 & 17 & 40 \\
\hline $\begin{array}{l}\text { Affiliation to multi- } \\
\text { national }\end{array}$ & 2001 & 43 & 27 & 5 & 17 & 19 \\
\hline $\begin{array}{l}\text { Change after estab- } \\
\text { lishment }\end{array}$ & 2001 & 23 & 35 & 16 & 29 & 24 \\
\hline \multirow{3}{*}{ Main location $(\%)$} & Abu Dhabi - 2001 & 3 & 4 & 11 & 13 & 0 \\
\hline & Dubai- 2001 & 20 & 46 & 42 & 38 & 52 \\
\hline & Sharjah-2001 & 22 & 50 & 47 & 50 & 48 \\
\hline $\begin{array}{l}\text { Branches other than } \\
\text { main location }(\%)\end{array}$ & 2001 & 20 & 46 & 42 & 46 & 43 \\
\hline $\begin{array}{l}\text { A verage age/ opera- } \\
\text { tion years }\end{array}$ & 2001 & 43 & 17.7 & 15.6 & 18.9 & 14.4 \\
\hline \multirow{2}{*}{$\begin{array}{l}\text { Average rate of } \\
\text { diversification }\end{array}$} & Sales -2001 & 33 & 1.58 & 1.5 & 1.52 & 1.57 \\
\hline & Employment - 2001 & 27 & 1.35 & 1.3 & 1.2 & 1.5 \\
\hline
\end{tabular}

Notes: (1) All indicators are calculated from the firm survey (2002); some refer to observations over only one year (2001) and ofhers use observations over 3 years (1999-2001). (2) Some of the respondent firms reported a mixed share of local and foreign ownership. (3) Change after establishment refers to changes in ownership, management and structure (e.g. expansion; opening new branches or merger with other firms).

Sources: Firm Survey (2002)

\section{2 Differences in skill level and requirements and the implications across firms}

Our earlier findings in Chapter 5 indicate that the share of high skilled workers in total employment, the number of full time equivalent researchers, R\&D and ICT expenditure, patent, product and process innovations are higher within large size and chemical firms when 
compared to medium size and metal firms. Our result with respect to $R \& D$ and chemical sector is consistent with the standard classification developed by the OECD in the mid1980 s, which distinguishes between industries in terms of R\&D intensity (cf. OECD, 1997). For instance, in the mid-1980s, the OECD classification distinguished between industries in terms of R\&D intensity, considering pharmaceutical and ICT as high-technollogy, chemical and vehicle as medium-technology and food and textile as low technology (cf. $O E C D$, 1997). Our findings with respect to firm size are consistent with the literature and the Schumpeterian hypothesis, which indicate that large size/market concentration is conducive to R\&D investment (cf. Braga and Willmore, 1991). For instance, Kumar and Saqib (1994) suggest that the probability of undertaking R\&D increases with firm size only up to certain Jevel, while R\&D intensity increases with it linearly. However, one should also expect that these results could imply a possibility for reversed causality, mainly because $R \& D$ is a fixed cost that requires high financial capacity, which is most likely to be strong amongst large size firms.

In addition to earlier findings, we observe that skill levels and requirements (actual and required education and experience) and skills mismatch are not homogenous across firms and vary with industry and size. As we explained in Section 2, these findings can be used to test the first hypothesis that, irrespective of these differences, high skill requirements and low skill levels - due to high share of unskilled foreign workers - lead to skills mismatch, public-private duality and contribute to the productivity decline across private furms. In Sections 3 and 4, we then examined the second hypothesis that an increase in skill levels and firm size lead to improved relationships between actual and required education and experience; between actual education, experience and wages; and between skill, upskilling and technology (ICT). Finally, in Section 4, we also investigated the third hypothesis concerning the relationships between technology (the use of ICT) and input-output indicators at the micro/firm level.

\subsubsection{Differences in skill level and requirements (education and experi- ence) across firms}

Prior to investigating the first hypothesis on the extended implications of low skill levels as presented above, it is convenient to begin with explaining differences in skill levels and requirements across firms because understanding why and how they vary with industry and firm size can help in investigating both the first and second hypotheses.

In Figures $6.1-6.3$ below we explain differences in skill levels and requirements and low skill levels - defuned by education and occupation groups - across firms defined by size and industry. ${ }^{129}$ Figures 6.1 and 6.2 show the low share of high skilled - high educated and white-collar - workers, differences in skill levels according to education and occupation definitions and differences across firms. For instance, Figure 6.1 indicates that for $50 \%$ of all respondent firms, the share of high skilled (educated) represents $1-30 \%$ of total employed workers. For a further $40 \%$ of all respondent firms, the share of high skilled (educated) represents $31-50 \%$ of total employed workers, but for the remaining $10 \%$ the share is

\footnotetext{
${ }^{129}$ In Figures 6.1-6.3, the horizontal axis defines firms, industry, size (chemical/metal, large/medium), and skill level (high $(H)$, medium $(M)$ and low $(\mathrm{L}))$. The vertical axis defines the intensity/share of $\mathrm{H}, \mathrm{M}$ and $\mathrm{L}$ across firms. The information in the right margin defines the distribution of workers in Figures $6.1-6.2$, and the average required years of education in Figure 6.3.
} 
more than $50 \%$ of the workforce. Figure 6.2 shows, for example, that for $88 \%$ of all respondent firms, the share of white collar (WC) represents 1-30\% of total employed workers, for $4 \%$ of all respondent firms the WC share is $31-50 \%$ and for $8 \%$ the figure stands at $50 \%$ of total employed workers. The results show that the incidence of high educated and whitecollar workers constituting more than half of total employment is observed only within $10 \%$ and $8 \%$ of all respondent firms respectively. They also indicate that the share of high skilled - measured by education - is less than one third of total workers for $50 \%$ of all firms and the share of high skilled - white-collar measured by occupational level - is less than one third of total workers for $88 \%$ of all firms. That means that across all firms the share of high educated and white-collar respectively are less than one third and two thirds; therefore, the majority of employed workers are low and medium skilled.

Figuwe 6.1 Differences in the distribution of workers by educational lewel across firms (\%o share) 2001

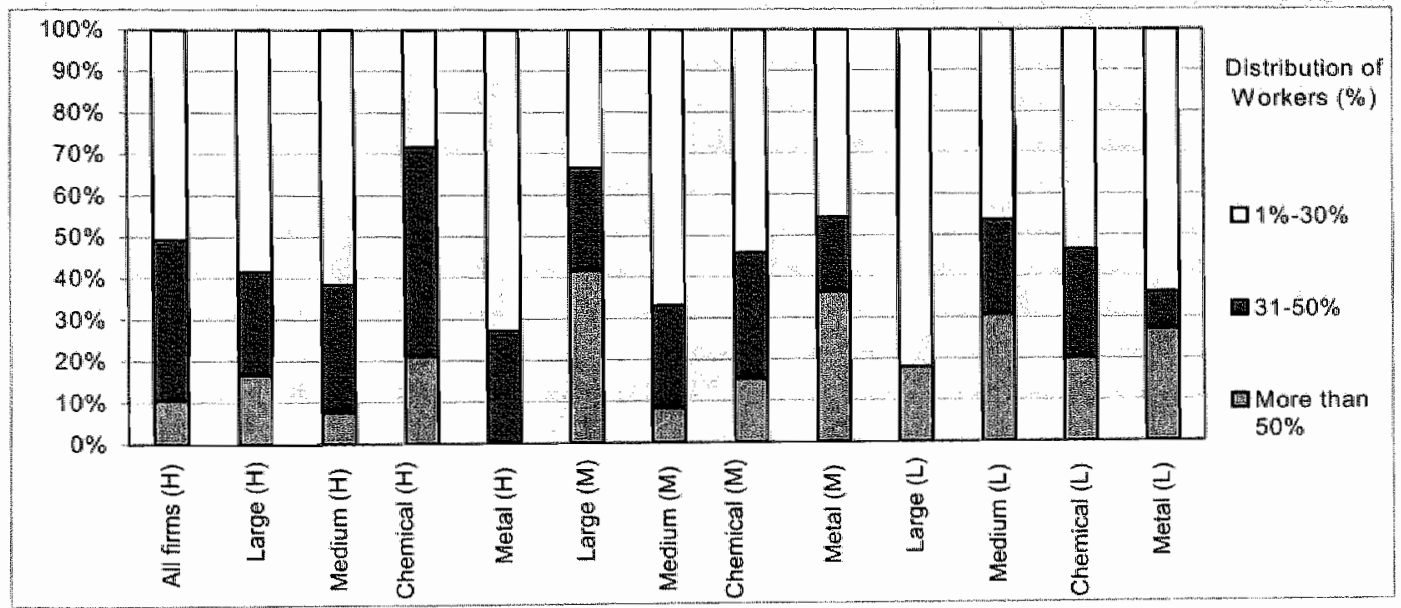

Source: Firm Survey (2002)

Figure 6.2 Differences in the distribution of workers by accuparional level across firms (\% whare) 2001

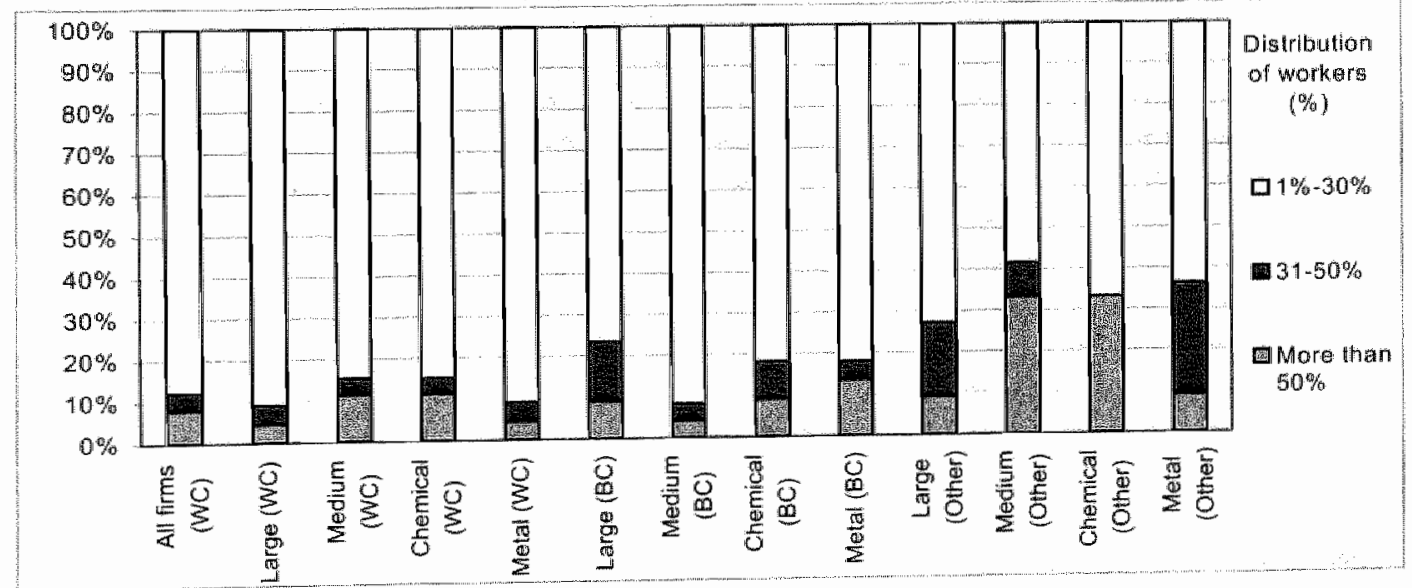

Source: Firm Survey (2002) 


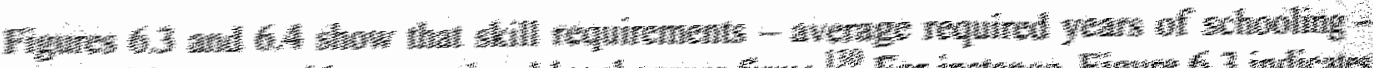

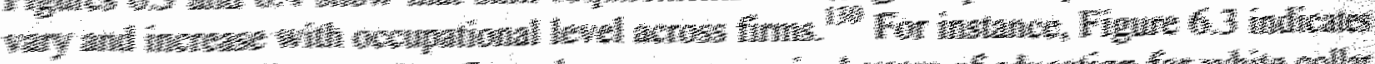

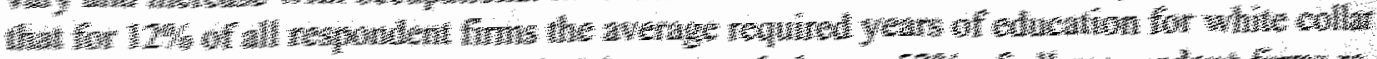

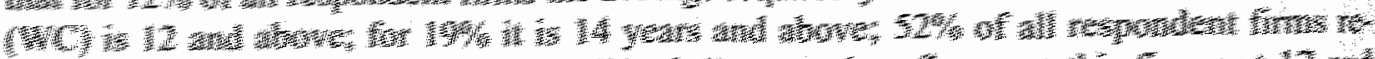

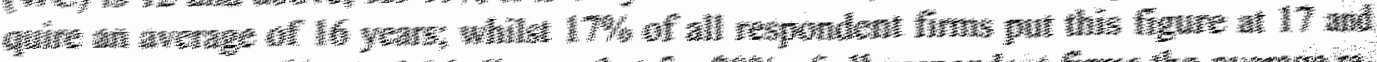

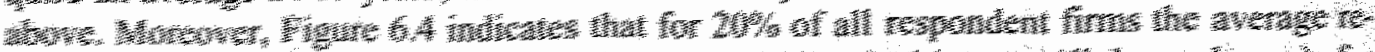

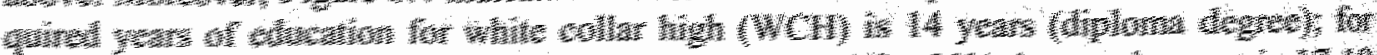

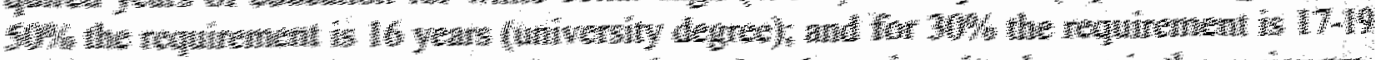

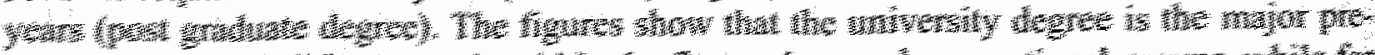

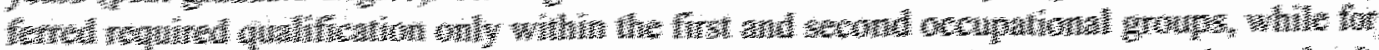

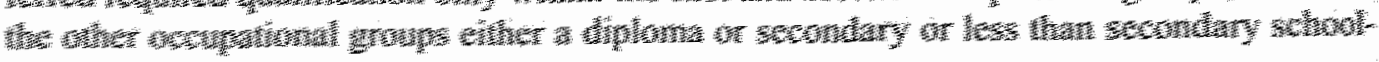

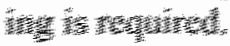

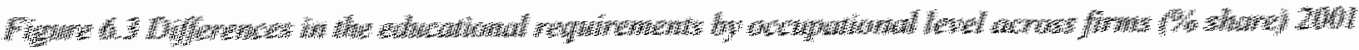

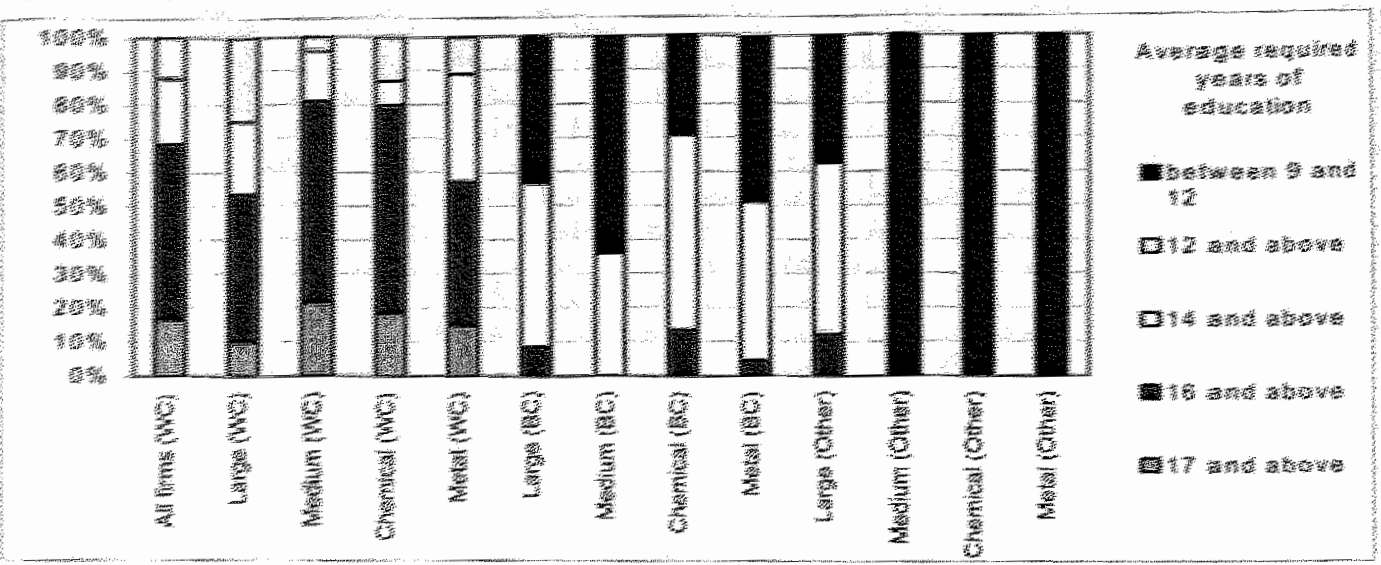

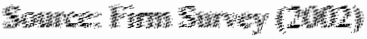

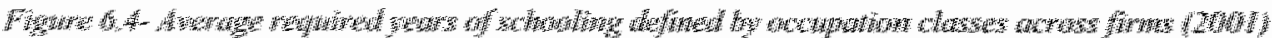

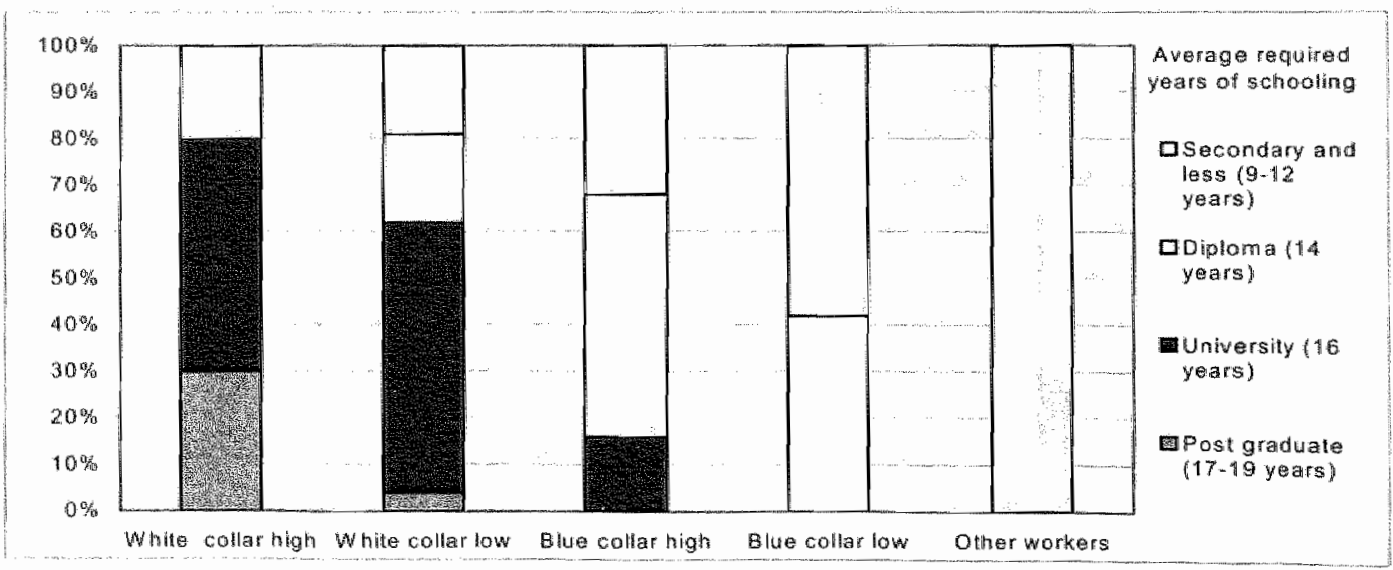

Sounce: Firm Survey (2002)

${ }^{130}$ White collar (WC) includes white collar high and low. Blue collar (BC) includes blue collar high and low. 
Figure 65 below indicates the variation in skill requirements (required years of expenience), defined by educational and occupational levels. For instance, for $8 \%$ of all respondents firms the average required years of expenience for white collar high $(W C H)$ is $5-10$ years: for $64 \%$ the experience requirement stands at $10-15$ years; and for $28 \%$ the figure is $15-20$ years. Figure 6.5 illustrates that average years of experience are increasing in educational and occtpational levels respectively. In the next section, we explain the relationships between required education/ actual education; occupation/required education; and experience and wages across firms.

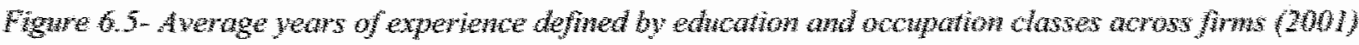

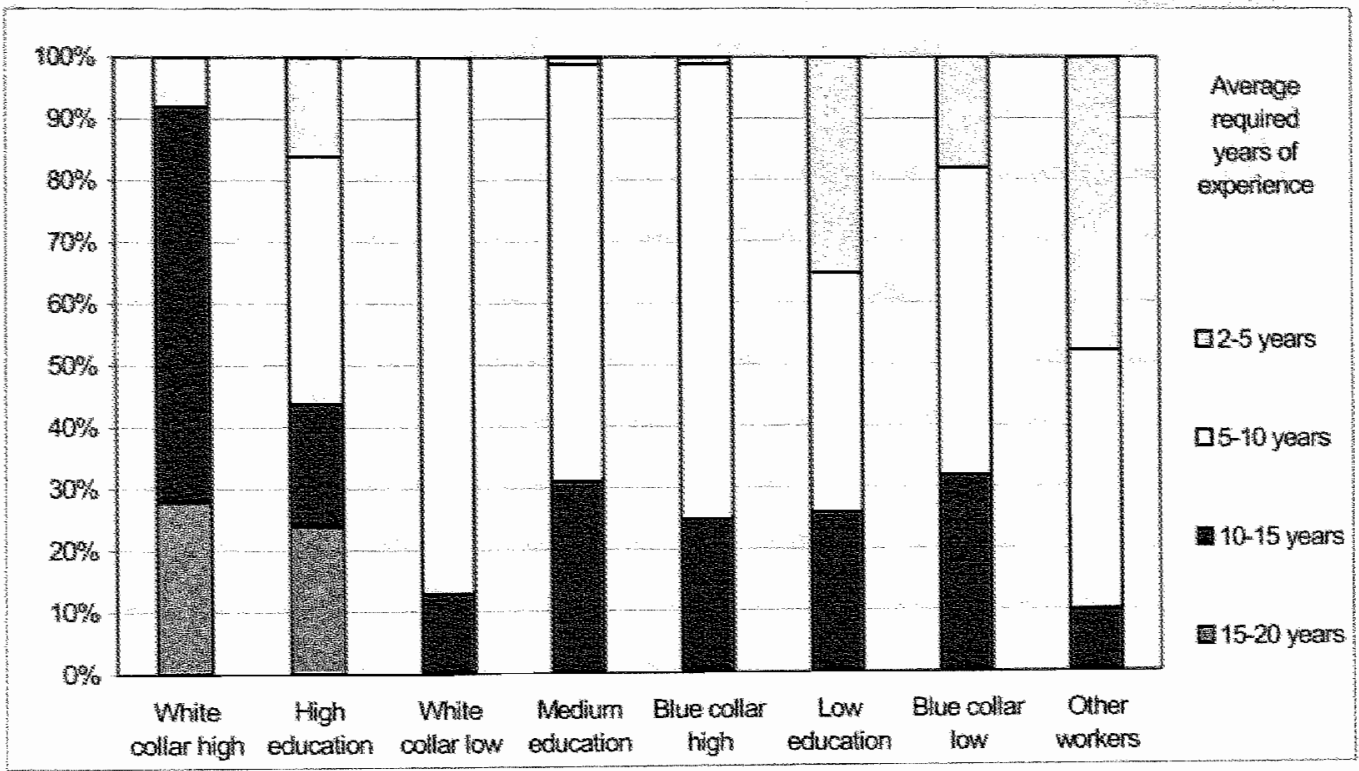

Sources: Fim Survey (2002)

\subsubsection{The implications of low skill levels across private firms}

In this section we examine the first hypothesis that, irrespective of the observed differences in skill levels and requirements and as we explained above, the low skill levels - due to high share of unskilled foreign workers - lead to skills mismatch, public-private duality and probably contribute to productivity decline across private firms.

\section{a. \\ Low skill levels and skills mismatch (differences in required and at- tained education)}

When comparing the required schooling with the actual/attained schooling, we find that differences in schooling requirements across firms have caused considerable variations between the required and actual/attained schooling for high, medium and low skilled groups. When we interpret the required schooling as the demand for skills and the actual/ attained schooling as the supply of skills, we observe that the inconsistency between the required and actual/attained schooling indicates an inconsistency between the demand for 
and supply of skills, which can be interpreted as skills mismatch. ${ }^{131}$ For instance, Figure 6.6 below illustrates the differences between the required and actual/ attained schooling across firms defined by firm size and industry level and skill levels. We observe that the inconsistency between the demand for and supply of skills, or skills mismatch, is particularly higher/ serious within both medium and low skilled groups respectively and across large and metal firms respectively. We find mismatch amongst all employment categories, especially within both medium and low skilled labour: for instance, we observe that for all firms, on average, the intensity of mismatch for high, medium and low skill groups accounts for $29 \%, 72 \%$ and $66 \%$ respectively. This implies that the educational attainment amongst medium skilled labour does not match the required skills/educational level for medium skilled jobs across approximately more than $70 \%$ of total respondents firms. The mismatch is highest for medium skills, probably because of both insufficient educational attainment and high educational requirements for medium skills - see Figure 6.3 above. Moreover, the intensity of mismatch is more prevalent across large size and metal firms compared to medium size and chemical firms. For instance, for metal firms, on average the mismatch intensity for high, medium and low skill groups accounts for 30\%,75\% and $71 \%$ respectively, while for large size firms the figures are $36 \%, 83 \%$ and $73 \%$ respectively. Hence, our results in this section concerning the presence of serious skills mismatch due to the excessive share of unskilled foreign workers at the micro level are consistent with our earlier findings in Chapter 5 above, which indicates the presence of serious skills mismatch at the macro level.

\footnotetext{
131 Our definition of actual education refers to educational attainment classified under three groups: high (post secondary) educational attainment: university degree and above (16 years of schooling); medium educational attainment: secondary education ( 12 years of schooling); and. low educational attaimment: less than secondary education ( 9 years of schooling). We define the required education by the translated merged required qualifications for each occupation group defined by average years of schooling. The occupational classification includes the following five categories/groups: (1) Managers, professional, management executive, scientific, technical and engineers; (2) Clerical and administrative; (3) Skilled craftsmen; (4) Plant machinery operators, assemblers and elementary occupation; and ( 5 ) Other workers. We translate the required qualifications associated with each occupational class into average years of schooling and group them in the following way. (1) PhD/postgraduate (19-20 years); (2) Professional, MSc/ postgraduates (18 years); (3) University graduate (16 years); (4) Diploma (14 years); (5) Higher/Secondary Schooling (12 years) and (6) Less than Secondary Schooling ( 9 years). We then merge the required qualifications into three groups, assuming that the high occupation group includes both the first and second occupation categories, the medium occupation group includes both the third and fourth occupation categories and, finally, the low occupation group includes the fifth occupation category. We then use this definition to compare between the required education for each occupation class and actual/ attained education, and we assume that the difference between these indicates the presence of skills mismatch between jobs requirements and educational attainment.
} 


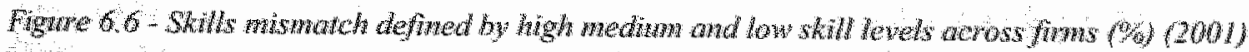

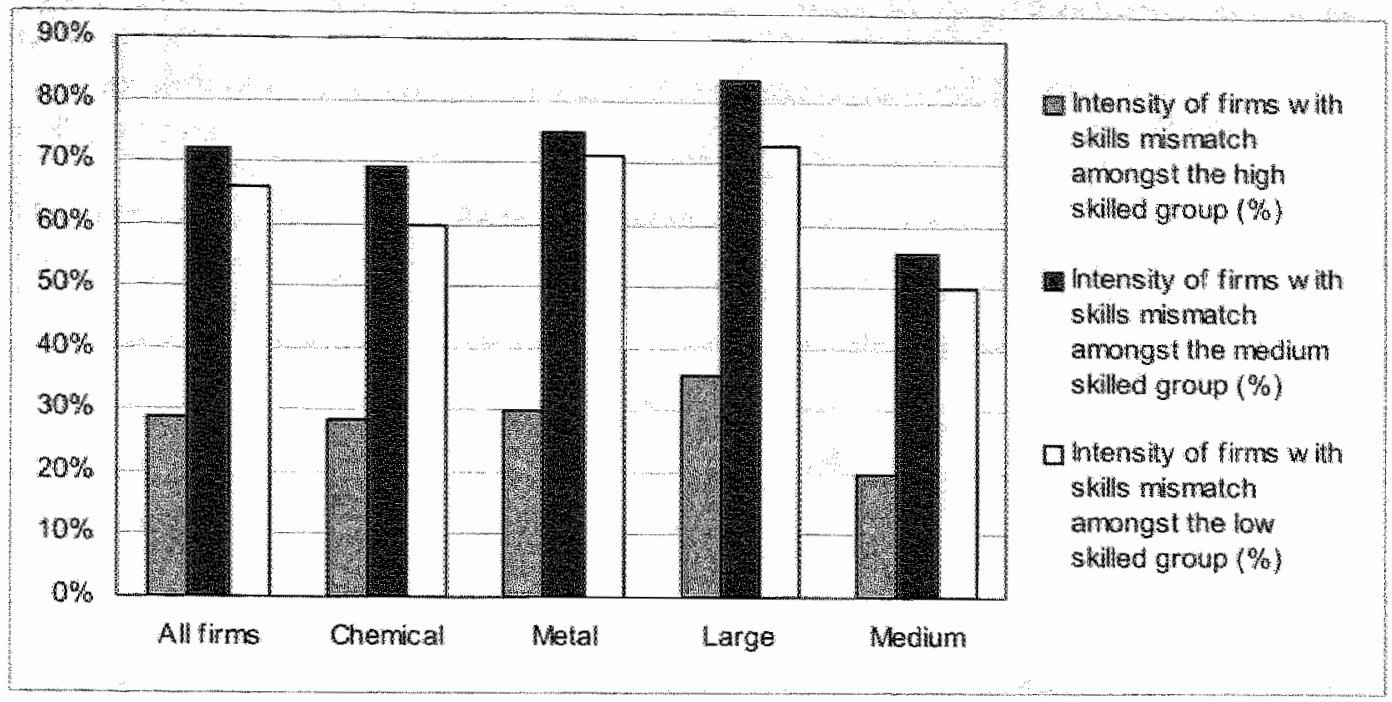

Sowce: Fim Survey (2002)

b.

Low skill levels and public-private duality within oil/chemical industwy

The low skill levels not only lead to skils mismatch across private firms, but probably also have an impact on public-private duality. For instance, when comparing two cases of large public and medium private fims active in the oll/chemical industry, our findings in Table 6.2 Iustrate several aspects of the public-private duality at the micro level. The observed duaty appears from skil indicators: the share of high silled workers in total employment; the average years of experience, defned by education and occupation levels; and the distributon of average wages, which are lower in the medium private compared to large publc firm. Moreover, the low skill levels in the medium private firm when compared to the large public firm are accompanied by further discrepancies in the trend of labour productivity and sales diversification. Over the period 1999-2001 the labour productivity shows an increasing trend in the large public firm, but an opposite declining trend in the medium private firm. These results are consistent with our earlier findings in Chapter 5 , which implies a public-private and macro-micro duality with respect to both upskilling efforts and the transfer of knowledge; our findings are also consistent with the findings in the Gulf literature (cf. Gray, 1999; Khorshid, 2000; Abdelkarim and Haan, 2002). Table 6.1 above shows the limited contribution of the public sector in the chemical industry in our sample; therefore, one can assume that the low skill and respective implications of private firms probably refect the dominant trend, at least across the respondents and chemical fums in particular.

Furthermore, our results from the firm survey - not reported in Table 6.2 below indicate that the low skill levels occurred along with low spending on ICT in the medium private firm compared to the large public firm. Our findings indicate a higher technology level (spending on ICT) and upskilling (ICT training) along with higher skill levels in the large public firm compared to the medium private firm. These results are plausible in view of the complementary relationships between skill, technology and upskilling -- see our dis- 
cussion below. One should also note the large swings in computers, telecommunication and training expenses. The substantial decline in total ICT expenses over the period 1999-2001 is probably due to a lack of plans for critical expansion in ICT sector or a general decrease in total spending across all firms. Another interpretation for the big decline in these components in the large public firm is probably related to a change in the strategy of the firm, which may have already established a sound basis for these components and probably. needed to shift priority to increase spending on maintenance and other items. The explanation for the substantial decline in total expenses on computers in the private medium firm can be attributed to the big decline in total ICT expenses and probably to the need to shift priority to increase expenses on training.

Table 6.2-Public-private dualty: differences in skill indicators, diversification and productivity (1999-2001) (\% and Dirhams

\begin{tabular}{|c|c|c|c|c|c|c|}
\hline Sector & \multicolumn{2}{|c|}{ Public large } & \multicolumn{4}{|c|}{ Private medium } \\
\hline a. Skill indicators (20011) & High & Medium & Low & High & Medium & Low \\
\hline $\begin{array}{l}\text { Share of high skilled workers in total } \\
\text { employment (education definition) (\%) }\end{array}$ & 0.885 & 0.115 & 0 & 0.34 & 0.25 & 0.41 \\
\hline $\begin{array}{l}\text { Share of high skilled workers in total } \\
\text { employment(occuparion definition) (\%) }\end{array}$ & 0.82 & 0.155 & 0.025 & 0.27 & 0.10 & 0.63 \\
\hline Experience (education defintition) & 18.5 & 7 & $\mathrm{n} / \mathrm{a}$ & 12 & 11 & 12 \\
\hline Experience (occupation definition) & 10.75 & 0 & 5 & 11.5 & 7 & 10 \\
\hline Wages (education definition) (Dirharns) & 11850 & 3662.5 & $\mathrm{Na}$ & 1280 & 768 & 512 \\
\hline $\begin{array}{l}\text { b. Labour productivity (output/labour) } \\
\text { and Sales diversification (1999-2001) }\end{array}$ & 1999 & 2000 & 2001 & 1999 & 2000 & 2001 \\
\hline $\begin{array}{l}\text { Labour productivity (output/labour) } \\
(1999-2001)\end{array}$ & $0.102^{\mathrm{i}}$ & $0.111^{2}$ & $0.113^{i n}$ & $0.135^{b}$ & $0.128^{b}$ & $0.110^{7}$ \\
\hline Sales diversification (2001) & & & 1.5 & & & $\|$ \\
\hline
\end{tabular}

Notes: (1) Productivity measured in physical term the unit refers to (a) million barrels per day; (b) metric tonne;

(2) Botll diversification and productivity are measured for all high, medium and low skilled workers.

Source: Firn Suvey (2002)

c. Low skill levels and the declining trend of labour productivity (output/labour and capital/labour ratios)

The low skill levels may contribute to productivity decline across private firms. Table 6.3 bellow illustrates the value and trend of labour productivity (output/labour ratio) and the average ratios of capital/labour and output (total sales value)/labour across firms. Over the period 1999-200I, the trends of these ratios show considerable variation across firms, and, in particular, the average capital/labour ratio and average labour productivity for numerous firms show a considerable decline. ${ }^{132}$

The declining labour productivity across many firms may not be surprising since the majority of employed workers are low skilled/educated foreign workers - see our discussion above- and a low skill level may lead to further decline in productivity. For instance, the bottom half of Table 6.3 below illustrates that, over the period 1999-2000 and 2000-2001, the declining trend of labour productivity is reversed across 3 out of $14(21.4 \%)$ of the respondent firms and the increasing trend continues across 3 out of $14(21.4 \%)$ firms;

132 Due to the small number of observations on the declining trend of labour productivity, our results should be interpreted carefuily as probably this may not be the only case; other possible explanations are either the steady or increasing trends amongst the non-respondent firms. 
however, the increasing trend turns into a declining one across 3 out of $14(21.4 \%)$ frms, or the declining trend continues across 5 out of $14(36 \%)$ of the respondent firms. Therefore, for the majority 8 out of $14(57 \%)$ of the respondent firms either the increasing trend turns into a declining one or the declining trend continues. ${ }^{133}$ These findings on the declining labour productivity at the micro level are consistent with the results regarding the declining value added and productivity at the macro level, as indicated in the Guff literature (cf. Wadi, 2001; Abdelkarim and Ibrahim, 2001). ${ }^{134}$

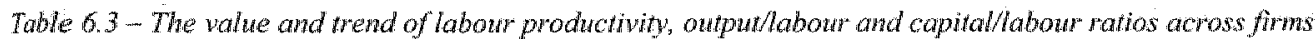
$1999-2001$

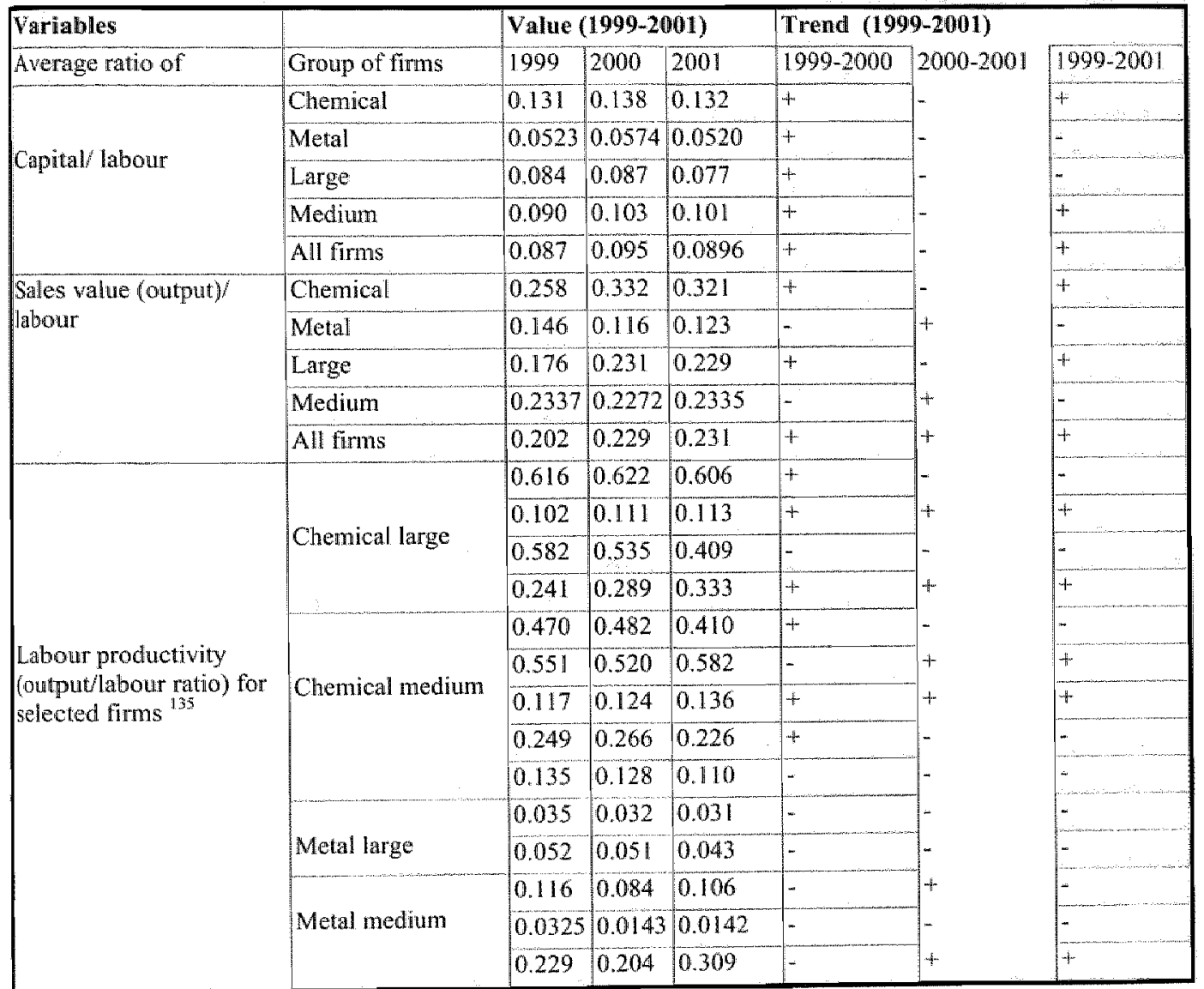

Source: Firm Survey (2002)

139 In Table 6.3 we limit our analysis of the productivity decline to compare only the change in labour productivity over the period 1999-2000 and 2000-2001 across 14 of the respondent firms. Since our data only reflects skill levels for the year 2001 , but does not reflect the change in skill levels over the period 1999-2001. That means we cannot compare the change in productivity with the change in skill levels, so as to attribute the declining trend in productivity over the period 1999-2001 to the declining trend in skill levels.

134 For instance, the results of Wadi (2001) and Abdelkarim and lbrahim (2001) indicate the declining growth rates and declining labour productivity in Kuwait and the UAE respectively.

${ }_{35}$ Productivity is measured in physical terms (tonne, litre, etc. ) for sellected firms according to availability of data. 
Therefore, our findings in this section verify the first bypothesis that high skill requirements and low skill levels - due to high share of unskilled foreign workers - lead to skills mismatch, public private duality and also probably contribute to productivity decline across private firms. In the next sections we examine the second and third hypotheses.

\subsection{Relationships between the required education (occupation), at- tained/actual education, experience and average wages}

Based on the above findings, in this section we examine a part of the second hypothesis that an increase in skill levels and firm size lead to improved relationships between actual and required education, and between actual education, experience and wages across firms.

We begin with the relationship between occupation and education. Using the above definitions of occupation and education/actual and required education respectively, we translate the required qualifications for each of the occupation groups into average years of schooling and use the OLS regression, assuming that the required schooling in each occupation class is dependent on the actual/attained education. Our findings in Table 6.4 and Figure 6.7 below illustrate that improvement in occupational status (measured by the required education) is positively correlated with education (measured by actual/attained education) across all firms. In addition, Table 6.4 illustrates that an increase in firm size and industry level lead to improved relationships between required and actual education. For instance, the required education appears to be more sensitive to and increasing in actual education within both large and chemical firms, but less sensitive within all firms. This result is plausible since the skill level - share of high skilled measured by educational attainment - is higher within large size and chemical firms compared to metal and medium size firms - see Figure 6.1 above. This is also probably because large size firms are more prevalent in the chemical industry - see Table 6.1 above - and may have more consistent recruitment strategies. These results confirm our earlier observations that skill levels and requirements (actual and required education) are non-homogenous across firms and are determined by size and industry.

Concerning the relationship between education, occupation and experience, Table 6.4 below shows that the average years of experience are positively correlated and increasing in education and occupation i.e. attained/actual and required education respectively. In particular, the average years of experience seem more sensitive to high and medium educational attainment and it is also sensitive to high, medium and low educational requirements. This finding is consistent with Figure 6.5 above, and probably reflects the fact that skill indicators - education and experience - are complementing rather than substituting each other.

Table 6.5 below illustrates a considerable variation in the distribution of average wages amongst high, medium and low skill -- educational and occupational - levels across firms. When using the occupational rather than the educational definition, the distribution of wages shows less fluctuation across firms. Therefore, the effect of occupation/required education on the distribution of average wages across firms seems to be less sensitive to differences in firm size and industry. In contrast, when using the educational definition, we observe that the effect of the actual/attained education on the distribution of average wages across firms seems to be more sensitive to differences in firm size and industry. 
Relationship betweer Sikill, Technology and Input-Ouput Indican

Table 6.4-Required and achual attaned edwcation and experience across 1 mms (2001)

\begin{tabular}{|c|c|c|c|c|c|c|}
\hline & & \multicolumn{3}{|c|}{$\begin{array}{l}\text { Coefficient } \\
\text { (t-value) }\end{array}$} & \multirow[t]{2}{*}{$\mathbf{R}^{2}$} & \multirow[t]{2}{*}{$\mathbf{N}^{136}$} \\
\hline Independent Variable & & $\begin{array}{l}\text { Actual } \\
\text { eductation }\end{array}$ & \multirow[t]{6}{*}{$\begin{array}{l}\text { Required } \\
\text { education }\end{array}$} & Constant & & \\
\hline Dependent Variable & Group of firms and skill & & & & & \\
\hline \multirow{3}{*}{$\begin{array}{l}\text { Regured education } \\
\text { All groups (Hight, } \\
\text { medium and Low) }\end{array}$} & Chemical & $\begin{array}{l}0.982^{*} \\
(1.628)\end{array}$ & & $\begin{array}{l}0.876 \\
(0.114)\end{array}$ & 0.275 & 9 \\
\hline & Large & $\begin{array}{l}0.71 .6^{*} \\
(2.559)\end{array}$ & & $\begin{array}{l}3.763 \\
(1.028)\end{array}$ & $0.62 \|$ & 6 \\
\hline & All firms & $\begin{array}{l}0.543 \\
(1.557)\end{array}$ & & $\begin{array}{l}6.573 \\
(1.480)\end{array}$ & 0.168 & 14 \\
\hline \multirow{5}{*}{$\begin{array}{l}\text { Average years experi- } \\
\text { ence } \\
\text { All firms }\end{array}$} & $\begin{array}{l}\text { All groups (High, me- } \\
\text { dium and Low) (All }\end{array}$ & $\begin{array}{l}0.108 \\
(1.557)\end{array}$ & & $\begin{array}{l}5.276 \\
(6.148)\end{array}$ & 0.108 & 22 \\
\hline & firms) & & \multirow[t]{3}{*}{$\begin{array}{l}0.127 * \\
(1.964)\end{array}$} & $\begin{array}{l}4.654 \\
(5.179)\end{array}$ & 0.355 & 9 \\
\hline & High and medium (All & $\begin{array}{l}0.309 * * \\
(3.567)\end{array}$ & & $\begin{array}{l}-2.142 \\
(-1.789)\end{array}$ & 0.377 & 23 \\
\hline & firms) & & & $\begin{array}{l}0.451 \\
(0.424) \\
\end{array}$ & 0.177 & 11 \\
\hline & & & $\begin{array}{l}0.104 \\
(1.390) \\
\end{array}$ & $\begin{array}{l}0.451 \\
(0.424) \\
\end{array}$ & 0.177 & 11 \\
\hline
\end{tabular}

Correlation is significant * at the 0.05 level (one-tailed) ** at the 0.01 level (one-tailed)

Figure 6.7 The distribution of occupation classes according to the translated average years of schooling across forms (2001)

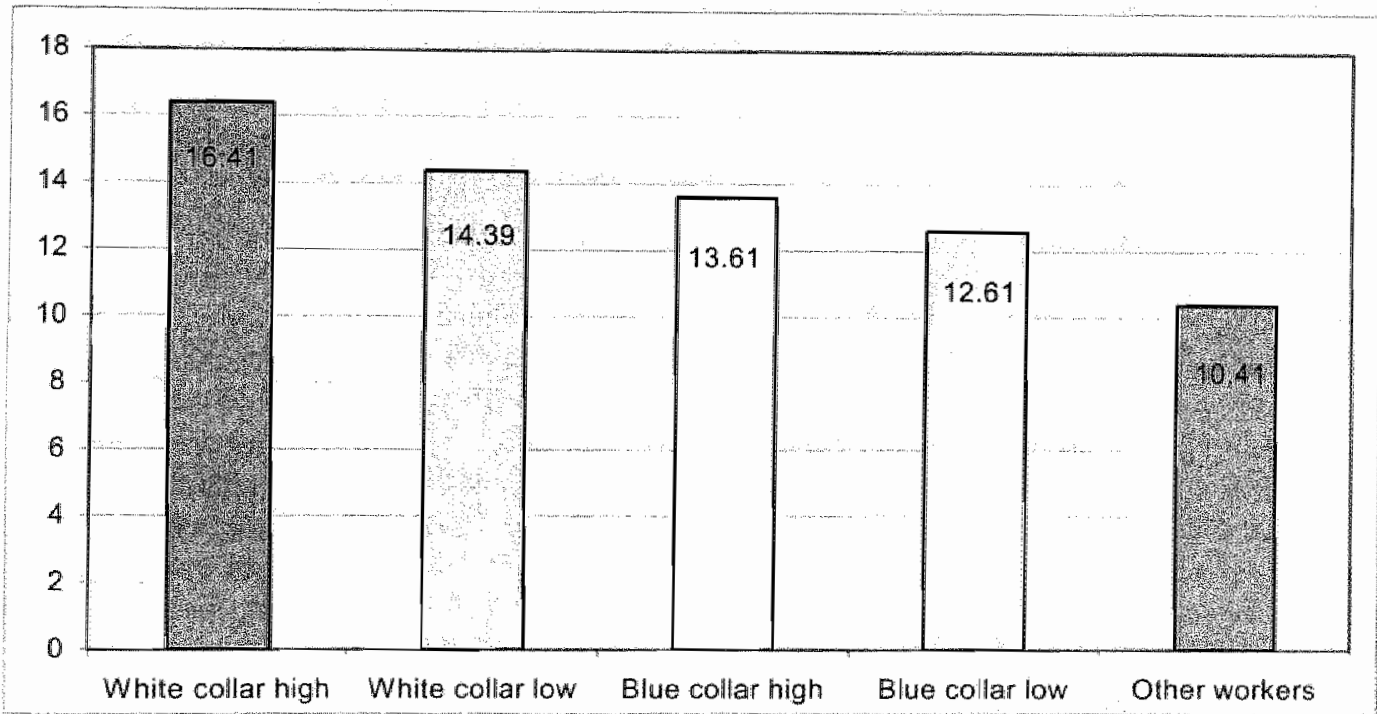

Source: Firm Survey (2002)

For this regression we use relatively few observations, because some of the respondent firms wert particularly reluctant to provide adequate quantitative data on skill indicators. Sometimes we exclude some observations due to inconsistency or unreliability; for instance, one observation is excluded in row 3 . As we explained in Chapter 4 above, the main problem is the varying response rate for different questions. (e.g. to measure education, occupation and wages) across firms. Moreover, the classification of firms into chemical/metal, medium/large also divided the few observations between them and so allow for only fow observations for regression for each group independently. 
Table 65-5yferences in the distribution of average wages defined by firm size and industry level (2001)

\begin{tabular}{|c|c|c|c|c|c|c|c|c|}
\hline \multirow{3}{*}{$\begin{array}{l}\text { Shill varbables: } \\
\text { Characteristics } \\
\text { Wages defined } \\
\text { by skill level }\end{array}$} & \multicolumn{4}{|c|}{ Education } & \multicolumn{4}{|c|}{ occupiation } \\
\hline & \multicolumn{2}{|c|}{ Size } & \multicolumn{2}{|l|}{ Industry } & \multicolumn{2}{|l|}{ size } & \multicolumn{2}{|l|}{ industry } \\
\hline & Large & nedum & Chenucal & Metal & large & medium & chemical & metal \\
\hline \multicolumn{9}{|c|}{ High educated/ white collar bigh } \\
\hline $10,001-25,000$ & $8.3 \%$ & 41.70 & $14.3 \%$ & $40 \%$ & $11.1 \%$ & $15.4 \%$ & $15.4 \%$ & \multirow{4}{*}{$\begin{array}{l}11.1 \% \\
77.8 \% \\
11.1 \% \\
0\end{array}$} \\
\hline $5,001-10,000$ & $58.3 \%$ & $33.3 \%$ & $42.9 \%$ & $50 \%$ & $88.9 \%$ & $61.5 \%$ & $69.2 \%$ & \\
\hline $2,001-5,000$ & $33.3 \%$ & $8,3 \%$ & $28.6 \%$ & $10 \%$ & a & $23.1 \%$ & $15.4 \%$ & \\
\hline $1,001-2,000$ & 0 & $16.7 \%$ & $14,3 \%$ & 0 & 0 & 0 & 0 & \\
\hline \multicolumn{9}{|c|}{ medium educated/ white collar low } \\
\hline $10,001-25,000$ & 0 & $9,1 \%$ & 0 & $10 \%$ & 0 & & 0 & \multirow{5}{*}{$\begin{array}{l}0 \\
11.1 \% \\
44.4 \% \\
44.4 \% \\
0\end{array}$} \\
\hline $5,001-10,000$ & $8.3 \%$ & $9.1 \%$ & $7.7 \%$ & $10 \%$ & 0 & $8.3 \%$ & 0 & \\
\hline $2,001.5,000$ & $33.3 \%$ & $18.2 \%$ & $23.1 \%$ & $30 \%$ & $55.6 \%$ & $50 \%$ & $58.3 \%$ & \\
\hline $1,001-2,000$ & $583 \%$ & $18.2 \%$ & $46.2 \%$ & $30 \%$ & $44.4 \%$ & $41.7 \%$ & $41.7 \%$ & \\
\hline $0,500-1,000$ & 0 & $45.5 \%$ & $23.1 \%$ & $20 \%$ & 0 & 0 & 0 & \\
\hline \multicolumn{9}{|c|}{ low educated/ blue collar high } \\
\hline $5,001-10,000$ & 0 & $10 \%$ & 0 & $12.5 \%$ & 0 & 0 & & \multirow{4}{*}{$\begin{array}{l}0 \\
0 \\
100 \% \\
0\end{array}$} \\
\hline $2,001-5,000$ & 0 & $10 \%$ & $7.7 \%$ & 0 & $33,3 \%$ & $20 \%$ & $45.5 \%$ & \\
\hline $1,001-2,000$ & $45.5 \%$ & $20 \%$ & $23.1 \%$ & $50 \%$ & $66.7 \%$ & $70 \%$ & $45.5 \%$ & \\
\hline $0,500-1,000$ & $54.6 \%$ & $60 \%$ & $69.2 \%$ & $37.5 \%$ & 0 & $10 \%$ & $9.1 \%$ & \\
\hline \multicolumn{9}{|l|}{ blue collar low } \\
\hline $2,001-5,000$ & & & & & $11.1 \%$ & $30 \%$ & $33.3 \%$ & \multirow{3}{*}{$\begin{array}{l}0 \\
85.7 \% \\
14.3 \%\end{array}$} \\
\hline $1,001-2,000$ & & & & & $66.7 \%$ & $50 \%$ & $41.7 \%$ & \\
\hline $0,500-1,000$ & & & & & $22.2 \%$ & $20 \%$ & $25 \%$ & \\
\hline \multicolumn{9}{|l|}{ Others } \\
\hline $1,001-2,000$ & & & & & $42.9 \%$ & $33.3 \%$ & $58.3 \%$ & \multirow{2}{*}{$\begin{array}{l}28.6 \% \\
71.4 \%\end{array}$} \\
\hline $0,500-1,000$ & & & & & $57.1 \%$ & $66.7 \%$ & $41.7 \%$ & \\
\hline
\end{tabular}

Sources: Firm Survey (2002)

The above results are consistent with the OLS regression reported in Table 6.6 below which indicates that the average wages are positively correlated with and more sensitive tc attained/actual education. For instance, Table 6.6 below illustrates that the average wages are increasing in actual/attained education and experience (cf. Mincer, 1974) and therefore is biased against less educated and experienced workers. These findings support our results from the firm survey, which indicate that wages are increasing in education and biased against low educated workers because the ratios of high skilled to low skilled wages, which can be interpreted as wages/skills premium, exceeds one. ${ }^{137}$ These results are consistent with the findings in the new growth literature, particularly skilled biased technical change theorems (cf. Aglion and Howitt, 1992; 1998; Acemoglu, 1998; Autor, Katz and Krueger, 1998). Our results that required education has no significant impact on wages are somewhat surprising and different from our expectation in view of the results of the overeducation literature (Hartog, 2000; Muysken et al. 2001; 2002a;b; 2003). We find that the positive correlations between actual education, experience and wages are particularly significant for large size firms, which may not be surprising since these firms have sufficient scope for a coherent wage policy (Muysken and Nour, 2005). This is also probably because large size firms may have more consistent recruitment strategies and high skill levels - share of high skilled workers in total employment - see Figure 6.1 above. These results imply that an

137 From the firm survey (2002) we find that the proportion of high skilled wages/low skilled wages accounts for $7.5,6.9,8.1,6.3$ and 8.4 for all firms, chemical, metal, large and medium size firms respectively. 
increase in skill level/actuall education and firm size leads to an improved relationship between actual education, experience and wages.

Table 6.6-Correlation between wages (log) actual and wequired education and expenence (200)

\begin{tabular}{|c|c|c|c|c|c|c|}
\hline & & \multicolumn{3}{|c|}{$\begin{array}{c}\text { Coefficient } \\
\text { (t-value) }\end{array}$} & \multirow[t]{2}{*}{$\mathbb{R}^{2}$} & \multirow[t]{2}{*}{$\mathrm{N}^{138}$} \\
\hline Independent variable & Group of firms & $\begin{array}{l}\text { Actual } \\
\text { education }\end{array}$ & Experience & \multirow[t]{4}{*}{$\begin{array}{l}\text { Required } \\
\text { education }\end{array}$} & & \\
\hline \multicolumn{6}{|c|}{ Dependent variable: Average wages (log) } & \\
\hline \multirow{7}{*}{$\begin{array}{l}\text { Average wages (log) } \\
\text { high, medium and } \\
\text { low skilled }\end{array}$} & All firms & $\begin{array}{l}0.231 * * \\
(2.259)\end{array}$ & & & 0.195 & 23 \\
\hline & Large & $\begin{array}{l}0.284^{* *} \\
(4.545)\end{array}$ & & & 0.674 & 12 \\
\hline & Ali firms & & & \multirow{5}{*}{$\begin{array}{l}0.159 \\
(1.275)\end{array}$} & 0.119 & 14 \\
\hline & All firms & $\begin{array}{l}0.170^{*} \\
(1.471)\end{array}$ & $\begin{array}{l}0.048 \\
(1.107)\end{array}$ & & $0 . \overline{242}$ & 23 \\
\hline & Large & $\begin{array}{l}0.193^{*} \\
(2.175)\end{array}$ & $\begin{array}{l}0.053^{*} \\
(1.374)\end{array}$ & & 0.730 & 13 \\
\hline & Chemical & $\begin{array}{l}0.243^{\text {*t }} \\
(2.001)\end{array}$ & $\begin{array}{l}0.05469 \\
(1.102)\end{array}$ & & 0.557 & 13 \\
\hline & All firms & $\begin{array}{l}0.192^{*} \\
(1.199)\end{array}$ & $\begin{array}{l}0.011 \\
(0.172)\end{array}$ & & 0.254 & 14 \\
\hline
\end{tabular}

Correlation is significant * at the 0.05 level (one-tailed) ** at the 0.01 level (one-tailed)

Therefore, our findings in this section corroborate the first part of the second hypothesis that an increase in skill levels and firm size leads to improved relationship between actual and required education and experience; and between actual education, experience and wages. In the next section we proceed to examine the second part of the second hypothesis that an increase in skill levels and firm size lead to improved relationships between skill, upskilling and technology (ICT). Finally, we test our third hypothesis on the relationship between technology (ICT) and input-output indicators at the micro/firm level.

\section{4 Skill, upskilling (ICT training) and technology (ICT) and input- output indicators}

Based on the above results, in this section we examine the other part of the second hypothesis that an increase in skill levels and firm size lead to improved relationships between skill, upskilling and technology (ICT) across firms. Before examining this hypothesis, it is useful to briefly show the variations in the use of technology (spending on ICT) and upskilling

\footnotetext{
${ }^{138}$ For this regression we use relatively few observations, because some of the respondent firms were particularly reluctant to provide adequate quantitative data to measure skill indicators. For instance, there are few observations when combining attained education, experience and required education, particularly so for required education. As we explained in Chapter 4 above, we excluded some observations due to inconsistency or unreliability. One major problem is the varying response rate for different questions (to measure attained and required education, experience and wages) across firms. Moreover, the classification of firms into chemical/metal, medium/large also divided the few observations between them and, therefore, allow for only a few observations for regression for each group independently.

139 The required education is not used as a variable in the upper half of Table 6.6 , because, we want to check the relation with respect to actual/attained education and experience independently ancl then compare the result when the required education is also included in the regression.
} 
(spending on ICT training) across firms, because the observed differences in skill and spending on ICT and ICT training can be used to interpret the complementary relationships between skill, technology and upskilling across firms.

\subsubsection{Skill and the share of spending on technology (ICT) and upskilling (ICT training)}

Table 6.7 shows considerable variations in the share and trend of total spending on ICT including computers, telecommunications, training, maintenance and other items defined by firm size and industry. The share of telecommunication exhibits continuous increasing trend for all firms, while that of training shows an opposite declining trend. Table 6.1 above shows that, on average, the share of large size and chemical firms represents about $98 \%$ and $76 \%$ of total spending on ICT respectively and about $98 \%$ and $94 \%$ of total spending on ICT training respectively. However, despite the big share of spending on ICT and ICT training, iarge size and chemical firms experienced declining trends of ICT and ICT training - cf. Figures $6.8-6.9$. The decline in total ICT spending can be interpreted as being due to a lack of plan for critical expansion in ICT sector or probably due to a general cutback in total. spending across chemical and large size firms. The declining expenses on both ICT training. and computers follow the general decline in total ICT spending, which can also be attributed to a lack of plan for critical expansion a possible change in the strategy of firms that, having already established a sound basis for these components, probably need to shift priority to increase spending on both telecommunications and maintenance.

Table 6.7-Spending on /CT defined by firn size and industry (1999-2001) (\% share in total spending)

\begin{tabular}{|c|c|c|c|c|c|c|c|c|c|c|c|c|c|c|c|}
\hline \multirow{2}{*}{$\begin{array}{l}\text { ICI" } \\
\text { Finns/Years }\end{array}$} & \multicolumn{3}{|c|}{ Computers } & \multicolumn{3}{|c|}{$\begin{array}{l}\text { Telecommunica } \\
\text { tions }\end{array}$} & \multicolumn{2}{|c|}{ Traiming } & \multicolumn{4}{|c|}{ Maintenance } & \multicolumn{2}{|l|}{ Other } & \multirow[b]{2}{*}{2001} \\
\hline & 1999 & 2000 & 2001 & 1999 & 2000 & 2001 & 1999 & 2000 & 2001 & 1999 & 2000 & 2001 & 1999 & 2000 & \\
\hline Chemical & $17 \%$ & $15 \%$ & $11 \%$ & $11 \%$ & $29 \%$ & $25 \%$ & $59 \%$ & $22 \%$ & $10 \%$ & $11 \%$ & $30 \%$ & $54 \%$ & $2 \%$ & $4 \%$ & $0.5 \%$ \\
\hline Metal & $19 \%$ & $6 \%$ & $9 \%$ & $21 \%$ & $6 \%$ & $27 \%$ & $7 \%$ & $2 \%$ & $13 \%$ & $53 \%$ & $86 \%$ & $51 \%$ & $0.1 \%$ & $0.02 \%$ & $0.1 \%$ \\
\hline Large & $17 \%$ & $13 \%$ & $11 \%$ & $11 \%$ & $22 \%$ & $24 \%$ & $57 \%$ & $17 \%$ & $11 \%$ & $13 \%$ & $45 \%$ & $54 \%$ & $2 \%$ & $3 \%$ & $0.5 \%$ \\
\hline Medium & $20 \%$ & $7 \%$ & $10 \%$ & $27 \%$ & $9 \%$ & $32 \%$ & $6 \%$ & $2 \%$ & $12 \%$ & $47 \%$ & $82 \%$ & $46 \%$ & 0 & 0 & 0 \\
\hline All finms & $17 \%$ & $11 \%$ & $11 \%$ & $12 \%$ & $19 \%$ & $25 \%$ & $54 \%$ & $13 \%$ & $11 \%$ & $15 \%$ & $55 \%$ & $53 \%$ & $2 \%$ & $2 \%$ & 0.40 \\
\hline
\end{tabular}

Soure: Firm Survey $(2002)$

Fighe 6.8 - The share and trend of totat spending on ICT across firms (1999-2001)

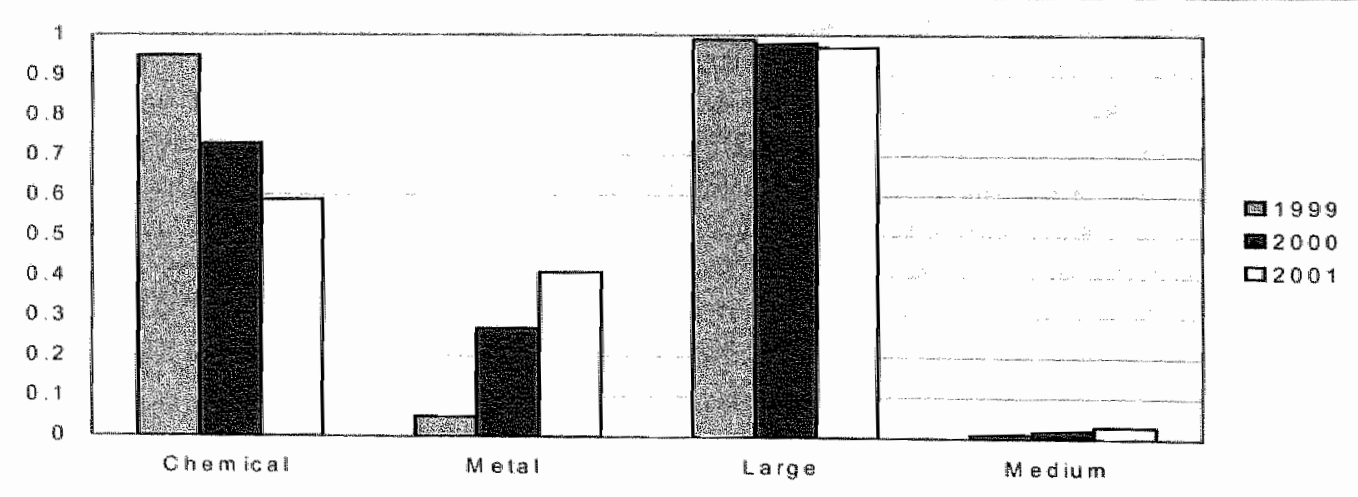

Source: Firm Survey (2002) 
Figure 6.9-The share and trend of spending on ICT traming across fins (1999-2001)

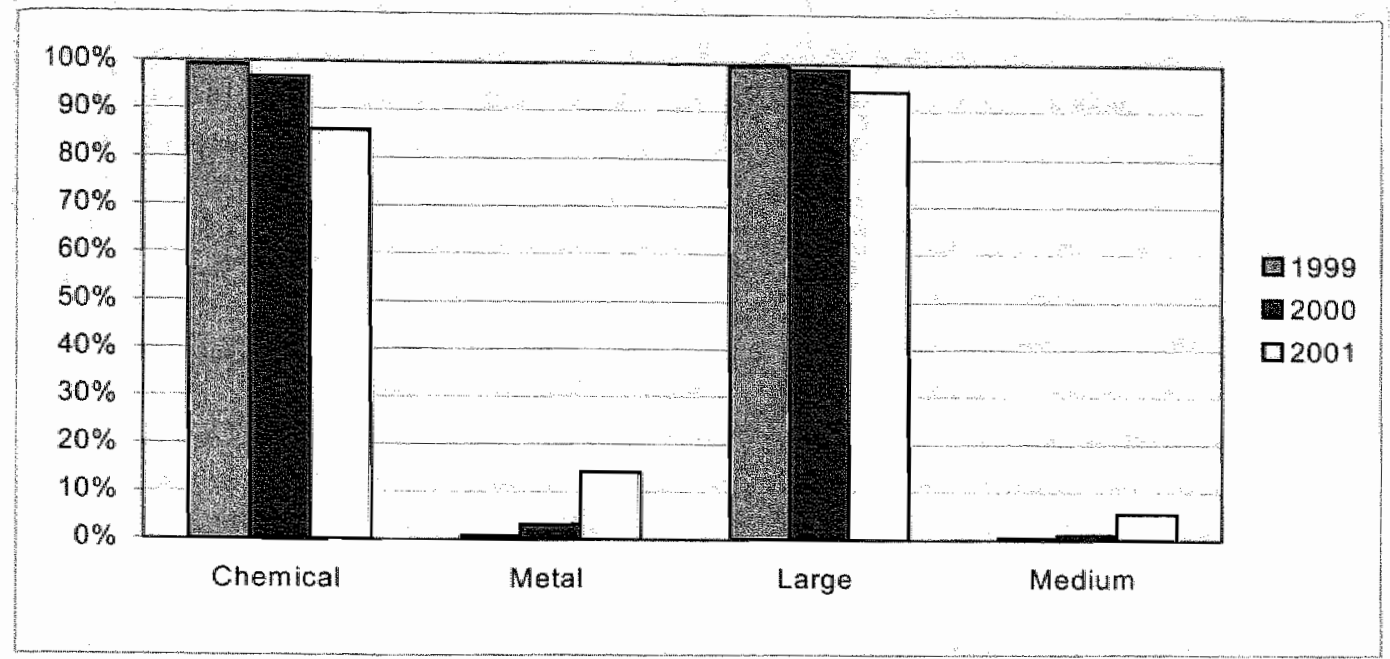

Source: Firm Survey (2002)

We now proceed to examine the second part of our second hypothesis that an increase in skill levels and firm size leads to improved complementary relationships between skill, technology (ICT) and upskilling (ICT training)- see Table 6.8 below. For instance, we observe the complementary relationship between the share of high education and the share of expenditure on [CT, which can be seen and understood as complementarity between skil] and technology (cf. Goldin and Katz, 1998; Acemoglu, 1998). We find a complementary relationship between the share of high education and the share of expenditure on ICT training, which can be interpreted as complementarity between skill and upskilling. Tables 6.86.9 show complementary relationships between the share of expenditure on ICT and ICT training, and between spending on computers, telecommunications and training, which can be read as complementarity between technology and upskilling (cf. Colecchia and Papaconstantinou, 1996; Bresnahan and Hitt, 1999). Our findings, that these complementarities are particularly significant for large size firms, are plausible since these firms have more spending on ICT and ICT training - see Table 6.1 above - and have high skill levels - share of high skilled workers in total employment - see Figure 6.1 above. These results are consistent with the second part of our second hypothesis that an increase in skill levels and firm size lead to improved complementary relationships between skill, upskilling and technology (ICT) (cf. Acemoglu, 1998). The results also imply the importance of a good education/high skill level for the enhancement of skill, technology and upskilling complementarity at the micro level. That also seems consistent with the endogenous growth framework and stylized facts concerning the relationships between human capital, technical progress and upskilling - see our theoretical framework in Chapter 3 above. 
Table 6.8 .

The relationship between $1 C$, skll and upsklling across firms (2001)

\begin{tabular}{|c|c|c|c|c|c|c|}
\hline & & \multicolumn{3}{|c|}{$\begin{array}{c}\text { Coefficient } \\
(\mathrm{t}-\mathrm{value})\end{array}$} & $\mathbf{R}^{2}$ & $\mathbf{N}$ \\
\hline \multicolumn{2}{|c|}{ Independent variables } & \multirow[t]{2}{*}{ ICT expenditures } & \multirow[t]{2}{*}{ Training expenditures } & \multirow[t]{2}{*}{ Constant } & & \\
\hline $\begin{array}{l}\text { Dependent } \\
\text { variables }\end{array}$ & $\begin{array}{l}\text { Group of } \\
\text { firms }\end{array}$ & & & & & \\
\hline \multirow{4}{*}{ High education } & $\begin{array}{l}\text { All fintins } \\
\text { (linear) }\end{array}$ & $\begin{array}{l}0.210^{\text {㕲 }} \\
(5.965)\end{array}$ & & $\begin{array}{l}-0.055 \\
-4.219)\end{array}$ & 0.703 & 17 \\
\hline & $\begin{array}{l}\text { Chemical } \\
\text { (linear) }\end{array}$ & $\begin{array}{l}0.029 * \\
(2,612)\end{array}$ & & $\begin{array}{l}0.356 \\
(6.317) \\
\end{array}$ & 0.363 & $\sqrt[114]{4}$ \\
\hline & $\begin{array}{l}\text { Large } \\
\text { (linear) }\end{array}$ & \multirow{2}{*}{$\begin{array}{l}0.0316 \\
(2.484) \\
0.330 \\
(1.248)\end{array}$} & \multirow{2}{*}{$\therefore \quad \therefore \ldots \ldots+\cdots+\infty$} & $\begin{array}{l}0.318 \\
(4.632)\end{array}$ & 0.382 & 12 \\
\hline & $\begin{array}{l}\text { Medium } \\
\text { (linear) }\end{array}$ & & & $\begin{array}{l}0.265 \\
(4.556)\end{array}$ & 0.163 & 10 \\
\hline \multirow{3}{*}{ High education } & $\begin{array}{l}\text { All firms } \\
\text { (linear) }\end{array}$ & & \multirow{2}{*}{$\begin{array}{l}0.03350 \\
(4.089) \\
0.280 \% \\
(2.040)\end{array}$} & $\begin{array}{l}0.266 \\
(6.733)\end{array}$ & 0.563 & 15 \\
\hline & $\begin{array}{l}\text { Chemical } \\
\text { (linedul) }\end{array}$ & & & $\begin{array}{l}0.353 \\
(4.871)\end{array}$ & 0.294 & 12 \\
\hline & $\begin{array}{l}\text { Large } \\
\text { (linear) }\end{array}$ & \multirow[b]{2}{*}{$\begin{array}{l}0.09425^{2} \\
(16.994)\end{array}$} & \multirow[t]{2}{*}{$\begin{array}{l}0.310^{*} \\
(2.258)\end{array}$} & $\begin{array}{l}0.304 \\
(4.107)\end{array}$ & 0.338 & 12 \\
\hline \multirow{3}{*}{$\begin{array}{l}\text { lraining ex- } \\
\text { perditures }\end{array}$} & $\begin{array}{l}\text { Alil firms } \\
\text { (linear) }\end{array}$ & & & $\begin{array}{l}38783.341 \\
(1.615)\end{array}$ & 0.944 & 19 \\
\hline & $\begin{array}{l}\text { Chemical } \\
\text { (log) }\end{array}$ & \multirow{2}{*}{$\begin{array}{l}0.683^{*} \\
(3.875) \\
0.743^{*} \\
(3.677)\end{array}$} & \multirow{2}{*}{$\frac{1}{2}$} & $\begin{array}{l}2.365 \\
(1.047)\end{array}$ & 0.600 & 12 \\
\hline & $\begin{array}{l}\text { Large } \\
(\log )\end{array}$ & & & $\begin{array}{l}1.472 \\
(0.564)\end{array}$ & 0.530 & 14 \\
\hline
\end{tabular}

Comelation is significant * at the 0.05 level (one-tailed) * at the 0.01 level (one-taled)

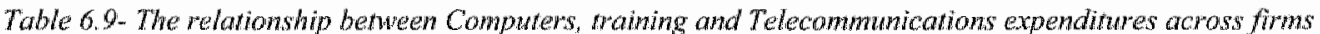
(1990-2001)

\begin{tabular}{|c|c|c|c|c|c|c|c|}
\hline \multirow{2}{*}{\multicolumn{2}{|c|}{ Independent variables }} & \multicolumn{4}{|c|}{$\begin{array}{l}\text { Coefficient } \\
\text { (t-value })\end{array}$} & \multirow[t]{2}{*}{$\mathbf{R}^{2}$} & \multirow[t]{2}{*}{$\mathbf{N}$} \\
\hline & & $\begin{array}{l}\text { Computer } \\
\text { expenditure }\end{array}$ & $\begin{array}{l}\text { Training } \\
\text { expenditure }\end{array}$ & $\begin{array}{l}\text { Telecommunication } \\
\text { expendinure }\end{array}$ & Constant & & \\
\hline \multicolumn{8}{|c|}{$\begin{array}{l}\text { Dependent variables } \\
\text { (All firms) }\end{array}$} \\
\hline \multirow{3}{*}{$\begin{array}{l}\text { Computer } \\
\text { expenditure: } \\
\text { All firms }\end{array}$} & 1999 & & $\begin{array}{l}0.620^{*} \\
(2.489)\end{array}$ & $\begin{array}{l}0.198 \\
(0.626)\end{array}$ & $\begin{array}{l}2.484 \\
(1.097)\end{array}$ & 0.815 & 10 \\
\hline & 2000 & & $\begin{array}{l}0.487 \\
(1.325)\end{array}$ & $\begin{array}{l}0.431 \\
(1.007)\end{array}$ & $\begin{array}{l}0.633 \\
(0.220)\end{array}$ & 0.677 & 12 \\
\hline & 2001 & & $\begin{array}{l}0.847 * \\
(1.627)\end{array}$ & $\begin{array}{l}-0.0564 \\
(-0.125)\end{array}$ & $\begin{array}{l}2.178 \\
(1.141)\end{array}$ & 0.670 & 14 \\
\hline \multirow{3}{*}{$\begin{array}{l}\text { Training } \\
\text { expenditure: } \\
\text { All finms }\end{array}$} & 1999 & $\begin{array}{l}0.820 \\
(2.489)\end{array}$ & & $\begin{array}{l}0.343 \\
(0.985)\end{array}$ & $\begin{array}{l}-2.544 \\
(0.957)\end{array}$ & 0.830 & 10 \\
\hline & 2000 & $\begin{array}{l}0.369 \\
(1.325)\end{array}$ & & $\begin{array}{l}0.639^{*} \\
(1.972)\end{array}$ & $\begin{array}{l}-0.936 \\
(-0.376)\end{array}$ & 0.755 & 12 \\
\hline & 2001 & $\begin{array}{l}0.247^{\circ} \\
(1.627)\end{array}$ & & $\begin{array}{l}0.661 \\
(5219)\end{array}$ & $\begin{array}{l}0.546 \\
(0.504)\end{array}$ & 0.911 & 14 \\
\hline \multirow{3}{*}{$\begin{array}{l}\text { Telecom- } \\
\text { munication } \\
\text { expenditure: } \\
\text { all lirms } \\
\text { All firms }\end{array}$} & 1999 & $\begin{array}{l}0.309 \\
(0.626)\end{array}$ & $\begin{array}{l}0.405 \\
(0.515)\end{array}$ & & $\begin{array}{l}3.720 \\
(1.377)\end{array}$ & 0.675 & 10 \\
\hline & 2000 & $\begin{array}{l}0.261 \\
(1.007)\end{array}$ & $\begin{array}{l}0.512 \\
(1.972)\end{array}$ & & $\begin{array}{l}3.601 \\
(1.934)\end{array}$ & 0.735 & 12 \\
\hline & 2001 & $\begin{array}{l}-0.0276 \\
(-0.125)\end{array}$ & $\begin{array}{l}1.107^{*} \\
(5.219)\end{array}$ & & $\begin{array}{l}-0.127 \\
(-0.090)\end{array}$ & 0.888 & 14 \\
\hline
\end{tabular}

Correlation is significant at the 0.05 level (one-tailed) * at the 0.01 level (one-tailed) 


\subsubsection{The use of technology, ICT, skill and the demand for skilled workers across firms}

One implication of the above complementary relationship between skill and technology is that the demand for skilled workers has changed in response to the increasing uses of ICT and other technologies. For instance, during the period 1999-2001 the uses of ICT $(61 \%)$ increased faster than that of other technologies $(56 \%)$; however, the corresponding rise in the demand for skilled workers needed for ICT $(57 \%)$ was less than that for other technologies (61\%) across all respondents firms - see Figure 6.10 below. This trend may reflect the fact that the real demand for skilled workers needed for ICT is less than that of other technologies across firms, which may not be surprising given the recent history of IT diffusion in the Gulf countries. For instance, according to the UNDP-HDR (2004), in 1990 there was a zero/no access/use of Internet (per 1,000 population) amongst the Gulf population, which may imply that the use of Internet started after 1990. Moreover, data from MADAR Research Group (2002) indicates that the introduction of Internet was between 1992 and 1996 and the commercial or public use of Internet was between 1994 and 1999 in the Gulf countries. The introduction and commercial use started in 1992 and 1994 respectively in Kuwait, they both started in 1995 in both the UAE and Bahrain, and in 1996 in both Qatar and Oman and finally they started in 1996 and 1999 respectively in Saudi Arabia (cf. MADAR Research Group, 2002: 4)

Figure 6.10- The increasing use of technology, ICT and the demand for high skilled workers across firms, $1999-2001$

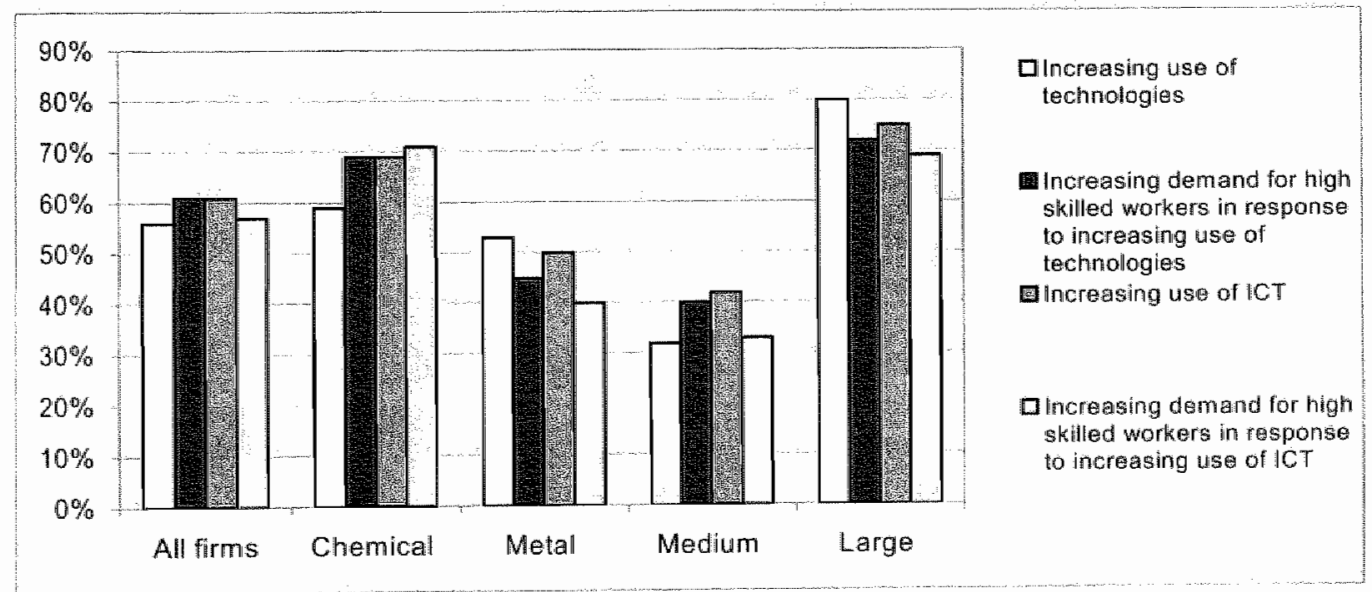

Source: Firm survey (2002)

According to the respondent firms, the increasing use of new technologies caused an increase in both the demand for more skilled workers and the required skill levels of the respective workers involved with them. Table 6.10 indicates that the increasing use of new technologies has important effects on increasing the general skill levels and the demand for skilled workers amongst $79 \%$ and $62 \%$ of the respondent firms respectively. ${ }^{140}$ However, it

${ }^{140}$ Firms reported the use of different types of new technologies such as mass petrochemicals plants, ad wanced process controls, gas plants installation, $C N C$ machines, new advanced machines and ICT. 
has only slight effects on increasing skill levels mainly for unskilled workers, and decreasing and substituting the demand for unskilled workers due to reduction and elimina tion/substitution of some unskilled jobs. This implies change in the structure of employment/demand for workers in response to the increasing uses of new technologies and is also evidence of skilled-biased technical change theorem. ${ }^{1+1}$

Table 610 - The effects of new technologies on skill hevel and the demand for workers in the UAE 2001

\begin{tabular}{llllll}
\hline The effects of new technologies in: & All & Chemical & Metal & Medium & Large \\
\hline Increasing the general skill level. & firns & & & & \\
Increasing skill lewel mainly for unskilled workers. & $59 \%$ & $79 \%$ & $80 \%$ & $63 \%$ & $94 \%$ \\
Increasing the demand for skilled workers (more & $62 \%$ & $63 \%$ & $53 \%$ & $56 \%$ & $61 \%$ \\
educated, trained and experienced workers). & & $58 \%$ & $67 \%$ & $63 \%$ & $61 \%$ \\
Increasing the demand for more professional workers & $62 \%$ & $53 \%$ & $73 \%$ & $50 \%$ & $72 \%$ \\
Decreasing the demand for less skilled workers (less & $35 \%$ & $32 \%$ & $40 \%$ & $31 \%$ & $39 \%$ \\
edlucated, trained and experienced workers). & & & & & \\
Decreasing the demand for production workers. & $29 \%$ & $16 \%$ & $47 \%$ & $25 \%$ & $33 \%$ \\
Substituing the demand for less skilled workers. & $29 \%$ & $26 \%$ & $33 \%$ & $31 \%$ & $28 \%$ \\
Reduction in some unskilled jobs & $53 \%$ & $53 \%$ & $53 \%$ & $69 \%$ & $39 \%$ \\
Elimination substitution of some unskilled jobs & $47 \%$ & $47 \%$ & $47 \%$ & $69 \%$ & $28 \%$ \\
Total response & 34 & 19 & 15 & 16 & 18 \\
\hline
\end{tabular}

Source: Own calculation based on the firm survey (2002).

Moreover, from the firm survey we find that the increasing use of new technologies has not only raised the demand for high skilled workers in the past years, but also encouraged firms to predict a future/ long run increase in the demand for high skilled workers. For instance, for $61 \%$ of the respondent firms the interpretations of the predicted long run increase in the demand for skilled workers are related to planned/expected expansion of production, product diversification, implementation of new process, output technologies, purchases of new machines and equipment and increasing R\&D activities. ${ }^{142}$ This result seems consistent with the assumption made by Aghion and Howitt (1992) that an expectation of more research in the next period must correspond to an expectation of higher demand for skilled labour in research in the next period.

\subsection{The share of spending on ICT and input-output indicators}

Finally, in this section we investigate the third hypothesis on the positive relationships between technology (total expenditures on ICT) and input-output indicators across firms and over time. For instance, when investigating the relationship between ICT and input variables, we find from Tables 6.11 that the total spending on ICT is positively correlated and more sensitive to labour (firm size), and industry level and less sensitive to capital (net worth) throughout the period 1999-2001. The relationship between ICT and labour (firm size) is particularly significant for the large size and chemical firms. The different results across chemical and metal or large and medium size firms is plausible and can be attributed

\footnotetext{
141 This result is consistent with SBTC theorem and our earlier findings indicating that wages are increas-
ing in education and biased against unskilled workers.

"42 Moreover, other factors are: the expected increases in market share, turnover, sales, adoption of international standards and enhancement of production, advanced control systems, shortage of manpower, competition, increasing motivation to reduce costs, achieving high standard precision work, improving productiw-
ity, quality of work and demand for more specialized skills in IT.
} 
to differences in the skill levels - share of high skilled workers in total employment - see Figure 6.1 above. This is also because large size firms are more prevalent in the chemical industry, they have high share in total ICT spending, employment, capital, output and profit - see Table 6.1 above - and probably have more consistent entrepreneurial/organizational strategies.

Table 6.11-Tonal spending on ICT, labow and capital across finms (1999-2001)

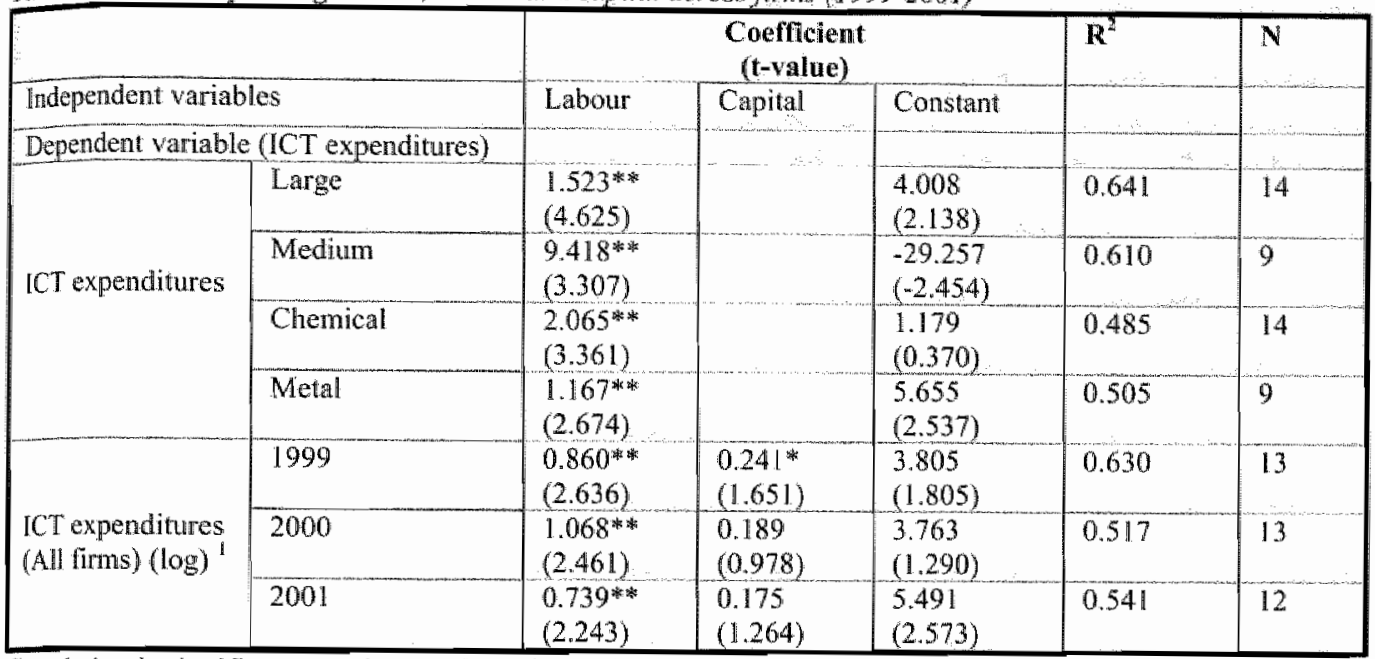

Correlation is significant * at the 0.05 level (one-tailed) ** at the 0.01 level (one-tailed)

Note: (1) Log vallue for all estimated variables: ICT, labour and capital.

We examine the relationship between the total expenditures on ICT, profit and output: Table 6.12 illustrates plausible positive ${ }^{143}$ significant correlations between total expenditures on ICT and capital and total output (total sales value) and positive insignificant correlations with profit. These results prove our third hypothesis concerning the positive correlation between ICT and input-output indicators at the micro/firm level. However, our results should be interpreted carefully as they probably have a two-ways causality and may leave open the possibility for reversed causality. Mainly because more profit and output would imply more financial capacity that permits more spending on ICT, on the other hand, more spending on ICT implies higher costs and lower profit.

Our findings concerning the significant positive correlations between ICT and output and the insignificant correlation between ICT and profit imply an inconclusive effect at the micro level. These results agree with our observations at the aggregate level, which imply that the growing expenditures on ICT in the Gulf countries raises the shares of the population using the Internet, enhances e-business, e-education and e-government. However, despite the growing ICT expenditures, their effects are inconclusive at the aggregate level, probably due to low skill levels and inadequate investment in education. ${ }^{1.44}$ The macro abservations are consistent with the recent literature indicating the growing but limited

\footnotetext{
${ }^{143}$ Except in 2000, where the correlations between ICT and both output and profit are negative.

${ }^{144}$ At the aggregate level, when using the most recent data (2002) on the share of spending on ICT relative to GDP across four Gulf countries: Bahrain, Saudi Arabia, UAE, and Kuwait, we find an inconclusive effect of ICT. Because the share of spending on ICT/GDP shows a significant positive correlation with GDP, but a significant negative correlation with GDP per capita across the four Gulf countries.
} 
effects of ICT diffusion in the developing countries due to a lack of sufficient investment in the complementary infrastructure such as education, skills and technical skills (cf. Pohjola, 2002; Kenny, 2002). Therefore, these results prove the third hypothesis in Chapter 1 above about the inconclusive effect of ICT at the micro level.

Table 6.12-Tatal spending on ICT, labour capital, output and profit across fims (1999-2001)

\begin{tabular}{|c|c|c|c|c|c|c|c|}
\hline \multirow{2}{*}{\multicolumn{2}{|c|}{ Independent variables }} & \multicolumn{4}{|c|}{$\begin{array}{l}\text { Coefficient } \\
\text { (t-value) }\end{array}$} & \multirow[t]{2}{*}{$\mathbb{R}^{2}$} & \multirow[t]{2}{*}{$\mathbf{N}$} \\
\hline & & Labour & Capital & ICT spending & Constant & & \\
\hline \multicolumn{8}{|c|}{$\begin{array}{l}\text { Dependent variables All firms } \\
\text { (log) }\end{array}$} \\
\hline \multirow{3}{*}{$\begin{array}{l}\text { Total output } \\
\text { (total sales } \\
\text { value) }\end{array}$} & 1999 & $\begin{array}{l}-45897.058 \\
(-1.606)\end{array}$ & $\begin{array}{l}1.207 * * \\
(5.623)\end{array}$ & $\begin{array}{l}53.858 \text { * } \\
(11.852)\end{array}$ & $\begin{array}{l}8423985.9 \\
(2.570)\end{array}$ & 0.993 & 12 \\
\hline & 2000 & $\begin{array}{l}-52249.455 \\
(-1.477)\end{array}$ & $\begin{array}{l}2.120^{* * *} \\
(7.150)\end{array}$ & $\begin{array}{l}-1.473 \\
(-1.615)\end{array}$ & $\begin{array}{l}7906055.0 \\
(1.891)\end{array}$ & 0.978 & 12 \\
\hline & 2001 & $\begin{array}{l}-48147.057 * \\
(-1.936)\end{array}$ & $\begin{array}{l}1.808 * * \\
(8.189)\end{array}$ & $\begin{array}{l}13.133^{*} \\
(1.922)\end{array}$ & $\begin{array}{l}10655725 \\
(3.004)\end{array}$ & 0.984 & 11 \\
\hline \multirow{3}{*}{ Profit } & 1999 & $\begin{array}{l}-1527.002 \\
(-0.130)\end{array}$ & $\begin{array}{l}0.140 \\
(0.560)\end{array}$ & $\begin{array}{l}1.988 \\
(0.496)\end{array}$ & $\begin{array}{l}129363.28 \\
(0.101)\end{array}$ & 0.730 & 11 \\
\hline & 2000 & $\begin{array}{l}-5014.495 \\
(-0.641)\end{array}$ & $\begin{array}{l}0.3 \cdot 10^{*} \\
(1.820)\end{array}$ & $\begin{array}{l}-0.710 \\
(-0.921)\end{array}$ & $\begin{array}{l}15621.632 \\
(0.012)\end{array}$ & 0.652 & 11 \\
\hline & 2001 & $\begin{array}{l}-11348.674 \\
(-1.236)\end{array}$ & $\begin{array}{l}0.182 \\
(0.608)\end{array}$ & $\begin{array}{l}1.561 \\
(0.240)\end{array}$ & $\begin{array}{l}1888472.6 \\
(1.657)\end{array}$ & 0.515 & 10 \\
\hline
\end{tabular}

Correlation is significant * at the 0.05 level (one-tailed) ** at the 0.01 level (one»tailed)

\subsection{Conclusions}

In this chapter we use the data from the firm survey (2002) to examine skill indicators, their implications and relationships with average wages, and with upskilling (ICT training) and technology (ICT), ICT and input-output indicators at the micro/firm level.

Our findings in Section 2 illustrate the low skill levels -due to the excessive share of unskilled foreign workers (Figures 6.1-6.2) - and the implications on skills mismatch (Figure 6.6), public-private duality and productivity decline across private firms (Tables 6.2-6.3). These results are consistent with the micro-macro findings in Chapter 5 above, which indicate the low share of high skilled in total population and employment - measured by both educational and occupational levels - and the serious implications on skills mismatch and the macro-micro duality with respect to upskilling efforts. These findings together with those in Chapter 5 above verify hypotheses 3.b and 4.a in Scheme 1.1 Chapter 1 above regarding the implications of the interaction between the deficient educational system and high use of unskilled foreign workers. These findings then confirm our first hypothesis, which we proved in Chapter 2 above, concerning the pressing need for upskilling, particularly within the private sector.

Our results in Section 3 show positive correlations between actual and required education, experience and average wages (Tables 6. 4-6.6). We verify hypothesis 4.b. in Scheme 1.1. Chapter 1 above that an increase in skill level and firm size lead to improved relationships between actual and required education (Table 6.4), and between actual education, experience and wages (Table 6.6).

In Section 4 our findings with respect to the positive complementary relationships between skill, technology (ICT) and upskilling (ICT training) and between computers, telecommunications and ICT training (Tables 6.8-6.9) are consistent with the findings in the 
new growth literature. We illustrate and corroborate hypothesis 4.c. in Scheme 1.1. Chapter 1 above that an increase in skill level and firm size lead to an improvement in the complementary relationships between skill, upskilling and technology (ICT).

Taken together, all these results imply the importance of a good education for bridging differences between firms and also for enhancing skill, technology and upskilling complementarity at the micro level. These findings seem consistent with the endogenous growth framework and stylized facts concerning the relationships between human capital, technical progress and upskilling and our theoretical framework in Chapter 3 above.

Finally, our results in Section 4 indicate positive significant correlations between total spending on ICT and output, but insignificant correlations between total spending on ICT and profit at the micro/firm level (Table 6.12). This result confirms the fifth hypothesis in Scheme 1.1 Chapter 1 above, which implies an inconclusive effect of ICT at the micro level and supports the observations at the macro level in the Gulf countries and the recent literature in the developing countries.

Moreover, our results in Sections 3 and 4 show the relationships between actual and required education, experience and wages; and between skill, technology (ICT) and upskilling (ICT training) defined by firm size and industry level. These results are consistent with our findings in Chapter 5 above, which imply that both skill and technology indicators vary across firms and increase with firm size and industry level.

Therefore, our findings in this chapter are consistent with hypotheses 3.b. and 4.a. in Scheme 1.1 Chapter 1 above with respect to the implications of the excessive use of unskilled foreign workers at the micro level. In addition, our results verify hypotheses 4.b. and 4.c. in Scheme 1.1 Chapter 1 above concerning the relationships between actual and required education and experience and between actual education, experience and wages and the relationships between technology (ICT), skill and upskilling (ICT training). Finally, we corroborate the fifth hypothesis in Scheme 1.1 Chapter 1 above regarding the inconclusive effect of ICT at the micro level. 


\section{Chapter 7}

\section{The Importance (Impacts) of Knowledge at the Macro-Micro Levels}

\section{1 Introduction}

Our earlier findings in Chapter 5 indicate that the transfer of knowledge is successful within firms, but is somewhat doubtful between firms and universities and within society at large. Our analysis shows that within society at large, the transfer of knowledge is hindered by low skill levels, deficient educational and training systems, lack of incentives and an imbalanced structure of the population. The transfer of knowledge between universities and firms is hindered by the lack of incentives such as subsidies, and the lack of a networks, information systems, cooperation and interest in conducting joint research between universities and firms and matching the relevance of universities' research to firms needs.

One implication of our earlier analysis is that the Gulf countries need to stimulate the incidence and transfer of knowledge at the aggregate level by providing more incentives, for example through subsidies, to education and training to upgrade skill levels, and also by raising spending on R\&D and ICT, organization, coordination and cooperation. Further incentives, such as subsidies, should be provided to stimulate the transfer of knowledge between universities and firms that requires a good knowledge base within firms and further incentives, for example subsidies to education and training to enhance skill levels, and subsidies to R\&D, networks organization, information, coordination and cooperation. In this Chapter we extend our earlier analysis and explain the importance (impacts) of knowledge at both micro and macro levels in the Gulf countries in more detail. In addition, we show the factors contributing to improve the tacit knowledge within firms. Due to the lack of relevant data to assess the transfer of knowledge amongst firms and between firms and universities, we focus only on the impacts of knowledge within the firms and at the aggregate/macro level.

The rest of this chapter is organized as follows: Section 2 briefly shows the importance and sources of knowledge in the growth literature; Section 3 presents hypothesis 7 in Chapter $I$ above to test some stylized facts about the importance of knowledge and explains the data used to test them; Section 4 discusses the main findings; and Section 5 provides the conclusions. 


\section{2 Definition, importance, sources and measurement of knowledge in the growth literature}

Endogenous growth literature recognized the importance of knowledge and its accumulation as a unique source of endogenous technologicall progress, innovation and economic growth. For instance, in the Lucas (1988) model, knowledge accumulation is vital for the growth process, for knowledge creation, accumulation and acceleration, contribution to scientific and technological progress, innovation, economic growth performance and development.

In defining 'knowledge' the literature makes a distinction between codified and tacit knowledge (Dasgupta and David (1994)). "Codified knowledge implies that knowledge is transformed into information which can either be embodied in new material goods (machines, new consumer goods) or easily transmitted through information infrastructure. While, the tacit knowledge refers to that which cannot easily transferred because it has not been stated or measured in an explicit form, skill is an important kind of tacit knowledge" ${ }^{145}$ (cf. Freeman and Soete, 1997: 404-405).

In addition, the definition of codified knowledge in the literature is closely related with investment in public spending on education, training, R\&D and ICT. Several studies perceive knowledge as a public good, produced through R\&D activities that generate spillover and thereby increasing returns (Romer, 1994; Grossman and Helpman, 1994). Other studies use broader terms to interpret knowledge created and embodied in institutions (cf. Langlois, 2001). For instance, Nelson (1993) and Lundvall (1992) emphasize the importance of institutions for the flows of knowledge and information to innovative capability. According to Smith (2002): "R\&D is but one component of knowledge and innovation expenditures, and by no means the largest. Because, R\&D data tend to either overemphasize the discovery of new scientific or technical innovations, or to exclude a wide range of activities that involve the creation or use of new knowledge in innovation. Thus, innovation rests not only on discovery and R\&D but also on learning, external environment (network) of the firm, non-R\&D expenditures such as training, market research, design, trail production and tooling up and IPR costs. In addition to capital expenditure, which is a key mode of 'embodied' knowledge spillover from the capital good sector to using industries"(Smith, 2002:14-18).

Moreover, the evolutionary framework developed by Nelson and Winter (1982) makes the nature of knowledge and firms' investment in it a central factor in explaining the size, structure and dynamics of industries. Recent empirical literature (cf. Loof and Heshmati, 2002) shows that knowledge capital (defined as the ratio of innovation sales to total sales) is found to be a significant factor contributing to performance heterogeneity and a firm's innovative level. Knowledge capital rises with innovation input, the firm's internal knowledge for innovation and cooperation with domestic universities on matters of innovation. Some empirical studies indicate that survival and growth amongst firms is determined by/ or at least influenced by differential rates of investment in knowledge (such as R\&D) (cf. Klepper and Simon, 1997) or intersectoral differences in the size and R\&D intensity of firm (cf. Levin et al., 1985). In addition, Brusoni et al. (2002) and David and Foray (1995) show that an increasing codification of knowledge stock would increase a firm's innovative performance.

${ }^{145}$ Disembodied flows of knowledge can be transmitted through movement of people, publications, etc. 
In addition, differential in the productivity and growth of different countries is significantly related to improvement in the quality of human capital, technical progress, factors of production and the capacity to create new knowledge and ideas and incorporate them in equipment and people. "Recent growth literature show increasing evidences of the growing relative importance of intangible capital in total productive wealth and the rising relative share of GDP attributable to intangible capital (Abramovitz and David, 1996; 1998). Intangible capital largely falls into two main categories: on the one hand, investment geared to the production and dissemination of knowledge (i.e. training, education, R\&D, information and coordination); on the other hand, investment geared to sustaining the physicall state of human capital (health expenditures). In the US, the current value of the stock of intangible capital (devoted to knowledge creation and human capital) began to outweigh that of tangible capital (physical infrastructure and equipment, inventories, natural resources) at the end of the 1960s. Moreover, since 1960 s annual investment rates in R\&D, public education and software have grown steadily at an annual rate of $3 \%$ in the OECD countries" (David and Foray, 2001: ]-2).

Furthermore, Drucker (1998: 15) suggests: "knowledge is now becoming the one factor of production, sidelining both capital and labour". In addition, the OECD (1999: 7) has suggested "... the role of knowlledge (as compared with natural resources, physical capital and low skill. labour) has taken on greater importance". ${ }^{146}$ Smith (2002) argues that in recent years, learning and knowledge have attracted increasing attention as a result of the claims that knowledge-intensive industries are now at the core of a growth, knowledge driven economy or even a knowledge society. The role of knowledge as an input to economic processes has fundamentally changed, probably due to rapid technological changes/ advances in ICT; ICT is seen as factor increasing knowledge and increasing the common availability of codified knowledge (David and Foray, 1995; Smith, 2002). For instance, Van Zon (2001) extends Lucas' (1988) model by incorporating the effects of ICT - capital investment and assuming that ICT has positive influence on growth performance, both by improving the intensity of production and total factor productivity and enhancing the efficiency of knowledge accumulation and learning process.

Moreover, the empirical literature shows that knowledge is positively related to human capital (mainly tacit skill or skill level). For instance, Winter (1987) suggests that tacit and codified knowledge need not be substitutes, but can be seen as complements in the learning process. Brusoni et al., (2002) show a strong positive relationship between the codification of the knowledge base of the industry and its investment in skilled people (high levels of investment in tacit skills) and R\&D.

In addition, Cowan, Soete and Tchervonnaya (2001: 9) examine knowledge transfer in the services sector as a process by which knowledge travels from a knowledge holder (a person or organization possessing the knowledge)" to a knowledge recipient (a person or organization receiving the knowledge). In their analysis "knowledge holder is important as the "point of departure" of the knowledge being transmitted since they can influence knowledge flows".

Furthermore, the literature indicates a substantial contribution to innovation and therefore to economic growth and public welfare that can be related to an unintended spillover associated with knowledge flows. ${ }^{147}$ Distinction has been made between three sources

\footnotetext{
${ }^{146}$ See Drucker (1998: 15) and OECD (1999:7) respectively.

1 th Verspagen and Schoenmakers (2000) use patent citations to measure knowledge spillover.
} 
for the flows and transfer of knowledge: for instance, Brusoni et al. (2002) highlight the importance of knowledge sources within the enterprise for innovation among innovative firms in Europe, in particular, the internal divisions (including R\&D, design, sales and marketing and senior management). Several other studies have focused on knowledge flows between firms through inter-firm research collaborations. (Hagedoorn et al., 2001), userproducer networks (Lundvall, 1992), or linkages between competing firms (von Hippel, 1988). Yet other studies examine knowledge flows between firms and public research organizations such as universities, public research institutes, government laboratories, and publicly-funded technical institutes (cf. Arundel et al., 2001; Mansfield, 1991; Mansfield and Lee, 1996). At the aggregate level, the transfer of knowledge is related to several variables such as the overall quantity of scientific research (publications) and the public research base as measured by the ratio between the total amount of higher education R\&D expenditure and the country GDP (cf. Arundel et al., 2001: 3,5).

The notion that knowledge is a public good, produced through education, training and $R \& D$ activities that generate spillovers and increasing returns, provides a plausible justification for government intervention to compensate the private sector for the positive externalities they generate and to provide more incentives to support investment and accumulation of knowledge. While Lucas' (1988) model emphasizes investment in human capital, it only implicitly allows for a role for public policy through subsidies (Haslinger and Ziesemer, 1996: 230). Subsequent studies attempted to fill this gap in Lucas' (1988) model and explicitly indicate a potential role for government intervention and public policies to support the creation and accumulation of knowledge. The main channels are through taxation or subsidisation to the provision of R\&D (cf. Romer, 1990; Barro and Sala-i-Martin, 1992; 1995), public knowledge: basic education and basic scientific research (cf. Ziesemer, 1990 ; 1995) and subsidising training (cf. Chatterji, 1995) - see our discussion in Chapter 3 above.

\section{3 The hypothesis, stylized facts and data}

Based on the above background, this section presents hypothesis 7 in Chapter 1 above to test some stylized facts about the importance of knowledge in the Gulf countries and explains the data used to test them.

\subsubsection{The importance (impacts) of knowledge at the micro-macro levels in the Gulf countries}

In recent times, few studies discuss the status of knowledge in the Arab countries. The UNDP-AHDR (2003) examines the weak status of demand, production and dissemination of knowledge in the Arab states. Aubert and Reiffers (2003) assess the challenges and underline a strategy for the development of knowledge-based economies in the Middle East and North Africa countries (MENA). Both reports provide significant contribution, but a somewhat general analysis at the aggregate/macro level that refers to all Arab and MENA countries respectively. Since the Gulf countries show considerable disparity from the other Arab and MENA countries, at least in respect of some indicators such as structure and size of the economy, level of income and structure of labour market, it might be useful to look at them separately. Thus, one obvious advantage of our analysis is that we provide a more specific analysis that focuses only on the Gulf countries. Moreover, different from earlier studies, we provide a new empirical investigation of both the importance (impacts) of tacit 
knowledge at the micro level - see our discussion below - as well as the discrepancy in the transfer of knowledge/external schooling effects at the macro-micro levels - see our discussion in Chapter 5 above.

In this chapter we use the literature presented above to examine hypothesis 7 in Scheme 1.1 in Chapter 1 above concerning the importance (impacts) of tacit and codified knowledge at the macro (within society)-micro (ivside the firms) levels. In particular, our aim is to test the following stylized facts:

1. At the macro level codified knowledge is positively correlated with economic growth (GDP), and tacit knowledge is positively correlated with schooling.

2. At the macro level codified knowledge and Full Time Equivalent Researchers (FTER) are positively correlated with each other and also with technology (patents), publications and cooperation.

3. At the micro (firm) level tacit knowledge is positively correlated with technology (ICT), upskilling (training), profit, productivity, output and output diversification.

4. At the micro (firm) level tacit knowledge is posilively correlated with market size (firm size; capital; and investment) and firm age.

\subsection{Definition of data and variables}

We use the broad definition of knowledge found in the new growth literature that highlights both the tacit and codified components of knowledge. In particular, we define tacit knowledge by the percentage share of high skilled workers in total employment at the micro level ${ }^{148}$ and the share of enrolment in tertiary education at the macro level. In addition, we use the number of full time equivalent researchers (FTER ${ }^{149}$ ) as another indicator of tacit knowledge at the macro level. ${ }^{150}$ We define codified knowledge by the embodied knowledge distributed in many indicators, including the share of spending on R\&D, education and ICT as percentage of GDP at the macro level. ${ }^{151}$ In addition, we use several variables related to knowledge such as patents, publications, cooperation - measured by joint publications, and schooling years - defined by school life expectancy - across the Gulf countries. Table 7.1 below presents the data and variables, which we use in our analysis of the importance (impacts) of knowledge at the macro/aggregate level in the Gulf countries.

\footnotetext{
148 As in Chapter 6 above, our definition of high skilled workers refer to workers with post secondary educational attaimment: university degree and above ( 16 years of schooling).

149. The concept of full-time equivalent researcher is adopted by UNESCO statistics on R\&D personnel.

150 The main limitations of our clata at the macro/aggregate level are the definition of tacit knowledge by the share/ ratios of enrolment in tertiary education (despite their drawback), the adjustment of the variables for different years and the use of unified ratio of ICT spending, due to scarcity of data.

15: At the micro level, the definition of codified knowledge by the relative term or the share of these indicators to total output or sales value does not provide relevant results.
} 


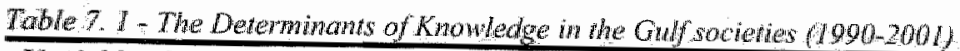

\begin{tabular}{|c|c|c|c|c|c|c|}
\hline Wariable Country & UAE & Kuwait & Bahrain & Omany & Qatmi & $\begin{array}{l}\text { Sacudi } \\
\text { Arabia }\end{array}$ \\
\hline GDP(USS bilton) $(2001)^{9(1)}$ & 69.23 & 32.0 & 7.9 & 19.8 & 16.5 & 1865 \\
\hline Schooling years $(2000)^{6(2)}$ & 10.7 & 8.7 & 13 & 8.7 & 13.1 & 9.5 \\
\hline $\begin{array}{l}\text { High skilled (share of enrolment in } \\
\text { tertiary education) }(\% \text { o }(1998) \text { bo }\end{array}$ & 12 & 21 & 25 & 8 & 28 & 21 \\
\hline FTER $(1996)^{\circ}$ & 107 & 440 & 86 & 82 & 34 & 846 \\
\hline Publications $(1990-1995)^{\text {d }}$ & 579 & 1936 & 453 & 466 & 377 & 8306 \\
\hline Coppertation $(1995)^{1}$ & 55 & 117 & 29 & 37 & 36 & 294 \\
\hline $\begin{array}{l}\text { Share of public Spending on R\&D as } \\
\text { \% of GDP }(1996)^{\circ}\end{array}$ & 0.02 & 0.22 & 0.06 & 0.07 & 0.06 & 0.14 \\
\hline $\begin{array}{l}\text { Shwre of public spending on education } \\
\text { as } \% \text { of GDP }(1995-1997)^{\text {t }}\end{array}$ & 1.7 & 5.0 & 4.4 & 4.5 & 3.4 & 7.5 \\
\hline Spending on ICT/GDP(2001) & 3.6 & 3.6 & 3.6 & 3.6 & 3.6 & 3.6 \\
\hline Codified knowledge & 5.32 & 8.82 & 8.06 & 8.17 & 7.06 & 11.24 \\
\hline Patents $(1991-1999)^{h}$ & 15 & 27 & 2 & 3 & 0 & 103 \\
\hline
\end{tabular}
10 1997 from $\mathbb{E R F}, 2002$ (3) data for Oman refers to 2000-2001.

Sources: (a) UNDP (2003) "UNDP Human Development Repor", (b) UNESCO-UIS (2003): www unesco.0rg, (c) ESCWAJUNESCO (1998), (d) Zahlan (1999a; b), (e) Qasem (1998) and GOIC (2000a), (f) UNDP (2002)

"UNDP Human Development Report", (g) WTTSA (2002), (h) US Patent and Trademark Office web site:

Maw. uspto.gow.

As in Chapter 6 above, we obtain our micro/firm data from the firm survey (2002) and use three sets of indicators, including tacit knowledge (technical and non technical skills), technology and input-output variables. We define tacit knowledge by the share of high skilled/educated workers in total employment, and technology by expenditures on ICT; imputs indicators are labour (employment size) and capital (net worth), output (total sales value), output diversification (sales diversification), productivity and profit. ${ }^{1}$

\section{4 The empirical results}

We use the data presented above and the linear and log linear OLS regression techniques to test and compare the importance (impacts) of tacit and codified knowledge at the micro and macro levels respectively and compare the relevance of our findings to those in the knowledge literature. Based on Table 7.1 above, Tables $7.2-7.3$ below present a panel data analysis reflecting the average across the Gulf countries over the period 1990-2001. Based on data from the firm survey (2002), Tables 7.4 -7.6 reflect the results across firms.

Tables $7.2-7.5$ present our results, which indicate the importance (impacts) of tacit and codified sources of knowledge at the macro (aggregate) and micro (firm) levels respectively. Some of these results are consistent with the findings in the literature (cf. Abramovitz and David, 1996; 1998; David and Foray, 2001; Loof and Heshmati, 2002). Our results in Tables 7.2 and 7.3 illustrate the importance of knowledge at the aggregate/macro level. Table 7.2 shows that tacit knowledge - defined by the number of FTER and codified knowledge show significant positive correlations with publications, cooperation and technology (patents). The correlations between tacit knowledge -defined by the number of FTER- and these variables appear more significant than those with codified

is2 As in Chapter 6 above, we use the same defmitions of educational qualifications, ICT, diversification, output, capital, labour (firm's size) and frm's age (total years in operation) - see our definitions in Chapter 6 above. In addition, we obtained information on investment variables from GOIC databases. 
knowledge. When defining the number of FTER as one form of tacit knowledge, we find a significant positive correlation between the number of FTER and codified knowledge, which can be interpreted as complementary relationship between tacit and codified knowledge (cf. Winter, 1987; Brusoni et al,, 2002). Moreover, Table 7.3 indicates a positive significant correlation between tacit knowledge - defined by tertiary school enrolment ratios and schooling years, while codified knowledge shows a positive correlation with GDP. ${ }^{153}$ In addition, we observe from Table 7.1 above that the share of public spending on R\&D is associated with an increase in the number of FTER, publications, cooperation and technology (patents), while cooperation is associated with an increase in both publications and technology (patents). Therefore, these results verify the first and second stylized facts that at the macro/aggregate level knowledge is positively correlated with GDP (economic growth), schooling years and technology (patents) across the Gulf countries.

Table 7.2 The impacts of FTER and codified knowledge on publications, copperation and patent across the Oulf cowniries (1990-2001)

\begin{tabular}{|c|c|c|c|c|}
\hline & \multicolumn{3}{|c|}{$\begin{array}{l}\text { Coefficient } \\
\text { (t-vallue) }\end{array}$} & \multirow[t]{2}{*}{$\mathbf{R}^{2}$} \\
\hline & Constant & $\begin{array}{l}\text { Tacit knowledge } \\
\text { (Number of FTER) }\end{array}$ & $\begin{array}{l}\text { Codified knowledge } \\
\text { (share of education, R\&D and ICT in } \\
\text { GDP) }\end{array}$ & \\
\hline Number of FTER & $\begin{array}{l}-843.173 \\
(-2.272)\end{array}$ & & $\begin{array}{l}136.717^{* * *} \\
(3.060)\end{array}$ & 0.701 \\
\hline $\begin{array}{l}\text { Codified knowl- } \\
\text { edge }\end{array}$ & $\begin{array}{l}6.749 \\
(10.202)\end{array}$ & $0.005^{*}$ & & 0.701 \\
\hline \multirow{2}{*}{$\begin{array}{l}\text { Number of publi- } \\
\text { cations }\end{array}$} & $\begin{array}{l}-477.469 \\
(6.729)\end{array}$ & $\begin{array}{l}9.393 * * \\
(6.729)\end{array}$ & & 0.919 \\
\hline & $\begin{array}{l}8692.351 \\
(-2.314)\end{array}$ & & $\begin{array}{l}1320.549^{* * *} \\
(2.921)\end{array}$ & 0.681 \\
\hline \multirow[t]{2}{*}{ Cooperation } & $\begin{array}{l}10.640 \\
(0.928)\end{array}$ & $\begin{array}{l}0.316^{*} \\
(10.884)\end{array}$ & & 0.967 \\
\hline & $\begin{array}{l}-248.444 \\
(-1.924) \\
\end{array}$ & & $\begin{array}{l}42.298 * \\
(2.722)\end{array}$ & 0.649 \\
\hline \multirow{2}{*}{$\begin{array}{l}\text { Technology } \\
\text { (Patents) }\end{array}$} & $\begin{array}{l}-6.755 \\
(-1.074)\end{array}$ & $\begin{array}{l}0.119 * * \\
(7.502)\end{array}$ & & 0.934 \\
\hline & $\begin{array}{l}-101.592 \\
(-1.909) \\
\end{array}$ & & $\begin{array}{l}15.606^{\text {*** }} \\
(2.436) \\
\end{array}$ & 0.597 \\
\hline
\end{tabular}

Comelation is significant * at the 0.01 level (one-tailed)

Noles: $N=6$

${ }^{153}$ In contrast to our expectations, the findings at the macro level indicate insignificant correlations between codified knowledge and schooling, and between tacit knowledge - defined by tertiary enrolment ratios - and both GDP and codified knowledge. 
Table 7.3 - The impacts of tacit and codifed hnowledge on schoolng and GDP acmoss the Gulf counmien (1990-2001)

\begin{tabular}{|c|c|c|c|c|}
\hline & \multicolumn{3}{|c|}{$\begin{array}{c}\text { Coefficient } \\
\text { (t-vialue) }\end{array}$} & $\mathrm{R}^{2}$ \\
\hline & Constant & $\begin{array}{l}\text { Tacit knowledge } \\
\text { (tertiary school enrolment } \\
\text { natios) }\end{array}$ & $\begin{array}{l}\text { Codified knowledge (share of } \\
\text { education, R\&D and ICT in } \\
\text { GDP) }\end{array}$ & \\
\hline Schooling & $\begin{array}{l}7.296 \\
(3.605)\end{array}$ & $\begin{array}{l}17.326 * \\
(1.747)\end{array}$ & & 0.433 \\
\hline $\begin{array}{l}\text { Growth of } \\
\text { GDP }\end{array}$ & $\begin{array}{l}-112 \\
(-0.976)\end{array}$ & & $\begin{array}{l}20.7^{12} \\
(1.493)\end{array}$ & 0.358 \\
\hline
\end{tabular}

Correlation is significant * at the 0.05 level (one-tailed)

Table 7.4 verifies the third stylized fact that at the micro/firms level tacit knowledge shows positive significant correlations with technology (total expenditures on ICT) and skill upgrading (total expenditures on training), total output (defined by total sales value), output diversification (defined by sales diversification), productivity and profit. ${ }^{155}$ From the perspective of the new growth literature, the positive correlation between tacit knowledge and output is important to prevent the diminishing returns to scale and to ensure the increasing returns and dynamic growth in the production function. This would imply that with the assumption of a potential role for public policies, the government could prevent the diminishing returns to scale and ensure increasing returns to scale, mainly through improving tacit knowledge by stimulating investment in education (basic, secondary and tertiary).

Table 7.4 - The significance of tacit knowledge across firms, 2001

\begin{tabular}{|c|c|c|c|c|}
\hline & \multicolumn{2}{|r|}{$\begin{array}{l}\text { Coefficient } \\
\text { (t-value) }\end{array}$} & \multirow[t]{2}{*}{$\mathbf{R}^{2}$} & \multirow[t]{2}{*}{$\mathbf{N}$} \\
\hline & Constant & $\begin{array}{l}\text { Tacit knowledge (share of high skilled in } \\
\text { total employment) }\end{array}$ & & \\
\hline ICT expenditures & $\begin{array}{l}-0.055 \\
(-4.219)\end{array}$ & $\begin{array}{l}0.210^{* * *} \\
(5.965)\end{array}$ & 0.703 & 17 \\
\hline Training expenditures & $\begin{array}{l}-0.036 \\
(-2.276)\end{array}$ & $\begin{array}{l}0.168^{* * *} \\
(4.089)\end{array}$ & 0.563 & 15 \\
\hline Total profit & $\begin{array}{l}-0.041 \\
(-2.590)\end{array}$ & $\begin{array}{l}0.278^{* * *} \\
(5.858)\end{array}$ & 0.710 & 16 \\
\hline Total output (total sales value) & $\begin{array}{l}0.071 \\
0.3712\end{array}$ & $\begin{array}{l}0.141 * * \\
(2.038)\end{array}$ & 0206 & 18 \\
\hline $\begin{array}{l}\text { Productivity (total sales value } \\
\text { per workers) }\end{array}$ & $\begin{array}{l}0.0529 \\
(0.768)\end{array}$ & $\begin{array}{l}0.637 \\
(2.985)\end{array}$ & 0.358 & 18 \\
\hline $\begin{array}{l}\text { Output diversification (sales } \\
\text { diversification) }\end{array}$ & $\begin{array}{l}1.178 \\
(8.029) \\
\end{array}$ & $\begin{array}{l}0.634^{*} \\
(1.901) \\
\end{array}$ & 0.194 & 17 \\
\hline
\end{tabular}

Correlation is significant * at the 0.05 level (one-tailed) ** at the 0.01 level (one-tailed)

Our results from the firm survey (2002) in Table 7.5 bear out the assumption that the increased use of tacit knowledge - defined by skilled workers, scientists and engineers -

154 When excluding the observations for the UAE, the coefficient in the regression equation turns significant. This result is plausible since the UAE has a low share of public spending on education and R\&D relative to GDP, when compared to other Gulf couniries. This result can then be used to argue that am increase in public spending on these components would imply an increase in GDP.

${ }_{155}$ There are also positive correlations between tacit knowledge and output, output diversification, productivity and profit that exceed the combined correlations of traditional inputs such as labour and capital not reported in Table 7.4; these results are consistent with the findings in the literature (cf. Drucker, 1998; OECD, (999). 
shows significant effects across firms. In particular, this contributes towards the improvement in firm production, the level of competitiveness in the local market, faster adaptation of foreign technology, utilization of technology and product quality. Moreover, Table 7.5 indicates that the increased use of scientists and engineers would imply additions to acquisition of existing knowledge within the firm, as well as the shortening of development time and acquisition of new knowledge, the latter regarded as of somewhat less importance. ${ }^{156}$

Toble 7.5 - The increased use and effecr of skilled workers, scientists and engimeers across firms in the UAE, 2002 (measured in \% as indicated by respondents)

\begin{tabular}{|c|c|c|c|c|c|}
\hline $\begin{array}{l}\text { The increased use of skilled workers and } \\
\text { their effects }\end{array}$ & All firms & Chemical & Metal & Medium & Large \\
\hline $\begin{array}{l}\text { (a) Increased use of skilled workers (1999- } \\
2001 \text { ) }\end{array}$ & $44 \%$ & $33 \%$ & $60 \%$ & $29 \%$ & $58 \%$ \\
\hline \multicolumn{6}{|l|}{ (b) The effects of increased use of skilled workers } \\
\hline Increase in fimn production & $90 \%$ & $78 \%$ & $100 \%$ & $75 \%$ & $100 \%$ \\
\hline Effective utilization of technologies & $75 \%$ & $89 \%$ & $64 \%$ & $75 \%$ & $75 \%$ \\
\hline Improve product quality & $60 \%$ & $67 \%$ & $55 \%$ & $63 \%$ & $58 \%$ \\
\hline $\begin{array}{l}\text { Improve the lewel of compelitiveness in the } \\
\text { local market }\end{array}$ & $90 \%$ & $78 \%$ & $100 \%$ & $88 \%$ & $92 \%$ \\
\hline Faster adaptation of technologies & $80 \%$ & $78 \%$ & $82 \%$ & $88 \%$ & $75 \%$ \\
\hline $\begin{array}{l}\text { Improve the level of competitiveness in the } \\
\text { international market }\end{array}$ & $50 \%$ & $78 \%$ & $27 \%$ & $50 \%$ & $50 \%$ \\
\hline Tolal response & 20 & 9 & 11 & 8 & 12 \\
\hline \multicolumn{6}{|c|}{ (c) The effects of scientists and engineers on firm production and acquisition of knowledge } \\
\hline The effects of scientist and engineers & All firms & Chemical & Metal & Medium & Large \\
\hline $\begin{array}{l}\text { Add technical, scientific or marketing knowledge } \\
\text { to areas where firms already had expertise }\end{array}$ & $80 \%$ & $90 \%$ & $67 \%$ & $76 \%$ & $83 \%$ \\
\hline Shorten development time & $57 \%$ & $60 \%$ & $53 \%$ & $53 \%$ & $61 \%$ \\
\hline $\begin{array}{l}\text { Add new technical, scientific or marketing } \\
\text { knowledge to areas where firms lacked expertise }\end{array}$ & $51 \%$ & $60 \%$ & $40 \%$ & $41 \%$ & $61 \%$ \\
\hline Total response & 35 & 20 & 15 & 17 & 18 \\
\hline
\end{tabular}

Source: Own calculation based on the \% as indicated by respondent firms to firm survey (2002).

Our findings in Table 7.6 prove the fourth stylized fact that at the micro/firm level tacit knowledge is significantly and positively correlated with market size: total investment, capital and firm size. Therefore at the micro/firm level an increase in total investment, capital and firm size would coincide with more tacit knowledge.

Table 7.6 - The deternimans factors enthancing tacit howledge across firms, 2001

\begin{tabular}{|c|c|c|c|c|}
\hline & \multicolumn{2}{|r|}{$\begin{array}{c}\text { Coefficient } \\
\text { (t-value) }\end{array}$} & $\mathbf{R}^{2}$ & $\mathbf{N}$ \\
\hline & Constant & Tacit knowledge (share of high skilled in total employment) & & \\
\hline Fitm size & $\begin{array}{l}-2.887 \\
(-3.804)\end{array}$ & $\begin{array}{l}0.273^{*} \\
(1.832)^{!}\end{array}$ & 0.150 & 21 \\
\hline Capital & $\begin{array}{l}0.195 \\
(6.689)\end{array}$ & $\begin{array}{l}0.0016^{*} \\
(2.353)\end{array}$ & 0.257 & 18 \\
\hline Imestment & $\begin{array}{l}-4.520 \\
(-3.167)\end{array}$ & $\begin{array}{l}0.195^{* k} \\
(2.139)^{k}\end{array}$ & 0.260 & 15 \\
\hline Firm age & 0.262 & $\begin{array}{l}0.004 \\
(0.670) \\
\end{array}$ & 0.018 & 26 \\
\hline
\end{tabular}

Correlation is significant * at the 0.05 level (one-tailed) *** at the 0.0 l level (one-tailed)

"The logarithm of the variable is taken.

${ }^{156}$ Knowledge includes technical, scientific or marketing knowledge. 


\subsection{Conclusions}

In this chapter we use the firm survey (2002) data at the micro level and secondary data at the macro level to examine hypothesis 7 in Scheme 1.1 in Chapter 1 above concerning the importance/impacts of tacit and codified sources of knowledge at the micro and macro levels respectively in the Gulf countries. Our results prove this hypothesis and show that at the macro level tacit knowledge is positively correlated with schooling years, while codified knowledge is positively correlated with GDP (economic growth). Moreover, we find that at the macro level codified knowledge and the number of FTER show positive cortelations with the number of publications, cooperation and technology (patents). Furthermore, at the aggregate level, our results imply a significant positive complementary relationship between the number of FTER and codified knowledge, which we interpret as a complementary relationship between tacit knowledge and codified knowledge. At the micro (fim) level, we illustrate the importance of tacit knowledge, which shows positive significant correlations with technology (expenditures on ICT) and upskilling (expenditures on training), output, output diversification, productivity and profit. Finally, we find that at the micro (firm) level, tacit knowledge shows positive significant correlations with total investment, capital, and firm size. This can be interpreted that higher levels of total investment, capital and firm size would correspond to more tacit knowledge across firms. Our results at the micro and macro levels verify the four stylized facts presented in the introduction, which are consistent with the general findings in the knowledge literature. The major implication of our findings is that knowledge shows positive significant correlations with many variables at both the micro and macro levels. Therefore, this would imply that public policy should provide further incentives to improve tacit and codified sources of knowledge at both the macro and micro levels. Another implication is that the positive impact of tacit knowledge also underlines the importance of good education, since tacit knowledge is often embodied in educated people and thus human capital. Moreover, from the perspective of the new growth literature, the positive correlation between tacit knowledge and output is important to prevent the diminishing returns to scale and to ensure the increasing returns and dynamic growth in the production function. This would imply that, with the assumption of a potential role for public policies, governments could prevent the diminishing returns to scale and ensure increasing returns to scale, mainly through improving tacit knowledge by stimulating investment in education (basic, secondary and tertiary). In addition, at the aggregate/macro level, the positive correlation between GDP and codified knowledge - the share of public spending on education, R\&D and ICT relative to GDP - would imply a positive role for public policy to support codified knowledge by increasing spending on education, R\&D and ICT. These results are consistent with the literature that substantiate the role of public policies to support the creation and accumulation of knowledge, as we explained in Section 2 of this chapter and Section 5 in Chapter 3 above. 
PART IV

\section{POLICY RECOMMENDATIONS, SUMMARY AND CONCLUSIONS}




\section{Chapter 8}

\section{Education, Training and Skill Development Policies in the Gulf countries: Macro-Micro Overview}

\section{Introduction}

Chapter 5 investigates the causes and consequences of deficient educational and training systems, the lack of knowledge transfer and upskilling. The results that are set out in Chapters 6 and 7 imply the importance of a good education. From that perspective, therefore, it is convenient to conclude our study by discussing the educational policies in the Gulf countries, and the training and skill upgrading plans, mechanisms and policies implemented to improve them. In particular, this chapter examines hypothesis 8 in Scheme 1.1 in Chapter I above concerning the need for skill and technological upgrading through relevant policies for skills development: enhancing the educational system, and provision of training and transfer of knowledge/external schooling effects at the macro-micro levels in the UAE.

The rest of this chapter is organized as follows: Section 1 discusses the supplydemand sides: major characteristics and implications of educational policies in the Gulf countries based on data and information obtained from the UNESCO, UNDP and other relevant sources. Section 2 examines the training and skill upgrading policies implemented by the large public firms in the UAE based on data and information obtained from these firms. Section 3 uses the results of the macro and firm surveys (2002) and the follow-up interviews to present the macro-micro views and suggestions for relevant mechanisms and policies for skill development: enhancing the educational system, provision of training and transfer of knowledge/external schooling effect. Section 4 provides the conclusions.

\section{1 Characteristics of educational policies in the Gulf countries: supply, demand, quality and impacts}

Before proceeding to discuss upskilling policies, it may be useful to begin with a brief explanation of the major characteristics of educational policies in the Gulf countries, in particular the structure and pattern of educational policies, the supply side as measured by resources or priority of financial and human investment in education. In addition, we examine the demand for education as indicated by enrolment ratios and access to schooling and the impacts on literacy, school life expectancy, training and quality of education.

The UNESCO-UIS (2004b) information on the structure/nature of educational system implies an insufficient duration of compulsory education in most of the Gulf countries. ${ }^{157}$ For instance, the duration of compulsory education in the UAE, Saudi Arabia and

157 Al-Sulayti (2002: 15) indicates the insufficient laws/regulations regarding compulsory education attendance. 
Kuwait lasts for 6-8 years and falls behind the international standard of 12-13 years of compulsory education attendance in the advanced countries such as the USA, UK and Germany. and $9-11$ years in Korea and Singapore respectively. ${ }^{158}$

"Moreover, the educational policies in the Gulf countries are characterizing by central administration pattern, which implies a high degree of centralization and interven. tion from the governments/ ministries of education to control all the educational institu. tions" (cf. Al-Sulayti, 2002: 29-30). "The ministries of education administer around $95 \%$ of educational affairs, consequently the educational institutions are lacking independence, moreover, the educational institutions are characterizing by bureaucracy, routine, institutional rigidity and lacking perfect understanding of educational policies, dynamism, flexibility, planning, organizational development, monitoring, assessment, cooperation and problems solving ability. (cf. Fahmey and Mahmoed, 1993)" (cf. Al-Sulayti, 2002: 30).

\subsubsection{The supply side of educational policies: financial and human re- sources}

We use the UNESCO definition to show the supply side/priority of educational investment as measured by financial resources (public and private educational investment, the percentage share of public spending on education in GDP and total government spending) and human resources (teaching staff). Next, we show the demand for education (enrolment ratios) and the impacts in the Gulf countries.

Priority of public investment in education is measured by financial resources devoted to education, which is indicated by the share of public spending on education as a percentage of GDP and total government expenditures. For instance, Table 8.1 illustrates that the priority of public spending on education, as measured by public spending on education as a percentage of total government spending, in some of the Gulf countries are close to the levels in the developed countries. However, only in Saudi Arabia and Kuwait is this spending as a percentage of GDP close to the levels prevalent in the developed countries, while the rest of the Gulf countries lag behind in this respect. Public spending on education as a percentage of GDP shows considerable disparity and fluctuation across the Gulf countries. For instance, in the period 1998-2002, the highest public spending on education as percentage of GDP in Saudi Arabia was close to tive and three times those of the UAE and Bahrain respectively. Moreover, the wide variations also hold for public spending on education as a percentage of total government expenditure, particularly evident between Saudi Arabia (22.8\%) and Bahrain (12\%). In addition, the trends of public spending on education as a percentage of total government expenditures vary across most of the Gulf countries, with large increase in Kuwait, Saudi Arabia and the UAE but a decline in Bahrain.

\footnotetext{
15: See the UNESCO Education Statistics: UNESCO- UIS (2004b) UIS web site global statistics on educa-
tion: www. unesco.org.
} 


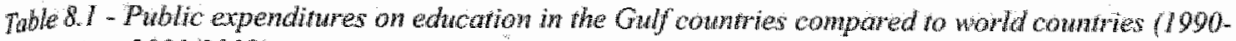
$2001 / 2002)$

\begin{tabular}{|c|c|c|c|c|c|c|}
\hline \multirow[t]{3}{*}{ Country } & \multicolumn{6}{|c|}{ Public expenditure on education as pereentage of } \\
\hline & \multicolumn{3}{|c|}{ GDP a } & \multicolumn{3}{|c|}{ Total govenment expenditures ${ }^{\text {i, }}$} \\
\hline & $1990^{\mathrm{gn}}$ & $1998 / 1999^{6}$ & $1999.2001^{2}$ & $1990^{\circ}$ & $19951.997^{\mathrm{d}}$ & $2000 / 2001^{12}$ \\
\hline Bahrain? & 4.2 & 3.67 & 3.00 & 14.6 & 12 & 11.41 \\
\hline Kuwait & 4.8 & $\mathrm{~d} / \mathrm{g}$ & $\mathrm{n} / \mathrm{a}$ & 3.4 & 14 & $\mathrm{n} / \mathrm{a}$ \\
\hline Oman & 3.1 & 3.87 & 4.2 & $\mathrm{n} / \mathrm{a}$ & 16.4 & $\mathrm{n} / \mathrm{a}$ \\
\hline Qatar & 3.5 & 3.58 & $3.6^{\mathrm{e}}$ & 11.1 & $\mathrm{n} / \mathrm{a}$ & $n / a$ \\
\hline Saudi Arabia & 6.5 & 9.47 & $8.3^{\mathrm{c}}$ & 17.8 & 22.8 & $\pi / a$ \\
\hline United Arab Enirates & 1.9 & 1.95 & $1.9^{\mathrm{C}}$ & 14.6 & 20.3 & $n / a$ \\
\hline United States & 5.2 & 5.01 & 5.6 & 12.3 & 14.4 & na \\
\hline Swedlen & 7.4 & 7.98 & 7.6 & 13.8 & 12.2 & 13,40 \\
\hline Norway & 7.1 & 7.68 & 6.8 & 14.6 & 16.8 & 16.18 \\
\hline Republic of Korea & 3.5 & 4.07 & 3.6 & 22.4 & 17.5 & 17.38 \\
\hline United Kingdom & 4.9 & 4.71 & 4.6 & $\mathrm{n} / \mathrm{a}$ & 11.6 & $n / a$ \\
\hline
\end{tabular}

Sources: (a) UNDP Human Development Report (2004), (b) UNESCO-UIS (2003), (c) UNESCO-UIS (2004c) country profile: data refers to the most recent years between 1998-2002, (d) UNDP Human Development Report (2002)

Moreover, the priority and trend of distributing the public spending varies over time between the Gulf countries. Table 8.2 shows that one common characteristic of educational policies in the Gulf countries is that the distribution/allocation of public spending on various educational levels tend to prioritize either primary or secondary education and seriously neglect tertiary education. Despite the recent gradual change in the distribution of public funding on education to increase spending on secondary education, in general the share of spending on tertiary education remains marginal and insufficient and even shows a declining trend in Saudi Arabia and Oman. Generally, there is a wide gap between Saudi Arabia, Kuwait and other Gulf countries, namely Oman and the UAE. Table 8.2 shows that the distribution of public spending by educational levels may be related to the costs of various educational levels measured by spending per pupils, thus the low spending in tertiary education is probably related to high costs of spending on tertiary compared to secondary and primary pupils.

Toble 8.2 - Percentages distibution af current expendinte and current expenditure per puph as a percentage of GNP per capita by educational level and in the Gulf cowntries (1990-2001)

\begin{tabular}{|c|c|c|c|c|c|c|c|c|c|c|c|c|}
\hline \multirow[t]{3}{*}{ Country } & \multicolumn{6}{|c|}{ Distribution of current expenditure by level $(\%)$} & \multicolumn{6}{|c|}{ Expenditure per pupil as "/o of GNP per capita } \\
\hline & \multicolumn{2}{|c|}{$\begin{array}{l}\text { Pre primary } \\
\text { and primary }\end{array}$} & \multicolumn{2}{|c|}{ Secondary } & \multicolumn{2}{|c|}{ Tertiary } & \multicolumn{2}{|c|}{$\begin{array}{l}\text { Pre primary } \\
\text { and primary }\end{array}$} & \multicolumn{2}{|c|}{ Secondary } & \multicolumn{2}{|c|}{ Terligry } \\
\hline & 1990 & 2999 & 1990 & $\begin{array}{l}1999 / \\
200 \|\end{array}$ & $1990^{b}$ & $\begin{array}{l}1999 / \\
2001^{\circ}\end{array}$ & 1990 & 1996 & 1990 & 1996 & 1990 & 1996 \\
\hline Bahrain & $\mathrm{n} / \mathrm{a}$ & 68.8 & 45.8 & n'a & $n / 2$ & $\mathrm{n} / \mathrm{ad}$ & 9 & 8 & 23 & 19 & $n / 1$ & $n / a$ \\
\hline Kuwati & 53.4 & $68.5^{1}$ & 13.6 & $\mathbf{n}$ & 16.0 & $30 n 2^{3}$ & 16 & 14 & $\mathrm{n} / \mathrm{a}$ & Di & $\mathrm{n} / \mathrm{a}$ & 87 \\
\hline Oman & 54.1 & 36.4 & 37.0 & 51.4 & 7.8 & 1.8 & 12 & $\mathrm{n} / \mathrm{a}$ & $2 !$ & $\mathrm{n} / \mathrm{tat}$ & 68 & $n / a$ \\
\hline $\mathrm{KSA}$ & 78.8 & $82.2^{1}$ & $\mathrm{n} / \mathrm{a}$ & $84.4^{2}$ & 21.2 & $15.6^{3}$ & 25 & 19 & $\mathrm{n} / \mathrm{a}$ & $\mathrm{In} / \mathrm{a}$ & 126 & 58 \\
\hline UAE & $53.8^{2}$ & 51.9 & $46.2^{2}$ & 46.4 & $\mathrm{~m} / \mathrm{a}$ & $\mathrm{n} / \mathrm{a}$ & $\mathrm{n} / \mathrm{a}$ & $\mathrm{n} / \mathrm{a}$ & $\mathrm{n} / \mathrm{a}$ & n'a & nia & $\mathrm{n} / \mathrm{a}$ \\
\hline
\end{tabular}

Note: (1) Data refers to $1996 ;$; 2 ) data refers to 1995-1997; (3) data refers to 1998.

Sources: (a) UNDP Human Development Report (2004), (b) UNESCO UIS (2000) World Education Report (2000), and (c) UNESCO-UIS (2003).

One common characteristic of educational policies in the Gulf countries is the lack of incentives or marginal contribution of the private sector on educational investment. Table 8.3 
shows that the educational investment is almost entirely dependant on the public sector, with a very minimal contribution from private sector. More recently though, following the: declining trends of public spending, private spending on education shows an opposite in: creasing trend to fill the gap in most of the Gulf countries. The extent of privatization shows an increasing trend in the UAE, Qatar and Oman but a declining trend in Bahrain.

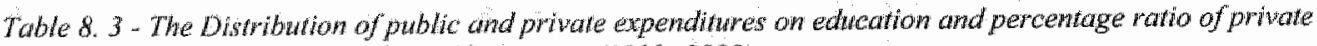
encolment rario in the Gulf cowntes (1990-2000)

\begin{tabular}{|c|c|c|c|c|c|c|c|c|}
\hline \multirow[t]{3}{*}{ Country } & \multicolumn{4}{|c|}{$\begin{array}{l}\text { Public and private spending on } \\
\text { education }(\%)^{a}\end{array}$} & \multicolumn{4}{|c|}{ Private enrolment at secondary and primary levels (\%) } \\
\hline & \multicolumn{2}{|l|}{ Public } & \multicolumn{2}{|c|}{ Private } & \multicolumn{2}{|c|}{ Secondary level } & \multicolumn{2}{|c|}{ Primary level } \\
\hline & 1990 & 1996 & 1990 & 1996 & 199011991 & $1999 / 2000$ & $1990 / 1991$ & $1999 / 2000$ \\
\hline Bathain & 94.3 & 94.8 & 5.7 & 5.2 & 8.8 & 15.8 & 13.2 & 19.1 \\
\hline Kuwait & $\mathrm{n} / \mathrm{a}$ & $n / a$ & $\mathrm{n} / \mathrm{a}$ & $\mathrm{n} / \mathrm{a}$ & $n / a$ & 27.9 & 25.0 & 31.1 \\
\hline Oman & 92.0 & 89.7 & 8 & 10.3 & 0.7 & $\mathrm{n} / \mathrm{a}$ & 1.7 & 4.5 \\
\hline Qatar & 97.3 & 91.8 & 2.7 & 8.2 & 12.3 & $\mathrm{n} / \mathfrak{a}$ & 23.4 & $\mathrm{~N} / \mathrm{a}$ \\
\hline$K S A$ & 94.4 & 93.4 & 5.6 & 6.6 & 2.8 & $\mathrm{n} / \mathrm{a}$ & 4.1 & 6.4 \\
\hline UAE & 95.4 & 92.3 & 4.6 & 7.7 & 20.6 & 32.0 & 32.2 & 45.0 \\
\hline
\end{tabular}

Sources: (a) UNESCO-UIS (2000) World Education Report (2000): UNESCO'S World Education Indicators, (b) UNESCO- UIS (2003).

The adequacy of human resources in education or teaching staff can be defined by pupilteacher ratios; Table 8.4 shows that the adequacy of teaching staff varies across the Gulf countries and is generally better for secondary education when compared to primary education and, in most cases, to tertiary education. One serious common problem with respect to human resources in education is the low quality of teaching staff as reported in the Gulf literature. "The educational system in the Gulf countries suffers from serious weak performance/low quality of teachers due to a lack of teaching skills and knowledge of recent teaching and learning techniques. For instance, a study investigates the teaching skills amongst university graduates who applied for Arabic, English and Mathematics teaching jobs in the public schools in Bahrain (1995/1996) shows that applicants success ${ }^{159}$ in engineering studies, science, social science, commercial science and English are respectively $10 \%, 43 \%, 49 \%, 39 \%$ and $59 \% \%$. ${ }^{160}$

Table 8. 4-Pupit-reacher ratio by level of education in the Gulf countries (1990-2001/2002)

\begin{tabular}{|c|c|c|c|c|c|c|c|c|}
\hline \multirow[t]{2}{*}{ Countey } & \multicolumn{3}{|c|}{ Primary } & \multicolumn{3}{|c|}{ Secondary } & \multicolumn{2}{|c|}{ Tertiary } \\
\hline & $1990^{4}$ & $\begin{array}{l}1998 / \\
2002^{\circ}\end{array}$ & $\begin{array}{l}2001 / \\
2002^{\circ}\end{array}$ & $1990^{\pi / 7}$ & $1996^{18}$ & $\begin{array}{l}2001 / \\
2002^{\circ}\end{array}$ & $\begin{array}{l}1998 \\
11999^{\circ} \\
\end{array}$ & $\begin{array}{l}2001 \\
2002^{\circ}\end{array}$ \\
\hline Bahain & 19 & 16 & 16 & 16 & 15 & 12 & n: & $\mathrm{n} / \mathrm{a}$ \\
\hline Kuwait & 18 & 14 & 14 & 10 & 11 & 10 & 1.5 & $\mathrm{n} / \mathrm{a}$ \\
\hline Oman & 28 & 23 & 23 & 16 & 18 & 18 & $\mathrm{n} / \mathrm{a}$ & 31 \\
\hline Qatar & 11 & 12 & 12 & 9 & 10 & 10 & 14 & 13 \\
\hline KSA & 16 & 12 & 12 & 13 & 13 & 13 & 18 & 20 \\
\hline$\cup A E$ & 18 & 15 & 16 & $\mathrm{n} / \mathrm{a}$ & 13 & 1.3 & 13 & $\mathrm{n} / \mathrm{a}$ \\
\hline
\end{tabular}

Sources: (a) UNESCO - UIS (2000), World Education Report 2000; wWw unesco,org, (b) UNESCO- UIS (2004c) country profile: Data refers to most recent years between 1998-2002 and (c) UNESCO- UIS (2004d) Educational statistics (1998-2002)

\footnotetext{
${ }^{159}$ The applicants who passed the exams.

164) See the Ministry of Edtcation in Bahrain State (1995-1996) Unpublished Report in Al-Sulayti (2002:
} 


\subsection{The demand side of educational policies: the demand for and enrol- ment in education}

Apart from the supply side, it is also important to examine the demand for education as measured by enrolment ratios. Table 8.5 illustrates that enrolment ratios vary across the Gulf countries, decline with the increase of educational level and, on average, lag far behind the levels in the developed countries. In particular, average enrolment ratios in tertiary education in all Gulf countries (21.35-18.52\%) remain very low and lag far behind the levels of the developed countries $(58.39-85 \%)$. That also holds for net enrolment ratios in primary and secondary education in the Gulf, except Bahrain and Qatar, which have enrolment ratios approaching those of the developed countries and are higher than in other Gulf countries. ${ }^{16}$

Table 85- Enrolment ratios by educational level in the Gulf compared to world coumtries (1990-2001/2002) (04)

\begin{tabular}{|c|c|c|c|c|c|c|c|c|c|c|c|}
\hline \multirow{2}{*}{$\begin{array}{l}\text { Edu- } \\
\text { cati- } \\
\text { omal } \\
\text { leviel } \\
\text { Year! } \\
\text { Country }\end{array}$} & \multicolumn{2}{|c|}{ Primary level } & \multicolumn{2}{|c|}{$\begin{array}{l}\text { Secondary } \\
\text { level }^{\text {*t }}\end{array}$} & \multicolumn{2}{|c|}{ Tertiary level ${ }^{\mathrm{a}, \mathrm{b}}$} & \multicolumn{3}{|c|}{$\begin{array}{l}\text { Tertiary students in } \\
\text { Science, Matli and } \\
\text { Engineering }{ }^{\mathrm{a}, \mathrm{b}}\end{array}$} & \multicolumn{2}{|c|}{$\begin{array}{l}\text { Vocational } \\
\text { education (1990- } \\
1995)^{*}\end{array}$} \\
\hline & $\begin{array}{l}1990 / \\
1991 \\
\end{array}$ & $\begin{array}{l}2001 / \\
2002 \\
\end{array}$ & $\begin{array}{l}1990 / \\
1991 \\
\end{array}$ & $\begin{array}{l}2001 / \\
2002 \\
\end{array}$ & $\begin{array}{l}1998 / \\
1999^{\circ}\end{array}$ & $\begin{array}{l}2000 / \\
2001 \\
\end{array}$ & $\begin{array}{l}1994 / \\
1997\end{array}$ & $1996^{6}$ & $\begin{array}{l}1996 \\
c(4)\end{array}$ & $\begin{array}{l}1990 / \\
1991\end{array}$ & $\begin{array}{l}1994 t \\
1995\end{array}$ \\
\hline Bahrain & 99 & 91 & 85 & 81 & 25.20 & $\mathrm{n} / \mathrm{a}$ & $n / a$ & $n / a$ & 42 & 13.25 & 12.69 \\
\hline Kuwait & 49 & 85 & $\mathrm{n} / \mathrm{a}$ & 77 & 21.08 & $\mathrm{n} / \mathrm{a}$ & 23 & 27 & $\mathrm{n} / \mathrm{at}$ & $0.62^{(1)}$ & 0.69 \\
\hline Oman & 69 & 75 & $\mathrm{n} / \mathrm{a}$ & 68 & $\mathrm{n} / \mathrm{a}$ & 8.49 & 30 & 36 & 32 & 2.79 & $1.41^{(5)}$ \\
\hline Qatar & 89 & 94 & 70 & 78 & 27.66 & 24.62 & $\mathrm{n} / \mathrm{a}$ & $\mathrm{n} / \mathrm{a}$ & 19 & 2.92 & 1.78 \\
\hline KSA & 59 & 59 & 31 & 53 & 20.71 & $22.4^{(2)}$ & 18 & 21 & 24 & 2.78 & $2.34^{(3)}$ \\
\hline UAE & 100 & 81 & 58 & 72 & 12.10 & $\mathrm{n} / \mathrm{a}$ & 27 & 29 & 25 & 0.71 & 1.41 \\
\hline Average & 77.5 & 80.83 & 61 & 71.5 & 21.35 & 18.52 & 24.5 & 28.3 & 28.4 & 3.85 & 3.39 \\
\hline Gulf & & & & & & & & & & & \\
\hline US & 97 & 93 & 85 & 85 & 75.66 & 72.62 & $\mathrm{n} / \mathrm{a}$ & $\mathrm{n} / \mathrm{a}$ & $n / a$ & $\mathrm{nu} / \mathrm{a}$ & $\mathrm{n} / \mathrm{a}$ \\
\hline Sweden & 100 & 102 & 85 & 99 & 62.30 & 70.04 & 31 & $\mathrm{n} / \mathrm{a}$ & $\mathrm{n} / \mathrm{a}$ & $\mathrm{n} / \mathrm{a}$ & $n / a$ \\
\hline Korea & 104 & 101 & 86 & 89 & $65^{\mathrm{s}}$ & 77.62 & 34 & $\mathrm{n} / \mathrm{a}$ & $\mathrm{n} / \mathrm{a}$ & 18.04 & 18.64 \\
\hline UK & 100 & 101 & 81 & 95 & 58.39 & 59.53 & 29 & $\mathrm{n} / \mathrm{a}$ & $\mathrm{r} / \mathrm{a}$ & $\mathrm{n} /$ a & $\mathrm{n} / \mathrm{a}$ \\
\hline Finland & 98 & 100 & 93 & 95 & $83^{\circ}$ & $85^{\circ}$ & 37 & $\mathrm{n} / \mathrm{a}$ & $\mathrm{n} / \mathrm{a}$ & $\mathrm{n} / \mathrm{a}$ & $\mathrm{n} / \mathrm{a}$ \\
\hline
\end{tabular}

Notes: (1) Data refers to $1992 / 1993$, (2) data refers to 1999/2000, (3) data refers to (\%) of tertiary sudents in natural science, engineering, agriculture and medical sciences 1996 (4) data refers to (\%) of tertiary graduates in natural science, engineering, agriculture and medical sciences 1996 (5) data refers to $1993 / 1994$.

Sources: (a) UNDP Human Development Report (2004), (b) UNDP Human Development Report (2002), (c) UNESCO- UIS (2000) UNESCO's: World Education Report 2000, (d) UNESCO (1996) Statistical Yearibook and UNESCO Statistics: www unesco.org. (e) UNESCO- UIS (2004b) UIS web sile global statistics on education: yww unesco.org.

One major problem of educational system in the Gulf countries is the recent stagnation in enrolment in tertiary education, for instance, after considerable improvement in enrolment in tertiary education in the UAE until around 1994, the enrolment figures have stagnated in recent years - see Figure 8.1 below. Therefore, this implies an ample role for policy making to improve enrolment in tertiary education. In addition, as in most other developing countries, one serious problematic feature concerning the tertiary education in the Gulf is that enrolment and graduation ratios in tertiary education are biased against scientific, technical,

\footnotetext{
161 "Probably, the low enrolment at secondary level is attributed to high drop out in transition from primary to secondary schooling and lack of effective actions in educational policy to legitimize the compulsory education" (Al-Sulayti, 2002: 15).
} 
engineering, agriculture, medical and natural sciences and focused on art, humanities, law and social sciences. For instance, in the period 1990-1996, enrolment and graduation ratios in medical sciences, natural sciences, engineering and agriculture accounted for onlly $28 \%$ as compared to $72 \%$ for art, humanities, law and social sciences; these biases are particularly serious in Saudi Arabia, Qatar, Oman and the UAE - see Table 8.5 above. ${ }^{162}$ The share of tertiary students enrolled in sciences, math and engineering in the Gulf is low compared to Korea (34\%), Algería (50\%) and China (53\%) - cf. Figure 8.2 below. A further problematic feature of higher education in the Gulf appears from the relative distribution of tertiary education students by attainment levels. Figure 8.3 below shows that for the majority $(96 \%)$ of tertiary students the attainment was less than a university degree, while only a few (4\%) obtained the first university degree or higher, falling far behind China (48\%) and Korea $(41 \%)$.

Figure 8.1" Gross enrolment in tertiany education in the UAE, Bahrain, Brazil and the Netherlands (1980$1998)(\%)$

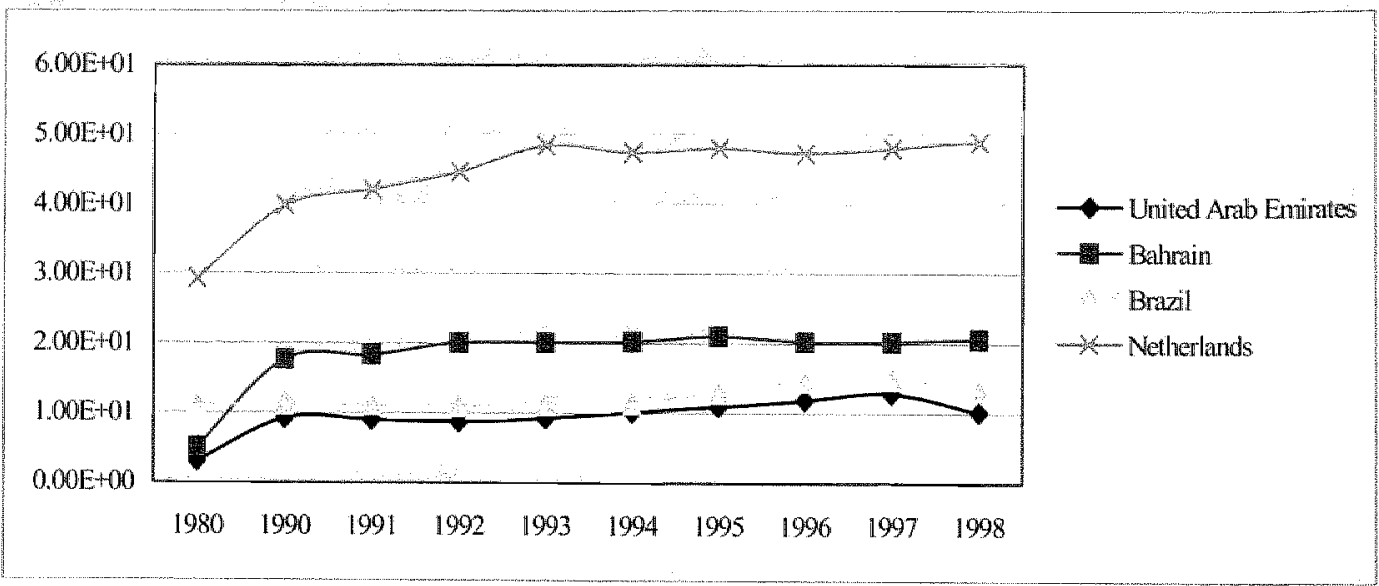

Source: WDI (2004) Database

162 "The irrelevant wrong policy for admission in higher education leatls to focus on humanities and social science and biases against science, technology and engineering studies leads to mismatch, unemployment, shortage of technical skills that leads to dependence on foreign technical skills" (Al-Sulayti, 2002: 16-18), "The low share of enrolment in technical education relative to total enrolment in tertiary education, is probably attributed to both social/cultural aspect in the society that discourage the involvement in technical work and the weak relationship between educational policies and development planning" (Alfakhery, 1999: $82)$. 
Figme 8.2- Relative distribution of tertiary education students (o) by fields in the Gulf coumres comparet to Algeria, India. China and Korea (1994/1997-1999/2000)

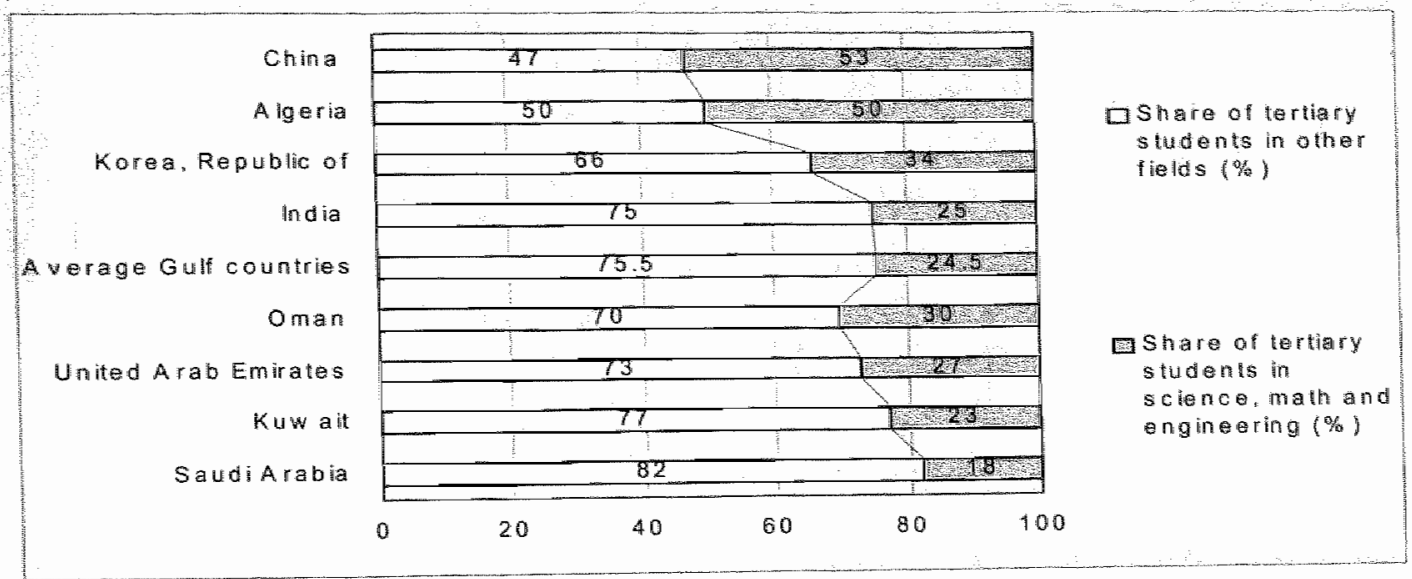

Source: UNDP (2004)

Figure 8.3-Rellative distribution of tertiary education students (\%) by atiainment levels of higher edhcation in the Gulf countries compared to China and Korea (1999/2000)

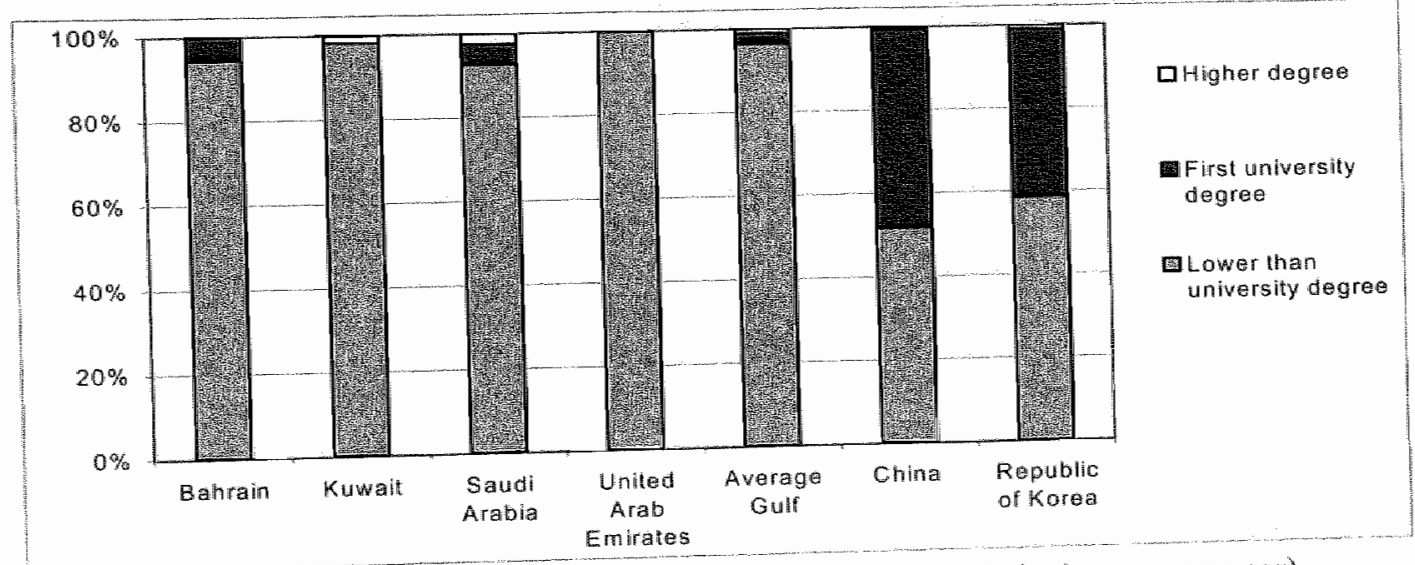

Sources: UNDP - AHDR (2003) and UNESCO-UIS (2003): UNESCO web site (www.unesco.org)

Further serious problems include the negligence of vocational education across the Gulf countries (except Bahrain) and the problem of the declining trend in the enrolment ratios in wocational education in the Gulf countries (except the UAE and Kuwait), see Table 8.5 above.

Moreover, another problematic feature is the lack of incentives/minimal enrolment in private schooling compared to intensive enrolment in public schooling, which may be related to the high cost of private schooling and the minimal contribution of the private sector spending in total spending on education compared to the public sector. Similar to public enrolment, private enrolment ratios decline with the increase of educational level, i.e. are higher at primary level and lower at secondary level. Private primary and secondary enrolment ratios show an increasing trend over time with considerable variation across the 
Gulf countries, namely between the UAE and Saudi Arabia and Oman, see Table 83 above. ${ }^{163}$

\subsubsection{Return and quality of educational policies}

Another common characteristic of the educational system in the Gulf countries is the weak internal efficiency/quality of both primary and secondary education; the severity of the problem varies across the Gulf countries. ${ }^{\text {If }}{ }^{\text {For }}$ For instance, Table 8.6 illustrates that in the period 1990-2002, the percentage of repeaters in primary schooling is higher in both Saudi Arabia and Oman, while the percentages of transition to secondary and tertiary education are low in both Saudi Arabia and UAE ${ }^{16}$

The average for all Gulf countries in terms of quality of education has improved over time, as is apparent from the considerable decline in the percentage of repeaters in primary schooling and increase in the percentages of transition from primary to secondary education, however, across individual Gulf countries poor quality is still obvious. For instance, Table 8.6 indicates that throughout the period 1990-2002, the percentages of repeaters in primary schooling remained the same in Kuwait. In half of the Gulf countries namely, Bahrain, Oman and Qatar- the percentages of transition from primary to secondary education has declined. Therefore, further efforts are needed to enhance the quality of education at all levels, in order to avoid the exacerbation of the problems that will result in the event of a failure to implement some effective polices to improve the quality of education.

\footnotetext{
16. The scarcity of reliable information limited our analysis from discussing two interesting issues related to educational policies: the contribution of private sector in both spending and enrolment in rertiary education: and the enrolment of the citizens from the Gulf countries in overseas educational institutions. The high GDP per capital has encouraged a considerable number of the citizens from the Gulf countries to seek higher education abroad. The only available information indicates that during the period 1999-2002/2003 the number of students from Saudi Arabia, Qatar and Oman who study in the United States declined by $31 \%, 26 \%$ and $25 \%$ respectively - see the UNDP - AHDR (2003: Table 1: 23). This may substantiate the need for improving domestic higher educational institutions to fill the gap and absorb the students who have neturned.

los No relevant daia and information are available to allow an assessment of the quality of tertiary education.

165. "The poor quality is attributed to: (a) High repetition rates, for instance, repetition rate at primary level for female in Saudi Arabia is around 14\%, at some secondary level in Kuwait increased to $31 \%$ and at industrial education level in Bahrain increased to $38 \%$. (b) Weak absorptive capacity and performance level of students at all levels. (c) Failure of educational strategy to motivate innovative skills and problem solving ability/skills. (e) Weak monitoring and examination systems due to traditional, inefficient and subjective assessment methods and lack of international recognition/ bases. (f) Lack of monitoring systems/ institutions to measure and assess the performance of educational and training institutions" (Al-Sulayti, $2002 ; 2(-24)$.
} 
Talde 8 - Ouality of Education in the Gulf counfies: percentage of repetition and transition (1900.2002)

\begin{tabular}{|c|c|c|c|c|c|}
\hline \multirow{2}{*}{ Indicatar } & \multicolumn{2}{|c|}{$\begin{array}{l}\text { Percentage of repeat- } \\
\text { ers: primary education } \\
(\%)\end{array}$} & \multicolumn{2}{|c|}{$\begin{array}{l}\text { Percentage of reaching secondary } \\
\text { and tertiary education (\%) }\end{array}$} & $\begin{array}{l}\text { Primary to secondary } \\
\text { tramsition rates }(\%)\end{array}$ \\
\hline & $1990^{31}$ & $1998-2002^{\mathrm{b}}$ & (Secondary) 1995 & (Tertiary) & $1998-2002^{6}$ \\
\hline Bathrain & 5 & 4 & 99 & 95 & 98 \\
\hline Kuwait & 3 & 3 & 97 & 96 & 98 \\
\hline Oman & 9 & 4 & 99 & 96 & 98 \\
\hline Qatar & 7 & 3 & 100 & 98 & 96 \\
\hline Saudi Arabia & 9 & 5 & 96 & 89 & 97 \\
\hline UAE & 4 & 3 & 93 & 83 & 98 \\
\hline Average Gulf & 6.17 & 3.67 & 97.33 & 92.83 & 97.5 \\
\hline
\end{tabular}

Sources: (a) UNESCO-ULS (2000) UNESCO's World Education Report (2000 (b) Calculated from UNESCO UIS (2004c) country profile: statistics refer to the most recent year between 1998-2002.

In addition, the poor quality of education can be observed from the results of the Third International Mathematics and Science Study Score for students during 1994-1995, where the poor performance of Kuwait [taken to represent the Gulf countries] in terms of mathematics and science school training fell far behind Singapore, USA, Japan and Europe. For instance, of the 41 countries in which half a million 13 years old were tested, Kuwait with Colombia and South Africa took the last three places in both subjects, while Singapore reached first place in both subjects ahead of the USA, Europe and Japan, which scored third place in both subjects. These figures indicate that there are indeed large quality differences in two subjects of critical importance to technological and skill development (cf. Lall, 1999; 2223).

\subsubsection{The impacts of educational policies on literacy and access to school- ing (school life expectancy)}

Educational policies in all the Gulf countries lead to only slight improvements in school life expectancy in the UAE, Kuwait and Qatar and enrolment in all educational levels in Bahrain and Qatar. However, the educational policies have insufficient effects on improving school life expectancy, which remains low and lags behind when compared to the international standard. One important positive implication of educational policies is the increase in literacy rates; however, the educational policies have so far only managed to alleviate rather than fully eliminate the youth illiteracy problem in the Gulf countries. For instance, Table 8.7 illustrates that in the year 2002, the illiteracy rates amongst the youth population are in excess of $5 \%$ in Qatar (5.2\%), Saudi Arabia (6.5\%), Kuwait (6.9\%) and the UAE (8.6\%), and are lower than $2 \%$ only in Oman $(1.5 \%)$ and Bahrain $(1.4 \%)$. This implies that there is an ample room for policy to increase the literacy rate among the young population.

Furthermore, when comparing the supply and demand sides, we observe that the supply side or public spending seems to be only one component in the educational policies, because higher public spending per se does not imply a higher demand, participation and enrolment ratios, access to schooling/school life expectancy and higher literacy rate. For instance, despite higher spending on all these counts, Saudi Arabia falls behind Bahrain, which reports moderate spending but better demand/enrolment ratios at all educational level, access to schooling/school life expectancy and literacy rates. 
Table 8.7- Educational outcomes: Youth itherocy rate and school hife expectancy in the Gulf cowntries (1990-

\begin{tabular}{|c|c|c|c|c|c|c|}
\hline \multirow[t]{2}{*}{ Country } & \multicolumn{2}{|c|}{$\begin{array}{l}\text { Youth illiteracy rane } \\
(\% \text { ages } 15-24)^{2}\end{array}$} & \multicolumn{2}{|c|}{ 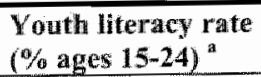 } & \multicolumn{2}{|c|}{ Sehool Life Expectancy ${ }^{\text {be }}$} \\
\hline & 1990 & 2002 & 1990 & 2002 & $1992^{b}$ & $1998^{\circ}$ \\
\hline Bahrain & 4.4 & 1.4 & 95.6 & 98.6 & 13.5 & 13.0 \\
\hline Kuwail & 12.5 & 6.9 & 87.5 & 93.1 & $7.0^{(1)}$ & 8.7 \\
\hline Oman & 14.4 & 1.5 & 85.6 & 98.5 & $\mathrm{n} / \mathrm{a}$ & $8.76-9.0^{(2)}$ \\
\hline Qutar & 9.7 & 5.2 & 90.3 & 94.8 & 11.8 & 13.1 \\
\hline Saudi Arabia & 14.6 & 6.5 & 85.4 & 93.5 & 8.5 & nia \\
\hline UAE & 15.3 & 8.6 & 84.7 & 91.4 & 10.6 & 10.7 \\
\hline
\end{tabular}

Note: (1) Data refers to 1991 (2) Data refers to 2000/2001

Sources: (a) Callculated from UNDP Human Development Report (2004) (b) UNESCO-UIS Statistical Yearboogh (1999): www unesco org (c) UIS-UNESCO (2003): www. unesco.org.

\section{2 The impact of educational policies on training policies: large public firms and public policies of training and skills upgrading}

Educational policies in the Gulf countries have insufficient effect on training provision and failed to integrate sufficiently with training policies. "The relationship between the educational and training policies vary across the Gulf countries, as technical education and training are either integrated with or separated from educational institutions. ${ }^{166}$ Despite these differences, however, in both cases the educational policies in the Gulf countries are still in need to enhance the fruitful cooperation, co-ordination and integration with training policies" (Al-Sulayli, 2002: 20-21).

Earlier findings in Chapter 5 show that the lack of interaction between educational and training systems hinders the provision of training and upskilling plans within private firms, and also leads to duality/discrepancy between macro-micro views with respect to implementation of upskilling plans. We will illustrate below that the interaction between educational and training policies appears to be effective only within large public firms that adopt training policies consistent / in line with public policies.

Table 8.8 illustrates that the three largest public enterprises in the UAE, namely, the Gulf Pharmaceutical Industries (JULPHAR), Abu Dhabi National Oil Company (ADNOC) and Dubai Aluminium Company (DUBAL), all seem committed to implement diversiffied training and skill upgrading policies that are quite consistent with the line taken by public policies. In particular, they adopt similar strategies that highlight training and upskilling of workers, linkages with universities to absorb national graduates, active human resources development units and recruitment policies to set up and implement regular internal and external training plans and wide use of ICT to upskilling workers especially national workers. Therefore, in contrast to the private firms, the large public firms (JULPHAR, ADNOC and DUBAL) have successfully contributed to serve the public policies for enhancing training and skill upgrading, especially amongst the national workers - cf. Table 8.8 below. However, it is less clear whether the large public firms induce positive effects on upskilling workers in private firms. In our view, the interpretation of the serious public-private dis-

\footnotetext{
${ }^{166}$ In most of the Gulf countries - Bahrain, Qatar, Oman and the UAE - both the educational and training institutions are integrated withim one entity administered by the ministries of education, whereas in both Saudi Arabia and Kuwait the technical education and training are administered by independent institutions headed by the minister of labour and social affairs and the minister of education respectively (Al-Sulayti,
$2002: 20$ ).
} 
crepancy can be attributed to presence of high resources, support and incentives within public firms, which are probably lacking within private firms. ${ }^{167,168}$

Table 8.3-Human nesounces development and raming policies in the large public fows in the UAE

\begin{tabular}{|c|c|}
\hline Wirmo & $\begin{array}{l}\text { Human resources develiopment strategies and training policies in JULPHAR, DUBAL, } \\
\text { and } A D N O C\end{array}$ \\
\hline 1. JULPHAR & 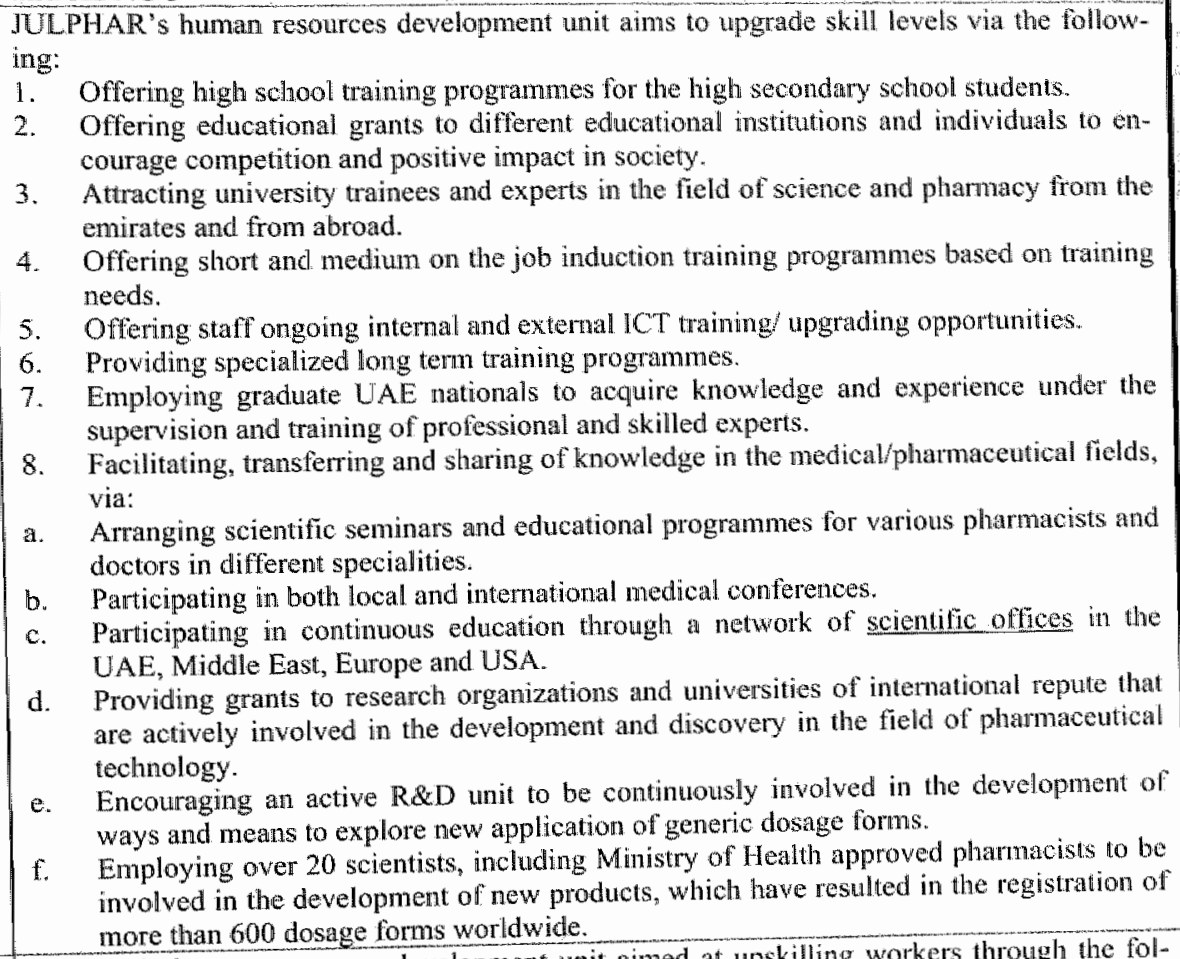 \\
\hline 2. DUBAL & 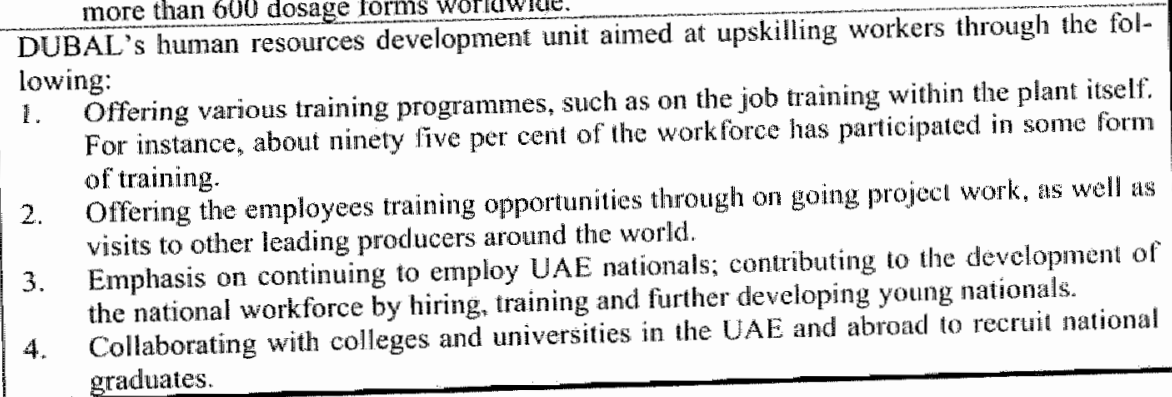 \\
\hline
\end{tabular}

167 For instance, the selected three largest public tirms have several common characteristics such as large market size, namely size of employment, capital (local capital), market, products, sales, sales revenues; investment in ICT, use of advanced technologies and active R\&D/technology development unit.

${ }^{168}$ From the results of the firm survey (2002) and the selected three cases of large public firms studied in this chapter, it may be true that public firms are systematically larger than private fintms. It is therefore plausible to expect that the large public firms to have higher financial capacity to support training and skill upgrading than private firms. However, it is less clear and hard to make generalization to conclude whether this applies to all other public firms as well, because the available information for the UAE indicate the classification of firms according to size, activities and ownership (nationality of matin owner(s)) rather than public-private sectors. 


\begin{tabular}{|c|c|}
\hline & 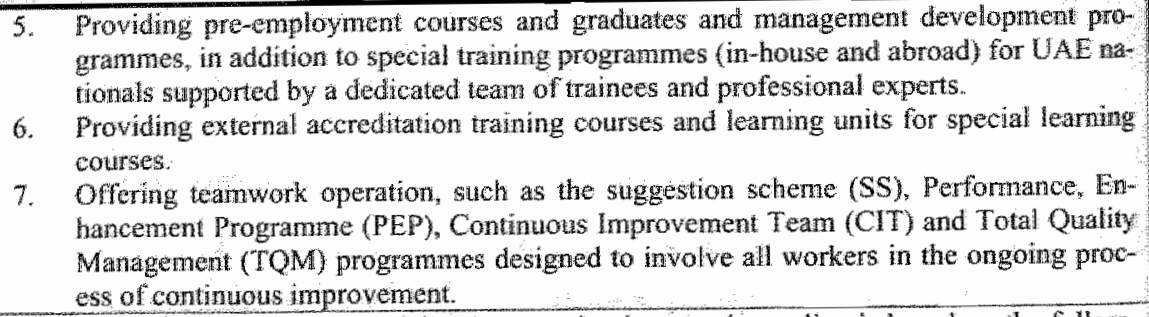 \\
\hline $3, A D N O C$ & 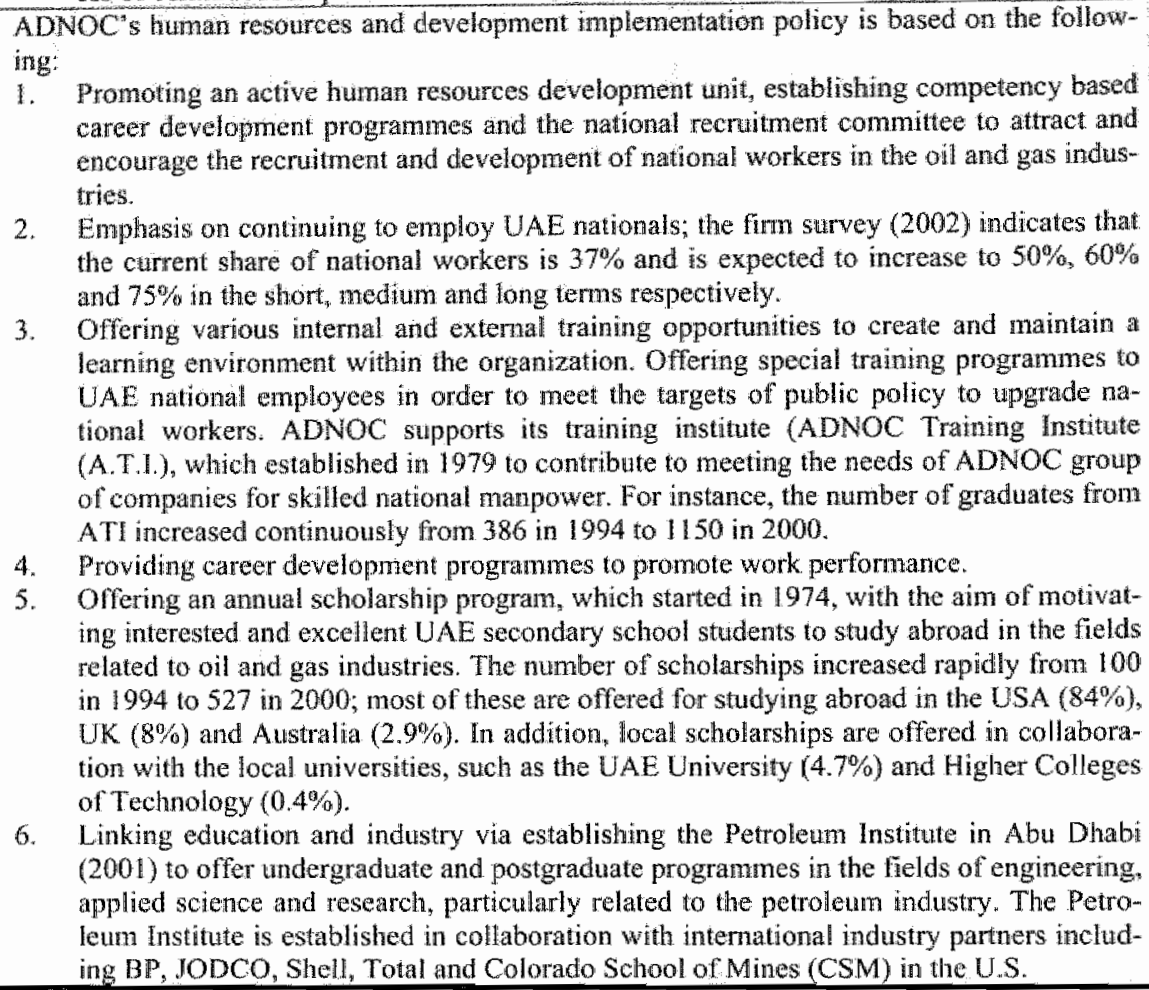 \\
\hline
\end{tabular}

Sources: (a) JULPHAR Achievement Report, publications and web site, (b) DUBAL Achievement Report, publications and web site and (c) ADNOC Achievement Report (1995-1999), A.DNOC Human Resources Developthent book, publications and web sites.

The major policy implication from these findings is that the improvement of the educational systems in the Gulf countries is essential and requires improvement of the quality/internal efficiency, supply (investment) and demand (enrolment) sides, particularly with respect to tertiary and technical education. From that perspective, we explain below the views of the policy makers and experts regarding the relevant plans and policies to reform the educational system, which is essential for skill development. After that, we show that policy makers, experts and firms all view the improvement of education as important for enhancing the provision of training and knowledge transfer/external schooling effects. 


\section{3 Plans, Policies and mechanisms for skill development: the macro- micro views}

It is useful in this section to discuss and compare first the relevant plans and then policies and mechanisms for skill development from both macro and micro perspectives/views.

\section{3.1 Plans for skill development: the macro-micro views}

In light of the above findings, we now use the results of the macro and firm surveys (2002) to provide insights to help generate policies to enhance skill levels by implementation of short and long terms plans at the macro-micro levels. We then compare and integrate the macro (official: policy makers and experts) and micro (firms) views concerning the important tools and plans for skills development in the current, short run and long run.

The policy makers and experts suggest several important instruments for skills development, some of which have already been implemented and others being implemented now or in the near future. For instance, Table 8.9 shows that the policy makers and experts highlight investment in vocational training and formal education, improving the quality of teachers, trainers and mentors, and investment in training of existing employees. This is to be coupled with learning on the job, sending teachers and mentors abroad to acquire knowledge and skills, using ICT to upgrade skill levels, enhancing the system of accreditation and licensing and enhancing the system or programme of apprenticeship. Measures such as sending students abroad to acquire knowledge and skills, supporting long distance learning, sending workers abroad to acquire skills and bringing/attracting new foreign skills, scientists and engineers from abroad are viewed as somewhat less important factors. Plans currently implemented include investment in education, investment in training of existing employees, using ICT to upgrade skill levels, encouraging learning on the job, investment in vocational training, bringing/ attracting new foreign skills, scientists and engineers from abroad and sending students abroad to acquire knowledge and skills. However, our earlier discussion in this chapter and in Chapter 5 above, illustrates the serious shortcomings of some of these components, particularly with respect to investment in education, training and vocational education. Hence, the officials' view suggests further efforts in the short run to motivate investment in education, investment in training of existing employees, investment in vocational training, sending workers abroad to acquire skills and improving the quality of teachers, trainers and mentors. Further efforts considered important in the long run to enhance the system or programme of apprenticeship, support long distance learning, encourage the system of accreditation and licensing, send teachers/instructors and trainers abroad to acquire knowledge and skills and to improve the quality of teachers, trainers and mentors.

On the other side, at the micro level/across firms, the results of the firm survey suggest differing points of view with different priorities that highlight learning on the job as main priority, ${ }^{169}$ especially in the short run. ${ }^{170}$ Where as, investment in training of existing employees, using ICT to upgrade skill levels, bringing/attracting new foreign skills, scientists and engineers, supporting long distance learning, sending trainers, mentors and workers abroad to acquire skills and knowledge are receiving less attention, particularly in the

$16 \%$ As reported by $86 \%$ of the respondents firms.

170 As indicated by $61 \%$ of the respondents firms. 
short run. Firms highlight these components and learning on the job in the long run- see Table 8.10 below.

Table 8 - Plans and lools for shill development; macro-policy wakers and experts view

\begin{tabular}{|c|c|c|c|c|}
\hline Tools for skill development $(\%)$ & $\begin{array}{c}\text { Immor } \\
\text { teamuee } \\
\end{array}$ & $\begin{array}{l}\text { Has been } \\
\text { already } \\
\text { imple- } \\
\text { mented }\end{array}$ & $\begin{array}{l}\text { Short } \\
\text { runt } \\
\text { culrent } \\
\text { plan }\end{array}$ & $\begin{array}{l}\text { Long } \\
\text { run } \\
\text { future } \\
\text { plan }\end{array}$ \\
\hline Investment in formal education. & $96 \%$ & $61 \%$ & $29 \%$ & $11 \%$ \\
\hline Investment in wocational training. & $100 \%$ & $46 \%$ & $29 \%$ & $14 \%$ \\
\hline Investment in traning of existing employees & $93 \%$ & $57 \%$ & $29 \%$ & $7 \%$ \\
\hline Improving the quality of teachers, trainers and mentors. & $96 \%$ & $36 \%$ & $25 \%$ & $25 \%$ \\
\hline $\begin{array}{l}\text { Sending teachers/instructors/trainers abroad to acquire } \\
\text { knowledge andskills. }\end{array}$ & $79 \%$ & $25 \%$ & $21 \%$ & $32 \%$ \\
\hline Sending sudents abroad to acquine knowledge and skills & $68 \%$ & $43 \%$ & $14 \%$ & $21 \%$ \\
\hline Sending worker abroad to acqune skills. & $61 \%$ & $36 \%$ & $29 \%$ & $18 \%$ \\
\hline Bringing " attracting new foreign skills, scientist and engineers & $57 \%$ & $46 \%$ & $21 \%$ & $11 \%$ \\
\hline Using ICT to upgrade skill levels. & $75 \%$ & $54 \%$ & $11 \%$ & $14 \%$ \\
\hline Encouraging Learning on the job. & $86^{\circ}$ & $50 \%$ & $21 \%$ & $18 \%$ \\
\hline Supporting long distance larning. & $64 \%$ & $25 \%$ & $7 \%$ & $39 \%$ \\
\hline Enhancing the system of accreditation and Licensing. & $75 \%$ & $25 \%$ & $11 \%$ & $36 \%$ \\
\hline Enhancing the system or programme of apprenticeship. & $75 \%$ & $21 \%$ & - & $43 \%$ \\
\hline Total response & 28 & 28 & 28 & 28 \\
\hline
\end{tabular}

Sounce: Own calculation based on the macro survey (2002).

Table 8. 10-Plans and tools for shill development: micro-firm view

\begin{tabular}{|c|c|c|c|c|c|c|c|c|c|c|c|c|c|c|c|}
\hline $\begin{array}{l}\text { Tools for skill } \\
\text { development }\end{array}$ & \multicolumn{5}{|c|}{ Of special Importance (\%) } & \multicolumn{5}{|c|}{$\begin{array}{l}\text { To be pulsued now/ in the } \\
\text { short rum }(\%)\end{array}$} & \multicolumn{5}{|c|}{$\begin{array}{l}\text { To be pursued in the near } \\
\text { future/long run ( } \%)\end{array}$} \\
\hline Response Rate: & $\sum_{\Sigma}^{E}$ & $\frac{\overline{8}}{\tilde{E}}$ & 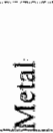 & to & $\frac{\Xi}{\Xi}$ & $\stackrel{E}{E}$ & $\frac{\vec{E}}{\tilde{E}}$ & $\frac{\bar{g}}{2}$ & 量 & 总 & $\stackrel{\stackrel{E}{E}}{E}$ & 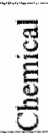 & $\sum$ & $\stackrel{8}{3}$ & $\sum_{3}^{5}$ \\
\hline $\begin{array}{l}\text { Investment in } \\
\text { training of exist- } \\
\text { ing employees }\end{array}$ & 53 & 50 & 57 & 56 & 50 & 39 & 40 & 36 & 50 & 27 & 55 & 60 & 45 & 44 & 67 \\
\hline $\begin{array}{l}\text { Sending tramers } \\
\text { and mentors } \\
\text { abrond to ancquine } \\
\text { skills. }\end{array}$ & 22 & 14 & 36 & 17 & 28 & 6 & 10 & 0 & 6 & 7 & 71 & 60 & 91 & 75 & 67 \\
\hline $\begin{array}{l}\text { Sending workers } \\
\text { abroat to acquine } \\
\text { skills. }\end{array}$ & 11 & 5 & 21 & 11 & 11 & 3 & 5 & 0 & 6 & 0 & 61 & 50 & 82 & 63 & 60 \\
\hline $\begin{array}{l}\text { Bringing / athack } \\
\text { ing new foreign } \\
\text { skills, scientists } \\
\text { and engineers. }\end{array}$ & 42 & 32 & 57 & 39 & 44 & 29 & 15 & 55 & 19 & 40 & 55 & 65 & 36 & 56 & 53 \\
\hline $\begin{array}{l}\text { Using ICT to } \\
\text { upgrade skill } \\
\text { levels. }\end{array}$ & 47 & 55 & 36 & 61 & 33 & 35 & 45 & 18 & 50 & 20 & 39 & 35 & 45 & 25 & 53 \\
\hline $\begin{array}{l}\text { Jincouraging } \\
\text { lentming on the } \\
\text { job. }\end{array}$ & 86 & 82 & 93 & 94 & 78 & 61 & 60 & 64 & 56 & 67 & 32 & 35 & 27 & 31 & 33 \\
\hline $\begin{array}{l}\text { Supporting long } \\
\text { distance learning. }\end{array}$ & 33 & 18 & 57 & 28 & 39 & 19 & 20 & 18 & 13 & 27 & 58 & 60 & 55 & 63 & 53 \\
\hline Total resporsse & 36 & 22 & 14 & 18 & 18 & 31 & 20 & 11 & 16 & 15 & 31 & 20 & 11 & 16 & 15 \\
\hline
\end{tabular}

Source: Own calculation based on the finm survey (2002). 
From Tables 8.9-8.10 we observe the discrepancy in the macro-micro views/perspectives concerning the selection of both tools and plans for skill development. For instance, the macro/policy makers and experts' view tends to highlight investment in vocational training and formal education, improving the quality of trainers and mentors and investment in training of existing employees as top priorities. Their next priorities are: encouraging learning on the job, sending trainers and mentors abroad to acquire skills, using ICT to upgrade skill levels. Supporting long distance learning, sending workers abroad to acquire skills and bringing/attracting new foreign skills, scientists and engineers from abroad are viewed as somewhat less important tools. On the other side, the micro (firm) view highlights learning on the job as main priority. The rank of the firms' other priorities are: investment in training of existing employees, using ICT to upgrade skill levels, bringing/attracting new foreign skills, scientists and engineers, supporting long distance learning, and sending trainers, mentors and workers abroad to acquire skills and knowledge.

From the policy makers, experts and firms' perspectives the top priorities in the short run are investment in education, training (including vocational training), sending workers abroad to acquire skills, improving the quality of teachers, trainers and mentors, learning on the job, using ICT to upgrade skill levels and bringing new foreign skills, scientists and engineers. From the policy makers, experts and firms' perspectives the top priorities in the long run highlight enhancing the system or programme of apprenticeship, supporting long distance learning, encouraging the system of accreditation and licensing, sending teachers, mentors, workers and students abroad to acquire knowledge and skills.

From the macro/policy makers and experts' perspective, the top priorities in the short run are investment in education, training (including vocational training) of existing employees, sending workers abroad to acquire skills and improving the quality of teachers, trainers and mentors. Less emphasis would be placed on learning on the job, bringing new foreign skills, scientists and engineers, sending trainers and mentors abroad to acquire skill, using ICT to upgrade skill levels, supporting long distance learning and sending trainers, mentors and workers abroad to acquire skills. On the other side, firms highlight encouraging learning on the job as top short run priority, followed by investment in training of existing employees, using ICT to upgrade skill levels and bringing new foreign skills, scientists and engineers. Less emphasis would be placed on supporting long distance learning and sending trainers, mentors and workers abroad to acquire skills.

Furthermore, from the macro/policy makers and experts perspective, the top priorities in the long run would be on enhancing the system or programme of apprenticeship, supporting long distance learning, encouraging the system of accreditation and licensing. This followed by sending teachers/ instructors and trainers abroad to acquire knowledge and skills and improving the quality of teachers, trainers and mentors. Less emphasis would be on sending students and workers abroad to acquire skills, supporting learning on the job, using ICT to upgrade skill levels, bringing new foreign skills, scientists and engineers and investment in training of existing employees. On the other hand, firms tend to highlight sending trainers, mentors and workers abroad to acquire skills as main long run priority, followed by supporting long distance learning, investment in training of existing employees and bringing new foreign skills, scientists and engineers. Less emphasis would be placed by firms on using ICT to upgrade skill levels and encouraging learning on the job.

In addition to the above observed discrepancies between macro-micro views concerning the selection of plans and tools and arrangement of priorities and policies for enhancing skill, we explain below the visible differences in the macro-micro perspectives in 
suggesting policies for improving the provision of training and transfer of knowledge Therefore, this implies that further efforts are needed to enhance the consistency between the macro-micro wiews and public-private sectors, particularly with respect to the arrangement of priorities and plans to ensure more successful and consistent implementation of policies for skills development and encouraging private sector participation in education and training.

\subsubsection{Policies and mechanisms for skill development: the macro-micro views}

The implementation of the above plans for skills development requires an integration of the macro-micro policies; the results of the macro and firm surveys (2002) are usefull for discussing and integrating these policy perspectives. From the macro survey we find that the policy makers and experts' view concerning skill development policies highlights the mechanisms/policies for enhancing the efficiency of educational system, enhancing the provision of training, planning skill needs and enhancing the external schooling effects/transfer of knowledge. Additional mechanisms/policies identified include monitoring skill needs on a regular basis, enhancing social partnership and collaboration between educational and training institutions, employers, workers and the state to determine skill needs and the most effective ways of meeting and financing them, promoting of resources allocation and importing skills from abroad. ${ }^{1 \text { ? }}$

Our analysis below discusses the mechanisms for enhancing the educational system, transfer of knowledge/external schooling effects and provision of training. Other components include: planning skill needs, monitoring skill needs on a regular basis, enhancing social partnership in skill development, promoting of resources allocation and importing skill from abroad are somewhat integrated in the above components. We begin with the reform of educational system because we want to argue that both training provision and transfer of knowledge can be enhanced by an efficient educational system.

\section{a. Reform of educational system}

Beginning with the reform of the educational system, Table 8.11 summarizes the official view concerning the reform of the educational system, which highlights improvement of the quality of teachers and mentors, improvement of infrastructure, encouragement of modernization and dynamism in the educational system and enhancing planning for educational need. In addition, they prioritize the improvement of internal efficiency/quality of basic, secondary and tertiary education; enhancing the linkages (network) between universities, colleges, technical and training institutes; monitoring educational needs on a regular basis; and encouraging the system of flexibility of educational institutions. Further reform measures include increasing the harmony/consistency between educational output and market needs by focusing on particular future skill needs, increasing public spending on education, increasing motivation and incentives to change student attitudes, increasing spending and incentives to encourage enrolment in technical education and increasing private sector in171 As reported by $97 \%, 93 \%, 93 \%, 83 \%, 79 \%, 79 \%, 76 \%$ and $72 \%$ of the respondent policy makers and
experts respectively. 
volwement on education. Finally, we suggest an improvement of duration of compulsory education and autonomy of educational institutions.

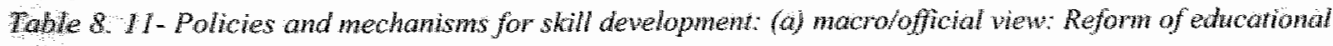
system

\begin{tabular}{|c|c|}
\hline Macro policies and mechanisms for enhancing the efficiency of education system: & Ho \\
\hline Improve the quality of teschers or mentors. & $97 \%$ \\
\hline Encourage the system of modernization and dynamism. & $97 \%$ \\
\hline Improve the infrastructures. & $97 \%$ \\
\hline Better planning for educational needs. & $93 \%$ \\
\hline Tmprove the internal efficiency/quality of basic education. & $93 \%$ \\
\hline Improwe the internal efficiency/ quality of tertiary education. & $90 \%$ \\
\hline Enhance the linkages [newworks] between universities, colleges, technical and training institutes. & $90 \%$ \\
\hline Monitoring educational needs on a regular basis. & $90 \%$ \\
\hline Encourage the system of flexibility of educational institutions. & $86 \%$ \\
\hline $\begin{array}{l}\text { Increase the hamony/comsistency between educational output and market needs by focusing on } \\
\text { particular future skill needs. }\end{array}$ & $86 \%$ \\
\hline Increase public spending on education. & $86 \%$ \\
\hline $\begin{array}{l}\text { lncreasing the motivation and incentives to change the attitudes of educated economically active } \\
\text { population. }\end{array}$ & $83 \%$ \\
\hline Increase spending and incentives to ancourage enrolment in teclunical education. & $79 \%$ \\
\hline lncrease private sector spending and inwolvement on education. & $72 \%$ \\
\hline $\begin{array}{l}\text { Wotal response. } \\
\text { Thot }\end{array}$ & 29 \\
\hline
\end{tabular}

Sotrce: Own calculation based on the macro survey (2002).

In recent years, there have been several recent initiatives in the Gulf countries aimed at long term solutions to develop human resources, reform educational and training programmes and the labour market. For instance, the UAE has established the National Human Resources Development and Employment Authority (TANMIA)- affiliated to the UAE Ministry of Labour and Social Affairs to help improve the skills of the UAE nationals looking for jobs. In our view, these recent initiatives would be more effective if the governments in the Gulf collaborate with the private sector to work actively to influence both the supply and demand sides by implementing more effective policies to increase incentives, for example through subsidies to improve both education and training. For instance, public policies can influence the demand side for education and change the low enrolment ratios at the tertiary level, especially technical education, by providing more fellowships, scholarships and prizes for engineering and science students, and increasing incentives for students to increase attraction for enrolment into science and engineering at secondary schools levels. The governments should continue to upgrade schooling and increase enrolment at all levels, especially in higher education.

In our view the Gulf countries can benefit from the experiences of other advanced countries to improve the coordination and planning to avoid the mismatch between supply and demand and to meet critical skills needs. For instance, the Gulf countries can benefit from the experiences of the European countries, where the government limits itself to pay teachers" salaries and leaves the coordination problem to employers' federations. The Gulf countries should continue to upgrade schooling and increase enrolment in all levels especially in higher education and should also induce firms to organize in a federation, which has the task to organize branch specific education, by using taxes as a stick and the payment of teachers' salaries as a carrot. 


\section{b. Enhancing the transfer of knowledge/ external schooling effect}

The reform of the educational system is expected to have a direct positive effect on motivat ing/enhancing the transfer of knowledge/external schooling effects. For instance, Table 8.12 shows that the macro-micro views highlight the potential positive implications of improving the qualifications of skilled and unskilled workers, the quality of education and training in enhancing the transfer of knowledge/external schooling effects. The macro-micro views differ with respect to the potential effect of improving firm conditions to encourage external effects and sponsoring educational scholarship. Moreover, the macro survey shows that the policy makers and experts' view indicates that the transfer of knowledge/external schooling effect can be motivated via increasing the information about future educational, training and skill needs in the productive sectors. There is also a need to increase awareness about the future value of investments in education and training to minimize the risk aversion: preference of more certain short term returns to available jobs than long term skill investments; in addition to increasing the interaction to market needs and enhancing a system of certification of skills acquired. Both the provision of adequate incentives for trainers and minimization of education, learning and training costs are expected to have somewhat less important potential effects in the transfer of knowledge/external schooling effect. ${ }^{172}$

Table 8. 12- Policies and mechanisms for shill development: (b) macro-micro views: factors ewhancing the transfer of knowledgei extemal schooling effect

\begin{tabular}{|c|c|c|c|c|c|c|}
\hline $\begin{array}{l}\text { Factors enhance external schooling } \\
\text { effect/knowledge transfer }\end{array}$ & $\begin{array}{l}\text { All } \\
\text { Firms } \\
\end{array}$ & Chemical & Metal & Large & Medium & Official \\
\hline $\begin{array}{l}\text { Improves the qualifications and ability of } \\
\text { unskilled workers to learn from skilled } \\
\text { workers. }\end{array}$ & $87 \%$ & $82 \%$ & $94 \%$ & $90 \%$ & $84 \%$ & $100 \%$ \\
\hline $\begin{array}{l}\text { Improves the qualitications of skilled } \\
\text { workers to permit the positive effects on } \\
\text { unskilled workers. }\end{array}$ & $82 \%$ & $73 \%$ & $94 \%$ & $80 \%$ & $84 \%$ & $95 \%$ \\
\hline $\begin{array}{l}\text { Improves the quality of training to coin- } \\
\text { cide with international standard. }\end{array}$ & $62 \%$ & $55 \%$ & $71 \%$ & $65 \%$ & $58 \%$ & $100 \%$ \\
\hline Improves the quality of education. & $56 \%$ & $50 \%$ & $65 \%$ & $55 \%$ & $58 \%$ & $100 \%$ \\
\hline $\begin{array}{l}\text { Improves firm conditions to encourage the } \\
\text { external effects. }\end{array}$ & $41 \%$ & $36 \%$ & $47 \%$ & $35 \%$ & $47 \%$ & $100 \%$ \\
\hline Sponsors educational scholarship. & $26 \%$ & $27 \%$ & $24 \%$ & $35 \%$ & $16 \%$ & $90 \%$ \\
\hline Tolal response & 39 & 22 & 17 & 20 & 19 & 20 \\
\hline
\end{tabular}

Sources: Own calculation based on the macro survey (2002) and firm survey (2002).

$c_{n}$

Enhancing training provision

From the macro-firm surveys it appears that views of the policy makers and experts and those of the firms are consistent in highlighting the reform of educational system as an important mechanism to improve the provision of training, and the reform of educational and training systems for the enhancement of knowledge transfer/external schooling effects. However, on the other hand, there appears to be clear discrepancies between the macromicro views (and also across firms) concerning the arrangement of priorities of other mechanisms for improving the provision of training. For instance, Table 8.13 presents the

172 As indicated by $86 \%, 83 \%, 83 \%, 83 \%, 69 \%$ and $55 \%$ of the respondent policy makers and experts
respectively. 
pohy makers and experts" view to improve the provision of traning that highlights enhanomg training programmes to fit both the changing skill needs and changing technical needs, and enhancing planning for training needs and avallablity of trainers and mentors. Other measures towards enhancing the educational qualifications of workers, increasing the availability of training materials and equipment, regular/adequate assessment and monitoring of raming needs, increasing the appreciation of/ information on the benefits of training, enhancing the avalability of funance to cover training costs and enhancing the specialized raming institutions are also highlighted. Further, measures aimed at improving the quality of trainers and mentors, enhancing the interactions between training institutions and frms, enhancing the appropriability of the retum from investment in training, enhancing the system of training certification, increasing the participation of private training institutions and decentralization of decision-making are also mentioned.

Table 8. 13-Policies and mechamisms for skil development (c) macro-micro wiews promotion of training

\begin{tabular}{|c|c|c|c|c|c|c|}
\hline $\begin{array}{l}\text { Policies intervention for enhancing train- } \\
\text { ing provision }\end{array}$ & Official & $\begin{array}{l}\text { All } \\
\text { Finns }\end{array}$ & Chemical & Metal & Large & Medium \\
\hline $\begin{array}{l}\text { Enhancing the educational qualifications of } \\
\text { workers. }\end{array}$ & $93 \%$ & $56 \%$ & $44 \%$ & $7: \%$ & $40 \%$ & $64 \%$ \\
\hline $\begin{array}{l}\text { Enhancing the avallability of traning mate- } \\
\text { rials and equpment. }\end{array}$ & $93 \%$ & $63 \%$ & $67 \%$ & $57 \%$ & $60 \%$ & $64 \%$ \\
\hline $\begin{array}{l}\text { Enhaming training programmes to fit the } \\
\text { changing technical needs. }\end{array}$ & $97 \%$ & $63 \%$ & $67 \%$ & $57 \%$ & $60 \%$ & $64 \%$ \\
\hline $\begin{array}{l}\text { lncreasing the appreciation of or informa- } \\
\text { lion on the benefits of training. }\end{array}$ & $90 \%$ & $63 \%$ & $67 \%$ & $57 \%$ & $60 \%$ & $64 \%$ \\
\hline $\begin{array}{l}\text { Regular/adequate assessment and monitor- } \\
\text { ing of training needs. }\end{array}$ & $93 \%$ & $56 \%$ & $67 \%$ & $43 \%$ & $60 \%$ & $55 \%$ \\
\hline $\begin{array}{l}\text { limproving the quality of trainers and men- } \\
\text { toms. }\end{array}$ & $83 \%$ & $50 \%$ & $56 \%$ & $43 \%$ & $60 \%$ & $45 \%$ \\
\hline $\begin{array}{l}\text { Enhancing training programmes to fit the } \\
\text { changing skill needs. }\end{array}$ & $100 \%$ & $50 \%$ & $56 \%$ & $43 \%$ & $60 \%$ & $45 \%$ \\
\hline $\begin{array}{l}\text { Ancreasing availability of trainers and men- } \\
\text { hors. }\end{array}$ & $97 \%$ & $50 \%$ & $56 \%$ & $43 \%$ & $60 \%$ & $45 \%$ \\
\hline $\begin{array}{l}\text { Eors. } \\
\text { Enhancing adequate planning for training } \\
\text { programme / needs. }\end{array}$ & $97 \%$ & $50 \%$ & $56 \%$ & $43 \%$ & $40 \%$ & $55 \%$ \\
\hline $\begin{array}{l}\text { Programinang the avalability of finance to } \\
\text { cover training costs. }\end{array}$ & $90 \%$ & $56 \%$ & $56 \%$ & $570 \%$ & $60 \%$ & $55 \%$ \\
\hline $\begin{array}{l}\text { Cover tranning cosls. } \\
\text { Enhancing/ encouraging the specialized } \\
\text { training institutions. }\end{array}$ & $86 \%$ & & & & & \\
\hline $\begin{array}{l}\text { Enthancing the interactions between training } \\
\text { instinutions and firm. }\end{array}$ & $76 \%$ & $31 \%$ & $22 \%$ & $43 \%$ & $20 \%$ & $36 \%$ \\
\hline $\begin{array}{l}\text { Enstutuons and timing } \\
\text { Enhancing the full appropriability of the } \\
\text { return from investment in training. }\end{array}$ & $76 \%$ & $44 \%$ & $44 \%$ & $43 \%$ & $40 \%$ & $45 \%$ \\
\hline $\begin{array}{l}\text { Enhancing the system of training certifica- } \\
\text { tion of skills acquired. }\end{array}$ & $76 \%$ & $38 \%$ & $22 \%$ & $57 \%$ & $40 \%$ & $36 \%$ \\
\hline $\begin{array}{l}\text { Increasing the participation of priwate } \\
\text { training institutions. }\end{array}$ & $76 \%$ & & & & & \\
\hline $\begin{array}{l}\text { training institutions. } \\
\text { Decentralization of decision-making. } \\
\text { Restriction the mobility of trainees. }\end{array}$ & $72 \%$ & $38 \%$ & $33 \%$ & $43 \%$ & $40 \%$ & $36 \%$ \\
\hline $\begin{array}{l}\text { Restruction me moothty } \\
\text { Total response }\end{array}$ & 29 & 16 & 9 & 7 & 5 & \\
\hline
\end{tabular}

Total response

Sources: Own calculation based on the macro sirvey (2002) and firm survey (2002)

The firms" view indicates that the provision of training could be improved by enhancing training programmes to fit the changing technical needs, increasing the appreciation of information on the benefits of training, enhancing the availability of training materials and 
equipment and enhancing educational qualifications of workers. Mechanisms such as en hancing the availability of finance to cover training costs, regular/adequate assessment and monitoring of training needs, increasing availability and improving the quality of trainers and mentors, enhancing training programmes to fit the changing skill needs and enhancing planning for training needs are viewed by the firms as being of somewhat less importance. That also holds for enhancing the appropriability of the return from investment in training. enhaneing the system of training certification, restricting the mobility of trainers and enhancing the interaction between training institutions and firms. Since training is coslly, firms prefer policy interventions to finance training; however, it is less clear to what extent firms have a sound policy to contribute to training costs, as only $55 \%$ of all respondent firms thave upskilling plan - cf. Table 5.9 in Chapter 5 above.

Finally, in view of the complementary relationship between skill, skill upgrading and technological progress - see our discussion in Chapters 3 and 6 above - the development of education, training, transfer of knowledge and skill levels may have further positive implications on the development of local technologies. Accordingly, the promotion of local technologies depends on skill upgrading, the promotion of R\&D activities and enhancement of networks systems, collaboration between universities, firms, public and private sectors and the implementation of an explicit technology policy.

\section{4 Conclusions}

In this chapter we use some secondary data and information and the macro and firm surveys (2002) to analyse the educational, training and skill development policies in the Gulf countries. We prove hypothesis 8 in Scheme 1.1 in Chapter 1 above concerning the need for skill and technological upgrading through the reform of the educational and training systems/policies and the transfer of knowledge. In particular, we show that skill development depends on: (a) reforming the educational system; (b) enhancing the provision of training; (c) planning skill needs and matching educational output with market needs; (e) enhancing the transfer of knowledge/schooling effect; and (d) incentives and collaboration between public and private institutions. We explain that the promotion of local technologies and adoption of appropriate foreign technologies and the interaction between both these to foster economic growth in the Gulf countries depends on skill development. Particularly, on an enhancement of: (a) skill upgrading: educational and training systems; (b) R\&D activities; (c) the transfer of knowledge/schooling effect; (d) networks system; and (e) incentives to motivate collaboration between universities and firms and between public and private institutions.

Our findings in Section I show that the educational policies in the Gulf countries share several problematic features such as an insufficient duration of compulsory education, the dominance of public sector and the lack of incentives/marginal contribution of the private sector on educational investment. Additional problems include poor quality, insufficient demand (enrolment ratios), an insufficient supply (spending) and the biased structure of tertiary education. However, despite these similarities, we also observe enormous variations, particularly with respect to the supply and demand sides of educational policies. Differences in the supply side include financial resources or priority of public expenditures on education relative to GDP and total government expenditures, allocation/distribution of public spending and spending per pupils at various educational levels, human resources or availability of teaching staff and the extent of privatization. Differences regarding the de- 
mand side include enrolment ratios and outcomes or implications on literacy rates, access to schooling/school life expectancy and interaction with training.

We find that the priority of investment in education, as measured by public expenditures on education as a percentage of total government expenditures, is approaching the level prevalent in developed countries; however, the priority of investment as a percentage of GDP in most of the Gulf countries lags far behind the level of the developed countries. When comparing supply-demand sides, it turns out that the supply side or public spending seems to be only one component in educational policies, because higher public spending per se does not lead to higher demand, participation and enrolment ratios, access to schooling/ school life expectancy and higher literacy rates. For instance, despite higher spending in Saudi Arabia, the demand/ enrolment ratios, access to schooling/school life expectancy and literacy rates are all falling behind those in Bahrain, which shows moderate spending, but better demand/enrolment ratios at all educational levels, better access to schooling/school life expectancy and literacy rates.

We observe that while the educational policies in the Gulf countries have raised enrolment ratios and literacy rates, they have failed to show satisfactory outcomes with respect to access to schooling/school life expectancy and training. This is due to serious deficiencies concerning the quality of education, coupled with the serious problems of biased structure and inadequate spending and enrolment in tertiary education in these countries. Hence, the major policy implication from our findings is that the improvement of the educational policies in the Gulf countries is vital and requires an improvement in the quality/internal efficiency, in the supply (investment) and demand (enrolment) sides, particularly in tertiary and technical education, and encouraging private sector investment in education.

Our results in Section 2 show that the implication and interaction between educational and training policies seem to be effective only within the largest public firms, which appear more committed to implement skill upgrading policies that are consistent with the line of public policies. The large public firms successfully contribute to serve public policies of training and skill upgrading via establishing active human resources development units, recruitment policies and specialized training centres to implement various regular and special internal and external training programmes, especially for national workers. In addition they encourage the use of ICT to upgrade skill levels, offer scholarships and collaborate with universities to absorb young national graduates. These results oppose our earlier findings in Chapter 5, which indicate a lack of effective interaction between educational and training policies and a lack of incentives for provision of training within private firms. Hence, these findings imply a further duality/discrepancy at the micro level/across publicprivate firms.

In Section 3 we use the results of the macro and firm surveys (2002) to integrate the divergent macro-micro views concerning plans and mechanisms for skill development in the short and long run and propose some policies and recommendations. The short run plans include investment in education and training of existing employees, the use of ICT to upgrade skill levels, and tools to encourage learning on the job and investment in vocational training. The long run plan highlights sending trainers, mentors and workers abroad to acquire skills, supporting long distance learning, beside continued investment in the above tools to ensure implementation of the short run plan. We show that the macro-micro views and policies for skill development highlight planning and monitoring skills needs on a regular basis, promoting resources allocation, reforming the educational system as an important 
mechanism for enhancing the provision of training and transfer of knowledge/external schooling effects.

The policy makers and experts' view concerning the reform of the educational system highlights improving the quality of teachers and mentors, improvement of infrastructure, encouragement of modernization and dynamism in the educational system and enhancing planning for educational needs. They also prioritize the improvement of internal efficiency/ quality of basic, secondary and tertiary education; enhancement of the linkages (networks) between universities, colleges, technical and training institutes; monitoring of educational needs on a regular basis; and encouraging the system of flexibility in educational institutions.

In recent years, there have been several initiatives in the Gulf countries aimed at long term solutions to develop human resources, reform educational and training programmes and the labour market. In our view, these recent initiatives would be more effective if the governments in the Gulf collaborated with the private sector to work actively to influence both the supply and demand sides by implementing more effective policies to increase incentives, for example subsidies, to improve both education and training. For instance, public policies can influence the demand side for education and change the low enrolment at the tertiary level, especially technical education, by providing more fellowships, scholarships and prizes for engineering and science students, and increasing incentives for students to increase attraction for enrolment into science and engineering at secondary schools levels.

In our view the Gulf countries can benefit from the experiences of other advanced countries to improve the coordination and planning, to avoid the mismatch between supply and demand and to meet critical skills needs. For instance, the Gulf countries can benefit from the experiences of the European countries, where the government limits itself to paying teachers' salaries and leaves the coordination problem to the employer's federation. The Gulf countries should continue to upgrade schooling and increase enrolment in all levels especially in higher education and should also induce firms to organize in a federation, which has the task to organize branch specific education, by using taxes as a stick and payment of teachers' salaries as a carrot.

Moreover, the macro-micro suggestions with respect to knowledge transfer/external schooling effects stress the improvement of quality of educational and training systems, qualifications of skilled and unskilled workers. In addition, recommendations include increasing information about future skill needs and the value of investments in education and training, interaction/consistency to market needs and a certification system.

Furthermore, the macro-micro views regarding improvement of the provision of training vary in arranging priorities, but generally emphasize the enhancement of training programmes to fit both the changing skill and technical needs, enhancing planning for training needs and quality and availability of trainers and mentors. Other measures include the enhancing of training materials and equipment, and the educational qualifications of workers, assessing and monitoring of training needs regularly/adequately, increasing the appreciation of/ information on the benefits of training, enhancing the availability of finance to cover training costs and enhancing specialized training institutions.

In addition, in view of the complementary relationship between skills, skill upgrading and technological progress - see earlier discussion in Chapters 3 and 6 - the development of education, training, transfer of knowledge and skill levels may have further positive implications on the development of local technologies. Accordingly, the promotion of local 
technologies depends on skill upgrading, promotion of R\&D activities and enhancement of networks system, collaborations between universities, firms, public and private sectors and the implementation of an explicit technology policy

Finally, our results show a serious discrepancy between private and large public firms regarding the implementation of public policies of training and skill upgrading and also divergent macro-micro views concerning the arrangement of priorities to implement plans, mechanisms and policies for enhancing skill, provision of training and transfer of knowledge. Therefore, we recommend further efforts to be made to enhance the consistency between the macro-micro views and public-private sectors, particularly with respect to arrangement of priorities, plans and mechanisms to ensure more consistent, effective and successful policies for skill development and encouraging private sector participation in education and training. 


\section{Chapter 9}

\section{Summary and Conclusions}

This concluding chapter summarizes the major findings and contributions of the research. Section 1 briefly identifies the research problem and the major findings of the research; in Section 2 we show the relevance of the research findings to the general literature and contribution to the Gulf literature; and, finally, Section 3 presents short outlines on policy recommendations.

\section{1 Research problem, methodology and major findings}

This thesis is composed of four parts and nine chapters: Part One includes both Chapters 1 and 2 and presents the introduction and motivation of the research; Part Two contains Chapter 3, which presents the conceptual and theoretical frameworks; Part Three comprises Chapters 4 to 7 and presents the empirical application; and, finally, Part Four encompasses Chapters 8 and 9 on policies, recommendations and conclusions. We explain below the main findings of each chapter.

Chapter 1 presents a brief introduction that gives a general overview of the research problem, its importance, relevance, objectives, questions, hypotheses and the structure of the research. We explain that the central themes of discussion in this research are the required skills formation and upskilling of the workers, together with their interaction with technological change in the Gulf countries. In particular, we intend to provide an empirical investigation of the causes and consequences of deficient educational systems, their interaction with the excessive share of low educated foreign workers and their implications on skill levels, skills mismatch, transfer of knowledge, provision of training, level of local technologies and dependence on foreign technologies. In addition, we aim to present an in-depth macro-micro analysis to assess technology and skinl levels using a more comprehensive set of indicators.

Following the identification of the research problem in Chapter 1, we then present the background that motivated the research in Chapter 2 . In particular, we show some stylized facts about the Gulf countries, to examine the research problem more extensively, along with other strategic problems confronting economic development in these countries. We explain that oil greatly contributed to economic development in the Gulf countries; however, the heavy dependence on oil poses serious challenges since oil is an exhaustible resource and, because of the instability of oil prices, the revenue from oil is uncertain and volatile. Hence, economic growth and sustainable development strategy in the Gulf depends on economic diversification, which in turn is contingent upon the availability of adequate and appropriate skilss and technologies. We also ilustrate the other serions structural problems in the Gulf countries that relate to the Dutch disease, structural imbalances in the labour market, duality between the public and private sectors, growing unemployment, slow- 
down in economic growth and declining labour productivity. We illustrate the low skill and technology indicators and the substantial gap prevalent in the Gulf countries when compared to the world's rapidly advanced countries. In our view, the Gulf countries need to upgrade skill levels and encourage the development of local technologies to narrow the technological gap and achieve economic development in the region. In particular, skill upgrading is imperative to facilitating economic diversification, restructuring the labour market, enhancing productivity of labour, lessening dependence on foreign workers and, consequently, duality and unemployment in the labour market. Skill upgrading through enhancing educational and training systems is essential to facilitate the adoption of appropriate foreign technologies in the short run, and to encourage the development of local technologies through encrouging R\&D activities to reduce the technological gap and dependence on foreign technologies in the long run. Therefore, our findings in Chapter 2 confirm our first hypothesis in Scheme 1.1 Chapter 1 above: that the Gulf countries need to promote the local skill and local technologies to face the challenges created by the depletion of oil resources. They need to implement the three strategies of diversification, building local technological capacity and restructuring the labour market. Our results confirm part of the second hypothesis in Scheme 1.1 Chapter 1 above: that in the short and medium term, the Gulf countries are unable to rely on local skills and local teclnologies and remain heavily dependent on both foreign skills and foreign technologies at the macro level.

In light of the findings in Chapter 2, it becomes more plausible to highlight the need for improvement of education or skill upgrading and the development of local technologies or technological progress to facilitate economic diversification and ensure long run economic growth and sustainable development in the Gulf countries. Before commencing with the empirical analysis, Chapter 3 briefly explains the concepts, measures and theoretical and empirical literature in relation to human capital (education), technological change and economic growth. We provide a background for the empirical analysis in the subsequent chapters by surveying the theoretical and empirical literature that emphasize the positive endogenous growth effects of technical change and human capital in increasing and sustaining economic growth. We explain that economic growth theories recognized and provided different perceptions and analytical frameworks for modelling the various effects of technical change, innovation and human capital on economic growth. The major differences arise because exogenous growth theories perceive and model technical progress and human capital as exogenous variables in growth accounting model, while, in contrast, the endogenous growth theory envisages and models technical progress and human capital as endogenous variables determining the rates and differences of economic growth across countries. The endogenous growth theory contributes towards improving the understanding of the interaction between technological change, human capital and economic growth and fills the gap in earlier growth theories by considering the important endogenous effects of human capital, technological progress and innovation. It also predicts that in the long run economic growth at the aggregate level is determined by endogenous sources of technological change: human capital, learning by doing, spillovers of knowledge and external effect of human capital. The presence of increasing returns to scale and externalities prevent diminishing returns to the accumulation of capital and thereby ensure the steady state of growth in the long run. While the feature of spillovers of knowledge supports endogenous growth, it also creates a form of externality and implies that private investments generate a positive external effect and the private returns from investment tend to be lower than the social returns. The outcomes tend not to be Pareto optimal but sub optimal and they require gov- 
ernment intervention to correct the distortion using various instruments, such as providing subsidies (which can be financed by taxation) to improve the accumulation of technology and human capital, the incentives and returns from investment for private investors. We ilustrate that the inclusion of human capital and technological change in growth accounting models motivate the endogenous growth literature to provide several interesting explana. tions of the relationship between human capital and technical progress. In particular, it stimulates considerable debate about the complementary relationship between human capital and technical progress, skilled biased technical change, the role of technical progress in skill upgrading and the role of skills and improvement in the accumulation of human capital in skill upgrading. These explanations imply that next to the important endogenous effects of technical progress and human capital in economic growth, the complementary relationships amongst these and between them and skill upgrading are also important for enhancing economic growth. Finally, we show the advantages and limitations of various measures of technological change and human capital that have been used in the theoretical and empirical literature, and we then select the most relevant measures for our empirical analysis in the subsequent Chapters according to the availability of data.

We consider the endogenous growth framework as a useful background for the empirical investigation in the following chapters. Before we go into the empirical analysis, we define the methods of data collection including both surveys and interviews in Chapter 4. We utilize the surveys data in our analysis and use the descriptive, comparative and statistical (OLS regression) methods of analysis. We explain that the basic objective of performing the macro and firm surveys is to obtain specific information to provide insights into the factors influencing or the causes and consequences of low skill and technology and to help to generate policies to improve skill and technology at the macro-micro levels. The macro survey examines the causes and consequences of the deficiency of the educational system and the firm survey discusses the implications of the excessive use of unskilled foreign workers. The field research to collect our primary data was held in the period from February to April 2002 in the UAE as a case study of the Gulf countries. The selection and focus of our analysis on the UAE was attributed to the easy accessibility to data and information, the availability of facilities for the fulfilment of the fieldwork/surveys, because the UAE ranks first in terms of ICT diffusion and has the highest per capita manufacturing product in the Gulf region.

In Chapter 4 we explain the selection of the sample, its composition, operation, coverage, advantages and limitations of the surveys data, and show the structure and design of the questionnaire. The firm survey (2002) on "Technological change and skill development" covers 106 of the medium and large size firms working in two industries in the manufacturing sector: the chemical and metal industries. The selection of both industries was based on many reasons, the most important of which is that the argument for both upskilling and technological upgrading is promising in both sectors and can be used to reduce the dependence on foreign workers. The sample in the firm survey was drawn from the medium and large size firms active in the chemical and metal industries, which are located in three emirates of Abu Dhabi, Dubai and Sharjah. The selection of these emirates was based on their significant average share in total employment, capital investment and total number of factories engaged in the chemical and fabricated metal industries. The macro survey (2002) on "Skill creation, human resources development and policy intervention" was sent to 40 of policy makers and experts in 1.4 public and university institutions in the UAE. The number of responding firms and policy makers are 44 and 30 respectively. 
The data from the firm and macro surveys provide us with the required information, which is particularly useful for presenting a macro-micro comparative analysis to identify the causes and consequences of the skills problem and the policies for skill development from a macro-micro perspective. The results of the macro survey seem quite representative, since the selection covers governments, universities, and educational and training institutions. One advantage of the macro survey is that it examines the problem after integrating the two different perspectives of policy makers and experts. The results of the firm survey are also quite representative, since the selection and coverage of firms in the survey includes a broad range of firms working in the chemical and metal industries, which provides us with relevant data and information that is of considerable use in our analysis. Such coverage also has the advantage of enabling us to compare between firms according to two criteria: the size of employment and the industrial activity. One major limitation with respect to the firm survey is the low response rate for some questions, especially when the answers or data required quantitative measurement. Such problems arise because some of the respondents firms were unwilling to provide complete and reliable quantitative data, while others offered somewhat selective answers.

Apart from this limitation, the data from the firm and macro surveys remains useful, not only for the empirical investigation in Chapters 5 to 7 , but also for the policy analysis and suggestions in Chapter 8 . We begin our analysis in Chapter 5 , by using the results from the macro and firm surveys to verify our third hypothesis in Scheme 1.1 in Chapter 1 above, about the serious implications of the interaction between the deficient educational system and the high incidence of unskilled foreign workers. In particular, the results from the macro survey show that the deficient educational system is attributed to many causes such as the poor quality of education that leads to many serious consequences including low skill levels, poor provision of training, skills mismatch and low transfer of knowledge at the macro level. In addition, the results from the firm survey illustrate that the excessive use of low educated foreign workers leads to several serious implications such as low skill levels, poor provision of training, skills mismatch, poor technology indicators, weak adaptation of imported technologies and a heavy dependence on foreign technologies. Our findings from the surveys and follow-up interviews indicate that the poor technology indicators/indigenous capability to build the local technology and heavy dependence on foreign technology can be attributed to low skill levels, lack of R\&D activities, weak linkages, lack of networks systems, and low transfer of knowledge. These findings at the micro level seem consistent with those at the macro level.

When distinguishing between firms according to firm size and industry level, we find that skill and technology indicators show considerable variation across firms. Our findings show two surprising contradicting macro-micro views. The first contradicting optimistic-pessimistic micro and macro view regarding the incidence and success of knowledge transfer/external schooling effect implies that the transfer of knowledge/the external effects of schooling is probably successful within firms, but is unsuccessful within society at large. This is probably because the transfer of knowledge is hindered by: the low quality of eductition; the weak linkages and a lack of networks between universities, colleges, technical and training institutes and the productive sectors; and the imbalanced structure of the population and labour market. Our observation of the second contradicting optimistic-pessimistic macro and micro view, concerning the self-reliance on local skill and the role of both technological upgrading and upskilling in reinforcing it, implies that the self-reliance strategy is probably a preferred government strategy but not necessarily favoured by private firms. 
This is probably because profit maximizing private firms are motivated to continue in hiring cheap readymade skilled foreign workers rather than hiring, training and upskilling expensive national workers. These results corroborate a part of the sixth hypothesis in Scheme 1.1 in Chapter 1 above with respect to the failure and the factors hindering the transfer of knowledge/extemal schooling effects at the macro level. But, on the other hand, our findings surprisingly reject a part of the sixth hypothesis concerning the failure of the transfer of knowledge/external schooling effect at the micro level, and also reject hypothesis 8.c. in Scheme 1.1 in Chapter 1 above about the consistency of upskilling and transfer of knowledge at the macro-micro levels.

The surprising results from Chapter 5 motivate our research to attempt a more comprehensive analysis of skills problem and the implications of unskilled foreign workers at the micro level/across private firms. Therefore, in Chapter 6, we then use the data from the firm survey (2002) to broaden our earlier analysis in Chapter 5 by providing an in-depth analysis of skill indicators, their implications and relationships with wages, upskilling (ICT training) and technology (ICT) indicators at the micro/firm level. Our findings illustrate the low skill levels - due to the excessive share of unskilled foreign workers - and the implications on skills mismatch, public-private duality and productivity decline across private firms. These results are consistent with the micro-macro findings in Chapter 5, which indicate the low share of high skilled workers in total population and employment - measured by both educational and occupational levels -and the serious implications on skills mismatch and the macro-micro duality with respect to upskilling efforts. Furthermore, we show that difference between required and actual education indicates severe skills mismatch across all firms and all skill levels, especially, across medium and low skilled workers. These findings, together with those in Chapter 5, verify hypotheses 3 and 4.a in Scheme 1.1 in Chapter 1 above regarding the implications of low skill levels and the argument, earlier in Chapter 2, about the pressing need for upskilling, mainly in the private sector.

Our results show positive correlations between skill (actual and required education and experience) and average wages. We show that differences in skill levels/stock of human capital (share of high skilled in total employment) across firms are related to market size (share in total employment, capital, output/sales and profit). We also find that an increase in skill level -share of high skilled in total employment - and firm size lead to improved relationships between actual and required education and experience and wages. Next, our results show positive complementary relationships between technology (ICT), skill and upskilling (ICT training). We illustrate that an increase in skill level - share of high skilled in total employment -and firm size lead to improved in the complementary relationships between skill, upskilling and technology (ICT). The relationships between skill indicators and wages, and between skill, technology (ICT) and upskilling (ICT training) substantiate our fourth hypothesis (4.b-4.c) in Scheme 1.1 in Chapter 1 , and agree with the findings in Chapter 5 concerning the differences in skill and technology indicators across firms according to firm size and industry. These results imply the importance of good education/skill levels for bridging differences between firms and also for improving skills, technology and upskilling
complementarity at the micro level.

These results guide us in Chapter 7 to use the firm survey (2002) data at the micro level and secondary data at the macro level to examine and verify hypothesis 7 in Scheme 1.1 in Chapter 1 above concerning the importance/impacts of tacit and codified knowledge at the micro-macro levels respectively. We find that at the macro level tacit knowledge is positively correlated with schooling years, while codified knowledge is positively correlated 
with GDP (economic growth). Moreover, our results at the macro level show significant positive complementary relationships between codified knowledge and the number of FIER and between these and the number of publications, cooperation and technology (patents). Furthermore, at the micro (firm) level, we illustrate that tacit knowledge is positively correlated with technology (expenditures on ICT), upskilling (expenditures on ICT training), output, output diversification, productivity and profit. In addition, we find that at the micro (firm) level tacit knowledge is positively correlated with market size: total investment, capital and firm size. The major implication of our findings is the positive correlation between knowledge and various variables at both the micro and macro levels. Therefore, further incentives should be provided to improve tacit and codified sources of knowledge at the macro and micro levels. Another implication is that the positive impact of tacit knowledge also implies the importance of a good education since tacit knowledge is often embodied in educated people and so in human capital.

In view of the findings in Chapters $2-3$, and 5-7, which indicate the importance of a good education, in Chapter 8 we use the data from the firm and macro surveys to conclude our study with policy analysis. We corroborate hypothesis 8 (8.a-8.b) in Scheme 1.1 in Chapter 1 above concerning the need for skill and technological upgrading through the reform of the educational and training systems and the transfer of knowledge. Moreover, we use secondary data and information and the macro and firm surveys (2002) to present a policy analysis of the educational (supply-demand sides) and training systems in the Gulf countries. We show that the educational policies in the Gulf countries shared several problematic features such as the dominance of public sector, the lack of incentives/marginal contribution of the private sector in educational investment, poor quality, insufficient supply (spending) and demand (enrolment) and the biased structure of tertiary education. On the other hand, our results show an enormous variation in the supply-demand sides of educational policies across the Gulf countries. When comparing supply-demand sides, it turns out that the supply side or public spending seems to be only one component in the educational policies, because higher public spending per se does not imply a higher demand for enrolment of children in education. That also does not imply higher participation and enrolment ratios, access to schoolling/school life expectancy and higher literacy rates. Moreover, we find that although the priority of spending on education - measured by the share of public spending on education as percentage of total government spending - in some of the Gulf countries is close to the levels in developed countries, the quality of education is low in al! Gulf countries. The major policy implication from these findings is that the improvement of the educational systems in the Gulf countries is vital and requires improvement of the quality/internal efficiency, supply (investment) and demand (enrolment) sides, particularly by increasing incentives at tertiary and technical education. We next discuss the macro-micro views concerning plans, mechanisms and policies for skill development through enhancing the educational system, provision of training, transfer of knowledge/external schooling effects, effective collaboration between public and private institutions and increasing incentives for private sector investment in education and training in the UAE. Our results show a serious discrepancy with respect to the implementation of public policies of training and skill upgrading between private and large public firms and divergence in arranging priorities to implement plans, mechanisms and policies for enhancing skill levels, provision of training and transfer of knowledge at the macro-micro levels. These results are consistent with earlier observations in Chapter 5 concerning the contradicting optimistic-pessinistic macro and micro views with respect to upskilling efforts and/or the self-reliance on local 
Will and the role of both techologixal upgrading and upskilling in reinforcing it. Therefore, we recomnetu further gfforts be made to entance the consistency between the macro-micro wew and the public private sectors, particularly in the arrangement of priorities, plans and mechanins to ensure more consistent, effective and successful policies for skils development.

\section{2 Relevance and Contribution of the Research}

Most of our findings in this research are consistent with both the new growh literature and the Gulf literature. Compared to the endogenous growth framework, we provide further evidence in support of the endogenous and new growth literature, in particular with respect to the positive correlation between actual education, experience and wages. Our results in Chapter 6 show positue complementary relationships between technology (ICT), skill and upskiling (ICT training), these findings seem consistent with the theoretical framework in Chapter 3 , endogenous growth framework and the stylized facts in the new growth literature concernimg the relationships between human capital, technical progress and upskilling. Our findings are broadly consistent with and provide further evidence in support of the findings in the new growth literature concerning the skilled biased technical change theorem. In addition, our results concar both with the general literature that defines both skill and technology in relation to firm characteristics (size and industry), and also the recent literature highlighting the growing effects of new technologies, especially ICT diffusion. Our results in Chapter 7 verify four stylized facts about the importance/impacts of knowledge at the micro and macro levels, and are in line with the recent general findings in the knowledge literature. In particular, the complementary relationship between tacit knowledge and codified sources of chowledge at the macro level and the significant correlations between both facit knowledge and codified sources of knowledge and output and growth at the micro and macro levels respectively. Tacit knowledge is important not only through its direct effects, but also through its further effects on upskilling and the use of technology (ICT). Our findings ate consistent with the recent results in the knowledge literature, which indicate that knowledge components have more significant impacts on output (total sales value) that exceed the effects of traditional variables (i.e. labour and capital).

On the other hand, we find a positive significant correlation between the use of/total spending on ICT and total output, but an insignificant correlation between the use of/total spending on ICT and profit at the micro/firm level. This result proves our fifth hypothesis in Scheme 1.1 in Chapter 1 above and the observations about the insignificant/inconclusive effect of ICT at the macro level in the Gulf countries and the recent literature in the developing countries. However, our results with respect to ICT should be interpreted more carefully as they probably have two-ways causality and may imply a possibility for reversed causality. Mainly because more profit and output would imply more financial capacity that permits more spending on ICT, on the other hand, more spending on ICT implies higher costs and lower profit.

Our findings about the insignificant correlation between the required education and wages are in contrast to the findings in the new growth literature on the importance of job characteristics (skills required) in wages determination.

Compared to the Gulf literature, we provide new evidence and add to the few recent studies in the Gulf that highlight the need for upskilling, the low skill, low technological levell and dependency on foreign technologies, and the duality between public and pri- 
vate sectors. Compared to the Gulf literature, our research is important for elaborating and providing a more in-depth analysis, not only for assessing the Gulf technology-skill indicators using a more comprehensive set of indicators than often used in the new growth literature, but also for analysing the causes and consequences of low skills and technology, the relation between them at both the macro and micro levels, and for addressing policy aspects aiming to enhance them. Basically, we identify upskilling as an essential element for the fulfilment of three current strategies in the Gulf: diversification, technological development and restructuring/reducing the imbalances in the labour market. We show that the low skill lewel is basically attributed to the deficient educational system - due to low quality of education - and high incidence of unskilled foreign workers at the macro and the micro levels respectively. The importance of our analysis is the identification of the numerous implications of the interaction between a poor educational system and an excessive share of low educated foreign workers that leads to low skill levels, poor provision of training, skills mismatch, low transfer of knowledge, poor technology indicators and high dependence on foreign technologies. We add to the findings of Haan (1999) regarding the lack of technology policy, technical skills, R\&D, technology culture in the Gulf society and the mismatch in the labour market due to deficient educational system and cultural reasons. One important result from our analysis is that we illustrate that the lack of local efforts for technology development is basically related to low R\&D efforts that are attributed to low skill level, lack of networks systems, fruitful cooperation between universities and firms, lack of resources, social awareness and concern. We provide basic and new contributions and fill the gap in the Gulf literature by investigating the significance of the incidence and transfer of knowledge/external schooling effects, the factors hindering and those contributing towards enhancing them at the macro and micro levels in the Gulf. We show the significance of tacit and codified sources of knowledge at the micro-macro levels. Unlike the few recent studies of knowledge in the Arab countries, one advantage of our analysis is that we provide a more specific analysis that focuses only on the Gulf countries. Different from earlier studies, we provide new empirical investigation of both the importance (impacts) of tacit knowledge at the micro level - see our discussion in Chapter 7 - and the discrepancy in the transfer of knowledge/external schooling effects at the macro-micro levels - see our discus-

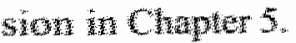

型存 sow

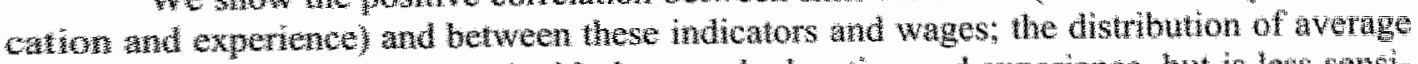

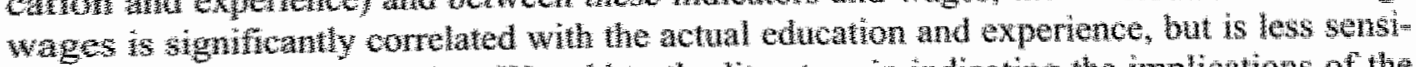

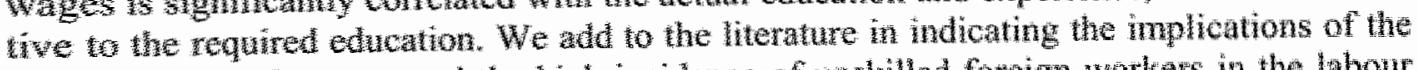

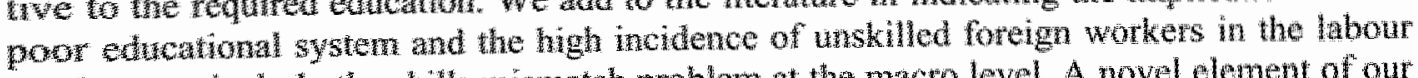

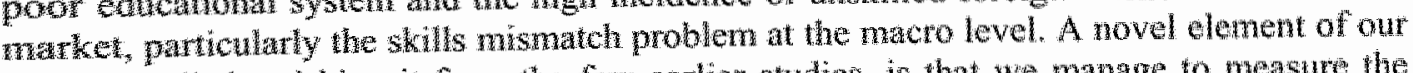

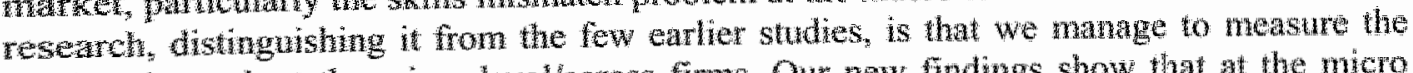

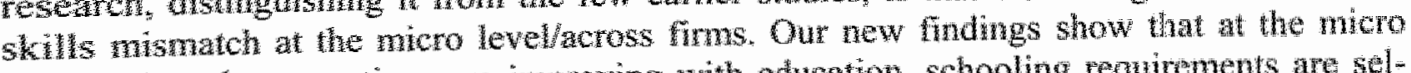

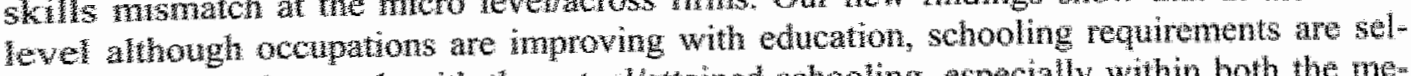

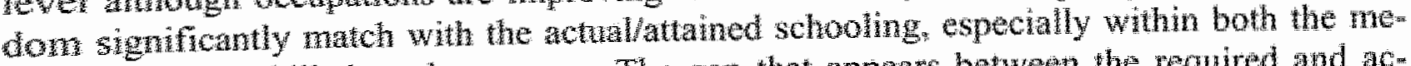
dum and low skined worker groups. The gap that appears between the required and actualataned schoolng indicates a mismach at we moro level, which is notably higher whin boult medium and low skilled workers.

Our findings concerning the channels of technology transfer and the wide variation between the level of technology manser in the different industrial scales and activiies/sectors go beyond the findugs in the Gulf literature (e.g. Elsabaa, 1997). This is be- 
cause we Identify wide variations in the preferred channels of technology transfer that include not only joint ventures and foreign industrial projects, but also strategic alliances, hiring foreign skill/technologically advanced workers and consultants, technology licensing and FDI. We show that across firms not only the level of technology use and channels of transfer are determined by firm size and industry, but also skill and technology indicators (the use of ICT, R\&D, patent, product and process innovations) are significantly defined by firm's characteristics i.e. size and industry. These results are consistent with the generall literature, which illustrates that both large size firms and high intensive/active industry (e.g. chemical) are more intensive in terms of the use of technology and skills. However, one should also expect that these results might imply a possibility for reversed causality, mainly because $R \& D$ is a fixed cost that requires high financial capacity, which is most likely to be stronger amongst large size firms.

We add to the very few literature in the Gulf concerning the positive impacts the technology transfer brings to output/production (Elsabaa, 1997) and the negative impact the use of technology induces in the demand for unskilled workers/labour saving effect (Haan. 1999). We provide a more elaborate analysis, relying not only on the qualitative effects of the use of technologies, particularly ICT diffusion on the demand for labour and the effects. of increasing use of technologies on product and process imnovations, but also on the quantitative effects of ICT on output and profit.

Our results provide further evidence that is consistent with the Gulf literature on the duality between the public and private sectors. We show new aspects not only with regard to the public-private duality in skill and technology levels, the use of ICT and upskilling, but also in relation to the macro-micro duality and the surprising contradicting views concerning the transfer of knowledge, upskilling and the impact of ICT.

Our new results from chapter 8 show that the implication and interaction between educational and training policies seem to be effective only within the largest public firms, which appear more committed to implement skill upgrading policies that are consistent with the line taken by public policies. The large public firms successfully contribute to serve public policies of training and skill upgrading via establishing active human resources development units, recruitment policies and specialized training centres to implement various regular and special internal and external training programmes, especially for national workers. In addition, these firms encourage the use of ICT to upgrade skill levels, offer scholarships and collaborate with universities to absorb young national graduates. These results oppose our earlier findings in Chapter 5 , which indicate a lack of effective interaction between educational and training policies and a lack of incentives for provision of training within private firms. Hence, these findings imply a further duality/discrepancy at the micro level/across public-private firms. That also leads to duality/discrepancy between macromicro views with respect to implementation of upskilling plans. Therefore, we observe that, in contrast to the private firms, the large public firms (JULPHAR, ADNOC and DUBAL) in the UAE have successfully contributed to serve the public policies for enhancing training and skill upgrading, especially among the national workers. However, it is less clear whether the large public firms induce positive effect to upskill workers in private firms. In our view the interpretation of the serious public-private discrepancy can be attributed to the presence of high resources, support and incentives within large public firms, which are probably lacking within private firms. 


\section{3 Policy recommendations}

The major policy recommendation from this research is that skill development policies can be enhanced by making improvements to the educational and training systems and enthancing the transfer of knowledge/external schooling effects. As for improving of education, the major policy recommendations include the improvement in the quality of teachers or mentors, infrastructure, planning for educational needs, the internal efficiency/quality of basic, secondary and tertiary education, encouraging the system of modernization and dynamism. In addition, measures should be undertaken to enhance the linkages (networks) between universities, colleges, technical and training institutes, monitor educational needs on a regular basis, encourage the system of flexibility of educational institutions, and increase the harmony/consistency between educational output and market needs. In addition, further measures include: increasing incentives for enrolment and spending on education by both public and private sectors, particularly in tertiary and technical education, changing the attitudes of educated economically active population, improvement of regulations/laws to legitimize sufficient duration of compulsory education and decentralization of decisionmaking.

Concerning the improvement of training, the major policy recommendations include enhancing the educational qualifications of workers, availability of training materials and equipment, planning and regular/ adequate assessment and monitoring of training programmes to fit the changing technical and skill needs. Further recommendations include increasing the appreciation of or information on the benefits of training, improving the quality and availability of trainers and mentors, enhancing availability of finance to cover training costs. In addition, there should be measures aimed at encouraging specialized training institutions, the interactions between training institutions and firms, enhancing the full appropriability of the return from investment in training, enhancing the system of training certification of skill acquired, increasing the participation of private training institutions and decentralization of training provision.

With respect to improvement of the transfer of knowledge, the major policy recommendations include an improvement of the quality of education and training and the qualifications of both skilled and unskilled workers to permit the positive effects of skilled workers on unskilled workers. In addition, there are recommendations that aim at the improvement of firms conditions to encourage the external effects, sponsoring educational scholarships, increasing the interaction to market needs through increasing the information about future educational, training and skill needs, especially in the productive sectors and their demand for graduate students. The policy recommendations also aim at increasing awareness about future value of investments in education and training, enhancing a system of certification of skill acquired, providing adequate incentives for trainers and minimization of education, learning and training costs.

Since the skills problem is partially attributed to the high presence of unskilled foreign workers, skill upgrading requires both a reduction in numbers and an upgrading of unskilled foreign workers. There is much to be learned from the successful stories in the rapidly advanced countries, in particular, the experiences of skill upgrading in Singapore and Korea - cf. our discussion in Chapter 3.

Finally, in view of the complementary relationship between skills, skill upgrading and technological progress - see our discussion in Chapters 3 and 6- the development of education, training, transfer of knowledge and skill levels may have further positive impli- 
cations on the development of local technologies. Accordingly, the promotion of local technologies depends on skill upgrading, promotion of R\&D activities and the enhancement of networks systems, collaboration between universities, firms, public and private sectors and implementation of an explicit technology policy.

\section{4 Direction for future research}

We plan to utilize and extend the major findings of this study for future empirical research to improve understanding of the causes and consequences of low skill and technological level in other developing countries with similar circumstances. It is hoped that our future research makes reference/ would be relevant to more than one country and the results could be generalized and extended to be of value/use and benefit to other developing countries. It is also hoped that the results would generate some useful insights for international comparisons across developing countries and contribute to enhancing the accumulation of human capital, external schooling effects/transfer of knowledge, uskilling, technological capacity, social welfare and economic development in the developing countries. 


\section{References}

Abdelkarim, A and Haan, H. (2002), "Skills and Training in the UAE: The need for and the Dimensions of Institutional Intervention," Centre for Labour Market Reseanch and Information. Policy Research No. 5 - Dubai - UAE - January (2002).

Abdelkarim, A. and Ibrahim, S. (2001), "Productivity Problems in the UAE: The Role of Productivity organization," Centre for Labour Market Research and Information. Policy Research Series, Non 4 . Dubai - UAE - December (2001).

Abramovitz, M. (1956), "Resource and Output Trends in the United States since 1870," American Economic Review, Papers and Proceedings, Vol. 46, (May 1956): pp. 5-23.

Abramovitz, M. (1986), "Catching up, forging ahead and falling behind," Journal of Econowic History, Vol. 46, pp. 385- 406 .

Abramovitz, M and David, P.A. (1996),"Technological Change and the Rise of Intangible Investments: the US Economy's Growth -Path in the Twentieth Century" In D. Foray and B-A. Lundvall (eds.) "Employment and Growth in the Knowledge based Economy, "OECD Documents. Paris. OECD.

Abramovitz, M and David, P.A. (1998) "American Macro Economic Growth in the Era of Knowledge Based Progress: The Long -Run Perspective" In S. L. Engerman and R. E. Gallman, (eds.) "An Economic History of the United States: the Twentieth Century," Vol. 3, New York: Cambridge University Press, pp. 1-92.

Acemoglu, D. (1998), "Why Do New Technologies Complement Skills? Directed Technical Change and Wage Inequality," Quarterly Jownal of Economics, Voll 113. No. 4, November (1998): pp. 10551089.

Aghion, P. and Howitt, P. (1990), "A Model of Growth through Creative Destruction," NBER Working Paper Series, No. 3223.

Aghion, P. and Howitt, P. (1992), "A Model of Growth Through Creative Destruction," Econometrica, Vol. 60. No.2. (1992): pp.323-351.

Aghion, P., and Howitt, P. (1998), "Endogenous Growth Theory," MIT Press, Cambridge MA.

Alfakhery, J. J. (1999), "Human Development Indicators in the UAE: A comparative study of UNDP Human Development Reports 1994- 1998," Labour and Social Research and Studies Series No. 1The UAE Ministry of Labour and Social Affairs - Department of studies, research and statistics Dubai (1999): pp. 81-82. (in Arabic)

A1-Sulayti, H.A. (2002), "Education and Human Development in the GCC Countries: An Analytical Study," ECSSR Strategic Studies, No. 71, Abu Dhabi, ECSSR, (in Arabic).

A.1-Tony, M.N. (2002), "Employment policies and human development in the Arab countries: Analysis of the experience of Kuwait," Arab Planning Institute Working Paper Series, 0204, April, Kuwait, (in Arabic)

Arab Fund for Social and Economic Development (2001) "The Joint (Unified) Arab Economic Report," A joint publication by the Arab Fund for Economic and Social Development, The Arab Monetary Fund, The Arab Organization for Petroleum Exporting Countries, and the league of Arab. States, Abu-Dhabi- UAE.

Arundel, A. and Geuna A. (2001), "Does Proximity Matter for Knowledge Transfer from Public Institute. and Universities to Firms?" SPRU Electronic Working Paper Series, No. 73, University of Sussex, pp. 3,5 .

Askari, H., Nowshirvani, V. and Jaber, M. (1997), "Economic Development in the GCC: The Blessing and the Curse of Oil". Greenwich, CT: JAI Press. In Datta, S. K., Nugent J. B. and Samman, H. (2000) "Labor Market and Private Sector Development Policies in a Labor Scare, Oill Exporting Country: A Theoretical Exploration," Conference Paper, The Seventh Annual Conference of the Economic Research Forum (ERF) Jordan, 26-29 October 2000. P. 16. 
Auberi, J-E. and J-L. Reiffers (eds.) (2003) "Knowledge Economies in the Middle East and North Africa: Toward New Development Strategies," Vol.1, World Bank Instinute Leaning Resoumces Series. The World Bank (2003) Report No. 28038.

Autor, D. H. (2000)" "Why do Temporary Help Finn Provide Free General Skills Training?" NBER Working Paper Series, No. 7637: p. 37.

Autor, D. H. Katz, L. F. and Krueger, A. B. (1998), "Computing Inequality" Have Computers Changed the Labour Marker?". The Quarrerly Joumal of Economics, Vol. 113, Issue No. 4, November, 1998 : $1169-1213$

Arrow, K. J. (1962), "The Economic Implication of Leaming by Doing," Review of Ecomamic Studies Vol. 29. (June 1962): pp.155-173.

Azariadis, C., and Drazen. A (1990), "Threshold Externalities in Economic Development," Quarterly Journal of Economics, Vol. $105 \mathrm{No}$. (2): $50 \mathrm{I}-526$.

Barro, R. (1991), "Econonic Growth in a Cross Section of Countries," Quarterly Jowmal of Economics CHI (1991) Vol. 106, No. 2: pp.407-443.

Barro, R. (1996), "Determinants of Economic Growth: A Cross- Country Empirical Study," NBER Working Paper Series, No. 5698.

Barro, R. J. and W. Lee (1993), "International Comparison of Educational Attainment," Joumal of Monetary Economics Vol. 32, No. 3: pp. 363-394.

Barro, R. J. and W. Lee (1996), "International Neasures of Schooling Years and Schooling Quality," American Economic Review, Paper and Proceedings, Vol. 86, No. 2: pp. 218-223.

Barro, R. J. and Lee. W. (2000), "Intemational Data on Educational Attaimment Updates and Implications," NBER Working Paper Series, No. 7911.

Barro, R. J. and Sala-i- Martin, X. (1992), "Public Finance in Models of Economic Growth," The Review of Economic Studies, Vol, 59, No, 4 (October, 1992), 645-661.

Barro, R. J. and X. Sala -i- Martin (1995) "Economic Growth," - New York, McGraw Hill.

Bartel, A. P., and Lichtenberg F. (1987) "The Comparative Advantage of Educated Workers in Implementing New Technology," The Review of Economic and Statistics, Vol. 69, No. 1 (February): 1-11

Bartel, A. P. and Sicherman, N. (1995) "Technological Change and the Skill Acquisition of Young Workers," NBER Working Paper Series, No. 5107. (1995)

Becker, G. S. (1962), "Investment in Human Capital: A theoretical Anelysis," Journal of Political Economy, Vol.70, No.l: pp. 9-49.

Becker, G. (1964), "Human Capital," Chicago: the University of Chicago press (1964).

Benhabib, J and Spiegel M. M. (1994), "The Role of Human Capital in Economic Development: Evidence from aggregate cross-country data," Journal of Monetary Economics (34) (1994): 143-173, New York 1994.

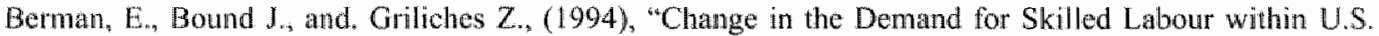
Manufacturing Industries: Evidence trom the Annual Survey of Manufacturing, "Qnarterly Journal of Economics, Vol. CIX, No.2: pp. $367-397$ (pp.367-398 (Vol. 109 May).

Berman, E. Bound, J, and Machin, S. (1998), "Implications of Skill-Biased Technological Change: International Evidence," Quarrerly doumal of Economics. Vol. 113, No.4, November 1998: pp. 1245. 1279 .

Braga, H. and L. Willmore (1991), "Technological Imports and Technological Efforts: An Analysis of their Determinants in Brazilian Firms," The Jourmal of Industriol Econowics. 39 (4), 421-432.

Bresnahan, T. F. Brynjolfsson, E. and Hitt, L. M. (1999), "Information Technology, Workplace Organization, and the Demand for Skilled Labour: Firm- Level Evidence," NBER Working Paper Series, No. 7136

Brusoni, S. Marsili. O. and Salter, A. (2002), "The Role of Codified Sources of Knowledge in Innovation: Empirical Evidence from Dutch Manufacturing," SPRU Electronic Working Paper Series. No. 80, University of Sussex.

Bound, J. and Johnson C. (1992), "Change in the Structure of Wages in the 1980s: An Evaluation of Alternative Explamations," American Economic Review, Vol. 82 No. 3, (June): pp.371- 392.

Chatterji, M. (1995), "Training Subsidies, Technical Progress and Economic Growth," The Manchester School Vol. LXIII No. 3 September 1995. Blackwell Publishers Ltd and the Victoria Uniwersity of Manchester, 1995. 
Cheal, B. H. (1997), "Can Government engmeer the transition from cheap labour to skill- based competitweness? The case of Singapore) - (Chapter 4) In Godfrey, M. (1997). "Skill Dewelopment for /htermovional Competitiveness". Edward Elgar- Cheltenham, UK, Brookfield, US.

Cheon, B-Y. (1999), "Employment, Occupations and Skills in increased Thternational Exposure: The Republic of Korea 1970 - 1990" Employnent and Troining Papers No. 39- ILO: pp. 2 -3, 12-15,18 $246-68$.

Cohen, S. 1. (2000) "Employment imbalances in the private sector: Problems, solution and policies," Specialist Report No. 9. The Ministry of Labour and Social Affairs: National Strategy for Labour Force Development and Emplloyment Project. Unpublished Report - Dubai - September 2000.

Colecchia, A. and Papaconstantinou, G. (1996), "The Evaluation of Skills in OECD Countries and the Role of Technology ". STI Working Paper 1996/6. OECD-Paris - OECD/GD (96) 183.

Corden, W. M. (1984) "Booming Sector and Dutch Disease Economics: Survey and Consolidation," $O x-$ ford Economic Papers 36(3): 359-80.

Cowan, R., Soete, L. and Tchervonnaya, O. (2001), "Knowledge Transfer and the Services Sector in the Context of the New Economy," MERIT-INFONOMIC Research Menorandum 2001-021, Maastricht University, Maastricht. p. 9.

Datta, S. K., Nugent J. B. and Samman, H. (2000) "Labor Market and Private Sector Development Policies in a Labor Scare, Oil Exporting Country: A Theoretical Exploration," Conference Paper, The Seventh Annual Conference of the Economic Research Forum (ERF) Jordan, 26-29 October 2000.

Dasgupta P, David P (1994) "Toward a new economics of science," Research Policy 23 (5): 487- 521.

David, P. A. and Foray, D (1995) "Accessing and expanding the science and technology knowledge base," STI Review. OECD, Paris.

David, P. A and Foray, D. (2001) "An Introduction to the Economy of the Knowledge Society," December 2001. MERIT-INFONOMIC Research Memorandum Series No. 2001-041. Maastricht University, Maastricht.

Dension, E. F. (1962), "Sources of Growth in the United States and the Alternatives Before Us," Supplement Paper 13, Committee for Economic Development, New York.

Devlin, J. (1998) (ed.) "Gulf Economies: Strategies for Growth in the 21 st Century," ECSSR International Studies, no. 20

Dosi, G., Freeman, C., Nelson, R. R., Silverberg, G., Soete, L. (eds.) (1988) "Technical Change and Economic Theory," Printer Publishers, London, New York.

Drucker, P. (1998) "From Capitalism to Knowledge Society" in D. Neef (ed.) "The Knowledge Economy" Woburn MA: Butterworth (1998). p. 15.

Economic Research Forum for the Arab Countries, Iran and Turkey (ERF) (2000), "Economic Trends in MENA Region 2000," Chapter Five: Labor Market and Human Resource Development: Overview of the Labor Market in the GCC Region, http:/www.erf.org.eg.

Economic Research Forum for the Arab Countries, Iran and Turkey (ERF) (2002), "Pconomic Trends in MENA Region 2002", Chapter Three: Export Competitiveness: Where the Region Stands?" The ERF and the American University in Cairo. p. 53

Economic Research Forum for the Arab Countries, Iran and Turkey (ERF) (2002), "Economic Trends in MENA Region 2002", Chapter Five: Labor Market and Human Resource Development; The GCC Labor Market: Private vs Public", "The ERF and the American University in Cairo.

El Sabaa. S. (1997) "Linking Technology to Industrial Development in the United Arab Emirates," Trade and Industry Magazine - Dubai - November (1997), Vol. 22. No. 263: pp. 16-29.

Enos, J.L. (1991) "The Creation of technological capability in developing countries" A study prepared for the Infernational Labour Office within she framework of the World Employment Programme. Pinter Publishers, London and New York, 1991.

ESCWA- UNESCO (1998) "Research and Development System in the Arab States: Development of Science and Technology Indicators" 1998 (E/ESCWA/TECH/1998/3). In ESCWA (1999) "Review' of Science and Technology in ESCWA Member Countries" Issue No. 1. 1999 (E/ ESCWA/TECH/ 1999/Rev. I). January 1999: pp.3-4.

Fahmey, M. S. and Mahmoud, H. A. (1993),"Problems of Educational Administration in the Gulf Cooperation Council countries," The Arab Education office for the Gulf coumtries - Riyadh (1993) in A.m Sulayti, H.A. (2002), "Education and Human Development in the GCC Countries: An Analytical Study," ECSSR Strategic Studies, No. 71, Abu Dhabi, ECSSR, (in Arabic) pp 29-30. 
Fasano, G. (2002), "With Open Economy and Sound Policies, U.A.E. Has Tumed Oil Curse into a Blessing," JMF Surrey (October 21, 2002): pp: 330-332. Washington: International Monetary Fund.

Fasano, G. and lqbal, Z (2003), "GCC Countries: From Oil Dependence to Diversification," IMF Publicafion, September 2003. Washington: International Monetary Fund.

Firm Survey (2002) "Technological Change and Skill Development. A Comparative Study of Chemical and Metal Medium and Large Scale Enterprises in the UAE," February / 2002 - April / 2002.

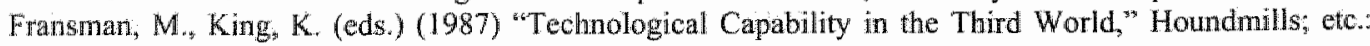
Macmillan Press, 1987.

Freeman, C. and Soete, L. (1994), "Work for all or Mass Unemployment? Computerised Technical Change into the Twenty - first Century," London, Printer, 1994.

Freeman, C. and Soete, L. (1997), "The Economic of Industrial Imnovation," third edition, Cassell, London: pp. 2, 24, 404-405

Gameldin, A. 1. (1994) "Labour Markets in the GCC Countries: A survey" Washington, D.C: World Bank.

Garcia Cervero, S. (1997) "Growth Technology, and Inequality: An Industrial Approach" EUI Working Paper $97-26$.

Girgis, M. (2000) In "Economic Research Form: Economic Trends" in MENA Region 2000 "Chapter Five: Labor Market and Human Resource Development: Overview of the Labor Market in the GCC Region," http://www.erf.org.eg.

Goldin, C and Katz, L, F. (1998), "The Origin of Technology Skill Complementarity," The Quarterly Jounal of Economics, Vol. 113, No. 3, November (1998): pp. 693-732.

Goyal, R. (2003) "Non-Oil Growth, Competitiveness, and the Labor Market," in United Arab Emirates: Selected 1ssuess and Statistical Appendix" IMF Country Report No. 03/67, March 2003. Washington: International Monetary Fund, pp. 4I-58.

Gray, L. (1999), "Private Sector Training and Employment: Evaluation and Intervention Strategies," Specialist Repont No.4- Dubañ, April (1999) - The Ministry of Labour and Social Affairs National Strategy for Labour Force Development and Employment Project. Dubai.

Griliches, Z. (1969), "Capital-Skill Complementarity," The Review of Economic and Statistics, Vol. LI, (1969) 69, November (1969): pp. $465-468$.

Grossman, G. M. and Helpman, E. (1991), "Innovation and Growth in the Global Economy," Cambridge, Mass.: MIT Press.

Grossman, G. M. and Helpman, E. (1994), "Endogenous Innovation in the Theory of the Growth," Jownat of Economic Perspectives 8 (1): 23-44.

Gulf Organization for Industrial Consulting GOIC (1996), "Features of Industrial Economy in the UAE," Data and Statistics (1996). p. 123. GOIC: Doha-Qatar.

Gulf Organization for Industrial Consulting GOIC (1998), "Gulf Statistical Profile 1998: GOIC Industrial Data Bank" (1998)-GOIC: Doha -Qatar.

Gulf Organization for Industrial Consulting GOIC (2000a), "Gulf Statistical Profile 2000: Industrial Data Bank" (2000) - GOlC: Doha -Qatar

Gulf Organization for Industrial Consulting GOIC (2000b) "Features of Industrial Economy in the Gulf Cooperation Council countries GCC countries: Gulf Industrial Base: Industrial Data Bank" GOIC, November 2000, Doha.

Haan, H. (1999), "The UAE: Assessment of Technology Use in Some Selected Sectors- Towards Introduction and Explaining Capital and Skill Intensive Technologies," Specialist Report No.6. Dubai/Amsterdam, January/March, 1999. National Human Resources Development and Employment Strategy Project.

Haddad, M (2001) "Export Competitiveness: where does the Middle East and North Africa Region Stand?" Background paper to Economic Trends in the MENA Region. Cairo: Economic Research Forum (ERF), In ERF (2002), "ERF Economic Trends in MENA Region 2002": Chapter 2: Financial and Capital Markets. Priwatization and FDI." ERF (2002), AUC -Cairo.

Hafsi, T. (2001) "Foreign Direct Investment in the Middle East and North Africa Regions: An Overview," Background note for Economic Trends in the MENA Region. Cairo: Economic Research Forum. In ERF (ERF Econonic Trends in MENA Region 2002," ERF (2002): p.41 (Box 2.2), AUC -Cairo.

Hagedoorn, J, A.N. Link and N. Vonortas (2001) "Research Partnership", Research Policy, 29:567-86.

Hanushek E. A. and Kim D. (1995), "Schooling, Labour Force Quallity and Economic Growth," NBER Working Paper Series, No. 5399. 
Hartog, J. (2000), "On Returns to Education: Wandering Along the Hills of Onu Land", in: H. Heijke and J. Muysken (eds.), Education and Training in a Knowledge based Economy, MacMillan Press Lid., England.

Haslinger, F. and Ziesemer, T. (1996), "Endogenous Growth and Distributional Conflict;" in C. Gore, G. Köhler, U. Peter Reich and T. Ziesemer (eds.) Qwestioning Development: Metroplis Verlag, Marburg, $1996,223-40$.

Hillebrand, W., Messner, D., Meyer-Stamer, J. (1994), "Strengthening Teclnnological Capability in Developing Countries: Lessons from German Technical Cooperation": German Development Institute Reports and Working Papers, nr. 12/94, German Development Institute, Berlin, 1994.

Hwang, Gyu-heui (2000), "Diffusion of Information and Communication Technologies and Changes in Skills". October 2000, SPRU Electronic Working Paper Series, No. 48.

ILO (1995) "World Employment 1995: An ILO Report," International Labour Office, Geneva. 1995: p.57.

ILO (1998) "World Employment Report 1998/1999: Employability in the Global Economy How training matters," Chapter 2 In "Globalization, technological change and demand for skilled labour". ILOGeneva - September (1998): p. 35.

Issawi, C. (1982) "An Economic History of the Middle East and North Africa," New York Columbia University Press 1982: pp. 1, 8, 79, 204.

Jones, C. (1998), "Introduction to Economic Growth," W.W. Norton and Company New York, London, 1998.

Jorgonson, D. W., Gallop, F. M and Fraumeni, B. M. (1987) "Productivity and U.S. Economic Growth," Cambridge MA. Harvard University Press.

Kahm, J. A. and Lim, J. S (1998), "Skilled Labor-Augmenting Technical Progress in U.S. Manufacturing," The Quarierly Joumal of Economics. Vol. 113, No. 4, November (1998): pp. 1281-1308.

Kenderik, J.W. (1956), "Productivity Trends: Capital and Labour," Review Econownic and Staristics, Vol. 39, Vol. 38, (August 1956): 248-257.

Kenderik, J. W. (1961), "Productivity Trends in the United States," New York Princeton University Press.

Kenny, C. (2002) "The Internet and Economic Growth in Least Developed Countries," UNU- WIDER Discussion Paper series: DP2002/75, August (2002).

Khorshid, M. (1997) "Analysis of Labour Markets Using Economy Wide Simulation Models- Theoretical Consideration and Practical Applications," Finance and Industry- The Industrial Bank of KuwaitNo.15, p.47.

Khorshid, M. (2000) "A prototype Labour Market Economic Interaction Modle for A Gulf Cooperation Council Country: Impact of Structural Imbalances and Policy Measures on Medium Term Performance," Paper presented at The Seventh Annual Conference of the Economic Research Forum (ERF) Jordan, 26-29 October 2000.

Klepper, S. and K. Simons (1997) "Technological Extinctions of Industrial Firms: An Enquiry into their Nature and Causes". Industrial Corporate Change, 6: 379-460.

Kumar, N. and M. Saqib (1994), "Firm Size, Opportunities for Adaptation, and In-house R\&D Activity in Developing Countries: The case of Indian Manufacturing", UNU/NTECH Working Paper.

No. 13, January.

Lall, S. (1987), "Learning to Industrialize: The Acquisition of Technological Capability by India," Houndmills; etc.: Macmillan Press, 1987.

Lall, S. (1999) "Competing with Labour: Skills and Competitiveness in Developing countries," Issues in Development Discussion Paper No. 31. Development Policies Department, ILO-Geneva. p. 17.

Langlois, R N (2001) "Knowledge, consumption, and endogenous growth," Journal of Evolutionary Eco" nomics 11:77-93.

Lee, W. and Barro, R. J. (1997), "Schooling Quality in A Cross Section of Countries," NBER Working Paper Series, No. 6198.

Lewin, R, Cohen, W. M and Mowery, D C (1985) "R\&D appropriabillity, opportunity and market structure: new evidence on some Schumpeterian hypotheses," Anerican Economic Reviaw 75:20-24.

Lillard, L. A. and Tan, H. W. (1986). "Training: Who Gets it and What are its Effects on Employment and Earning," Santa Monica RAND Corporation Report. R-333I, DOL/RC, 1986.

Low, L. (1998), "Jobs, Technology and Skills Requirements in a Globalized Economy: Country study on Singapore," Employment and Training Paper No. 13- Employment and Training Department-ILO. Geneva 
Lonf, H. and A. Heshmati (2002), "Knowledge Capital and Performance Heterogeneity: A firm" Level Innovation Study," Intemational Joumal of Production Economics 76 (2002) 61-85.

Lucas, R. E. (1988), "On the Mechanics of Economic Development," Jound of Monetary Economics, Vol. 22, pp. 3-42. North Holland.

Lundvall, B-A (ed.) (1992) "National Systems of Innovation: Towards a theory of Innovation and Interacting Learning," London: Printer Publishers.

Machin, S. and Van Reenen, J: (1998), "Technology and Changes in Skill Structure: Evidence from Seven OECD Countries," Quarterly Journal of Economics. Vol. 113, No. 4 (November 1998): pp. 12151244.

Macro Survey (2002) "Skill Creation, Human Resources Development and Pollicy Intervention: Interviews with Policy Makers and Experts in the UAE," February / 2002 - April / 2002.

MADAR Research Group (2002), "E-Market Trends: Internet Coming of Age in Arab World with Advent of the Third Wave" MADAR Research Journal Knowledge Economy Research on the Middle East. Vol. I, llssue Zero October 2002: p. 4.

Mankiw, N. G., Romer, D. and Weil, D. (1992), "A Contribution to the Empirics of Economic Growth," The Quarterly Journal of Economies, Vol. 107, No. 2, (May 1992): pp. 407- 437.

Mansfield, E.(1991). "Academic Research and Indusirial Innovation: An Update of Empirical Findings," Research Policy, 26:773-76.

Mansfield, E. and J. - Y. Lee (1996) "The Modern University: Contributor to Industrial Innovation and Recipient of Industrial R\&D Support ${ }^{\text {" }}$ Research Policy, 25:1047-58.

Mincer, J. (1974), "Schooling, experience and earnings," New York, Columbia University Press.

Mincer, J. (1989), "Human Capital Response to Technological Change in the Labor Market," NBER Working Paper" Series, No. 3207.

Mulligan, C. B. and X. Sala -i- Martin (1995), "Measuring Aggregate Human Capital," NBER Working Poper Series, No. 5016: p.2.

Muysken, If and ter Weel, B. (1998), "Overeducation and Crowding out of Low Skilled Workers," MER/T Research Memorandum 98-023, Maastricht University, Maastricht.

Muysken, J. and Ruholl, J. (2001),"The impact of education and mismatch on wages: The Netherlands, 1986-1998" MERIT Research Memoranda 2001-030, Maastricht University, Maastricht.

Muysken, I., Hoppe, M. and Rieder, H. (2002a),"The Impact of education and mismatch on wages: Germany, 1984-2000" MERIT Research Memoranda 2002-031, Maastricht University, Maastricht.

Muysken, J., Weissbrich, A and von Restorff, C. H. (2002b), "The impact of education and mismatch on wages: the USA, 1986-1996" MERIT Research Memoranda 2002-015, Maastricht University, Maastricht.

Muysken, J., Kiiver, H. and Hoppe, M.M. (2003), The impact of education and mismatch on wages: Germany, 1984-2000, in: F. Büchel, A. de Grip and A. Mertens (eds.), Overeducation in Europe: Whot do we know?, Cheltenham: Edward Elgar Publishing Ltd., pp. 109.132.

Muysken, $\mathrm{J}$, and Nour, $\mathrm{S}$. (2005), "Deficiencies in Education and Poor Prospects for Economic Growth in the Gulf Counries: The Case of the UAE," Paper presented at the ETIC European Doctonal Training Programme, Maastricht, October 2003. (forthcoming. the Jound of Development Studies, 2005, Taylor and trancis Ltd., UK),

Nelson, R. R. (1959), "The Simple Economics of Basic Scientific Research." Journal of Political Economy. 67, June, pp. 297-306.

Nelson, R. (ed.) (1993) "National Innovation Systems: A comparative Study," New York: Oxford Universily Press.

Nelson, R. and Phelps E. (1966), "Investment in Humans, Technological Diffusion and Economic Growh." American Ecomomic Revien: Papers and Proceedings, Vol. LVI, Vol. 61: 69-75.

Nelson, R. R., and Winter, S. G. (1977), "In Search of Useful Theory of Innovation", Research Policy, Vol. 6 , No.1, voll. 5 , pp. $36-76$.

Netson, R. R., and Winter, S. G. (1982), "An Evolutionary Theory of Economic Change", Cambridge, MA. Harvard University Press.

Nour, S. (2002a) "ICT Opportunities and Challenges for Development in the Arab World," Paper prepared for the UNU/WIDER Conference on the New Econony in Development, 10-11 May 2002, UNUWIDER Discussion Paper DP2002/83. Helsinki. (forthcoming Chapter 6 in A. P. D'Costa (ed) 
"The New Economy in Development. ACT Challenges and Opporwnines: series of Techology.

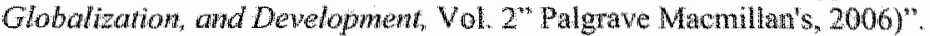

Nour, S. (2002b), "The Impact of ICT on Economic Development in the Arab World: A comparative study of Egypt and the Gulf countries". ERF Working Paper Series WP Number: 200237.

Nour, S. (2005), "Science and technology (S\&T) development indicators in the Arab region: a comparative study of Arab Gulf and Mediterranean countries" UNU-INTECH Discussion paper series DP 2005. 3. The Journal of Science, Technology and Society, 2005, Vol. 10, No.2, September, SAGE Publications.

OECD (1997), "The Second European Report On Science and Technology Indicators (1997)": pp.37, 9091. OECD, Paris, (1997).

OECD (1999) "The Knowledge Based Economy: A set of Figures and Facts," OECD. Paris, OECD (1999): "L'économie fondée sur le savoir. des faits et des chiffres", Paris, OECD.

OPEC (2002) "OPEC Annual Statistical Bulletin 2002," OPEC, Vientra, Austria.

Otani, 1. and Villanueva, D. (1990), "Long-Term Growth in Developing Countries and Its Determinants: An Empirical Analysis" World Developmem, Vol. 18, No. 6, 769-783.

Palma, G. (2003) "Four Sources of de-industrialisation and a new concept of the Dutch Disease," Unpublished paper presented at UNU-INTECH Research Seminar Series 2004-2, 19 May 2004: p. 21

Patel, S. (1995), "Technological Transformation: The Historic Process," Volume V, The United Nations University, Avebury Publishing Ltd., UK: p. 98.

Pohjola, M. (2002) "New Economy in Growth and Development" UNU- WIDER Discussion Paper series: DP2002/67, July (2002).

Qasen, S. (1998) "Research and Development in the Arab States: Development of Science and Technology Indicators (ESCWA and ROSTAS, 1998).

Rasiah, R. (2002), "TRIPs and Capability Building in Developing Economies," UNUINTECH Discussiom Paper series, No. 2002-1, March.

Rebelo. S. (1991), "Long -Run Policy Analysis and Long - Run Growth," Joumal of Political Economy, Vol.99, No.3, (June): $500-521$.

Richards, A. and J. Waterbury (1998) "A Political Economy of the Middle East," Second Edition. Boulder, Colo.: Westview Press.

Romer, P. M. (1986), "Increasing Returns and Long Run Growth," Joumal of Political Economy, Vol. 94. No. 5, (October): 1002-1037.

Romer, P. M. (1987), "Growth Based on Increasing Returns Due to Specialization," American Economic Review, Wol. 77, No. 2 (May): 56- 62.

Romer, P. (1989), "Increasing Returns and New Development in the Theory of Growth," NBER Working Paper Series, No. 3098, September, I1 1989. p. 22

Romer, P. M. (1990), "Endogenous Technological Change," Joumal of Political Ecomomy, Vol. 98, No.5, Part 2: pp. 71-102.

Romer, P. M. (1994), "The origin of Endogenous Growth," Jommal of Economic Perspectives 8:3-22

Romijn, H. (1999), "Acquisition of Technologica! Capability in Small Firms in Developing Countries" Houndmills; etc.: Macmillan Press, 1999.

Rosen, S. (1976), "A theory of Life Earnings," Joumal of Political Economy, Vol. 84. No.4: S45-S67.

Sanders, M. and ter Weel, B. (2000), "Skilled Biased Technical Change: Theoretical Concept, Entpirical Problems and a Survey of the Evidence," MERTT Reseanch Memorandunt- February (2000) 200012. Maastricht University, Maastricht.

Schumpeter, J. (1934), "The Theory of Economic Development," Cambridge MA Harvard University Press: p. 66

Schumpeter, J. (1942), "A Capitalism, Socilaism and Democracy," New York. Harper and Brothers, 1942.

Schultz, T. W. (1961), "Investment in Human Capital," American Economic Review, Vol. 51 , No. 1: pp. 117.

Schultz, T.W. (1964), "Transforming Traditional Agriculture," New Haven: Yale University Press.

Serageldin, Ismail Socknat, James A. Birks, Stace Li, Bob Sinclair, Clive A. (1983), "Manpower and ]nternational Labour Migration in the Middle East and North Africa," MNS. Report No. 10139, Vol. I.

Shell, K. (1967), "A model of Inventive Activity and Capital Accumulation," in K. Shell (ed.) Essay on the Theory of Optimal Economic Growth, Cambridge, Massachusetts: MIT Press, 67-85. 
Shiha, M. (2000), "Improving Competitiveness of Small and Medium Size Enterprises in the GCC Countries." Paper presented in Arab Experts Meeting on "Improving the performance of Arab Euterprises in the Global Economy" Turin - Italy, 29-2 June 2000 P. 20-22

Smith, $A .(1776)$, "An Inquiry into the Nature and Causes of the Wealth of Nations," Everyman Edition (1910), London, J.M. Dent. New York, Random House, 1937.

Smith, K. (2000), "Measurement of Innovation in Europe: Concepts, Experience and Results" STEP Group. Paper Presented to Conference on "The Measurement of Industrial, Technological Competitiveness for Knowledge - Based Ecommy "August 23-24 -2000. Taipei.

Smith. K. (2002) "What is Knowledge Econony"? Knowledge Intensity and Distributed Knowledge Bases," UNU-INTECH Discussion Paper Series No. 2002-6.June (2002).

Solow, R. (1956), "A contribution to the theory of Economic Growth," Qwarterly Joumal of Economies, Fol.70, (February 1956); pp. 65-94

Solow, R. (1957), "Technical Progress and the Aggregate Production Function," Review of Econownics and Statistics, Vol. 39, August, (1957): pp. 312-320.

Stokey, N. L. (1991), "Human Capital, Product Quality and Growth," Quarterly Journal of Eiconomics, Vol. 106, No. 2: pp. 587-616.

Swan, T. W. (1956), "Economic Growth and Capital Accumulation," Ecomomic Record, Vol. 32 (November): 334-361.

The International Monetary Fund (2002) World Economic Outlook: the Middle East and North Africa Regional Outlook," September, 2002.

The World Bank (1999a)"The World Development Report (1998/1999)

The World Bank (2003), "World Development Indicators (2003)"

"The World Bank MENA Development Report (2004) "Unlocking the Employment Potential in the Middle East and North Africa: Toward a New Social Contract," The World Bank (2004) Report No. 28815. The World Bank, Washington. pp. 104, 222, 225, 228 .

The UAE Ministry of Industry and Finance (1998): http:/www.uae.gov.ae/mofi/

The UAE Ministry of Industry and Finance (2000) "The UAE Industrial Statistical Book (2000)"

The UAE Population Census data (1985-1995).

The UAE Ministry of Planning: "Statistical data for the years $(1995-1997)$ ". The UAE Ministry of Planning - Statistical Administration - Annual Statistical Abstract (1995-1997). Issues No, 20, $21,22$. Table (17): pp. 40-42.

The UAE Ministry of Planning (1997) "UAE Ministry of Planning Report-Central Statistics Department $1997^{\prime *}$

The UAE Ministry of Planning (1998) "UAE Ministry of Planning Labour Report (1998)". p. 31.

The UAE Ministry of Labour (1999) "UAE Ministry of Labour Unpublished Labour Report (1999)": p. 14.

The United Arab Emirates (2004) - UAE Ministry of Planning "Annual Report (2004)".

The UAE University (1994) "The UAE Education Assessment Report," The UAE University (1994).

The UAE University (1997) "Private sector employment and labour market in the UAE," The UAE Universify $(1997)$.

Trostel, P. A. (2002), "Should Exlucation Be Publicly Provided?," Bullerin-of- Economic-Research. October $2002 ; 54(4): 373-91$

United Nations (1970)"United Nations Seience and Technology for Development, Proposals for the Second United Nations Development Decade," New York, 1970.

Uniled Nations Conference on Trade and Development- UNCTAD (1996) "New Technologies and Technological Capability-Building at the Enterprise Level: Some Policy Implications" - Science and Technology lssues- New York; etc.: UN, 1996.

UNDP (2001). "Summary Human Development Report (2001): Making new technologies work for human development", UNDP-New York-Oxford, Ox ford University Press.

UNDP (2002) "Human Development Report (2002): Deepening Democracy in a fragmental World," UNDP-New York-Oxford-Oxford University Press- July 2002.

UNDP (2003) "Human Development Report (2003): Millennium Development Goals: A compact anong nations to end human poverty" - UNDP - New York, Oxford- Oxford University Press- July 2003.

UNDP-AHDR (2003), "Arab Human Development Report (2003): Building a Knowledge Society", UNDP - RBAS-New York- National Press, Amman, Jordan, July. 
UNDP' (2004), "Human Dewelopment Report (2004): Cultural Liberry in Today's Diverse World," UNDPNew York-Oxford, Oxford University Press, July.

UNESCO Institute of Statistics Data and Statistics (1996), "UNESCO Statistical Yearbook": "The World Education Indicators on school life expectancy 1992": www unesco.org

UNESCO Data and Statistics (1999), "UIS-UNESCO Staristical Yearbook (1999)": whw unesco org

UNESCO- UTS (2000), "World Education Report (2000): UNESCO's World Education Indicators";

http//www unesco.org/education/information/wer/htmilENG/tablesmenu.htm

UNESCO-UIS, (2003), "The UNESCO Education Data and Statistics Indicators 1998-2001"" www.unesco.org.

UNESCO- UIS (2004a) "The UIS Bulletin on Science and Technology Statistics," Number 1 UNESCOUIS and Quebec's Institut National de la Recherche Scientifique (INRS), May (2004).

UNESCO- UIS (2004b) UIS web site global statistics on education: www unesco.org.

UNESCO -UIS Data and Statistics (2004c): Country Profile: whw uis.unesco.org.

UNESCO-UIS (2004d) Educational statistics (1998-2002)

UNESCO-UIS/OECD (2003) "Financing Education- Investment and Retums: Analysis of the World Education Indicators", 2002 Edition, UNESCO, 2003.

US Patent and Trade mark office web site: Www. uspto.gov.

Utton, M. A. (1979), "Diversification and Competition," The National listitute of Economic and Social Research 1979, Cambridge University Press, Cambridge. Pp. 15-16, 104-105

Uzawa, H. (1965), "Optimum Technical Change in an Aggregative Model of Econonic Growth," Internavional Economic Review. Vol. 6, No.1, (January) 1965: 18-31.

Wadi, M. A. (2001), "Education and Labour Market: The need for reform: The case of Kuwait," Arah Planning Institute Working Paper Series, No. 0104- -A rab Planning Institute- Kuwait

Winter, S.G. (1987), "Knowledge and Competence as strategic assets" In Teece D J (ed.): "The Comperitive Challenge: Strategies for Industrial Innovation and Renewal," Cambridge MA. Ballinger Publishing Company: 159-184.

WITSA (2002), "Digital Planet 2002: The Global Information Economy", The World Information Technology and Services Alliance. Arlington, USA, February (2002)

World Development Indicators in Datta, S. K., Nugent J. B. and Samman, H. (2000), "Labor Market and Private Sector Development Policies in a Labor Scare, Oil Exporting Country: A Theoretical Exploration," Conference Paper. The Seventh Annual Conference of the Economic Research Forum (ERF) Jordan, 26-29 October 2000. P. 16.

World Development Indicators Database

Verspagen, B. and Schoenmakers, W. (2000), "The Spatial Dimension of Knowledge Spillovers in Europe: Evidence from Firm Patenting Data". Paper Prepared for AEA Conference on Intellectual Property Econometrics, 19-20 April 2000, Alicante, Spain.

Von Hippel, E.(1988), "The Sources of Inunovation," Ox ford University Press.

Zahlan, A. B. (1999a), "The Arabs and the Challenges of Science and Technology: Progrogs Without Change," The Centre for the Study of Arab Unity, Bcirut, 1999.

Zahlan, A. B. (1999b), "Science Policy for the Twenty-First Century: Mobilization and Development," In "ESCWA Proceedings of the Exper Group Meeting on Science and Technology Policies and Strategies for the Twenty-First Century," ESCWA, Beirut, 10-12 March 1999: pp. 14-16.

Ziesemer, T. (1987), "Economic Theory of Underdevelopment", transfer verlag, Regensburg, 1987.

Ziesemer, T. (1990), "Public Factors and Democracy in Povery Anallysis", Oxford Ecowomic Papers, 1990, Special Issue on Public Economics, Vol. 42, January, 268-280. Reprinted in: P.J.N. Sinclair and M.D.E Slater (eds.), Taxation, Private Hnformation and Capiral, Clarendon Press, Oxford 1991

Ziesemer, T. (1991), "Human Capital, Market Structure and Taxation in a Growth Model with Endogenous Technical Progress", Jotwnal of Macroeconomics, Vol. 13, 1991, No.1, Winter, 47-68.

Ziesemer, T. (1995), "Endogenous Growth with Public Factors and Heterogeneous Human Capital Producers", Finchzarchiv, Neue Folge, Band 52, 1995, Heft 1, 1-20.

Ziesemer, T. (2004), "Multiple-5teady-State Growh Models Explaining Twin-Peak Empirics?" in Grözinger, G. and Aaken, van A. Inequality: New Analytical Approaches. Metropolis- Verlag Marburg 2004. Pp. 145-168.

Zon van, A. (2001), "ICT-Investment, Knowledge Accumulation and Endogenous Growth," MERIT INFONOMIC Research Memorandum Series, No. 2001- 038, Maastricht Uniwersity, Maastricht. 
Appendices 


\section{Appendix A- Questionnaire of the Firm Survey (2002)}

\section{"Technological Change and Skill Development: A Comparative Study of Chemical and Metal Medium and Large Scale Enterprises in the United Arab Emirates"}

\section{General Background Information}

1. Code (File No.): ...................... (For Coding Only: Please do not write in this item)

2. Name of firm;

3. Years in operation ( since the establishment):

4. If your fim has started in the UAE but has changed names, changed management, changed ownership, merged with other firms, or experienced any other changes, or if it is started in another country and then moved to the UAE, please specify the years in operation?

5. Location: Name of Emirate where the firm is located (please tick one box)

\begin{tabular}{|l|l|l|}
\hline Abu Dhabi. & Dubai & Sharjah. \\
\hline 1 & 2 & 3 \\
\hline
\end{tabular}

6. If your firm has branches in many parts of the country, please name the location?..............................

7. Sector (please lick one box)

\begin{tabular}{|l|l|l|}
\hline Public. & Private. & Mixed \\
\hline 1 & 2 & 3 \\
\hline
\end{tabular}

8. Main Product(s): (please tick up to four boxes)

\begin{tabular}{|l|l|l|l|l|l|l|l|}
\hline Chemical & Petroleum & Petrochemical & Plastic & Rubber & $\begin{array}{l}\text { Metal/ } \\
\text { Iron- } \\
\text { Steel }\end{array}$ & $\begin{array}{l}\text { Metal/ } \\
\text { Aluminium }\end{array}$ & $\begin{array}{l}\text { Others [please } \\
\text { specify below] }\end{array}$ \\
\hline $\mathbf{1}$ & 2 & 3 & 4 & 5 & 6 & 7 & 8 \\
\hline
\end{tabular}

9. Name up to four main products and the approximate proportion that each contributes to your total sales and total employment?

\begin{tabular}{|l|l|l|l|l|}
\hline Product Name & & & \\
\hline$\%$ Of total sales & & & \\
\hline$\%$ Of employment & & & \\
\hline
\end{tabular}

10. Is your firm a subsidiary or an affiliate of a multinational enterprise? (Please tick one box)

\begin{tabular}{|l|l|}
\hline Yes & No \\
\hline 1 & 2 \\
\hline
\end{tabular}

11. If your firm is an affiliate of a multinational enterprise, please give the origin of your parent company? (Please tick one box)

\begin{tabular}{|c|l|l|l|l|l|}
\hline Arab & $\begin{array}{l}\text { Non-Arab } \\
\text { Asian }\end{array}$ & European & $\begin{array}{l}\text { North } \\
\text { American }\end{array}$ & $\begin{array}{l}\text { Austral ian or New } \\
\text { Zealand }\end{array}$ & Others [please specify below] \\
\hline 1 & 2 & 3 & 4 & 5 & 6 \\
\hline
\end{tabular}

12. Ownership of the firm. (Please give the percentage)

\begin{tabular}{|l|l|l|}
\hline Local & Foreign & Total \\
\hline$\ldots \ldots \%$ & $\ldots \%$ & $109 \%$ \\
\hline
\end{tabular}

13. Nationality of the main owner(s). (Please tick the relevant box / boxes)

\begin{tabular}{|c|l|l|l|l|l|l|}
\hline Local & Arab & $\begin{array}{l}\text { Non-Arab } \\
\text { Asian }\end{array}$ & European & North American & $\begin{array}{l}\text { Australian or } \\
\text { New Zealand }\end{array}$ & $\begin{array}{l}\text { Others [please } \\
\text { specify below] }\end{array}$ \\
\hline 1 & 2 & 3 & 4 & 5 & 6
\end{tabular}

14. Firm size [Employment size]. (Please tick one box)

\begin{tabular}{|l|l|l|}
\hline $50-99$ & $100-499$ & $500+$ \\
\hline 1 & 2 & 3 \\
\hline
\end{tabular}


15. Fim Production and Firm Perfomance. (please grve an approxinate estimate of the following items)

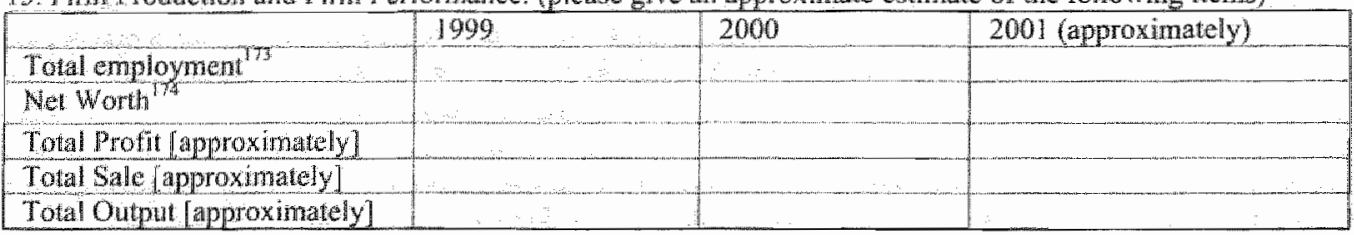

\section{The use of Technology ${ }^{175}$ and Firm Product}

2.1 General information: the wse of technology, spending on $1 C T$, dependence on foreign technology 16. Firn's own appreciation of its level of technology: (Please tick one box)

\begin{tabular}{|l|l|}
\hline Very advanced production technology. & 1 \\
\hline Advanced production technology. & 2 \\
\hline Basic/ simple production technology. & 3 \\
\hline Mixed: simple and advanced production technology. & 4 \\
\hline
\end{tabular}

17. Compared to the international standard of technology used in the activity in which you operate, how do you rate the level of technology used in firm production in the last three years? (Please tick one box)

\begin{tabular}{|l|l|}
\hline Higher than the International Standard. & 1 \\
\hline Similar to the International Standard. & 2 \\
\hline Lower than the International Standard. & 3 \\
\hline
\end{tabular}

18. In the last three years, approximately how much did your firm spend on ICT: Computer and Teleconmunication hardware and software techologies and other ICT related Services?

\begin{tabular}{|l|l|l|l|}
\hline Expendifure on: & 1999 & 2000 & 2001 (approximately) \\
\hline Computer. & & & \\
\hline Telecommumication & & \\
\hline Training and Software Development & & & \\
\hline Maintenance services & & & \\
\hline Hosting and other relevant ICT services & & & \\
\hline
\end{tabular}

19. Does your firm have an adequate capacity / ability to produce and develop local technologies ${ }^{176}$ at this moment? (Please tick one box)

\begin{tabular}{|l|l|}
\hline Yes & No \\
\hline 1 & 2 \\
\hline
\end{tabular}

20. Does your firm purchase equipment, machines and technigues from abroad? (Please tick one box)

\begin{tabular}{|l|l|}
\hline Yes & No \\
\hline 1 & $2 \longrightarrow$ skip to question $[22]$ \\
\hline
\end{tabular}

\footnotetext{
173 This term includes total number of workers including subcontractors, support services and other workers employed by the firm.

174 Net worth equals total assets minus total liabilities, this item refers to Capital which reflects the current market value of Fixed Assets, paid up capital in operation and investment / inflow.

17: According to Haan (1999:35) technology is more than just machinery and equipment. One can distinguish the following elements which in one form or combination constitutes at technology:

- Hard ware reters to materials, production tools and end-product.

- Soft wate concerns the documented - processes, techniques, methods, blue prints, etc.

- Human ware is the know-how [i.e. knowledge, skills and experiences] held by group of people.

- Institution ware includes institutions and wider networks/ systems of management structures, business services [eg. consulting and design firms], research and development [e.g. laboratories], policies and regulations [i.c. the political and legal franework], etc., that activate the interaction of the procluction system with the plysical and social environment.

thocal technology refers to ability / capability to build, develop, master, enhance and utilize the production and promotion of technology locally / for local purposes.
} 
21. If any, what are the main reason (s) of purchasing from abrodd (Muluple Answers Possible [MAD)

\begin{tabular}{|l|c|}
\hline Not available from local supptier. & 1 \\
\hline Better quality. & 2 \\
\hline Bether price. & 4 \\
\hline Others.... [please specify below].
\end{tabular}

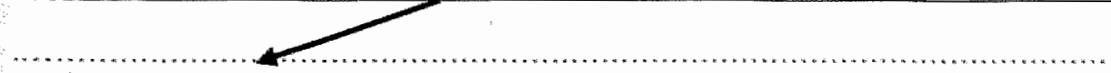

22. What was the percentage value of imported capital equipment to total capital equipment in the year 2001 ?

23. What was the percentage value of capital equipment to totat capital equipment that has been built by foraign companies?

24. What kind(s) of technology transfer ${ }^{\text {t77 }}$ did your fim use over the last thee years? (Multiple Answers Possible $[\mathrm{MAP}]$

Transfer that based on direct investment made by foreign firm(s) to facilitate the inflow of technoloines.

Transfer that based on an earlier contractual agreement to jointly share the losses [risks/ dangers] and prohts.

Transfer that required an issunce of a formal licensing,

Transfer that based on an allied between foreign firm and local thm to transfer stuategic technologies

to local firm

Transfer that made by hiring foreign skills/ technologically advanced workers consultants to build the local technology.

Others..... [please specify below].

25. How important is/ are the effect(s) of technology transferted in embancing firm production and anhancing the capacity to develop the local technologies in your firm over the last three years? (Please thck one box for each statement)

\begin{tabular}{|l|l|l|l|l|}
\hline & $\begin{array}{l}\text { Very impor- } \\
\text { tant }\end{array}$ & Important & $\begin{array}{l}\text { Important only in } \\
\text { restricted filed }\end{array}$ & $\begin{array}{l}\text { Unimportant } \\
\text { 1. Enhancing frm production }\end{array}$ \\
\hline $\begin{array}{l}\text { 2. Enhancing the capacity to develop } \\
\text { the local technologies }\end{array}$ & 1 & 2 & 3 & 4 \\
\hline
\end{tabular}

26. Did your firm hine technologically advanced workers/ consultants over the last three years? (Please tick one box)

\begin{tabular}{|l|l}
\hline Yes & $\mathrm{Na}$ \\
\hline $\mathrm{l}$ & $2 \rightarrow$ skip to question [28] \\
\hline
\end{tabular}

27. If any, how important is / are the effect(s) of technologically advanced workers/ consultants in enhamcing frrm production and enhancing the capacity to develop the local technologies in your firm over the last three years? (Please tick one box for each statement)

\begin{tabular}{|l|l|l|l|l|}
\hline & $\begin{array}{l}\text { Very impor } \\
\text { tant }\end{array}$ & $\begin{array}{l}\text { Important } \\
\text { 1. Enhancing firme production }\end{array}$ & $\begin{array}{l}\text { Impontant only in } \\
\text { restricted filed }\end{array}$ & Unimportant \\
\hline $\begin{array}{l}\text { 2. Enhancing the caprcity to develop } \\
\text { the local technologies }\end{array}$ & 1 & 2 & 3 & 4 \\
\hline
\end{tabular}

The transfer of technology from the developed countries to the developing countries takes different forms, such as:

- Foreign Direct Investment [FDI]: refers to a difect investment made by foreign lim to facilitate the inflow transfer of technology to the hosting / local firm.

- Joini ventures is a contractual agreement to facilitate the transfer $/$ inflow of technology to local firm based on an earlier agreement to share the [risk/danger] losses and profits between local firm and foreign firm.

- Technology Licensing is a form of technology transfer that required a permission or consent to permit or authorize the transfer of technology by issuance of a formal license.

- Strategic Alliances is a state or condition under which the local firm and the foreign firm fomed an allied to transfer strategic technologies to the hosting/local firm.

- Import and hire foreign skills and foreign technologically advanced workers/consultants to build the local rechinology. 
28. Does your frm have a plan to introduce, develop or improve the local technologies benefing from the inm ported technologies ? There are three statements below, Please respond to each one by thing yes or no box corresponding to wach one.

\begin{tabular}{|c|c|c|}
\hline 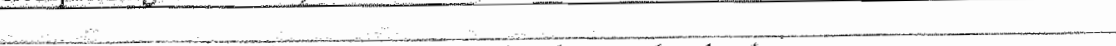 & Yes & \multirow[t]{4}{*}{$\mathrm{No}$} \\
\hline In the ghort rum you frim nueds to depend on imported technology. & & \\
\hline $\begin{array}{l}\text { In the medium term the use of imported technologies and accumulation of knowledge and } \\
\text { learning will allow your fin to begin produce its own technology or to use other sources of } \\
\text { local technologies. }\end{array}$ & & \\
\hline $\begin{array}{l}\text { In the very long rin to some extent your firm will manage to partially develop its own tech- } \\
\text { nologyes or to use other sources of local technologies. }\end{array}$ & & \\
\hline
\end{tabular}

29. Does your firm have plan to pursue the following strategies to accellerate the development promotion of local technologies? (There are three statements below, Please respond to each one by ticking yes or no box comesponding lo cach one).

\begin{tabular}{|c|c|c|}
\hline 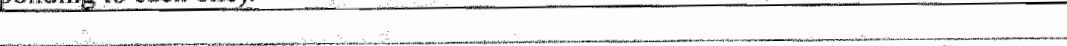 & Yes & $\mathrm{No}$ \\
\hline Atitonomous strategies [national - led strategy] to guide learning in domestic firms. & & \\
\hline $\begin{array}{l}\text { Foreign Direct Invesment- dependent strategies that rely on foreign companies to guide } \\
\text { learning/promotion of local technologies subject to government policies / regulations. }\end{array}$ & & \\
\hline $\begin{array}{l}\text { Foreign Direet lnvestment dependent strattegles that rely on foreign companies to guide } \\
\text { leaming / promotion of local technologias subject to market conditions. }\end{array}$ & & \\
\hline
\end{tabular}

30. How important are the effects of technology upgrading in fillilling the following long run strategies? Please, tick the relevant answer(s) in the respective columns (Multiple Answers Possibie [MA.P])

\begin{tabular}{|c|c|c|c|c|}
\hline$-1-2$ & $\begin{array}{c}\text { Extremely } \\
3\end{array}$ & $\begin{array}{l}\text { Importanco } \\
\text { Moderately } \\
2\end{array}$ & Slightly & $\begin{array}{l}\text { Not } \\
\text { Relevant } \\
0\end{array}$ \\
\hline \multicolumn{5}{|l|}{ Enhancing fitm production. } \\
\hline \multicolumn{5}{|l|}{ Raising skill level. } \\
\hline \multicolumn{5}{|l|}{ Reinforcing firm ability to promote its own technologies. } \\
\hline \multicolumn{5}{|l|}{ Upskilling national workers in the furm. } \\
\hline \multicolumn{5}{|l|}{ Híring more skilled nathonal workers. } \\
\hline Others [please specify below]. & & & & \\
\hline
\end{tabular}

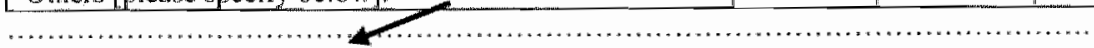

\subsection{Technology Indicators}

31. How many patents ${ }^{19}$ did your firm apply for in the last three years? (Pllease tick one box)

\begin{tabular}{|l|l|l|l|l|l|}
\hline Zero. & 1 & 2 & 3 & 11 and abowe \\
\hline 1 & 2 & 3 & 4 & 5 & 6 \\
\hline
\end{tabular}

32. Does yout Iirm pertorm research [including outsoureing research activities] for the purpose of dewelopment of production, development and adaptation of technology $\left[R \& D^{189}\right]$ ? (Please tick one box)

\begin{tabular}{|l|l|l|l|}
\hline Yes Contimionsly & Yes, Occosionally as needed & Not at all. \\
\hline 1 & 2 & 3 & skip to section (c), question $[40]$ \\
\hline
\end{tabular}

If the answer is [1] or [2] [or question [32] continues in answering questions [33] - [391].

33. If any, approximately how much did you firm spend on these research activities [including outsourcing research activitias during the year 2001 ?

34. Approximately what was the percentage of research expenditure [including outsourcing reseanch activities] to total output expenditure in the year 2001 ?

Short run refers to next three years, medium term refers to the next three to five years and long run refers to the next ten years.

${ }^{174}$ Patent is a protection of property rights especially for inventions.

${ }^{160}$ R \& D is a combination of activities / efforts or practical researches carried out with the aim to [1] develop and enhance the productive capacity; [2] introduce new technologies, or improve the old technologies and [3] nllow optimal adaptations of imported technologies to industrial/local needs. This item includes the outsourcing researcly activitios. 
35. In the year 2001 approximately what percentage of your researeth eforts and peroentage of tesenth expenditares [including outsourcing research activities] is devoted to the following activities? please approximate the percentage.

\begin{tabular}{|c|c|c|c|c|c|}
\hline & New product & Improved product & $\begin{array}{l}\text { New } \\
\text { process }\end{array}$ & $\begin{array}{l}\text { Improved } \\
\text { process }\end{array}$ & Total \\
\hline 1. $\%$ Of Research Efforts & $\ldots \ldots \%$ & .8 & 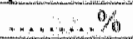 & $\ldots \ldots \times 0 \%$ & $100 \%$ \\
\hline 2. \% Of Research Expenditures & $\ldots \ldots \ldots$ & $\ldots \ldots \ldots \%$ & $\ldots \ldots+\ldots, 0 / 6$ & $\ldots+x+8,0$ & $100 \%$ \\
\hline
\end{tabular}

36. How many employees are engaged in research [including outsourcing research activities] in your firm? (Please tick one box)

\begin{tabular}{|c|c|c|c|c|c|c|c|}
\hline \multicolumn{4}{|c|}{ Full-Time } & \multicolumn{4}{|c|}{ Pant-Tine } \\
\hline Zero & $1-5$ & $6-110$ & $11 \%$ & Zero & $1-5$ & $6-10$ & $11+$ \\
\hline 1 & 2 & 3 & 4 & 1 & 2 & 3 & 4 \\
\hline
\end{tabular}

37. Does the performance of the research unit [including outsouncing research activitios] in your firm contribute to adaptation of imported technologies to fit the industrial need in your firm? (Ploase tick one box)

\begin{tabular}{|l|l|l|l|}
\hline Yes, to large degree & Yes, to acceptable degree & Yes, to minimum degree & Not at all \\
\hline 1 & 2 & 3 & 4 \\
\hline
\end{tabular}

38. If the research unit in your firm did not contribute to adaptation of imported technologies, how important is the shortage of skilled \& qualified workens in the performmce of the research actiwities in your frm? (Please tick one box)

\begin{tabular}{|l|l|l|}
\hline Very important & Important & Unimportant \\
\hline 1 & 2 & 3 \\
\hline
\end{tabular}

39. How important is the effect of research output in your fim in affecting research output in other firms working in your sector? (Please tick one box)

\begin{tabular}{|l|l|l|l|}
\hline Very important & Important & Important only in restricted filed(s) & Unimportant. \\
\hline 1 & 2 & 3 & \\
\hline
\end{tabular}

\subsection{Technology and Firm Product / Process Immovation ${ }^{\text {15t }}$}

40. In the last three years has the use of both technology and the $\mathbb{C T}$ in firm production ... (please tick one box)

\begin{tabular}{|c|c|c|c|c|c|}
\hline \multicolumn{3}{|c|}{ (a) The use of technology } & \multicolumn{3}{|c|}{ (b) The use of ICT technology } \\
\hline Increased & Decreased & Remained stable & Increased & Decreased & Remained stable \\
\hline 1 & 2 & 3 & 1 & 2 & 3 \\
\hline
\end{tabular}

If the answer is [1] for question [40] continue answering questions [41]-[43], if not proceed to section 3.a, question $[44]$

41. If the use of both technology and the IC I increased, did they require more workers with higher skills? (Please tick one box for each)

\begin{tabular}{|c|c|}
\hline $\begin{array}{l}\text { (a) The use of technology required more } \\
\text { workers with higher skills }\end{array}$ & (b) The use of ICT required more workers with higher skills \\
\hline Yes & Yes \\
\hline
\end{tabular}

42. In the last three years did the increasing use of technology enable your fim to introduce any new product/ process $^{182}$ or any product/process changes? If any, what were they? Please tick the relevant answer(s) in the respective columns (Multiple Answers Possible [MAP])

\begin{tabular}{|l|l|}
\hline & Yes \\
\hline To produce a row product. & \\
\hline To produce a new process. & \\
\hline To produce a new combination of old output. & \\
\hline To produce a new service. & \\
\hline To produce a new method of production. & \\
To produce a new organizational method. & \\
\hline To produce more output with low cost. & \\
\hline To produce the same output with low cost. & \\
\hline
\end{tabular}

18: Innovation is defined as firm. ability to involve in one or all of the following activities: introduction/ production of a new product/ process, a new combination of old ourput, a new method of production, a new orgatizational method, a significant improvement ins the quality of old product process, ability to produce at low costs and to open a new market.

182. New product/ process even just for your firm or for local market and not necessarily new for the international market. 


\begin{tabular}{|l|l|}
\hline To open a new market & \\
\hline To improve the quality of firm product. & \\
\hline To improve the process of personal selection. & \\
\hline To improve training within the firm. & \\
\hline To improve communication within the firm. & \\
\hline
\end{tabular}

43. If any, approximately, how much did these products / processes decrease / increase firm's costs, sales and profits? Please tick the televant answer in the respective columns.

\begin{tabular}{|c|c|c|c|c|c|c|c|}
\hline 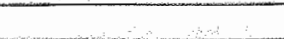 & \multicolumn{3}{|c|}{ Decrease by } & \multicolumn{3}{|c|}{ Increase by } & \multirow{2}{*}{$\begin{array}{l}\text { No change } \\
\text { No change }\end{array}$} \\
\hline & $\begin{array}{l}1 \%- \\
10 \%\end{array}$ & $\begin{array}{l}11 \% \\
25 \%\end{array}$ & $\begin{array}{l}\text { Oxer } \\
25 \%\end{array}$ & $\begin{array}{l}10 \%- \\
10 \%\end{array}$ & $\begin{array}{l}11 \%= \\
25 \%\end{array}$ & \multirow[t]{6}{*}{$\begin{array}{l}\text { Over } \\
25 \%\end{array}$} & \\
\hline \multicolumn{7}{|l|}{ Per unit energy costs } & \\
\hline \multicolumn{7}{|l|}{ Per unit material cosfs } & \\
\hline \multicolumn{7}{|l|}{ Total costs } & \\
\hline \multicolumn{7}{|l|}{ Totall sales } & \\
\hline Tolal profits. & & & & & & & \\
\hline
\end{tabular}

\section{Human Capital (Skill) and Firm Production ${ }^{183}$}

\subsection{Human Capiral [Skill Indicators}

44. Please give the approximate percentage of workers according to educational level in your firm in the year 2001 ?

\begin{tabular}{|l|l|l|}
\hline Level of Education & National & \\
\hline With Post Secondary education & & \\
\hline With Secondary education & & \\
\hline With Less than Secondary education & & $100 \%$ \\
\hline Total Percentage & $100 \%$ & \\
\hline
\end{tabular}

45. Please give the approximate percentage of workers according to occupation classification in your firm in the year 2001 ?

\begin{tabular}{|l|c|c|}
\hline Group of Occupation & National & Foreign \\
\hline Managers & & \\
\hline Professional/Management Executive/ Scientific / Technical and Engineers & & \\
\hline Clerical/ administrative & & \\
\hline Skilled craftsmen & & \\
\hline Plant machinery operators, assemblers and elementary occupation & $100 \%$ \\
\hline Other workers & \\
\hline Total Percentage & \\
\hline
\end{tabular}

46. Please approximate the average years of experience and average wages according to educational level in your firm in the year 2001 ?

\begin{tabular}{|l|}
\hline Level of Education \\
\hline With Post Secondary education \\
\hline With Secondary education \\
\hline With Less than Secondary education \\
\hline
\end{tabular}

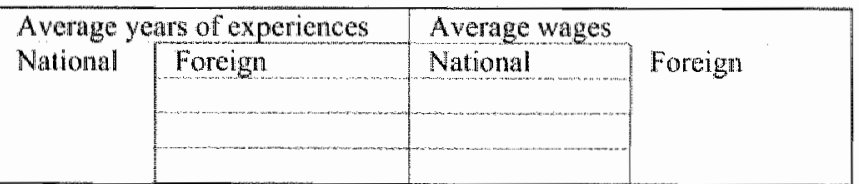

47. Please approximate the qualifications [level of education], awerage years of experience and average wages according to occupation classification in your firm in the year 2001?

\begin{tabular}{|l|l|l|l|}
\hline Group of Occupation & $\begin{array}{l}\text { Qualifications (Level } \\
\text { of Education) }\end{array}$ & $\begin{array}{l}\text { Average years } \\
\text { of experience }\end{array}$ & $\begin{array}{l}\text { Average } \\
\text { Wages }\end{array}$ \\
\hline Mantagers & & & \\
\hline $\begin{array}{l}\text { Professional / Management Executive/ Scientific / } \\
\text { Technical and Engineers }\end{array}$ & & \\
\hline \begin{tabular}{l} 
Clerical/administrative \\
\hline Skilled craftsmen
\end{tabular} & & \\
\hline $\begin{array}{l}\text { Plant machinery operators, assemblers and element- } \\
\text { tary occupation }\end{array}$ & & \\
\hline Other workers
\end{tabular}

18.3 Skilled workers are educated workers with college/ university degree [i.e. sixteen or more years of schooling] 
56. If no, in your opinion, how inportanl are the following factors in reducing the effect in your firm? Please tiok the relevant factors in the respective columns. (Multiple Answers Possible [MAP])

\begin{tabular}{|c|c|c|c|c|}
\hline & $\begin{array}{l}\text { Extrumely } \\
3\end{array}$ & $\begin{array}{l}\text { Importano } \\
\text { Moderately } \\
2\end{array}$ & Sllightly & $\begin{array}{l}\text { Not } \\
\text { Relevant } \\
0\end{array}$ \\
\hline $\begin{array}{l}\text { Skilled workers failed to del wer their knowledge and } \\
\text { experiences to benefit unskilled workers. }\end{array}$ & & & & \\
\hline $\begin{array}{l}\text { Unskilled workers were unable to acquire the knowl- } \\
\text { edge and experiences from skilled workers. }\end{array}$ & & & & \\
\hline Low retum from / quality of education. & & & & \\
\hline $\begin{array}{l}\text { Low retum from/ quality of training compared to } \\
\text { international standatd. }\end{array}$ & & & & \\
\hline Firm conditions do no encourage the external effects. & & & & \\
\hline Others [please specify below]. & & & & \\
\hline
\end{tabular}

57. In your opinion, how important are the following policies / solutions in inducing the effect in your firm? Please tick the relevant answer(s) in the respective columns. (Multiple Answers. Possible [MAP])

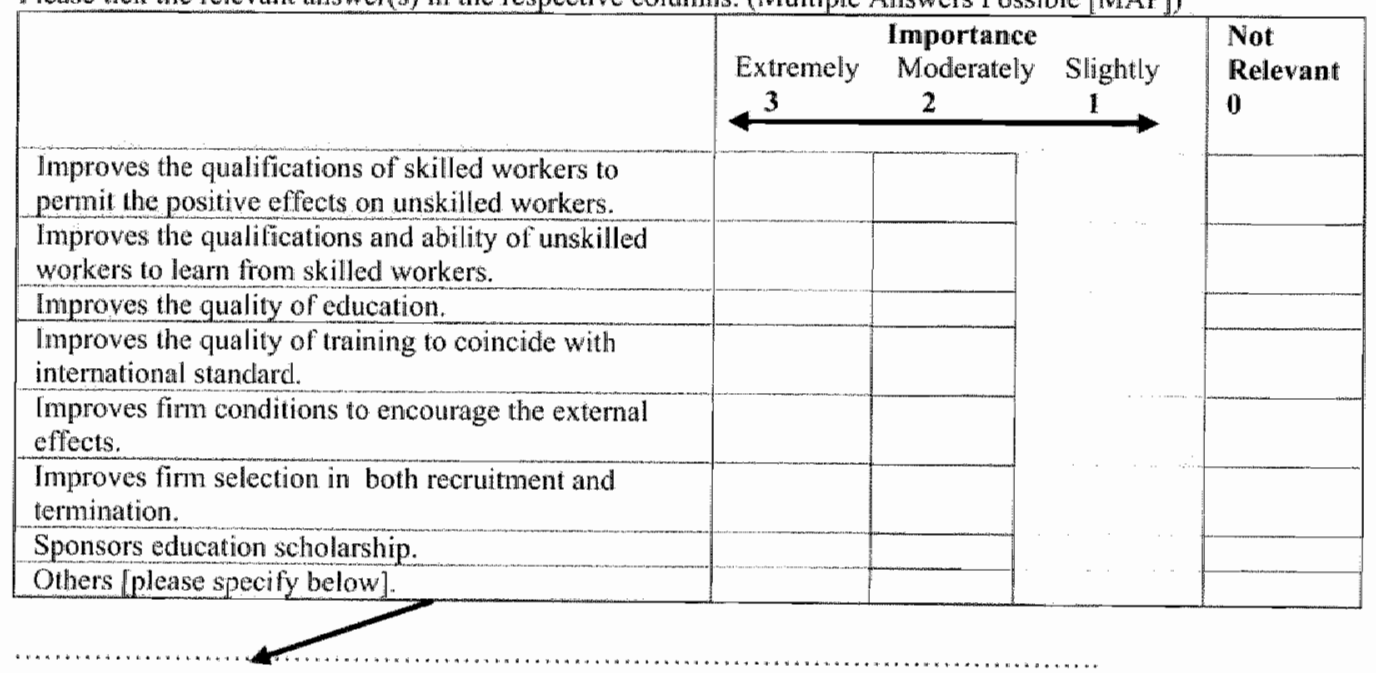

3.4 Plan and strategy for skill upgrading and potenial effects

58. Does your firm have a plan for the next three years to raise the general level of skill? (Please tick one box).

\begin{tabular}{|l|l|l|}
\hline Yes & No \\
\hline 1 & $2 \rightarrow$ skip to chapter [4] question [61]
\end{tabular}

59. If any how important is the effect of upskilling [raising skill level] in fulfilling the following strategies in your firm? Please tick the relevant answer in the respective columns.

\begin{tabular}{|c|c|c|c|}
\hline & $\begin{array}{c}\text { Extremely } \\
3\end{array}$ & $\begin{array}{l}\text { Importance } \\
\text { Moderately Slightly } \\
2\end{array}$ & $\begin{array}{l}\text { Not } \\
\text { Relewant } \\
0\end{array}$ \\
\hline Enhance / Inerease firm production. & & & \\
\hline Upskilling national workers in the frrm. & & & \\
\hline Hiring more skilled national workers. & & & \\
\hline Reduce fulure demand for foreign skilled workers. & & & \\
\hline Others [please specify below]. & & & \\
\hline
\end{tabular}


60. If the strategies [2] and [3] in question [59] ane important, how important are their effects in fulfulling the following strategies in your fim? Plase tick the relevant answer in the respective columns.

\begin{tabular}{|c|c|c|c|c|}
\hline & $\begin{array}{c}\text { Extremely } \\
3\end{array}$ & $\begin{array}{l}\text { Mmportan } \\
\text { Moderately } \\
2\end{array}$ & Shghtly & $\begin{array}{l}\text { Not } \\
\text { Relevant } \\
0\end{array}$ \\
\hline a. Upskilling national workers in the frrm: & & & & \\
\hline Increase the employment of national workers. & & & & \\
\hline Reduce future demand for foreign skilled workers. & & & & \\
\hline b. Hiring more skilled national workers: & & & & \\
\hline Increase the employment of national workers. & & & & \\
\hline Reduce future demand for foreign skilled workers & & & & \\
\hline Others [please specify below]. & & & & \\
\hline
\end{tabular}

\section{The use of Technology and the demand for skilled workers}

61. Firm demand for skilled workers: (please tick one box for each)

\begin{tabular}{|c|c|c|c|c|c|}
\hline \multicolumn{3}{|c|}{$\begin{array}{l}\text { (a) In the last three years has the demand for } \\
\text { skilled workers hired by your firm ....... }\end{array}$} & \multicolumn{3}{|c|}{$\begin{array}{l}\text { (b) In the long run do you expect the demand for skilled } \\
\text { workers needed in your firm to }\end{array}$} \\
\hline Increased & Decreased & Remained stable & Increase & Decrease & Remain stable \\
\hline 1 & 2 & 3 & 1 & 2 & 3 \\
\hline
\end{tabular}

62. If the long run demand for skilled workers needed in your firm is expected to inerease, decrease or remain stable, please give the reason(s) for the selected choice, increase, decrease or stable?

63. In the last three years, if your frm has used sevenal new technologies, please name them and specify their various effects on the demand for skilled workers?

64. In the last three years, has the use of new technologies induced a significant effectchange on skill level and the demand for skilled workers? (Please choose the more appropriate description of the eflect on the use of new technology)

\begin{tabular}{|l|l|l|l|l|l|}
\hline (a) Change in skill level & \multicolumn{3}{|c|}{ (b) Change in the demand for skilled workers } \\
\hline Increased & Decreased & $\begin{array}{l}\text { Has no effect on the } \\
\text { skill level of workers }\end{array}$ & Increased & Decreased & $\begin{array}{l}\text { Has no effect on the de- } \\
\text { mand for skilled workers }\end{array}$ \\
\hline 1 & 2 & 3 & 1 & 2 & 3 \\
\hline
\end{tabular}

65. If any, in your opinion, how important is the use of new technologies in changing both the skill level and the demand for workers hired by your firm? Please tick the relevant answer(s) in the respective columns. (Multiplo Answers Possible IMAPJ

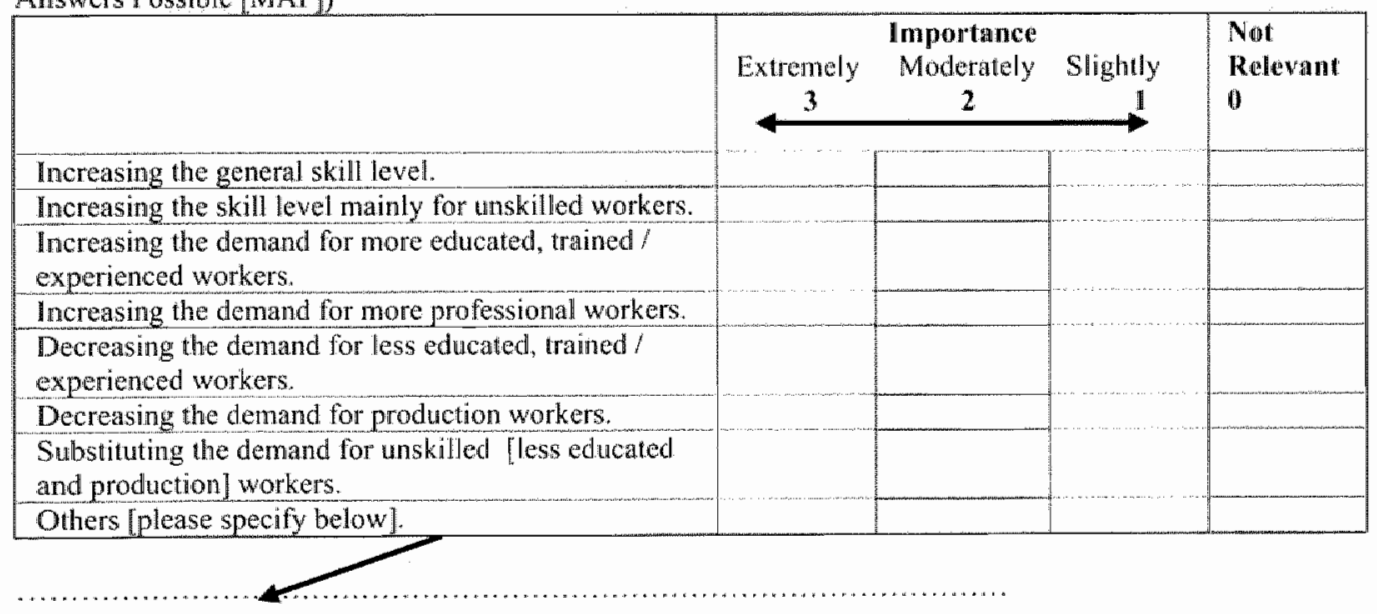


66. If the use of new technologies reduces the demand for unskilled workers, in your opinion, how important are the following factors? (Pledse tick the relevant answer(s) in the respective columns. (Multiple Answers Possible [MAP]).

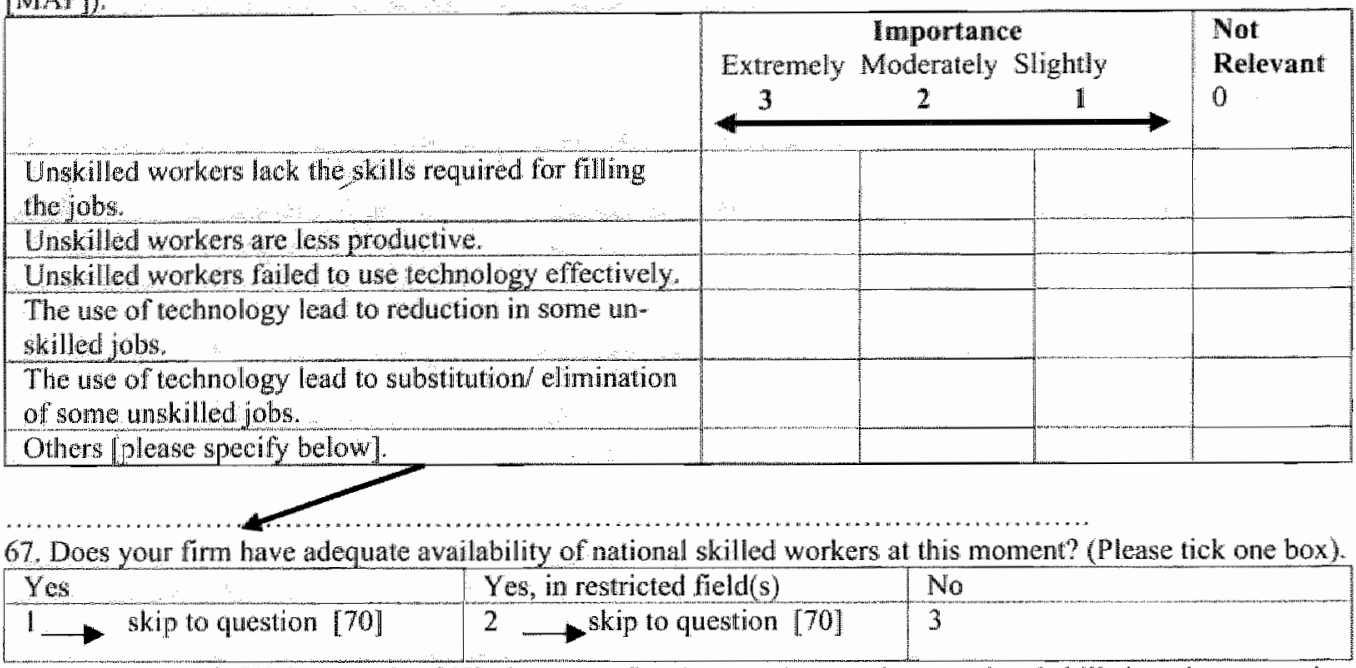

68. If the answer is [3] for question [67], does your firm have a plan to rely on national skilled workers over the coming period? Please tick the relevant answer in the respective columns.

\begin{tabular}{|l|l|l|}
\hline Yes & Yes in restricted field(s) & No \\
\hline 1 & 2 & $3 \rightarrow$ skip to question [70] \\
\hline
\end{tabular}

69. If the answer is [1] or [2] for question [68], what would be the percentage of national skilled workers in your firm in the short, medium and long term? Please approximate the percentage for each time period.

\begin{tabular}{|l|l|l|}
\hline Short term (Up to three years) & Medium term (three to five years) & Long term (five to ten years) \\
\hline$\ldots \ldots \ldots \ldots \%$ & $\ldots \ldots \ldots \%$ & $\ldots \ldots \ldots \%$ \\
\hline
\end{tabular}

70. How important are the effects of Upskilling [raising skill level] in fulfilling the following long run strategies? Please, tick the relevant answer(s) in the respective columns. (Multiple Answers Possible [MAP])

\begin{tabular}{|c|c|c|c|}
\hline & Extremely & $\begin{array}{l}\text { Importance } \\
\text { Moderately Slightly }\end{array}$ & $\begin{array}{l}\text { Not } \\
\text { Relevant }\end{array}$ \\
\hline & 3 & 2 & \\
\hline $\begin{array}{l}\text { Facilitating an effective utilization \& upgrading of tech- } \\
\text { nologies. }\end{array}$ & & & \\
\hline Reinforcing the employment of mational skills. & & & \\
\hline Others [please specify below]. & & & \\
\hline
\end{tabular}

\section{Training and short and long run plans for Skill Development}

71. How important are the following types of skill development activities in your firm? Please tick the relevant answer(s) in the respective columns. (Multiple Answers Possible [MAP])

\begin{tabular}{|c|c|c|c|c|}
\hline & $\begin{array}{l}\text { Extremely } \\
3\end{array}$ & $\begin{array}{l}\text { Importance } \\
\text { Moderately } \\
2\end{array}$ & Slightly & $\begin{array}{l}\text { Not } \\
\text { Relevant } \\
0\end{array}$ \\
\hline Investing in training to train existing employees. & & & & \\
\hline Sending trainers and mentors abroad to acquire skills. & & & & \\
\hline Sending workers abroad to acquire skills. & & & & \\
\hline $\begin{array}{l}\text { Bringing / attracting new foreign skilts, scientists and } \\
\text { enguneers. }\end{array}$ & & & & \\
\hline Using ICT to upgrade skill level. & & & & \\
\hline Encouraging leaming on the job. & & & & \\
\hline Supporting long distance learning. & & & & \\
\hline
\end{tabular}


Others [please specify below].

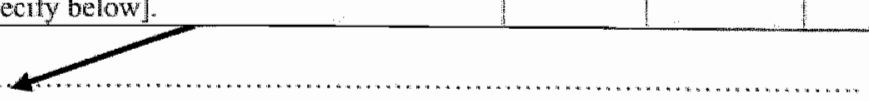

72. If any of the above types are important, please specify if these activities are to be pursted now or in the near future?

\begin{tabular}{|c|c|c|c|}
\hline & & $\begin{array}{l}\text { To be Pursued } \\
\text { now }\end{array}$ & $\begin{array}{l}\text { To be Pursued in } \\
\text { the near future }\end{array}$ \\
\hline Inve: & isting employees. & & \\
\hline Send & broad to acquire skills. & & \\
\hline Send & uire skills. & & \\
\hline Brin & ikkills, scientists and engineers. & & \\
\hline Usin & & & \\
\hline Enco & & & \\
\hline Supp & ing. & & \\
\hline Othe & & & \\
\hline 3. $\mathrm{Dc}$ & use training unit? (Please tick & $a x)$ & \\
\hline Yes & $\mathrm{No}$ & & \\
\hline 1 & $2 \rightarrow$ skip to question $[76]$ & & \\
\hline
\end{tabular}

74. If any, how much did your form spend on it in the year 2001 ?

75. How many staffs are there in the unit?

76. In the year 2001 , what was the percentage of government subsidies offered to support training in your firm? (Please tick one box).

\begin{tabular}{|l|l|l|l|l|}
\hline Zero & $1 \%-10 \%$ & $11 \%-20 \%$ & $21 \%-25 \%$ & Over $25 \%$ \\
\hline 1 & 2 & 3 & 4 & 5 \\
\hline
\end{tabular}

77. How does your firn find information about training oppontunities? (Multiple Answers Possible (MAP])

\begin{tabular}{|l|l|}
\hline Government deparments or semi government institutions. & 1 \\
\hline Chamber of Commerce. & 2 \\
\hline Public education and training institutions [Universities and specinlized colleges] & 3 \\
\hline Information from other firms in your sector. & 4 \\
\hline Foreign universities. & 5 \\
\hline Private trainers [local and foreign companies]. & 6 \\
\hline Others [please specify below].
\end{tabular}

78. How important are the following functions for the training unit in your firm? Please tick the relewant answer(s) in the respective columns. (Multiple Answers Possible [MAPD)

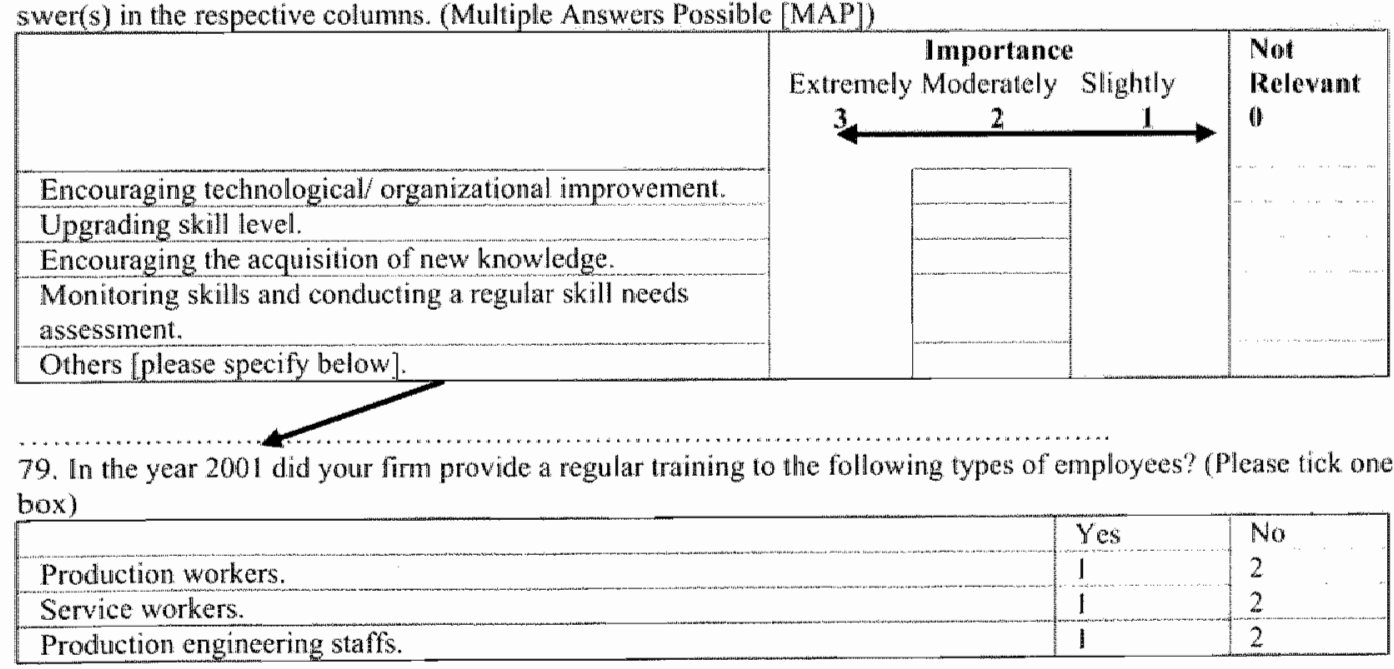




\begin{tabular}{|l|l|l|}
\hline Mandegient stafs. & 1 & 2 \\
\hline Other staffs not melided above. & 1 & 2 \\
\hline
\end{tabular}

80. If your firm provide a regular training, how important are the following categories of training modes in maximizing the return / efficiency of training in your firm?

\begin{tabular}{|l|c|l|}
\hline & \multicolumn{1}{|c|}{$\begin{array}{c}\text { Importance } \\
\text { Extremely Moderately Slightly } \\
1\end{array}$} & $\begin{array}{l}\text { Not } \\
\text { Relevant } \\
0\end{array}$ \\
\hline 1. On the job. & & \\
\hline 2. On the job and off- the job combined. & \\
\hline 3. Off - the job within the firm [training center]. & \\
\hline 4. Off- the job out side the firm [specialist training center in \\
side the country]
\end{tabular}

81. Please rank the most inportant type of training against each of the occupation category listed below?

\begin{tabular}{|c|c|c|c|c|}
\hline & Managerial & $\begin{array}{l}\text { Professional/ } \\
\text { scientists/technical } \\
\text { and engineers }\end{array}$ & $\begin{array}{l}\text { Cleri- } \\
\text { cal/administrat } \\
\text { ive and skilled } \\
\text { workers }\end{array}$ & Others \\
\hline 1. On- the job. & & & & \\
\hline 2. On - the job and off - the job combined. & & & & \\
\hline $\begin{array}{l}\text { 3. Off - the job within the firm [training } \\
\text { center]. }\end{array}$ & & & & \\
\hline $\begin{array}{l}\text { 4. Off-the job out side the firm [specialist } \\
\text { fraining center in side the country] }\end{array}$ & & & & \\
\hline $\begin{array}{l}\text { 5. Off- the job out side the firm out side } \\
\text { the country/abroad. }\end{array}$ & & & & \\
\hline
\end{tabular}

82. If any of that training offered exclusively for the national workers, please rank the most important type of training offered exclusively for the national workers against each of the occupation category listed below?

\begin{tabular}{|c|c|c|c|c|}
\hline & Managerial & $\begin{array}{l}\text { Professional/ } \\
\text { scientists/techni- } \\
\text { cal and angineers }\end{array}$ & $\begin{array}{l}\text { Cleri- } \\
\text { cal/administrat } \\
\text { ive and skillied } \\
\text { workers }\end{array}$ & Others \\
\hline 1. On-the job. & & & & \\
\hline 2. On - the job and Of - the job combined. & & & & \\
\hline $\begin{array}{l}\text { 3. Off - the job within the firms [training } \\
\text { center]. }\end{array}$ & & & & \\
\hline $\begin{array}{l}\text { 4. Orf the job out side the firm [special ist } \\
\text { training center in side the country] }\end{array}$ & & & & \\
\hline $\begin{array}{l}\text { 5. Orf- the job out side the firm out side } \\
\text { the country/abroad. }\end{array}$ & & & & \\
\hline
\end{tabular}

83. In the hast three years, has the performance of training unit contributed significantly in raising skill level of workers hired at your firm? (Please tick one box).

\begin{tabular}{|l|l|l|}
\hline Increased & Decreased & No notable change \\
\hline
\end{tabular}




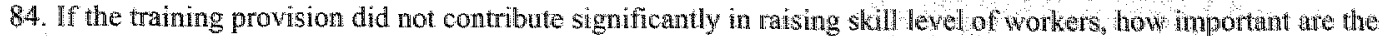

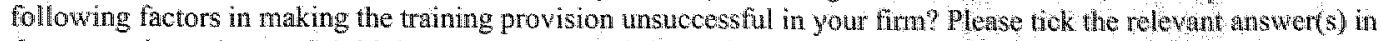
the respective collumins. (Multiple Answers Possible (MAPD)

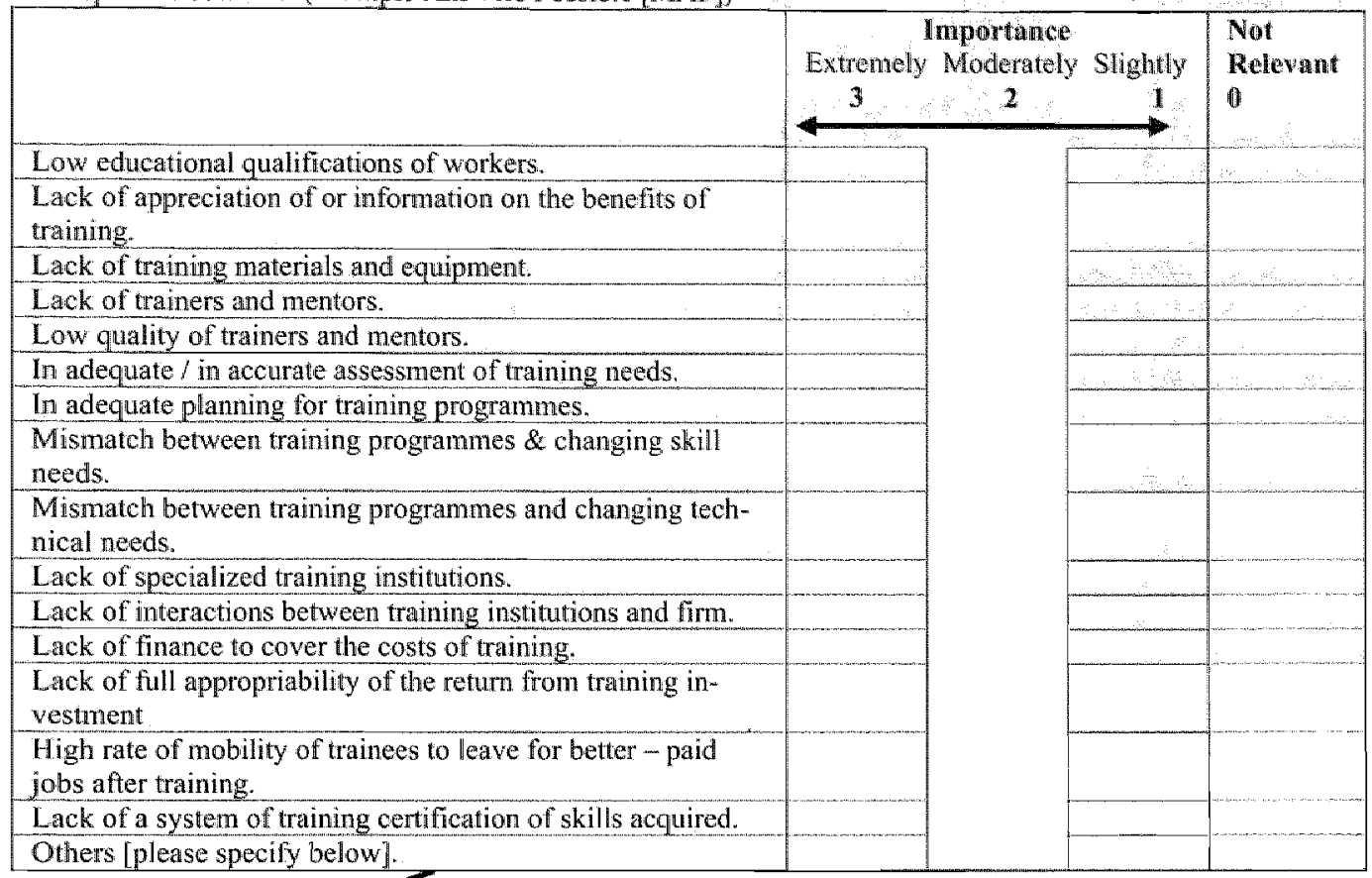

85. If any of the above problem(s) is /are important, how important are the following factors in making the training provision successful in your firm? Please tick the relevant answer(s) in the respective columns. (Multiple Answers Possible [MAP]]

\begin{tabular}{|c|c|c|c|c|}
\hline & $\begin{array}{c}\text { Extrenely } \\
3\end{array}$ & $\begin{array}{l}\text { mportance } \\
\text { Moderately } \\
2\end{array}$ & $\begin{array}{c}\text { Slightly } \\
1\end{array}$ & $\begin{array}{l}\text { Not } \\
\text { Relevant } \\
0\end{array}$ \\
\hline \multicolumn{5}{|l|}{ Enhancing the educational qualifications of workers. } \\
\hline \multicolumn{5}{|l|}{$\begin{array}{l}\text { Increasing the appreciation of } / \text { information on the benefits } \\
\text { of training. }\end{array}$} \\
\hline \multicolumn{5}{|l|}{$\begin{array}{l}\text { Enhancing the availability of traning materials and equip- } \\
\text { ment. }\end{array}$} \\
\hline \multicolumn{5}{|l|}{ Enhancing the availabillity of trainers and mentors } \\
\hline \multicolumn{5}{|l|}{ Enhancing the quality of traners and mentors. } \\
\hline \multicolumn{5}{|l|}{ Enhancing better $/$ accurate assessment of training needs. } \\
\hline \multicolumn{5}{|l|}{ Enhancing adeguate planning for traning progranumes. } \\
\hline \multicolumn{5}{|l|}{$\begin{array}{l}\text { Enliancing training programmes to lit the changing skill } \\
\text { needs. }\end{array}$} \\
\hline \multicolumn{5}{|l|}{$\begin{array}{l}\text { Erathancing training programmes to fit the changing techni- } \\
\text { cal meeds. }\end{array}$} \\
\hline \multicolumn{5}{|l|}{$\begin{array}{l}\text { Enthancing the interactions between training institutions and } \\
\text { firm. }\end{array}$} \\
\hline \multicolumn{5}{|l|}{ Enhancing the availability of finance to cover training costs. } \\
\hline \multicolumn{5}{|l|}{$\begin{array}{l}\text { Enhancing the full appropriability of the return from tran- } \\
\text { ing investment. }\end{array}$} \\
\hline Restriction the mobility of trainees. & & & & \\
\hline
\end{tabular}




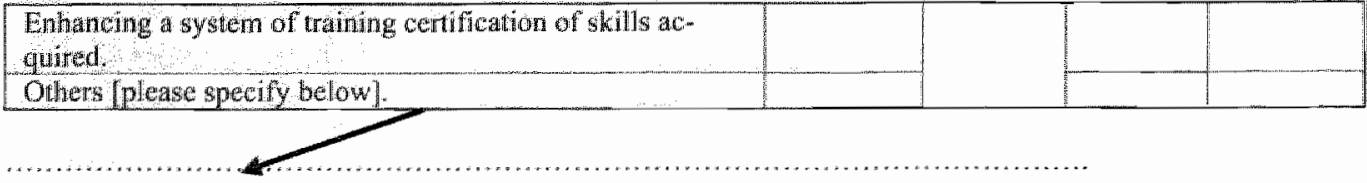

86. Would you be willing to participate in a follow - up interview as part of this research project?

\begin{tabular}{|l|l|}
\hline Yes No & No \\
\hline 1 & 2 \\
\hline
\end{tabular}

Wo would like to extend to you sincere thanks for your kind cooperation and for finding the time in completing this questionnaire. Please return it by $2 \mathbb{2} /$ February / 2002 .

Name of the person completing the questionnaire:

Telephone number:

Fax number:

Position in the company:

Date: 


\title{
Appendix B - Questionnaire of the Macro Survey (2002)
}

\author{
"Interview with Policy Makers in the Government and Experts: Skills Creation, Human \\ Resources Development and Policy Intervention in the United Arab Emirates"
}

Please answer the following questions:

1. General assessment of upskilling efforts

1. In your opinion, which of the following statements give the more appropriate description f judgment of skills creation efforts in the UAE? (Please choose one answer)

\begin{tabular}{|l|l|}
\hline Skills creation efforts have been fully / absolutely successful in all fields / sectors. & 1 \\
\hline Skills creation efforts have been largely successful in all fields / sectors. & 2 \\
\hline Skills creation efforts have been moderately successful in some fields / sectors. & 3 \\
\hline Skills creation efforts have been slightly successful in some fields / sectors. & 4 \\
\hline Skills creation efforts have been unsuccessful. & 5 \\
\hline
\end{tabular}

2. Please specify in what field(s)/ sector(s) the UAE has managed to create appropriate/ relevant skills and in what sectors/ fields it has made a relative progress to the development of local skills?

\begin{tabular}{|l|l|}
\hline & UAE has made a relative progress to develop the local skills \\
\hline Education and Higher Education sector. & \\
\hline Information and Communication sector. & \\
\hline Industrial sector. & \\
\hline Manufacturing sector. \\
\hline Agriculture and Live Stock sector. & \\
\hline Health and Medical Care sector. & \\
\hline Services sector. & \\
\hline Construction sector. & \\
\hline Technicall and Engineering field & \\
\hline Petroleum and Petrochemical field. & \\
\hline Others [please specify below]. & \\
\hline
\end{tabular}

Others [please specify below].

\section{Policies for enhancing skill creation and upgrading}

3. How important are the following factors/ components in promoting and enhancing skills creation eflorts in the UAE? Please tick the relevant answer(s) in the respective collumns. (Multiple Answers Possible [MAP])

\begin{tabular}{|l|l|l|}
\hline & \multicolumn{2}{|c|}{$\begin{array}{l}\text { Not } \\
\text { Relevant } \\
\text { Factors related to the trainee / educated workers. }\end{array}$} \\
\hline Education system. & & \\
\hline Training system.
\end{tabular}


4. If skills creation is linked/related to the side of trainee/ educated workers, how important are the following factors in encouraging trained educated workers to acquire skillsf enhancing skills creation? Please tick the relevant answer(s) in the respective columns. (Multiple Answers Possible [MAP])

\begin{tabular}{|l|l|l|l|}
\hline & \multicolumn{2}{|c|}{$\begin{array}{l}\text { Importance } \\
\text { Relevant } \\
0\end{array}$} \\
\hline $\begin{array}{l}\text { Enhancing the positive external effects of both education } \\
\text { and training. }\end{array}$ & & \\
\hline $\begin{array}{l}\text { Increasing the information about future skill needs / trends } \\
\text { Increasing the information on educational and training }\end{array}$ \\
needs in the productive sectors and their demand for gradu- \\
ate students.
\end{tabular}

5 . If skills creation is linked / related to enhancement of education system, how important / effective are the following factors / intervention policies in enhancing education system and so skills creation? Please tick the relevant answer(s) in the respective columns. (Multiple Answers Possible [MAP])

\begin{tabular}{|c|c|c|c|c|}
\hline Factors / Possible Policies intervention & $\begin{array}{l}\text { Extremely } \\
\mathbf{3}\end{array}$ & $\begin{array}{l}\text { Importance } \\
\text { Moderatel } \\
2\end{array}$ & $\begin{array}{c}\text { Slightly } \\
\mathbf{1}\end{array}$ & $\begin{array}{l}\text { Not } \\
\text { Relevant } \\
0\end{array}$ \\
\hline Improve the internal efficiency/quality of basic education. & & & & \\
\hline $\begin{array}{l}\text { Improve the internal efficiency/quality of tertiary educa- } \\
\text { tion. }\end{array}$ & & & & \\
\hline $\begin{array}{l}\text { Encourage the system of flexibility of educational institu- } \\
\text { tions. }\end{array}$ & & & & \\
\hline Encourage the system of modernization and dynamism. & & & & \\
\hline Improve the quality of teachers or mentors. & & & & \\
\hline Improve the infrastructures. & & & & \\
\hline Monitoring educational heeds on a regular basis. & & & & \\
\hline Better Planning for educational needs. & & & & \\
\hline Increase public spending on education. & & & & \\
\hline $\begin{array}{l}\text { Increase private sector spending and involvement on educa- } \\
\text { tion. }\end{array}$ & & & & \\
\hline $\begin{array}{l}\text { Increase spending and incentives to encourage enroliment } \\
\text { in technical education. }\end{array}$ & & & & \\
\hline $\begin{array}{l}\text { Enhance the linkages [network] between universities, col- } \\
\text { leges, technical and training insitutes and the productive } \\
\text { sectors. }\end{array}$ & & & & \\
\hline $\begin{array}{l}\text { Increase the harmony / consistency between education } \\
\text { output and market needs by focusing on particular future } \\
\text { skills needs. }\end{array}$ & & & & \\
\hline $\begin{array}{l}\text { Increasing the motivation and incentives to attract change } \\
\text { the attitudes of educated economically active population. }\end{array}$ & & & & \\
\hline Others [please specify below]. & & & & \\
\hline
\end{tabular}


6. If skill creation is linked/ related to enhancement of taining system, how importwheffenthe are tho follow wh factors / policies intervention in makmg training provision mone successful and so enthancing skills in the UAR? Please tick the relevant answer(s) in the respective columns, Mullple Answers Possible MAP])

\begin{tabular}{|c|c|c|c|}
\hline & Extremely & $\begin{array}{cc}\text { Importance } & \\
\text { Moderately Shighty } & \\
2 & 1\end{array}$ & $\begin{array}{l}\text { Not } \\
\text { Relevant } \\
0\end{array}$ \\
\hline Enhencing the educational qualifications of workers. & & & \\
\hline $\begin{array}{l}\text { Increasing the apprecintion of or information on the benefits } \\
\text { of training. }\end{array}$ & & & \\
\hline $\begin{array}{l}\text { Enhancing the avalability of training materials and equip- } \\
\text { ment. }\end{array}$ & & & \\
\hline Increasing the availability of tramers and mentors. & & & \\
\hline lmproving the quality of trainers and mentors. & & & \\
\hline $\begin{array}{l}\text { Regular / adequate assessment and monitoring of training } \\
\text { needs. }\end{array}$ & & & \\
\hline $\begin{array}{l}\text { Enhancing adequate planning for training programmes/ } \\
\text { needs. }\end{array}$ & & & \\
\hline $\begin{array}{l}\text { Enhancing training programmes to fit the changing skill } \\
\text { needs. }\end{array}$ & & & \\
\hline $\begin{array}{l}\text { Enhancing training prognammes to fit the changing techni- } \\
\text { cal needs. }\end{array}$ & & & \\
\hline $\begin{array}{l}\text { Enhancing/ encouraging the specialized training dnstitu- } \\
\text { tons. }\end{array}$ & & & \\
\hline $\begin{array}{l}\text { Enhancing the interactions between training winstitutions \& } \\
\text { finm. }\end{array}$ & & & \\
\hline $\begin{array}{l}\text { Enhancing the availability of finance to cover training } \\
\text { costs. }\end{array}$ & & & \\
\hline $\begin{array}{l}\text { Enhancing the full appropriability of the return from in- } \\
\text { vestment in training. }\end{array}$ & & & \\
\hline Decentralization of decision-making. & & & \\
\hline Increasing the participation of private training institutions. & & & \\
\hline $\begin{array}{l}\text { Enhancing the system of training certification of skills } \\
\text { acquired }\end{array}$ & & & \\
\hline Others [please specify below]. & & & \\
\hline
\end{tabular}

\section{Causes of low skill levels and fallure of skill ereation/upgrading efforts}

7. If there is some failure in skills creation, how important are the following factors components in causimg / explaining this failure? Please tick the relevant answer(s) in the respective columns. Multiple Answers Posstble $[\mathrm{M}$ AP])

\begin{tabular}{|l|c|c|}
\hline & \multicolumn{2}{|c|}{ Importance } \\
& Exiremely Moderately Slightiy & $\begin{array}{l}\text { Not } \\
\text { Relevant } \\
0\end{array}$ \\
\hline Factors related to trainee / educated workers. & 3 & 2 \\
\hline Deficient edlucation system. & & 1 \\
\hline Deficient training system. & & \\
\hline Factors related to resources al location. & & \\
\hline Others [please specify below]. & \\
\hline
\end{tabular}


8. If there is some fallure in skills creation linked / related to the side of trainee/ educated workers, how important are the following factors? Please tick the relevant answer(s) in the respective columns. (Multiple Answers Possible [MAPJ)

\begin{tabular}{|c|c|c|c|c|}
\hline 8 & $\begin{array}{l}\text { Extremely } \\
3\end{array}$ & $\begin{array}{l}\text { Importance } \\
\text { Moderately } \\
2\end{array}$ & Shightly & $\begin{array}{l}\text { Not } \\
\text { Relevant: } \\
0\end{array}$ \\
\hline $\begin{array}{l}\text { Externalities and failure to recoup all the benefits of educa } \\
\text { tional investments. }\end{array}$ & & & & \\
\hline $\begin{array}{l}\text { Lack of information on educational and training weeds in } \\
\text { the productive sectors and their demand for graduate stu- } \\
\text { dents. }\end{array}$ & & & & \\
\hline $\begin{array}{l}\text { Uncertainty about the future value of investments in educa- } \\
\text { tion and training. }\end{array}$ & & & & \\
\hline Uncertainties about future skill needs / trends. & & & & \\
\hline $\begin{array}{l}\text { Risk aversion: preference of more certain short - term } \\
\text { returns to available jobs than long - term skil! investments. }\end{array}$ & & & & \\
\hline Lack of a system of certification of skills acquired. & & & & \\
\hline High costs to finance education, learning and training. & & & & \\
\hline Inadequate incentives for trainers. & & & & \\
\hline Lack of interaction to market needs. & & & & \\
\hline 10. Others [plewse specify below]. & & & & \\
\hline
\end{tabular}

9. If there is some failure in skills creation linked/ related to education system, how important are the following reasons in lowering the returns from education? Please tick the relevant answer(s) in the respective columns. (Multiple Answers Possible [MAP])

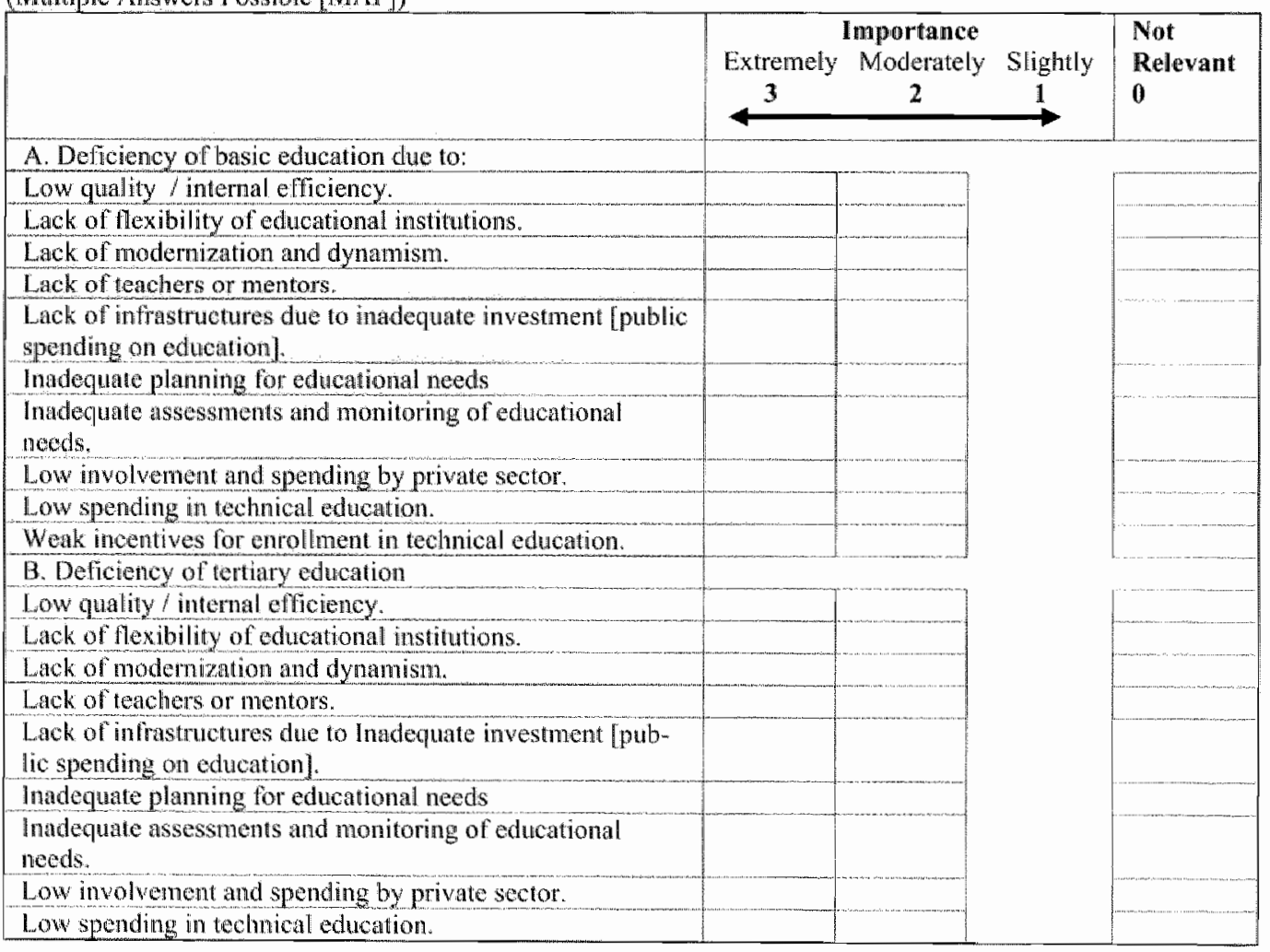




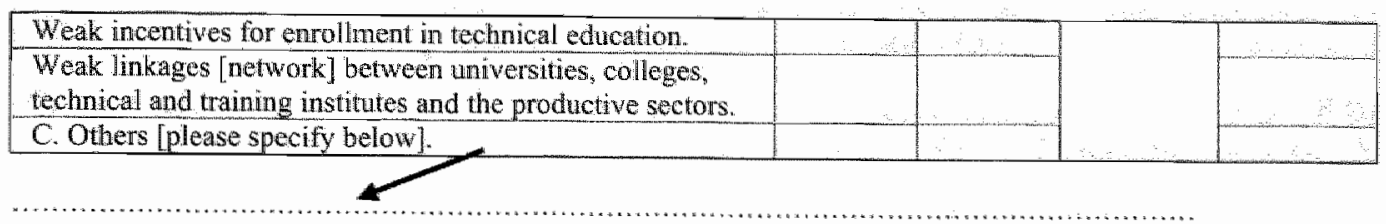

10. If there is some deficiency in education system mainly attributed to low quallity [internal efficiency] of education, how important are the following factors in reducing the internal efficiency/quality of education? Please tick the relevant answer(s) in the respective columns. (Multiple Answers Possible [MAP])

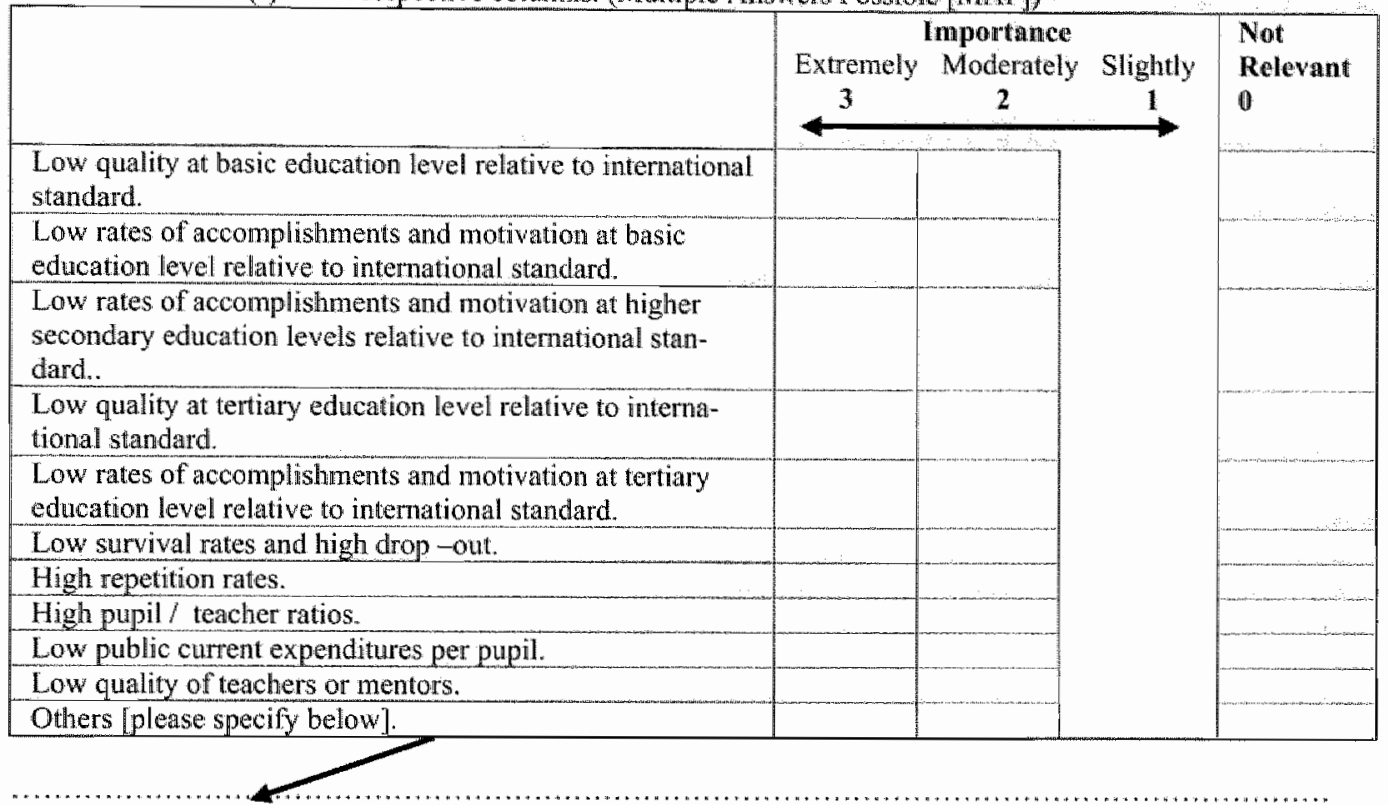

11. If there is some deficiency in education system, did both deficiency of basic education system and deficiency of tertiary education system lead to mismatch between the output of education and market needs in the UAE? [Please tick one box for (a) and (b)].

(a) deficiency of basic education lead to mismatch between the output of education and market needs. Yes No

(b) deficiency of tertiary education lead to mismatch between the output of education and market needs. 1 Yes No

12. If there is some failure in skills creation linked / related to training system, how important are the following factors in making the training provision unswccessful in the UAE? Please tick the relevant answer(s) in the respective columns. (Multiple Answers Possible [MAP])

\begin{tabular}{|l|l|l|}
\hline & \multicolumn{2}{c|}{$\begin{array}{c}\text { Importance } \\
\text { Low educational qualifications of workers. }\end{array}$} \\
\hline $\begin{array}{l}\text { Lack of appreciattion of or information on the benefits of } \\
\text { training. }\end{array}$ & & \\
\hline Lack of training materials and equipment & & \\
\hline Lack of trainers and mentors. & & \\
\hline Low quality of trainers and mentors. & & \\
\hline In adequate assessment of training needs. & & \\
\hline In adequate planning for training programmes. & \\
\hline Mismatch between training programmes and changing skill & & \\
\hline
\end{tabular}




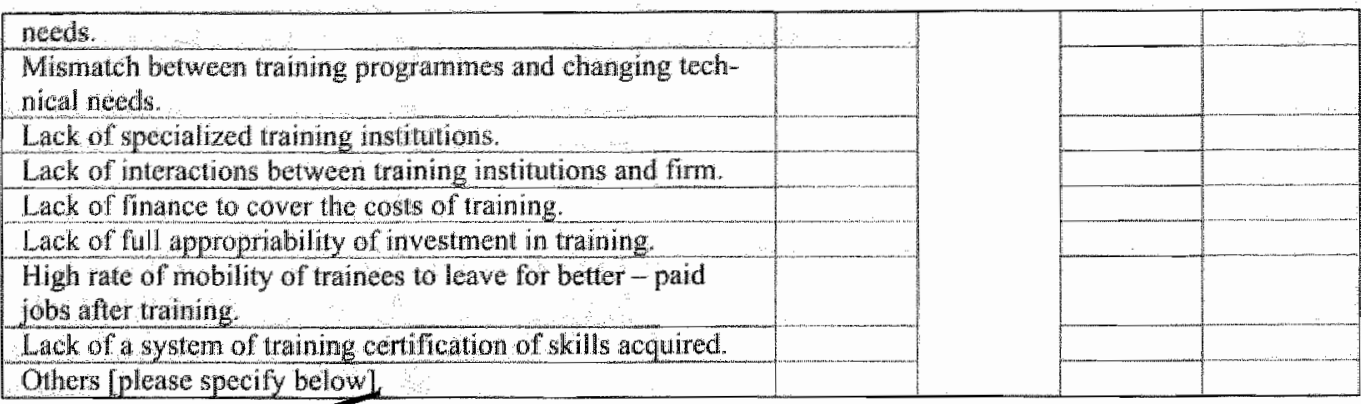

4.

\section{Short and Long terms mechanisms for skill upgrading and effects on technological upgrad-} ing and fulfilling socio-economic objectives

13. How important are the following types of skill formation in fulfilling / accelerating the long run economic growth strategies in the UAE? Please tick the relevant answer(s) in the respective colums. (Multiple Answers Possible [MAP])

\begin{tabular}{|c|c|c|c|c|}
\hline & $\begin{array}{c}\text { Extremely } \\
3\end{array}$ & $\begin{array}{c}\text { Importance } \\
\text { Moderately } \\
2\end{array}$ & Silightly & $\begin{array}{l}\text { Not } \\
\text { Relevant } \\
0\end{array}$ \\
\hline Investing in formal education. & & & & \\
\hline Investing in vocational training. & & & & \\
\hline Investing in- lirm traning to train existing employees. & & & & \\
\hline Improving the quality of teachers, trainers and mentors. & & & & \\
\hline $\begin{array}{l}\text { Sending teachers/instructors/trainers abroad to acquire } \\
\text { knowledge and skills. }\end{array}$ & & & & \\
\hline Sending students abroad to meguire knowledge and skills. & & & & \\
\hline Sendling workers abroad to acquire knowledge and skills. & & & & \\
\hline Attracting new foreign skills, scientists \& engineers. & & & & \\
\hline Using ICT to upgrade skill level. & & & & \\
\hline Encouraging leanning on the job. & & & & \\
\hline Supporting long distance learning. & & & & \\
\hline Enhancing the system of accreditation and Licensing. & & & & \\
\hline Enhancing the systern or programme of appoenticeship. & & & & \\
\hline Others [please specify below]. & & & & \\
\hline
\end{tabular}

14. If any of the above types are important, please specify if these activities have been already implemented, are to be pursued now or in the near future in the UAE? (Please tick one box for anch statement below)

\begin{tabular}{|c|c|c|c|}
\hline & \multirow[t]{10}{*}{$\begin{array}{l}\text { Has been } \\
\text { already } \\
\text { dimplemented }\end{array}$} & $\begin{array}{l}\text { To be } \\
\text { Pursued } \\
\text { now }\end{array}$ & \multirow[t]{10}{*}{$\begin{array}{l}\text { "To be Pursued } \\
\text { un the neart } \\
\text { future }\end{array}$} \\
\hline Investing in formal education. & & & \\
\hline Investing in vocational training. & & & \\
\hline Investing in training to train existing employees & & & \\
\hline lmproving the qualify of teachers, trainers and mentors. & & & \\
\hline $\begin{array}{l}\text { Sending teachers/nstructors trainers abrosd to acquire } \\
\text { knowledge and skills. }\end{array}$ & & & \\
\hline Sending students abroad to acquire knowledge and skills. & & & \\
\hline Sending worker abroad to acquire skills. & & & \\
\hline $\begin{array}{l}\text { Bringing /atracting new foreign skills, scientist and engi- } \\
\text { necrs. }\end{array}$ & & & \\
\hline Using ICT to upgrade skill level. & & & \\
\hline
\end{tabular}




\begin{tabular}{l}
\hline Encouraging Leaming on the job. \\
Supporting long distance learning. \\
Enhancing the system of accreditation and Licensing. \\
Enhancing the system or programme of apprenticeship. \\
\hline Ouhers [please specify].
\end{tabular}

15. How important are the effects of upskilling in fulfiling the following socio-economic goals? Please, tick the relevant answer(s) in the respective columns. (Multiple Answers Possible [MAP])

\begin{tabular}{|c|c|c|c|c|}
\hline & $\begin{array}{l}\text { Extremely } \\
\mathbf{3} \\
\end{array}$ & $\begin{array}{c}\text { Importance } \\
\text { Modorately } \\
2\end{array}$ & Slighty & $\begin{array}{l}\text { Not Rele- } \\
\text { vant } \\
0\end{array}$ \\
\hline Increasing / reinforcing economic growth. & & & & \\
\hline Enhancing / accelerating technological upgrading, & & & & \\
\hline $\begin{array}{l}\text { Solving imbalances in labour market: Reducing the futhre } \\
\text { demand for foreign skilled labour. }\end{array}$ & & & & \\
\hline Reducing unemployment rate. & & & & \\
\hline Reinforcing self-reliance strategy. & & & & \\
\hline Others [please specily below] & & & & \\
\hline
\end{tabular}

16. How important are the effects of upgrading of technologies in accelerating upskilling and fulfilling the following socio-economic goals? Please, tick the relevant answer(s) in the respective columns. (Multiple Answers Possible [MAP])

\begin{tabular}{|l|l|l|}
\hline & \multicolumn{2}{|c|}{ Importance } \\
\hline Increasing / reinforcing economic growth. & & \\
\hline Enhancing/ accelerating upskilling. \\
\hline $\begin{array}{l}\text { Solving imbalances in labour market: Reducing the future } \\
\text { demand for foreign skilled labour. }\end{array}$
\end{tabular}

\section{The incidence of external effect of schooling/transfer of knowledge the hindering and other promoting factors}

17. Does the external effect of schooling/education ${ }^{185}$ occur and contribute to upskilling in the UAE? (Please lick one box).

\begin{tabular}{|l|l|}
\hline$Y \mathrm{es}$ & No \\
\hline $1 \longrightarrow$ Skip to question [20] & 2 \\
\hline
\end{tabular}

If the answer is [2], please continue in answering questions [18】 and [19].

${ }^{135}$ This is a non-intentional extemal effect made by skilled worker and lead to an enhancement of the productivity of unskilled worker. 
18. If the external effect of schooling / education does not yet occur, how important are the following factors in reducing the external effect of schooling / education and in lowering its effects on upskilling? Please tick the relevant factors in the respective collumns. (Multiple Answers Possible [MAP])

\begin{tabular}{|c|c|c|c|c|}
\hline 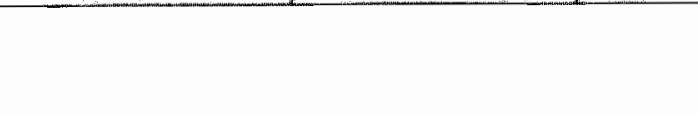 & $\begin{array}{l}\text { Extremelly } \\
3\end{array}$ & $\begin{array}{l}\text { Importance } \\
\text { Moderately }\end{array}$ & Slightly & $\begin{array}{l}\text { Not } \\
\text { Relevant } \\
0\end{array}$ \\
\hline $\begin{array}{l}\text { Skilled workers failed to deliver their knowledge and } \\
\text { expeniences to benefit unskilled workers. }\end{array}$ & & & & \\
\hline $\begin{array}{l}\text { Unskilled workers were unable to acquire the knowledge } \\
\text { and experiences from skilled workers. }\end{array}$ & & & & \\
\hline Low return from / quality of education. & & & & \\
\hline $\begin{array}{l}\text { Low return from/ quality of training compared to interna- } \\
\text { tional standard. }\end{array}$ & & & & \\
\hline Firm conditions do not encourage the external effects. & & & & \\
\hline Others [please specify below]. & & & & \\
\hline
\end{tabular}

19. If any of the above factor[s] is/ are important, how important are the following policies/solutions in inducing the external effect of schooling and in enhancing the upskilling? Please tick the relevant answer(s) in the respective columns. (Multiple Answers Possible [MAP])

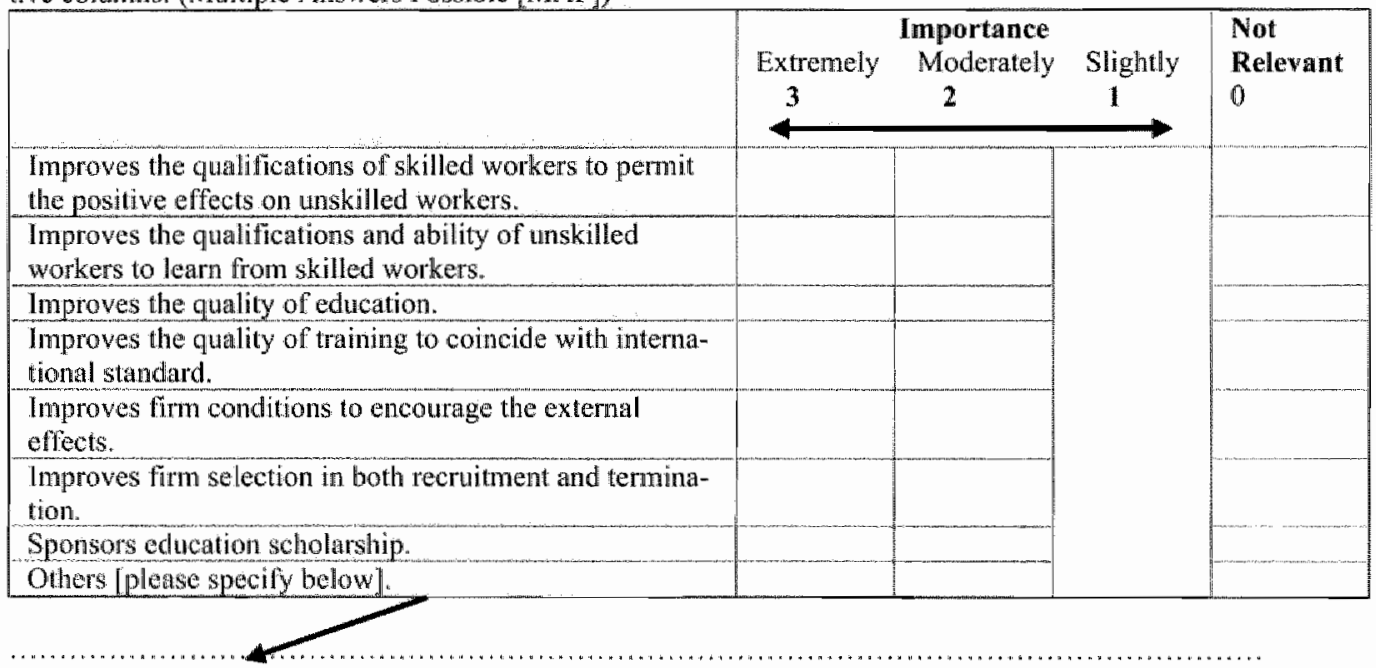

\section{Conclusions and further recommendations}

20. Do you want to add any other general comments or suggestions for skill formation and human resources development in the UAE?

We would like to extend to you sincere thanks for your kind cooperation and for finding the time in completing this questionnaire.

Name of the person completing the questionnaire:

Telephone number:

Fis number:

Position in the institution:

Date: 


\section{Samenvatting (Summary in Dutch)}

De centrale thema's van deze studie zijn de noodzakelijke scholing en de bijscholing van arbeiders de Golf Staten, in samenhang met de voortschrijdende technologische verandering. De Golf Staten spelen een strategische rol in de globale economie ondat deze regio $40 \%$ van de wereldolie voorraden bezit en daardoor de trends in olie-voorziening en -markt beinvloedt. Hoewel de sterke afhankelijkheid van olie de versterking van de economische ontwikkeling bevorderde, stelt ze de Golfstaten nu voor ernstige uitdagingen. Immers de opbrengsten uit olie zijn onzeker en volatiel, aangezien olie een uitputbare bron is en olieprijzen instabiel zijn. Andere ernstige structurele problemen als de "Dutch Disease" en de sterke aanwezigheid van ongeschoolde buitenlandse werknemers hebben geleid tot structurele onevenwichtigheden in de arbeidsmarkt in de Golf. Bijgevolg is economische groei op lange termijn en de strategie inzake duurzame ontwikkeling in de Golf afhankelijk zowel van een overgang van een economie gebaseerd op olieopbrengsten naar een economie gebaseerd op technologie en deskundigheid als van economische diversificatie. Tot deze strategie behoort eveneens de ontwikkeling van een economie die minder afhankelijk wordt van het aantrekken van hoogontwikkelde buitenlandse werkers ten gunste van plaatselijke geschoolde arbeiders. Naar onze mening is het succes van deze strategieën - locale technologische ontwikkeling, economische diversificatie en vetrouwen op de eigen lokale werknemers om de arbeidsmarkt te herstructueren, een voorwaarde voor de ontwikkeling van adequate en passende deskundigheid in de Golf.

Wij vinden dat de implementatie van deze stategieën in hoge mate wordt belemmerd door een falend onderwijssysteem, de hoge graad van ongeschoolde buitenlandse werkers en het ontbreken van gepaste economische prikkels in de Golf Staten. Als nieuw element in ons onderzoek benadrukken wij de rol en invloed van onvolkomenheden in het onderwijssysteem, naast de reeds eerder geconstateerde rol van het overdadig gebruik van ongeschoolde buitenlandse arbeiders en het ontbreken van economische prikkels op de arbeidsmarkt. We verrichten een meer uitgebreid onderzoek aangezien we het vakbekwaamheidsprobleem bestuderen vanuit twee verschillende perspectieven, waarbij we de invloed van het deficiënt onderwijssteem verbinden met de sterke aanwezigheid van ongeschoolde buitenlandse werknemers. Bovendien voeren we een meer uitgewerkte en diepgaande analyse uit van de oorzaken, gevolgen en de relatie tussen gebrekkige kennis en technologische prestaties in de Golf, vanuit het perspectief van vraag-en aanbodzijde, waarbij we gebruik maken van een set van indicatoren, die meer omvattend is dan diegenen die meestal beschreven worden in de literatuur. Tenslotte vult onze analyse de kloof in de Golf-literatuur, aangezien we het belang van kennis en externe effecten van scholing en kennisoverdracht benadrukken en we de factoren onderzoeken die ofwel de kennisoverdracht zowel op microals macroniveau hinderen of versterken.

Onze case studie inzake de Golf Staten handelt over de Verenigde Arabische Emi * raten. We gebruiken de resultaten van nieuwe survey data op macro- micro- en bedrijfsniveau. We tonen aan dat de interactie tussen een deficiënt onderwijssysteem - op macroniveau - en de sterke anwezigheid van ongeschoolde buitenlandse werknemers - op micro- 
niveau - leiden tot een laag scholings- en technologisch niveau met vele ernstige gevolgen, zoals een slechte trainingsvoorziening, gebrekkige aansluiting tussen gevraagde en aangeboden deskundigheid, een lage kennisoverdracht, publiek- private dualiteit, een slechte score op technologie indicatoren en een hoge mate van afhankelijkheid van buitenlandse technologieën. We tonen aan dat het gebrek aan lokale technologische ontwikkeling verband houdt met lage O\&O inspanningen, een laag opleidingsniveau, gebrek aan netwerksystemen, zwakke samenwerking tussen universiteiten en bedrijven, gebrek aan middelen en een lage kennisoverdracht.

Onze resultaten tonen twee verrassende, tegenstrijdige meningen inzake de overdracht van kennis, het vertrouwen op lokale deskundigheid en de rol van technologische opwaardering en bijscholing bij het versterken hiervan zowel op macro- en micro-niveau evenals in de publieke en private sector. Onze bevindingen impliceren dat mogelijk de kennisoverdracht en de externe effecten van scholing succesvol zijn binnen bedrijven, maar niet succesvol in de maatschappij in het algemeen. De strategie tot zelfvoorziening is mogelijkerwijs een overheidsstrategie die niet noodzakelijk wordt toegepast door private bedrijven. In tegenstelling tot de private bedrijven lijken grote openbare bedrijven wel genegen te zijn om het overheidsbeleid tot bijscholing toe te passen.

Onze bevindingen bevestigen de gegevens in de nieuwe groeiliteratuur inzake de positieve correlatie tussen gevolgde scholing, ervaring en lonen en de complementaire verbanden van technische vooruitgang met ICT technologie, menselijk kapitaal, deskundigheid en bijscholing (ICT training). We onderstrepen het belang van kennis en het complementaire verband tussen informele en gecodificeerde kennisbronnnen.

We stellen vast dat de Golf Staten de deskundigheid dienen aan te scherpen door middel van een hervorming van de onderwijs- en trainingssystemen, door kennistransfer en door nadere prikkels in te bouwen om de informele en gecodificeerde kennisbronnen op micro- en macroniveau te verbeteren. Zij dienen lokale technologieën te ontwikkelen door de promotie van vaardigheden, O\&O-activiteiten, kennisoverdracht, netwerksystemen, samenwerking tussen universiteiten, bedrijven, publieke en private sectoren en de implementatie van een expliciet technologiebeleid. 


\section{Summary in English}

The central themes of discussion in this research are the required skill formation and upskilling of workers, together with their interaction with technological change in the Gulf countries. The Gulf countries have strategic importance in the global economy because the region holds $40 \%$ of world oil reserves and therefore affects the trends of oil supply and market. While the heavy dependence on oil has contributed to the enhancement of economic development in the region, it has also led to serious challenges now confronting the Gulf countries since oil is an exhaustible resource and, because of the instability of oil prices, the revenue from oil is uncertain and vollatile. Other serious structural problems relate to the Dutch Disease, and the high incidence of unskilled foreign workers that have caused serious structural imbalances in the labour market in the Gulf. Hence, long run economic growth and sustainable development strategy in the Gulf depends on both a shift in the focus from a resources-oil based economy to a technology and skill based economy and on economic diversification. A key part of this strategy is to also manage the economy away from the dependency on the import of high skilled workers in favour of domestic skilled workers.

In our view, the success of these strategies - local technological development, economic diversification and self-reliance on domestic workers to restructuring the labour market - are all contingent upon the development of adequate and appropriate skills in the Gulf.

In our opinion, the implementation of these strategies is eminently impeded by the deficient educational system, the large share of unskilled foreign workers and the lack of incentives in the Gulf countries. A new element in our research is that we confirm the role and impacts of the deficiencies in the educational system alongside the well-investigated role of the excessive use of uneducated foreign workers and lack of incentives in the labour market. We provide a more comprehensive investigation since we discuss the skill problem from two different perspectives, combining the impacts of the deficient educational system and the high incidence of uneducated foreign workers. In addition, we present a more elaborate and in-depth analysis to assess the causes, consequences and relationships between poor skill and technological performance in the Gulf from both the supply and demand sides and the macro-micro perspectives, since we use a very comprehensive set of indicators compared to the ones usually used in the literature. Finally, our analysis fills the gap in the Gulf literature since we highlight the importance of knowledge and external effects of schooling/the transfer of knowledge and we explore the factors hindering and those contributing toward enhancing the transfer of knowledge at both the macro and micro levels.

We focus on the UAE as a case study of the Gulf countries and use the results from new survey data both at the macro and micro/firm levels. We show that the interaction between the deficient educational system - at the macro level - and the high incidence of unskilled foreign workers - at the micro level - leads to low skill and technology levels and many serious consequences. These include the poor provision of training, severe skills mismatch, low transfer of knowledge, public-private duality, poor technology indicators and 
a heavy dependence on foreign technologies. We explain that the lack of local efforts for technology development is basically related to low R\&D efforts that can be attributed to low skill levels, lack of networks systems, weak linkages/co-operation between universities and firms, the lack of resources and the low transfer of knowledge.

Our results show two surprising contradicting views concerning the incidence and transfer of knowledge, the self-reliance on local skill and the role of both technological upgrading and upskilling in reinforcing these at both the macro-micro levels and the publicprivate sectors. Our findings imply that the transfer of knowledge/the external effects of schooling is probably successful within firms but is unsuccessful within society at large. Our results indicate that the self-reliance strategy is probably a preferred government strategy, but not necessarily one favoured by private firms. We show that, in contrast to the private firms, the large public firms seem successful/committed to implementing public policies for skill upgrading.

Our findings confirm the stylized facts in the new growth literature concerning the positive correlations between actual education, experience and wages and the complementary relationships between technical progress/technology (ICT), human capita//skill and upskilling (ICT training). We corroborate the importance of knowledge and the complementary relationship between tacit and codified sources of knowledge.

We confirm that the Gulf countries need to improve skills through the reform of educational and training systems, transfer of knowledge and the provision of further incentives to improve tacit and codified sources of knowledge at the macro and micro levels. They need to develop the local technologies through the promotion of skill, R\&D activities, transfer of knowledge, networks system, collaboration between universities, firms, public and private sectors and implementation of explicit technology policy. 


\section{About the author}

Samia Satti Osman Mohamed Nour was born in Khartoum, Sudan on January 9, 1970. She studied Economics at the Faculty of Economic and Social Studies, University of Khartoum, Sudan, where she graduated with a B.Sc. (First Class Honours) in 1994. She obtained a M.Sc, in Economics from the Graduate College at Khartoum University in August 1999. She received a medal and five different best student faculty prizes during her undergraduate studies and several research awards during her postgraduate studies. In September 1999 she joined Maastricht University: MERIT/UNU-INTECH Ph.D. Programme in Economics and Policy Studies of Technical Change. In 2000 she started working on her Ph.D. thesis, her research falls under the broad UNU-INTECH research theme, 'Designing the Knowledge Economy'. After completing her Ph.D. Samia will return to University of Khartoum and will take up the position of Assistant Professor at the Department of Economics. She plans to continue with her academic career, either in teaching or research and to do further postdoctoral research in the area of technical change, human capital, endogenous growth, development economics, employment and labour economics. Between April 1995 and August 1999, she worked as a teaching assistant at the Department of Economics, Faculty of Economic and Social Studies of Khartoum University. She stayed at Maastricht University and UNU-INTECH, Maastricht, the Netherlands from September 1999 to November 2005 and at UNU-WIDER, Helsinki, Finland from May to July 2002. Samia has published three discussion and working papers and has contributed to two articles published in refereed journals. 